INSECTS AND MAN 

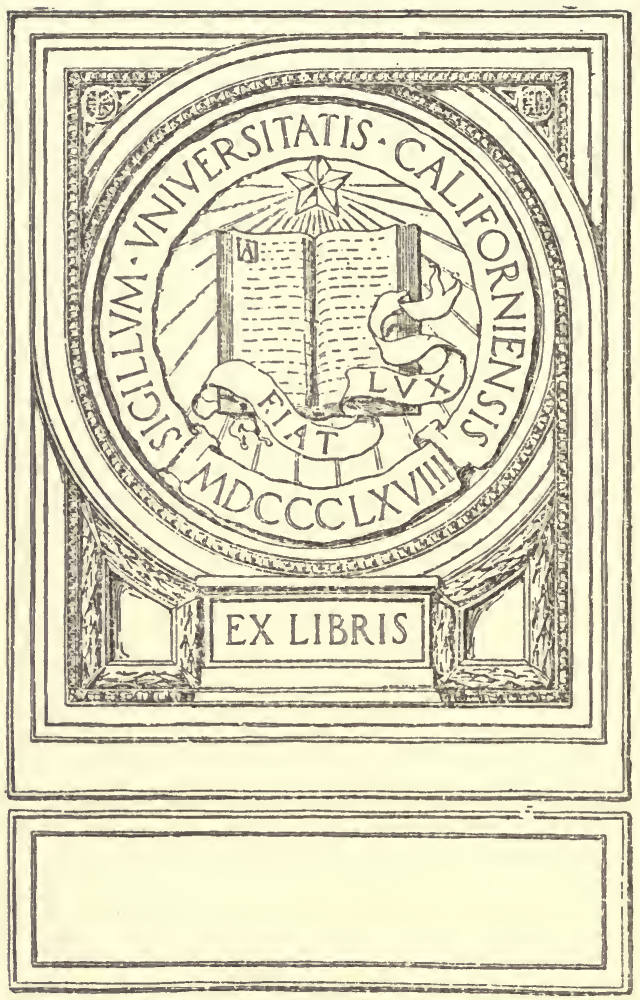


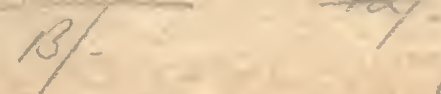

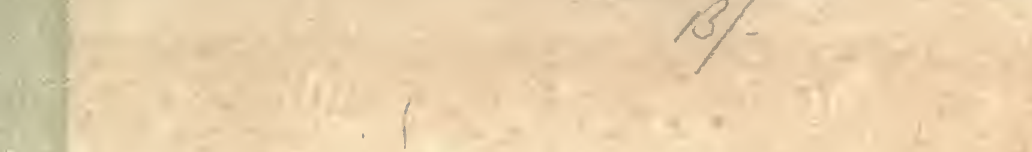

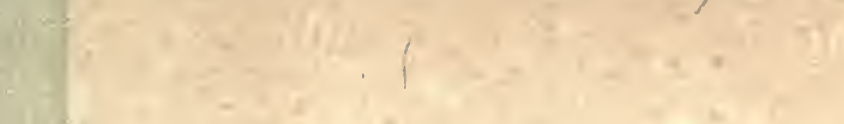

$\checkmark$

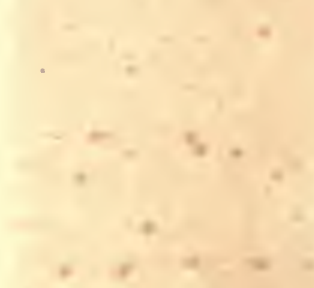

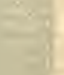

t.
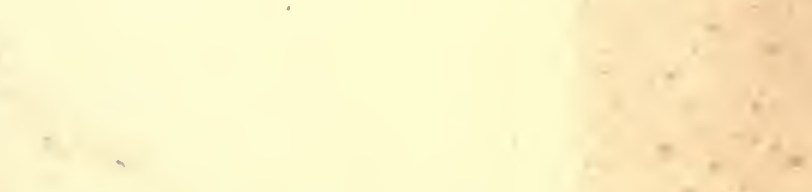
$+4$ 
INSECTS AND MAN 




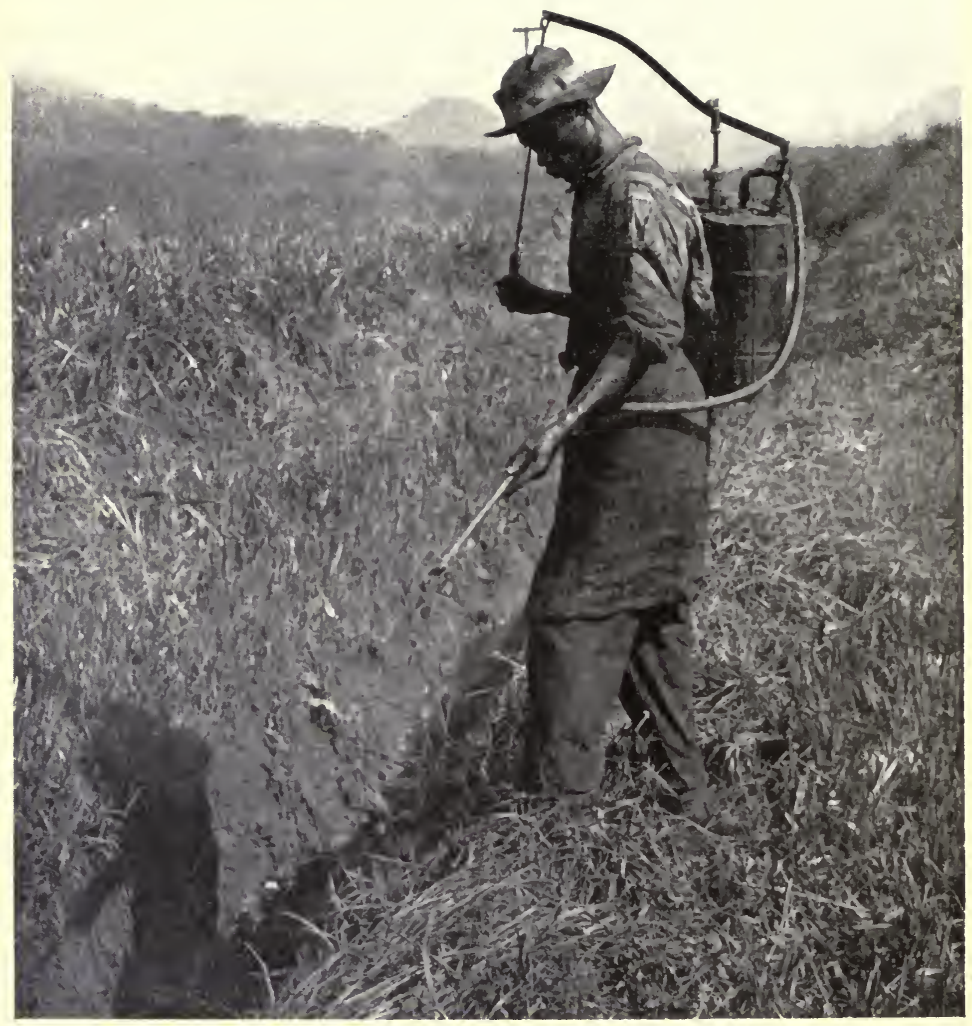

PIATE I

War on the Mosquito in the Panama Canal Zone. Application OF LARVICIDE FROM A KNAPSACK SPRAYER

(Sce p. 117) 


\title{
INSECTS AND MAN:
}

AN ACCOUN'T OF 'THE MORE IMPOR'TAN"T HARMFUL AND BENEFICIAL INSECTS, THEIR HABITS AND LIFE-HISTORIES, BEING AN INTRODUC'TION TO ECONOMIC ENTOMOLOGY FOR STUDENTS AND (GENERAL, READERS

\section{A. EALAND, M.A.}

LATE PKINCIPAL OF THE EAST ANGLIAN COLLEGE OF AGRICUITLKE:

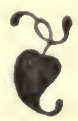

Illustrated with Drawings and Reproductions from Photographs

\author{
LONDON \\ GRANT RICHARDS LTD. \\ MDCCCCXV
}




$$
\begin{gathered}
S E Y=1 \\
E ?
\end{gathered}
$$


"When the moon shall have faled from the sky and the sun shall shine at noonday a dull cherry red, and the seas shall be frozen over, and the ice-cap shall have crept downward th the Equator from either pole, and no keel shall cut the waters, nor wheels turn in mills, when all cities shall have long been dead and crumbled into dust, and all life shall be on the very last verge of extinction on this globe, then, on a bit of lichen, growing on the bald rocks beside the eternal snows of Panama, shall be seated a tiny insect, preening its antenna in the glow of the worn-out sun, representing the sole survival of animal life on this, our earth, -a melancholy 'bug.,"

W. J. Holdani, Muth liook. 



\section{PREFACE}

I REGRET that it is impossible to thank, individually, everyone who has assisted me in the production of Insects and Man. My indebtedness to various authors, from whose works I have at times freely quoted, is expressed in the bibliography. I am also deeply indebted to those who have so kindly lent illustrations for the book. I wish to thank, especially, the Director of the Imperial Bureau of Entomology for the loan of several blocks; Professor Wilmon Newell for illustrations relating to the Argentine ant; the Panama Canal Commission for photographs illustrative of mosquito control; Dr Sambon for the plate of his mosquito-proof hut; the Hon. N. C. Rothschild for permission to copy his drawing of the plague flea; and Dr Britton for the photograph of the wood leopard moth. To Messrs Bailliere, Tindall \& Cox, who have kindly allowed me to use eight drawings from Castellani and Chalmers' Manual of Tropical Medicine; and to Messrs Cassell, who have similarly obliged with drawings from Manson's Tropical Diseases, I tender my hearty thanks. The majority of the figures have been most carefully copied, and in some cases drawn from life, by Hilda Haddock, and her painstaking work will, I believe, add to the interest of Insects and Man. Lastly, my thanks are due to my publishers for their never-failing kindness, courtesy, and patience.

$$
\text { C. A. E. }
$$

London, 1914. 



\section{CONTEN'TS}

1. INTRODCTION .

2. INSECTS AND PIANTS . . . . 33

3. INSECTS AND HUMAN DISFISF . . . . . . 88

4. INSECT ENEMILS OF LIFE STUCK . . . . . 160

5. IBENEFICIAL INSECTS . . . . . . . . 197

6. HOUSEHOLD INSECTS . . . . . . . . 234

7. SOME HOMAN PARASITYS . . . . . 274

8. INSECT CONTROL . . . . . . . . . . . 295

BIBLIOGRAPHY . . . . . . . . . . . 323

INDEX . . . . . . . . . . . . . 333

INUEX OF AUTHORITIFS, FTC. . . . . . . . 342 



\section{LIST OF PLATES}

YAQR:

I. War on the Mosquito: Application of Iarvicide Frontispiece

II. A Wood Leopard Moth . . . . . . . . 38

III. Hollow in a Breadfruit-Tree . . . . . . . 96

IV. A Mosquito-proof Hut . . . . . . . 106

V. Burning Undergrowth . . . . . . . 114

VI. Vessel containing Crude Mineral Oil placed over a Mosquito Breeding-place . . . . . . . 116

VII. Border of Inverted Bottles . . . . . . . 118

VIII. Natives Fishing in the Anwa River . . . . . 130

IX. Native catching Glossina . . . . . . . 132

X. (a) On the Niger at Jebba. (b) View near Bakan . . 146

XI. Verrugas Bridge . . . . . . . . . 150

XII. A Native Collector . . . . . . . . 164

XIII. The Cattle that sicken with Trypanosomiasis . . . 174

XIV. Argentine Ants on a Breakfast Table . . . . . . 248

XV. (a) A Bridge which the Argentine Ants cannot cross.

(b) One of the "Shelters" built by Argentine Ants . 260

XVI. Interior of an American Insectary . . . . . 318

Plates III., VII., VIII., IX., X., XI., XII., and XIII. are reproducal by permission of the Imperial Burean of Entomolocry; Plates I., V., and VI. by permission of the Panama Canal Commission; Plates XIV., XV., and XVI. by permission of Professor Wilmon Neroell ; Plate II. by permission of $\mathrm{Dr}$ Britton; and I'late IV. by permission of Dr Sambon. 



\section{LIST OF DRAWINGS}

FIG.

TO FACE PAGR

1. A woorl-boring beetle, Xyleborus dispar (female)

36

2. A female locust laying eggs. (After Milliken)

3. The Mexican cotton-boll weevil, Anthonomus yrandis. (After Hunter and Pierce)

4. The Mexican cotton-boll weevil, Anthonomus grandis, larvib and pupa. (After Hunter and Pierce)

5. Rostrum and beak of Mexican cotton-boll weevil. (After Hunter and Pierce)

6. Larval burrow of the cotton-boll worm, Chloridea obsoleta. (Dept. of Agriculture, U.S.A.)

7. The Periodical cicada, Cicada septendecim. (After Marlatt) .

8. Organ of song of the P'eriodical cicada. (After Marlatt)

9. Ovipositor of the Periodical cicarla. (After Marlatt) .

10. Periodical cicada larvæ. (After Marlatt)

11. P'eriodical cidada cones or chimneys. (Amended from Marlatt)

12. Gipsy moth (female), Porthetria dispar

13. Gipsy moth, first stage larva. (After Burgess)

14. San José scale (male), Aspidiolus perniciosus. (After Marlatt)

15. San José scale. (After Marlatt)

16. San José scale (female) before development of eggs. (After Marlatt)

17. Hessian fly (male), Cecidomyia destructor. (1)ept. of Agriculture, U.S.A.)

18. Hessian fly, eggs and pupa. (Dept. of Agriculture, U.S.A.)

19. Phylloxera, Phylloxerı vastatrix, larva

20. Phylloxera, winged adult

21. Blood parasites of malaria

22. Resting positions of mosquitoes

23. Anopheles larva. (After Sambon).

24. Culex larva. (After Sambon)

25. Mosquito eggs, Anopheles sp.

26. Pupre of Anopheles and Culex. (After Terzi in Manson's Tropical Diseases)

27. Adult Anopheles beginning to emerge from its pupal case. (After Brumpt).

28. Adult Anopheles almost free of its pupal case. (After Brumpt)

29. Mosquito egg rafts. (After Sambon)

30. Box designed by Dr L. Sambon for the transport of mosquitoes

31. The yellow-fever mosquito (female), Stegomyir fasciata. (Imperial Bureau of Entomology)

32. The stable fly, Stomoxys calcitrans. (Castellani and Chalmers' Manual of Tropical Medicine) . . . . . 128

33. A trypanosome 
FIG.

34. A tsetse fly, Glossina palpalis. (Castellani and Chalmers' Manual of Tropical Medicine) . • •

35. A tsetse fly in the act of giving birth to a larva. (Castellani and Chalmers' Manual of Tropical Medicine) . . . 134

36. The Phlebotomus fever $11 y$, Phlebotomus papatasi . 136

37. A buffalo gnat, Simuliurn mcridionale (nale). (Dept. of Agriculture, U.S.A.) . • . . . . . .

38. Larva of Simulium meridionale. (Dept. of Agriculture, U.S.A.)

39. Pupa and "pockets" of Simulium meridionale attached to a leaf. (Dept. of A griculture, U.S.A.)

40. The fever tick, Ornithodorus moubata. (After Brumpt)

41. A tick laying eggs. (After Sambon in Castellani and Chalmers' Manual of Tropical Medicine)

42. Lamus megistus. (After Chagas) .

43. Head of Lamus megistus. (After Carazzi)

152

44. A male plague flea. (After Jordan)

152

158

45. Evolution of the fowl tick, Argas persicus. (After Brumpt) .

46. Maryaropus annulatus australis. (After Terzi in Castellani and Chalmers' Manual of Tropical Medicine)

162

47. A canine disease-carrier, Dermacentor reticulatus (female). (After Carazzi) .

48. Eggs of horse bot fly, Gastrophilus equi. (After Collinge)

49. The ox warble fly, Hypoderma bovis. (After Terzi in Castellani and Chalmer's' Manual of Tropical Medicine)

50. The sheep bot fly, Estrus ovis. (After Terzi in Castellani and Chalmers' Manual of Tropical Medicine)

51. A sheep ked, Melophagus ovinus. (Dept.of Agriculture, U.S.A.)

52. Scab mite, Psoroptes communis var. equi. (From Murray after Furstenbergh)

53. Female fowl tick, Argas persicus (dorsal aspect) (After Terzi in Castellani and Chalmers' Manual of Tropical Medicine).

54. The hen flea, Sarcopsylla gallinacea (male). (Dept. of Agriculture, U.S.A.)

55. Air sac mites, Cytodites nudus

56. Giganthorhynchus hirundaceus. (After Nंeveu Lemaire) •

57. Legs of honey bees. (After Chester)
58. Lac insects, Tachardia lacca. (Adapted from Indian Forest Records)

59. House fly (Musca domestica) in the act of vomiting

60. Larva of house fly, Musca domestica. (After Packard) . $\quad$ 230

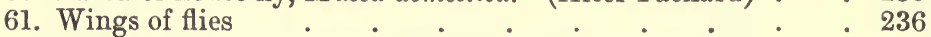

62. Larva of lesser house fly, Fannia canicularis. (After Chevrel) 236

63. Parasitic ticks on body of house fly . . . . . 240

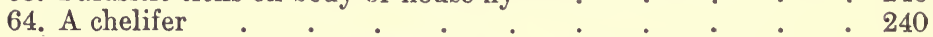

65. A cheese mite, Tyroglyphus longior. (Dept. of Agriculture, U.S.A.)

66. The cheese "skipper" fly, Piophila casei. (After Carazzi)

67. The cheese "skipper" larva, Piophila casei. (After Carazzi). 244

68. Argentine ants, Iridomyrmex humilis. (After Newell) . . 246 


\section{LIST OF DRAWINGS}

FIG.

TO FACE PAGE

69. Female cockroach, Periplanete orientalis. (Dept. of Agri-

culture, U.S.A.) . . . . . . . . . . 258

70. Egg case of a cockroach. . . . . . . . . . 258

71. A female termite . . . . . . . . . 258

72. A destructive household beetle, Anobium domesticum. (After

Butler) . . . . . . 266

73. Vibbium scotias . . . 266

74. The book louse, Atropos divinaturia. (Dept. of Agriculture, U.S.A.) . . . . . . . . .

75. The silver fish, Lepismu succharina. (1).pt. of Agriculture, U.S.A.)

(Dept. of Agriculture, U.S.A.) . . . . . . . . . .

76. The human flea, Pulex irritans.

77. A dog flea. (After Brumpt).

270

274

274

78. A female Chigoe fleat, llermutophilus penctruns . . . 278

79. 'The berl bug, Cimcx lectularius . . . . . . . 278

80. Rostrum of louse. (Dept. of Agriculture, U.S.A.) . . 278

81. Human lice: A, Head louse. B, Body louse. C', C'rab louse. 282

82. Egg or "nit" of head louse. (After Brmupt) . . . 284

83. The human hot fly, Jermutulia hominis. (After 'Terzi in Manson's Tropical liseases)

94. Early larval stage of Dermatobia hominis. (1)ept. of Agriculture, U.S.A.).

284

286

85. Later larval stage of Dermatobia hominis. (After surcouf) 288

86. A mosquito, Janthinosoma lutzi. (After Surcouf). . . 288

87. 'The 'Tumbu fly, Cordylobia anthropophagu. (After Terzi in Manson's Troprical Viseases)

88. The Cayor worm, Cordylobia anthropophaya. (After 'l'erzi iu Manson's Tropical Miseases)

89. The Congo floor maggot fly, A uchmeromyia luteola. (After Terzi in Manson's Tropical Liseases) .

90. The Congo floor maggot fly, Auchmeromyiu luteolu. (After Terzi in Manson's Tropical Diseases).

290

290

292

292

91. The screw worm tly, Chrysomyia macellaria. (After Terzi in Manson's Tropical Diseases)

92. The screw worm, Chrysomyia macellaria. (After 'Terzi in Manson's Tropical Diseases) . . . . . .

93. Human itch mites, Sarcoptes scabei. (After Carazizi) . .

94. The human follicle mite, Demodex fulliculorum var. hominis. (After Carazzi) .

95. A harvest mite, Leptus autumnalis. (After Carazii)

96. Conducting an experiment with Calosoma sycophanta larva. (After Howard and Fiske)

97. A hymenopterous parasite of the gipsy inoth, Anastatus bifasciatus (female). (After Howard and Fiske)

98. A hymenopterous parasite of the gipsy moth, Schedius kuvance (female). (After Howard and Fiske)

99. Parasitised eggs of the gipsy moth. (After Howard and Fiske)

100. Gipsy moth larva killed by the hymenopterous parasite Apanleles fulvipes. (After Howard and Fiske) . 



\section{INTRODUCTION}

"THERE is a certain school of biologists who regard any work which can at all be applied as something very inferior to the enumeration of the bones of some animal's skull, or a technical description of a new species. Such work has its place, but I certainly think that equal praise and reward are due to the man who can seize hold of the results of his or others' researches and weave them into the daily life of a nation or a community for their benefit." These words, uttered by an eminent scientist during an address at Bristol University, express, in some measure, the indifference, amounting almost to opposition, which has been meted out to the applied biologist by his confrères. The man who has attempted to use his knowledge of insect habit and habitat for the benefit of his fellow-men has been looked upon as a dabbler in science rather than as a serious worker. Underestimated by scientists, misunderstood by the very sections of the community who should have received him with open arms, the applied biologist has "ploughed his lonely furrow" till at length his work has come to be recognised.

A disintegration of opposition is taking place, or has taken place, in every civilised country. In America, the applied biologist has long been a power in the land; generously assisted by his government, he has not wasted his opportunities of showing that there is "something in it." In this country, at least, it is to such men as Manson, Ross, and Sambon, workers in the medical field of ento- 
mology, that the credit must be given for breaking down the barrier of prejudice. Their brilliant researches into the part played by insects in the spread of disease have appealed more strongly to the popular imagination than equally important discoveries in the domain of agricultural entomology. There is work to be done in the agricultural field every whit as important and far-reaching as anything that has been accomplished on the medical side. Insects, adapted to every climatic and topographical condition of the world, have developed into an incredible number of species - ten million it is said,-and, excepting microscopical plants and animals, they far outnumber all the other living beings put together.

It is fortunate for man that the insect world is a house divided against itself; except for this check the human race would be extinct in five or six years. The fecundity of many insects is enormous; Huxley estimated that, mishaps apart, a single green fly would, in ten generations, produce a mass of organic matter equivalent to five hundred million human beings, or as many as the whole population of the Chinese Empire. From the earliest times man has suffered from insect damage to his crops, his livestock, and himself. Locust plagues, rivalling those of Egypt, have come to man from time to time. Pliny mentions them; they visited Ukraine in 1645, and America at the close of the civil war; a vast swarm two thousand miles in extent crossed the Red Sea in 1889, and eight years previously one thousand three hundred tons of locust eggs were destroyed in Cyprus alone. But this is not all; the United States suffers damage annually to the extent of $\$ 40,000,000$ owing to the depredations of the Hessian fly; the cotton-boll weevil causes an annual loss of $\$ 30,000,000$; the codling moth $\$ 15,000,000$, and the chinch bug $\$ 7,000,000$; add to this the damage done by gipsy and brown-tail moths, and the San José scale, to say nothing of a host of minor pests, and the total assumes alarming proportions. Turning to our own 
country, an approximate valuation of the livestock in Great Britain alone amounts to $\mathfrak{\$} 450,000,000$, whilst the area under crops of all descriptions is probably $32,000,000$ acres. Every insect that is injurious to stock or crops is a factor, and a serious one, on the debit side of "the one industry that never dies." The damage occasioned by what may be termed agricultural insects is often not fully realised by the farmer himself; but doubly true to-day is the statement made more than fifty years ago by John Curtis in his Furm Insects, when he wrote: "They (insects) annually consume an amount of produce that sets calculation at defiance; and indeed if an approximation could be made to the quantity thus destroyed, the world would remain sceptical of the results obtained, considering it too marvellous to be received as truth."

How insects control the destinies of nations, how they render some of the fairest parts of the earth nigh uninhabitable, is perhaps not fully realised by the man in the street, who is apt to consider the insect world too insignificant and unimportant to concern him very much. But unity is strength, and the fact remains that insects and insects alone have held up great engineering schemes, and have been the cause of the abandonment, temporarily at any rate, of undertakings of world-wide importance. Even our homes are not free from the attentions of this tirelessly industrious underworld. Countless hosts of insects seek their livelihood on man himself, in and about his dwellings, his food, furniture, and clothing, whilst even his drugs and cigars pay toll to this insidious foe.

Not every insect, however, must be considered in the light of a potential enemy, far from it. Honey bees which give us honey, silkworms which spin our silk, lac insects from whose excretions we prepare shellac and sealing-wax, are cases in point. Add to these a number of insects that destroy noxious plants, act as scavengers, work the soil, carry pollen and provide food for mankind, and others 
that have been and, to a limited extent, are still used as drugs, and we obtain quite a respectable total on the credit side, though hardly a balance, it must be admitted, even when we include an enormous number of predatory and parasitic insects, which, by waging ceaseless warfare on their harmful relatives, serve to keep them in check.

That the struggle for supremacy between insects and man is a very real one the world over it is hoped that these pages will show.

In the words of a celebrated American entomologist: 'Man is but one of the forms of life struggling for existence, at continual warfare with surrounding forms, but by virtue of his surpassing intelligence-itself as gradually evolved as have been the physical characteristics of any given species-he has overrun the earth, has accommodated himself to the most unnatural environments; he has dominated all other species in nature; he has turned to his own uses and encouraged or hastened the evolution of species useful to him or of useful qualities in such species; he has wiped out of existence certain inimical forms and is gaining the control of others. $\mathrm{He}$ is the dominant type, and types whose existence or methods of life are opposed to his interests are being pushed to the wall. It is the culmination of a history which has many times repeated itself in past ages. The struggle of other forms of life to accommodate themselves to the conditions brought about by the rapid development of the dominant type is one of the interesting fields of study open to the biologist to-day. It would seem as if in man's efforts to make the face of the earth his own, all the complicated elements of life were arrayed against him; and the great and ultimate result of the labour of the biologist in his study of the relations of the different forms of life, and the laws which govern their development, will be to bring about the absolute control of all other life by man. Thus, it is not only the economic worker who looks for result of a practical kind from his 
labour-the scientific agriculturist, the horticulturist, the economic zoologist, the medical bacteriologist, who should command the respect of even the practical-minded manbut the biologist in whatever field, however restricted it may be, whether he is working towards the understanding of broad principles and general laws, or whether in some narrow corner of research he is accumulating material which will help ultimately to lead to wider understandings -all are working helpfully and practically towards the perfect well-being of the human race."

To the theories, the actualities, and the discoveries enumerated in this book the author makes no claim whatever. The work is the work of others, and has seen the light of day only, for the most part, in the scientific journals of Europe and America: here, for the first time, an attempt has been made to compile, in non-technical language, a concise summary of the varied relations of insects and man. A vast amount of literature has been consulted of necessity, and, as far as possible, every publication to which reference has been made is included in the bibliography at the end of the book. Details of anatomy, which are of interest only to the systematist, have been eschewed, as also have purely medical questions, except in so far as they concern the entomologist. In a book of this nature, despite every care, errors are liable to creep in unawares, and sins of omission are bound to occur: for these the reader's pardon is craved.

Before embarking on a consideration of the thousand and one ways in which the activities of man and insects harmonise, to their mutual benefit, or result in a war to the death for supremacy, it may be well to consider, for a moment, exactly what position insects occupy in the animal kingdom, and, having done so, to give a brief résumé of the various orders of insects dealt with in the ensuing pages. The animal kingdom as a whole is divided into two great divisions-Vertebrates and Invertebrates. In the former 
division is mankind, in the latter the insects. The Invertebrates are still further divided into a number of groups or phyla; the members of one phylum being known as Arthropods, that is to say, animals whose bodies, enclosed in a firm cuticle or exoskeleton, are composed of a series of segments or rings, and whose appendages are jointed. In all Arthropods, some of the anterior segments are fused to form the head, and in some members of the phylum the segments, posterior to the head, are fused to form the thorax. The appendages comprise the legs, mouth parts, and sensory organs-antennæ or "feelers." It is unnecessary in a book of this nature to enter into anatomical details, and the reader who desires to further his knowledge in this direction is referred to one of the general textbooks of entomology mentioned in the bibliography. It is sufficient for present purposes to notice that the Arthropods are further subdivided into classes, namely, the Crustacea, comprising crabs, lobsters, etc.; the Myriapoda, comprising centipedes, etc.; the Arachnoidea, still further subdivided into (a) Araneida-spiders, and (b) Acarina-mites and ticks, and the Hexapoda or Insecta, true insects.

The ensuing pages deal, for the most part, with the true insects, that is to say, animals usually terrestrial or aerial, with bodies, in the adults, divided into three distinct parts, head, thorax, and abdomen, provided also with a pair of antennæ, three pairs of legs, and, as a rule, two pairs of wings. Many important diseases of man and beast, however, have been definitely proved to be carried by ticks, and the mites are not without interest in their relations with man, so they have been included, although, strictly speaking, they do not come within the scope of this book. The ticks and mites may be distinguished from the true insects by the fact that they have a fused head and thorax-cephalothorax, -no antennæ, and, when adult, four pairs of legs.

Insects with similar general characters are arranged in orders as follows :- 
(a) Aptera (no wings), diminutive, wingless insects provided with three pairs of legs and often large antennæ.

(b) Orthoptera (straight wings), locusts, cockroaches, earwigs, etc., have four wings, the front pair usually leathery, with comparatively straight veins, the hind pair fan-shaped with radiating and concentric veins. They have biting mouths.

For the most part, the members of this order are exceedingly active, jumping and flying well; but some of them, on the other hand, are sluggish and also wingless. The grasshoppers and locusts, Locustidee and Acridiida, are very similar in habit, though, as a rule, the former lay their eggs on foliage, the latter in holes in the ground. The crickets, Gryllide, and earwigs, Forficulide, usually frequent damp places and are fond of hiding under stones, wood, etc. The cockroaches, Blattide, are household insects in this country, but, in other countries, Australia, for example, many species are found far from any habitation. The mantids, Mantida, and stick insects, Phasmide, have many points in common; both have a coloration adapted to their surroundings; the green species frequent green foliage, the brown species hide on dead leaves. The mantids, however, are carnivorous, whilst the stick insects are strictly vegetarian.

The termites, Termitida, form a connecting link between the Orthoptera and (c) Neuroptera (nerve wings), lace wings, etc. Their two pairs of wings are more or less uniform and much veined, whilst their mouths are adapted for biting.

This order is comprised of insects with very dissimilar habits, especially in their early stages. Larval ant-lions hide at the bottom of funnel-shaped pits, which they dig in the ground and there await their prey-some luckless insect that falls into the pit. Lace-wing fly larvæ crawl about among foliage seeking their prey, which consists of aphides and scale insects. Many members of the order are 
aquatic, and, among them, we may mention the dragon flies, May flies, and stone flies.

(d) Hymenoptera (membrane wings), bees, ants, wasps, etc., with four membranous, slightly veined wings, and biting and sucking mouths.

This is a large and important order, and a review of all the families is impossible, so we will mention some of the groups more frequently encountered. The bees, Apida, are the most important members of the order, and, in addition to the honey bee, there are many equally interesting, though less important, insects, such as the leaf-cutter bees, Megachile. They form burrows and line them with pieces of leaf which they cut from plants. The carpenter bees, $X y l o c o p a$, are also of great interest, their nests being a series of chambers in some plant stalk, in each one of which they place bee bread and an egg.

The ants, Formicidae, have been the subject of much research, mainly on account of their remarkable intelligence; but they must not be confounded with the related "cow ants," Mutillidae. Other members of the order are the sand wasps, Pompilida, which form burrows in the ground and store them with insects, previously rendered unconscious, but not lifeless, by a sting, so that their larvæ when they appear may have living food. The Vespidae, of which the common wasp is a nember, are well known to everyone. The saw flies, Tenthredinidae, are so called because the females are provided with a curious saw-like appendage with which to cut leaves of plants, preparatory to ovipositing therein. Of the other Hymenoptera we may mention the Chalcididce and Proctotrypidae-gall-producing and gall-destroying insects,-and the Braconidoe and Ichneumonidoe-parasites, with a habit of laying their eggs in the bodies of other insects.

(e) Coleoptera (sheath wings), beetles, have four wings, the upper pair horny; their mouth parts are designed for biting. 
This, too, is a large and curiously varied order. The tiger beetles, Cicindelida, and the ground beetles, Carabida, are carnivorous, and therefore of some economic importance; many of them are aboreal and seek their prey in trees. The rove beetles, Staphylinida, have shortened wing covers that look as if they had been broken off in the middle; they exist on decaying animal and vegetable matter and do a certain amount of good as scavengers. The leather beetles, Dermestida, are household or warehouse insects, and they do considerable damage to hides, bacon, and dried foods. The stag beetles, Lucunidce, are many of them exceedingly handsome, though not of great economic importance, for their food is dead or dying wood. The scarab or dung beetles, Scarabaida, live on excrement and on decaying animal matter; the Cetonidce or rose-chafers, on the other hand, are commonly met with on the blossoms of rose trees. The tastes of beetles are varied in the extreme. Other flower-frequenting families are the Buprestide and the Elaterida or click beetles, though the latter are chiefly notorious on account of the damage done to the roots of various plants by their grubs, commonly known as "wireworms." The Tenebrionida are a funereal-looking family, mostly black or dark brown, of which the meal-worm, mentioned elsewhere, is a common and destructive nember. The weevils or Curculionida are a very distinctive group, on account of their characteristic snouts, which have earned them the name of elephant beetles. Many of them are exceedingly destructive to crops. Another beautiful, though harmful, family is the Cerambycidae or Longicorn beetles, remarkable for their extraordinarily long antennæ and the wood-boring habits of their larvæ. The Chrysomelidae are brightly coloured beetles, and many of them are very destructive to plant foliage. Somewhat resembling them, on a small scale, though of course there are constant and important differences, are the Coccinellida, known to all as ladybirds, and, with few exceptions, as exceedingly useful insects. 
(f) Lepidoptera (scale wings), butterflies and moths, have four pairs of wings, usually covered with scales and mouths adapted for sucking.

Of the butterflies, the most important families are the Papilionidoe, containing the largest and handsomest species in the world: our swallow-tail butterfly belongs to this family; the Pieridae or cabbage butterflies, of which the destructive "cabbage white" is an example; the Lycaenidae or "blues," remarkable for the eccentric forms of their larvæ, and the "skippers" or Hesperida, curious insects forming a connecting link between the butterflies and moths, of which the best known families are the Sphingidae or hawk moths; the Bombycidce or silkworm moths; the Noctuidae, usually sombre-coloured moths, and, as a family, exceedingly destructive in the larval stage; the Tineidae, of which the clothes moths are examples; and the Tortricidae, harmful, in the main, to cultivated plants, the larvæ of the majority being leaf rollers.

(g) Diptera (two wings), house fly, tsetse fly, gnats, etc., provided with two wings only, the second pair being reduced to club-shaped stumps, known as halteres or balancers; their mouths are piercing or suctorial.

The flies are the most important order, from the medical standpoint, so many of them are carriers of disease in man or animals. There are two sub-orders, the Orthorrapha and the Cyclorrapha. Some important families of the former order are, the Culicidae or mosquitoes, a cosmopolitan family of blood-suckers; the Tipulidoe or crane flies, with crop-destroying larvæ known as "leather jackets"; the Cecidomyidae, minute gall-producing flies, for the most part, and, for the rest, enemies of the husbandman; Psychodidoe or owl midges, of which one species transmits disease; Chironomidae or midges, and Simulidae or buffalo gnats, some species of which are looked upon with suspicion, at the present time, by medical entomologists; the Mycetophilidae or fungus gnats, with a predilection for ovipositing 
in fungi; the Tabanidae or gad flies, many of them annoying and even harmful to stock-in fact they are proved carriers of disease in animals; and the robber flies or Asilida, almost bee-like insects which earn their livelihood by killing other insects, often much larger than themselves.

Of the Cyclorrapha, we may mention the Syrphide or hover flies, common objects as they remain, apparently motionless, though in reality with rapidly vibrating wings, over some favoured flower which they are visiting for the sake of its pollen or nectar: some of the aquatic larvæ of this family have curiously long breathing tubes, hence their name of rat-tailed larvæ. The best-known member of the family Sepsicle is the cheese skipper, whilst the families Oscinida and Trypetide supply many enemies of the farmer and gardener. The QEstricke or bot flies comprise species attacking man and animals; the Tuchinide are all parasitic in the larval stage on other insects, particularly lepidopterous caterpillars; the Surcophagide or flesh flies and the Anthomyide live on carrion and vegetable matter respectively: to the latter family belongs the lesser house fly. The Muscidee is the most important family of all ; it is subdivided into blood-sucking and non-blood-sucking flies. To the latter division belong the house fly, the blow fly, the green-bottle fly, the screw-worm fly, the Congo floor maggot, and the Tumbu fly; among the blood-sucking flies of the family the most notorious are the tsetse fly and the stable fly. Other important dipterous families are the tick flies or Hippoboscida, of which the best known is the sheep tick; all the members of the family are parasitic on mammals or birds, whilst the parasitic flies of the bats all belong to the family Nycteribiidce.

(h) Thysanoptera (tassel wings), thrips, etc., with four very narrow wings fringed with hairs. Their mouths, though weak, are adapted for biting.

(i) Rhynchota (beaked insects), bugs, scale insects, etc., with four wings, of which the upper pair may be leathery 
at the base, as in the bugs, quite transparent, as in the plant lice, or absent, as in the scale insects. Their mouths are adapted for piercing and sucking.

This is a varied order, its members assuming every imaginable shape and form, from the large-winged cicadas to minute forms, having the appearance of flakes of bran. To the uninitiated they resemble beetles, butterflies, and even stick insects, according to their species. Mostly vegetable feeders, some, however, the Reduviidoe, are carnivorous, certain species going so far as to attack man, whilst one at least is known to transmit disease. The Membracidce are remarkable for possessing horn-like projections of the thorax; the Psyllidae are called manna insects: they resemble miniature cicadas. The Pentatomida, Coreida, Lygoeidoe are as varied in habit as they are in form. The Coccidae or scale insects are, collectively, the most important family in the insect world, from an economic point of view, and, incidentally, the most harmful. As their popular name implies, they cover themselves with a scale which acts as a necessary protection from their enemies.

This brief survey of the insect world makes no pretensions to completeness, but is given as a guide to the better understanding of the ensuing pages.

The orders are comprised of sub-orders and families, and these again are made up of genera, each genus containing one or more species. Taking the human flea, known in scientific parlance as Pulex irritans, as an example, and studying its relationship to other animals, we find that it belongs to the division of Invertebrates, because it is provided with an exoskeleton, as opposed to an internal or endoskeleton; it is an Arthropod on account of its segmented body, to which are attached jointed appendages; seeing that it has a distinct head, thorax, and abdomen, six legs and antennæ, it is a true insect; being wingless and provided with a characteristic arrangement of its mouth parts, together with other anatomical details, which do not con- 
cern us here, it is placed in the order Siphonaptera; more detailed specific characters apportion it to the genus Pulex and finally to the species irritans. Certain orders have been omitted from the classification, not necessarily because they are unimportant, but because their members from one cause and another are not of great economic import to man.

An insect, unlike a man or a rabbit, does not, as a rule, begin its separate existence as a miniature replica of an adult, nor does it hatch from the egg in a form resembling its parents, as in the case with the barnyard fowl; it passes through several changes, or metamorphoses, in the course of its life. Taking the common house fly as an example and studying its life-cycle, we find that the eggs give rise to grubs or maggots, properly called larvæ, and bearing no manner of resemblance to the winged, six-legged mother fly. Needless to say the larvæ are small at first, but, as they are voracious feeders, they grow rapidly, and their skins, loosely fitting to begin with, are quickly filled out and made a good fit; then the larva moults, gets a new loosefitting coat, which is again similarly filled; thus growth takes place, though it is not so noticeable in the house fly as in some of the lepidopterous larvæ. When fully fed the maggot changes into the chrysalis or pupa-it is said to pupate. No food is eaten, and to all appearances this is an inert, resting stage, though, as a matter of fact, great and important changes are taking place within the pupal skin, for the insect is passing from the larval form to that of the perfect insect. When pupation is complete the adult fly emerges from its prison and is fully grown. It is a popular error to imagine that flies grow, a remark that also applies to butterflies and moths, bees, wasps, etc. Sometimes a newly emerged moth appears small by comparison with the same individual after the lapse of an hour or two, but this is simply due to the fact that the wings, moist and crumpled at first, have had time to dry and expand. Such 
a series of changes is known as complete metamorphosis, and this always occurs in the Coleoptera, Lepidoptera, Hymenoptera, and Diptera.

Now let us examine the common cockroach, popularly but erroneously called the black beetle. Needless to say the larvæ arise from eggs, but, unlike those of the house fly, they bear a very considerable resemblance to their parents. As the life-history of the cockroach is fully described elsewhere, there is no need to do more than mention here that the larva undergoes several moults, and that, at each one, it becomes larger and darker in colour, in fact more and more like the adult. When the penultimate moult is reached, the insect assumes the rudiments of wings and is then known as a nymph; the final moult produces the adult cockroach. In such a life-cycle there is no quiescent or pupal stage, and metamorphosis is accordingly said to be incomplete, and it is the rule in the Orthoptera, Neuroptera, Rhynchota, Thysanoptera. In the Aptera a third variety of life-cycle occurs; the young are similar to the adults, except in size, and attain maturity by a succession of moults, in other words, there is no metamorphosis. The life-cycles of all insects are not always quite so straightforward as in the selected examples; sometimes, for instance, the larvæ emerge within the body of the parent and are brought into the world in an active state; this is the case, on occasion, in the sheep bot fly, which for this reason is said to be viviparous. The length of time required for the completion of a life-cycle, whether metamorphosis be complete or incomplete, varies considerably in different insects; in some species the time may be reckoned in hours, whilst, in the periodical cicada, metamorphosis extends over a period of seventeen years. External conditions such as food supply and temperature exert a powerful influence on the duration of the various stages; too high or too low a temperature will influence the egg and pupal stages; a scarcity of food may also prolong the larvæ stage. In the case of the ticks, 
which also undergo a metamorphosis, such a shortage arrests this stage to an almost incredible extent.

During the varied changes that take place in the lifecycle of an insect, it is extremely rare for the parent to take any interest whatever in his or her progeny; in many cases, in fact, the sole duty of the adults is to increase their kind, and frequently the female dies after ovipositing. How then, one may ask, do the young fare so well, on the whole, in the struggle for existence? How do they know, without experience or parents to guide them, what food will be good for them and what harmful, for every herbivorous insect has its appointed food plant or, at most, two or three food plants and will not eat of all green things indiscriminately. The mother insect lays her eggs on the proper plant, one may airily reply, without advancing far, for something must guide the parent in its choice, and most people would call that something instinct, though another word, Chemotropism, is more correct. Chemotropism has been called "the guiding force perceived by an animal through its olfactory sense"; it is a very important force in insects, because it instructs them where to lay their eggs; it helps them in their search for food and for mates. Most people know that if the females of certain species of moths be confined in a gauze-covered cage, males of the same species will seek them out as swiftly and surely as a vulture seeks carrion. Verschaffelt, in 1910, published some interesting results of his experiments on the choice of food in insects. He studied the larvæ of the large and small cabbage butterflies and discovered that they would only feed on plants that contained a certain chemical known as a glucoside, in this case one of the mustard oils-nothing would induce them to feed on any plant which did not contain this substance; so he made a dough of the glucoside and smeared it on the leaves of a plant which the larvæ had previously refused, with the result that they now greedily partook of the proffered food, being misled by the presence of 
the mustard oil. Further experiments of a similar nature were made with a hymenopterous insect, Priophorus padi, which will only feed on plants of the rose family, because they contain a glucoside known as amygdaline.

Another scientist, Howlett, published confirmatory, though even more striking, results in 1912. His experiments with the flesh flies, Sarcophaga, were exceedingly interesting. The larvæ of these flies, as their popular name implies, live on decomposing animal matter: the eggs therefore are always laid on some substance that will provide suitable food. Howlett, however, prepared a substance known as sketol from decomposing albuminous matter, and, placing it in a bottle, caused the flies to oviposit in its vicinity. With the stable fly, Stomoxys calcitrans, which deposits its eggs in horse dung and decaying vegetable matter, the same observer performed a like experiment. Closeted with a rag moistened with valerianic acid-a product of decomposing vegetable matter-the befooled flies at once proceeded to the business of egg-laying, being, evidently, ignorant of the fact that there was not a morsel of food for their progeny. Speaking of this powerful guiding force, which must have an all-powerful effect on the survival of insect life, Dr Trägardh says "the ovipositing of the females is guided, even in those cases when the larvæ has a diet different from that of the adult, by Chemotropism." These discoveries have a value that is almost incalculable to the economic entomologist, for if, as their sequel, injurious insects can be induced to oviposit in places other than on the larval food, their ultimate eradication is only a question of time. 


\section{II}

\section{INSEC'TS AND PLAN'TS}

LET us consider, for a moment, what effect insects have upon plants. Their action may be direct or indirect; in the former case insects may do actual damage to plants, or they may cause definite diseases to arise as a result of their injuries; in the latter case they may introduce fungoid diseases.

In the case of direct injury, various parts of the plant may be destroyed, either in the process of feeding, nest. building, or oviposition. 'The loss of an organ is not such a serious matter to a plant as to an animal, nevertheless, growth is seriously impaired when large numbers of insects devour the leaves, which carry on carbon assimilation. Other insects, such as grain beetles and moths, destroy seeds and therefore impair reproduction, and this function may also be impaired, at an earlier stage, by insects eating the pollen. Others, also, interfere with the reproductive parts of plants, but are mainly noxious, because they damage parts of more use to man than to the plants coneerned; as examples we may mention the damage to apples by the codling moth and to cotton bolls by the cotton-boll weevil.

Insects also cause direct injury in other ways, by abstracting from the plant the liquid food so necessary for its nourishment, or by removing so much material from root or stem as to interfere with the plant's stability.

Various physiological truubles may ensue as a result of injury. Roots or stems may be so damaged that the plant cannot obtain water, and wilting then takes place, or the 
leaves may turn red or yellow, and finally dry up, from the same cause. Plants often hold out signals of distress, as it were, when suffering root or stem injury. Cabbage leaves, for instance, become more thickly coated with bloom, as protection against excessive transpiration, and the same result is achieved, in other plants, by a gradual shedding of leaves.

Not only is the passage of water and raw plant foods interrupted by insect damage, the elaborated foods, also, are often prevented from reaching the growing points, where they are most needed. Various leaf-mining insects prevent the passage of starch from those organs; other insects so damage certain stems that the organs below the wounds are starved, while swellings arise above the wounds owing to the accumulation of elaborated foodstuffs.

Buds may be damaged, with the result that branches, abnormal in number and position, are formed, or, in the case of the terminal buds of some pines, severe distortion follows insect injury. The excessive exudation of gum in certain trees, such as peaches and cherries, is often the result of damage by insects, and many trees are much weakened, and even killed, after defoliation by insects, owing to the strain imposed upon them by the production of new crops of leaves to take the place of those lost.

Of the injuries and diseases due to the presence of insects and their products, front rank must be given to the work of gall midges. Other allied injuries are those of the Hessian fly, which causes a dark green colour and swellings in wheat; the apple weevil, causing apples to swell and turn brown; leaf hoppers and thrips, causing leaf curl, etc. Diseases, due to the indirect agency of insects, may enter plants at the point of insect injury, or may even be carried to the plants by the insects themselves. A few examples of plant diseases, introduced by insects, may not be without interest. Potato rot is caused by a bacillus known as Bacillus solanacearum, and, experimentally at any rate, 
potatoes may be infected with the disease by means of the Colorado beetle. Similarly, Bacillus tracheiphilus, the cause of wilt disease in plants of the cucumber family, can be and has been transferred from plant to plant by the beetle Diabrotica vittata, and the bug, Anasa tristis. A common disease of plants of the genus Prunus results in the leaves curling to such an extent that they are unable to carry on their proper functions, and the fungoid cause of the disease thrives on the sugary secretion of aphides. The scale insects, in the Florida citrus groves, are often attacked by a fungus, Ophionectria coccicola. As these inseets pierce the orange twigs with their sucking beaks, the plants become inoculated with the fungus, which sets up a disease called gummosis, and guin, in considerable quantity, oozes from various parts of the tree, much to its detriment. A boring beetle, Xyleborus perforans, and a weevil, Sphenophorus sericeus, are given to making holes in sugar canes, thereby enabling the spores of a troublesome disease to enter the plants. The wood of a certain species of fir tree, Pinus ponderosa, is often rendered almost valueless owing to the fact of its being turned blue by a fungus, Ceratostomella pilifera, and it has been discovered that the fungus enters the tree through the borings of a beetle, Dendroctonus ponderose. Some very common and destructive plant diseases are known as "smuts," because of the coal-blackcoloured spores of the causative fungus. In one such disease, Ustilago violacea, the spores take the place of pollen in certain flowers, and are carried from flower to flower by insects. Other similar examples, in plenty, could be given, but enough has been said to show, in a general manner, how closely related plant diseases are to insect damage.

Aphides, too, apart from direct damage, are injurious to plants indirectly, for their sugary secretions, called honeydew, form an excellent medium for the growth of fungi, which, while not parasitic on plants, injure them consider- 
ably, by covering the leaves densely and blocking out air and light. That insects do a vast amount of direct damage to plant life is a commonplace fact, but their indirect effect is no less potent and is often more difficult to remedy.

A considerable amount of damage is done to forest and fruit trees by various boring beetles, and those belonging to the family Scolytidce are perhaps of the greatest interest. One of these beetles, Xyleborus dispar (fig. 1, B), deserves special mention on account of its habits. 'Trees of various kinds may be attacked, though, in justice to this industrious little insect, it should be mentioned that the trees most usually attacked are those which have previously suffered some injury. In the spring the fertilised females, having discovered a suitable tree, begin operations by boring a horizontal tunnel for a short distance into the wood, and from this a vertical tunnel is bored (fig. 1, A). That tunnelling operations are going on may be seen by the white frass, or sawdust, trickling down the tree from the hole made by the beetle. Having completed the horizontal tunnel and the first vertical tunnel, the mother beetle deposits her eggs in the latter, and closes the entrance with a wad of damp frass; she then proceeds to excavate a regular tunnel system, ovipositing, the while, in each vertical branch and closing each entrance with a damp wad. The eggs are laid in clusters of six; the total number, depending on the nature of the wood, varies from six to forty-five, and as they hatch in a few days, many of the tunnels contain larvæ long before the mother has completed her tunnelling. The larvæ have relatively weak mouth parts and no gizzards, so that they are unable to obtain any nourishment from the tree in which they begin life.

Unlike the majority of insects, this little mother beetle lavishes a considerable amount of forethought on her offspring. Through the walls of the tunnels a considerable amount of sap oozes and forms a moist lining, the moisture being retained by the wad of frass, carefully placed at the 

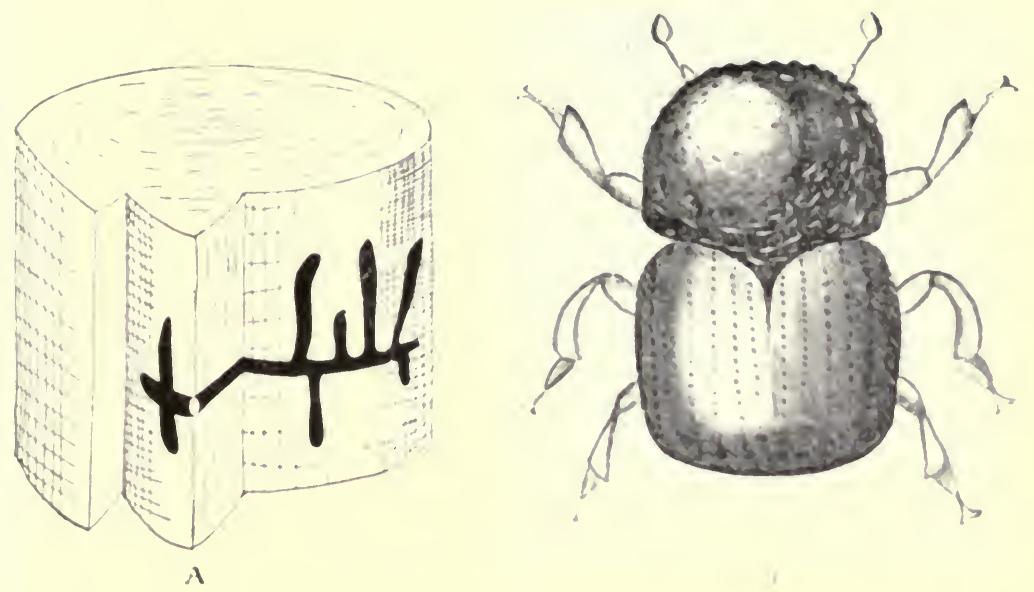

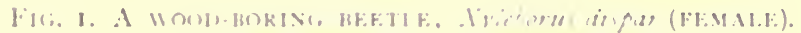

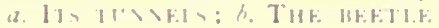

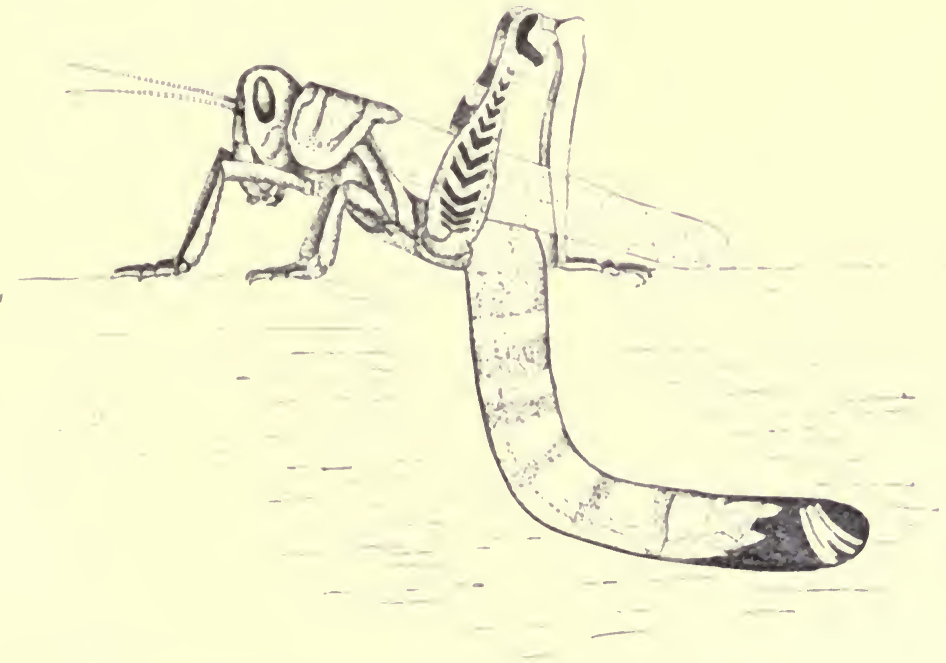

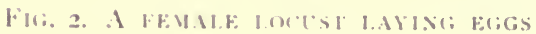



entrance to each tunnel by the mother beetle after she has deposited her eggs. This layer of sap forms a suitable nutrient medium for a fungus, Monilia candida, which, with the exception of two or three millimetres near the outer opening, completely fills the burrow by the time tunnelling operations are complete. The mother beetle then removes the wads, placed at the entrance of each side chamber, and the larve emerge to feed on the fungus fare provided for them. It must not be supposed that this fungus growth arises from the sap, or that it comes into being in some inexplicable manner; it is taken into the tunnel by the mother beetle. Fungi do not form seeds like the flowering plants, but they are propagated by exceedingly minute struetures, called spores. These spores have resistant coats, so that they can be carried in the gizzard of the mother beetle for as long as two and a half months without suffering any damage, and this, in fact, is the way they are carried. When the larva are fully fed they pass into the pupal stage, which extends over ten to fourteen days, when the young beetles emerge to pass the winter in the tunnel. A burrow, opened in the winter, will show no eggs, larvæ or pupæ, but a number of hibernating adults, both male and female, all lying with their heads towards the inner part of the burrow. In the spring mating takes place, and the females, their gizzards stored with fungus spores for the nutriment of the future generation, sally forth in quest of a suitable tree in which to rear their young.

Beetles of the Cerambycidce family are also notorious for their wood-boring propensities, as are also some of the Lepidoptera. Plate II. shows the male of one of our commonest boring moths, the wood leopard moth, Zeuzera assculi; he is resting at the end of a twig, drying his wings, for he has just emerged from the pupa case, which can be seen projecting from the twig below him. Of a greyishwhite colour, spotted with bluish-black markings, this moth is a beautiful, though, withal, destruetive insect. 'The large 
yellow, black-spotted larva lives within the branches of many species of trees, and, in doing so, destroys them. The goat moth, Cossus ligniperda, is an even worse offender in this direction. Its larva, when full-grown, attains a length of ten centimetres, is reddish-brown above and creamyyellow below, and has an evil "goaty" smell. As these larvæ live within the trees, willows for the most part, for three years and feed all the time, the amount of damage they do may be easily imagined. Other destructive, woodboring Lepidoptera are, the currant clearwing, Sesia tipuliformis, and the apple clearwing, Sesia myopiformis, damaging currant bushes and apple trees respectively.

\section{Locusts}

The majority of people, unscientific people that is, when questioned as to the most destructive economic insect, would assuredly reply, the locust. The reply might not be absolutely correct, but it would show that the locust is, by tradition, one might say, fixed in men's minds as an injurious insect. One of the plagues of Egypt took the form of a swarm of locusts, and, from that day to this, these insects have been the cause of very considerable financial loss to mankind. What is a locust? The name is loosely applied : in some countries grasshoppers are called locusts ; elsewhere, locusts become grasshoppers ; and again, at times, insects of other orders are named locust, apparently for the sole reason that they appear in swarms-the periodical cicada is a case in point. Strictly speaking, the locusts comprise about six species of the Acridiida, a family of the Orthoptera.

We will not attempt to describe the various species of locust, but will devote a few words to the habits of these insects in South Africa, where they have done more damage and hindered agricultural progress to a greater extent than anywhere else in the world. In our intro- 


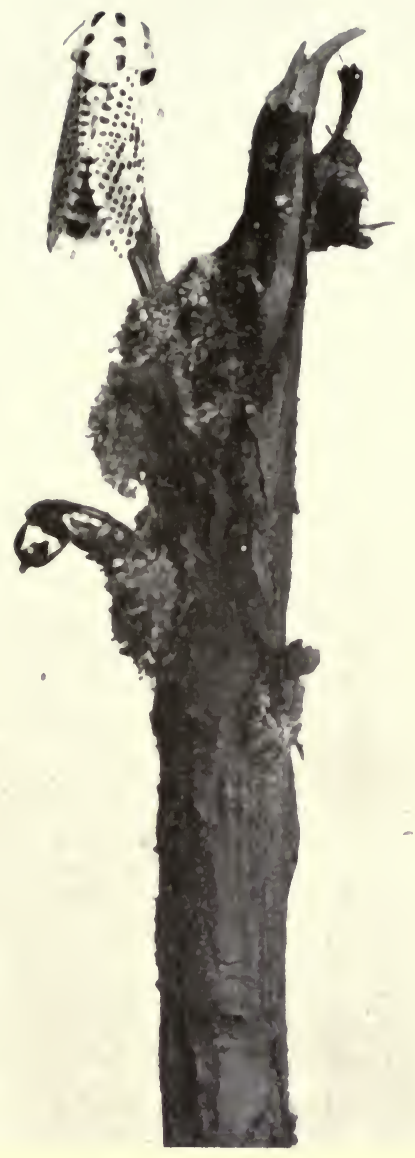

II.ATE, II

A WOOI) LFOPARI MOTH, MAI.F. (ZELYER.t AESCLLI.) 

ductory remarks, one or two noted locust swarms have been mentioned, but these were of exceptional magnitude; it is quite a common occurrence, however, for a South African locust swarm to have a frontage of fifteen to twenty miles, and a length of sixty to seventy miles, taking several days to pass a given point. One of these swarms is a sight never to be forgotten: the air is alive with a seething mass of insect life; now the sky is blackened and the sun almost blotted out, now the light, reflected from a myriad wings, resembles nothing so much as a violent snowstorm. As these insects pass over the country they devour practically every living green leaf. The veldt is stripped of grass in the dry season, and every winter erop cut down; trees are weighed down and broken by the sleeping locusts, and even washing hung out to dry has been devoured by these insects with insatiable appetites. Every inch of ground is covered with a thick carpet of their excrement; trains are stopped and delayed by the grease their crushed bodies exude on the rails; horses as a rule refuse to face a swarm. One swarm is capable of doing immense damage, but when there are dozens of such swarms in a country, the results to agriculture can easily be imagined-in the winter of 1906 the locust damage in South Africa was estimated at $£ 1,000,000$.

The adult, or flying locusts, usually appear in the dry season, when there are few growing crops and when the majority are in small plots and so easily protected; with the first rains come the immature forms, or "hoppers," called by the Dutch "voetgangers," a word meaning infantry. The "hoppers" often appear in swarms of some miles in extent, and so thick as to make the veldt appear brown. Nothing will turn them from their course; they go their way, like a relentless army, devouring every green thing in their path. There are two species of locust in South Africa, differing widely from one another in habits and distribution. The more destructive of the two is the 
brown locust, Pachytilus sulcicollis, a small insect of a general brown or straw order. The permanent habitat of the brown locust is in the Kalahari Desert and in German South-West Africa, whence winged swarms spread out over Central and Eastern Cape Colony, Orange River Colony, Basutoland, and Southern Rhodesia, from March to July. At certain seasons the general direction of the swarms is south-easterly, at others north-easterly, though the direction of flight seems little affected by winds. Oviposition (fig. 2) takes place about the first week in July, and each female perishes after laying two or three eggpouches or packets, each containing about forty eggs: the males live a month or two longer. These eggs remain in the ground, where they are laid, till the first rains come, early in October, and two weeks hence, unless the temperature has been low, the first hoppers appear. The larvæ closely resemble the adults, except that they are wingless; the swarms remain in compact formation, and, from time to time, adjacent swarms amalgamate, till miles of veldt are covered. By day they advance in columns, crossing rivers if necessary by swimming and forming bridges of their massed bodies; by night they sleep in grass and scrub. After moulting, the larvæ become nymphs, and in six to eight weeks the latter become adult, obtain their wings, and immediately fly back to the Kalahari Desert. Sometimes the females lay their eggs in regions, such as certain parts of Cape Colony, where rain only falls every six or seven years; in this event the eggs remain dormant, though fertile, for several years, and, when the rains come eventually, the larvæe emerge none the worse for their long developmental period.

The second South African species is the red locust, Cyrtacanthacris septemfasciata, so called because the newly mature insects are of a reddish-brown colour, whilst in the breeding season the hind wings are of a bright claret hue. This insect is considerably larger than the brown species, 
but is less destructive, being less widely distributed and occurring in smaller swarms. It is a coastal locust, and is, for the most part, confined to the warm humid districts at or near sea level, whilst its winter quarters are in Natal and Zululand. About the beginning of December each fernale deposits an egg-packet containing, approximately, ninety-five eggs, and then dies, but the males survive a little longer. In their choice of site for egg-laying these locusts are much more particular than the brown species, a newly formed sugar plantation being a favoured spot, and, as showing the enormous numbers of even these less numerous locusts, there exists an authentic record of twenty tons of eggs having been dug from ground of less than one hundred acres in extent. Sometimes these insects do not oviposit till after the rains have come, and then the hoppers appear in two or three weeks; another eight weeks sees them mature, winged, and returning to winter quarters.

One reason why locusts have, in the past, been such a power in the land in South Africa is because of the difficulty of eradicating them, a matter rendered doubly hard because the "old Boer was indolent enough to accept a locust plague as a punishment for his sins, and resorted to prayers and days of fasting, like our half-civilised ancestors of the middle ages, in the hopes of seeing a miracle wipe them out."

Now all this is changed; the Government have established a central bureau, from which and to which reports are constantly travelling. A well-organised postal system keeps the officials in touch with all the latest events in the locust world of the colony; the result is, that flights can often be predicted, and farmers, in the districts likely to be favoured with a visit, warned beforehand. This, however, is but a small portion of the work of the bureau, though, perhaps, the most interesting.

Needless to add, South Africa is not alone in suffering loss from locusts; in other parts of Africa, Asia, Australia, 
and America they do incalculable damage, and, on account of their extensive geographical range, there still remain districts where the losses they cause may be reckoned in millions of pounds. Take the case of the Philippine Islands as an example: in the latter half of 1912 locusts did damage to the amount of $£ 2,083,000$ in the island of Visaya, the northernmost of the group. Their breeding grounds were found to be in the extensive areas of uncultivated land in Mindanao. In these islands the immature locusts are called "lectones," and, as in other parts of the world, they attack practically every green plant in their path, though at times, for some unexplained reason, they will pass potatoes, sugarcane, tobacco, and beans. When mature these insects give off a characteristic odour, which is more pronounced in the breeding season, and, with a favourable wind, it is often possible to detect a swarm at a distance of five to eight kilometres by scent alone.

\section{Some Enemies of Cotton}

Of the various insects that have made themselves notorious by their attacks upon plants of economic importance, few have wrought more havoc than the Mexican cotton-boll weevil, Anthonomus grandis (fig. 3). The early history of this insect, which, being a weevil, belongs to the order Coleoptera and the family Curculionidoe, is somewhat obscure. It was first described by Boheman, in 1843, from specimens received from Vera Cruz; in 1871 it appeared in Cuba. In 1885 the beetle appeared, in force, in Northern Mexico, and in this year it was associated with cotton for the first time. In 1892, or probably a little earlier (the date of such events is difficult to determine), the weevil invaded the United States, effecting a landing at Brownsville, Texas, and in its first year became known as a serious pest of cotton. In less than three years the outlook had become so serious that the Federal Department of 

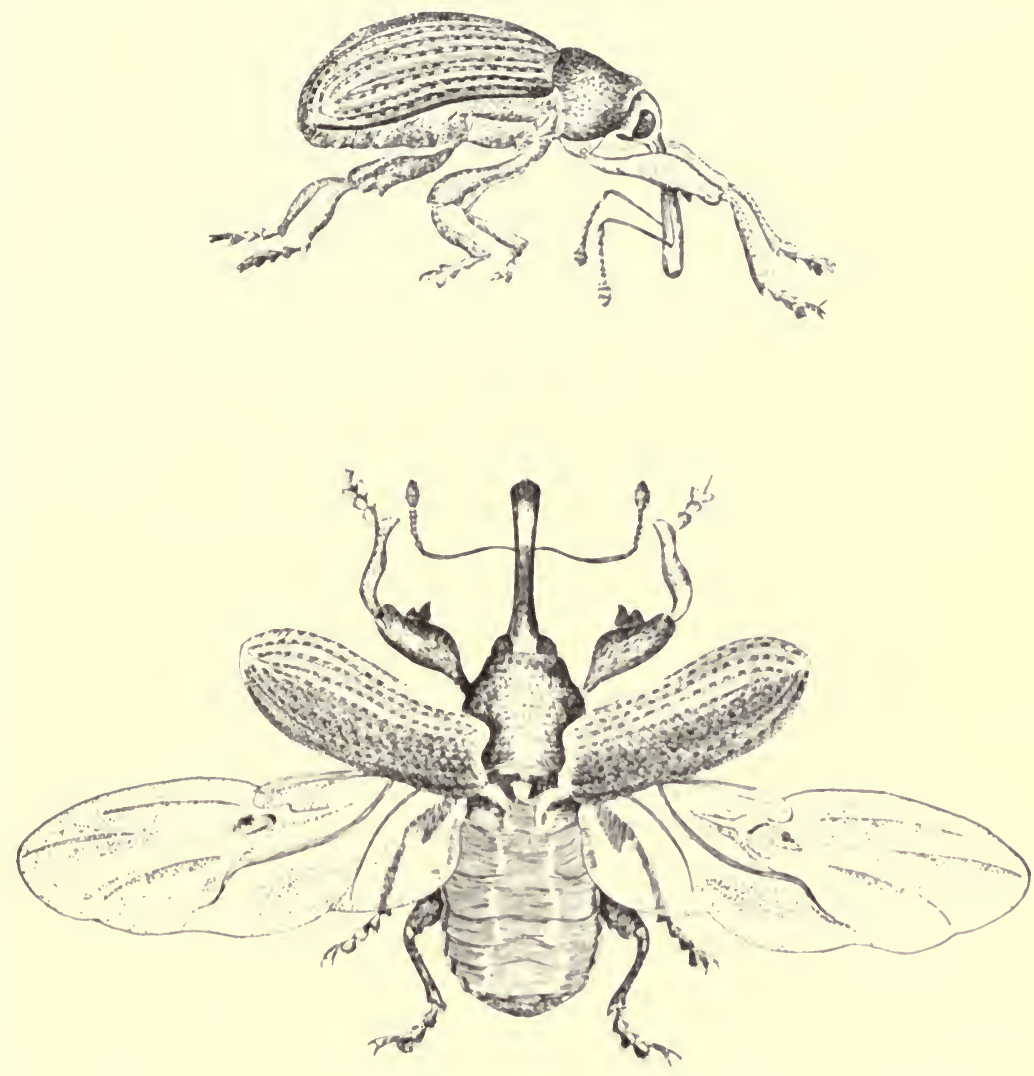

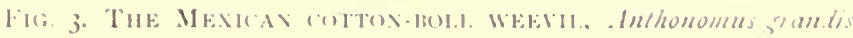



Agriculture had advised the Government of Texas to prohibit the cultivation of cotton, for the time being, along a belt coincident with its southern border, in order to prevent the advance of the invader. No notice was taken of this sage advice, with the result that the weevil spread northward and eastward, till it reached the margin of a rich cotton-growing district. The next two years saw the advancing tide stemmed somewhat by unfavourable climatic conditions; but the season of 1898 was very favourable to the insect, and the richest cotton-growing lands in the United States began to be invaded. As a result, a state entomologist was appointed, and a grant voted towards the control of the cotton-boll weevil. All efforts to prevent the insect gaining a firm footing in the American cottonfields appeared unavailing, and in 1903 the weevils entered Louisiana. At last, a general realisation of the enormous damage done by this minute insect led to the commencement of energetic work; with a view to its control, $\$ 250,000$ were voted, to enable the Secretary for Agriculture to meet the emergency caused by its ravages. In 1904 the insect became still more extensively dispersed in Texas and Louisiana. In 1905 observations were limited, owing to restrictions on travel imposed by the yellow-fever quarantine; but in the following year the area of infestation had reached to Oklahoma and Arkansas, and almost to the Mississippi river in Louisiana. The year 1907 marked the crossing of the Mississippi river into the state of Mississippi; the two following years saw a further spread of the weevil; but in the winter of 1909-10 it received a check, owing to the severity of the weather, and, although 1911 began with a low infestation, the lost ground was made up in Texas and Oklahoma, whilst remarkable gains were witnessed in Arkansas, Mississippi and Alabama, and Florida was invaded. In short, the Mexican cotton-boll weevil has conquered almost the entire cotton-growing section of the United States. "And there it stands to-day, now advanc- 
ing a little, now losing ground, in the face of a sudden frost or a concerted display of destructive work by the slowly awaking farmers, but probably the most harmful plant pest, and the heaviest tax upon the farmers of the South." Some authorities go further and say that the pest is the most serious danger that has ever threatened any agricultural industry.

The financial loss caused by this insect is difficult to estimate; cotton-growers are, somewhat naturally, prone to exaggerate the damage and to attribute losses to the insect which should more correctly be put down to bad cultivation or other sources. A careful estimate by the American Government officials, however, shows the difference in the average yield per acre in Texas, between the periods 18931901 and 1903-11, to amount to a loss of $\$ 2.7$ per acre, not counting the value of the seed, or, for the total cotton acreage of the state, $\$ 27,000,000$ per year! And this for Texas alone! "Out of evil comes good," and it is some compensation to know that the advent of the weevil has literally forced crop rotation upon the farmers of the afflicted districts. So profitable had the cotton-growing industry proved that the growers were loth to abandon, even temporarily, an industry that paid them so well. Before the coming of the weevil, the Texas growers believed they could keep pace with the ever-growing demand for cotton the world over, and at least double their normal production. The fertility of the land was so great that such important matters as seed selection, fertilisers, and rotation had received little or no consideration; but the boll weevil has put a different complexion on these affairs, and more scientific methods of cultivation must prevail if the insect is to be kept within reasonable bounds, for the only natural barrier to its spread is the cold of the more northerly states. As the same conditions regulate the northern limit of the cotton-growing districts, there is little comfort to be derived from the fact. 
So much for the history of the invasion of the cottonfields of the United States by the cotton-boll weevil. As for the insect itself, there are more than thirty different species of weevil to be found in the vicinity of the American cottonfields, so it is little to be wondered at that cases of mistaken identity occur, giving rise at times to local panics and a massacre of the innocents; for these other weevils do no harm to the cotton, though some of them visit the cottonflowers in search of nectar. Our subject, however, is not the only weevil that does damage to cotton, for another species, Anthonomus vestitus, has recently been discovered in Peru and Ecuador, where it is a serious cotton pest, though, fortunately, it is at present unknown outside those countries; three other species, in addition, are also known to do more or less serious damage to this useful plant.

Very careful observations have been carried out by American entomologists with a view to discovering the food plants of the Mexican cotton-boll weevil, and, according to their researches, the cotton plant is the original and only food plant of this weevil. The importance of this discovery may not be apparent at first glance, but, supposing that the cotton-planters of a whole region should abandon the cultivation of the plant, in order to escape the attentions of the boll weevil, their efforts would be unavailing, if the insect could subsist on some other plant or plants during the period and then attack the cotton with renewed vigour when its cultivation was resumed. If only on account of the fact that the weevil appears to have but one food plant, there is hope that crop rotation will materially decrease the pest in time.

The life-history of the cotton-boll weevil is not without interest. The female weevil bores a cavity, either among the immature anthers of a cotton square, or on the inner side of one of the carpels of a boll or bud, and there deposits a pearly-white egg. The covering of each egg is unmarked and soft but tough, thus allowing for consider- 
able changes in form; and, to a certain extent, it assumes the shape of the cavity in which it is deposited. In a few days the young larva hatches from the egg, and, at first, it is as inconspicuous as the egg from which it came, except for its brown head and mandibles. About $\frac{1}{25}$ of an inch in length, this legless grub (fig. 4, A) is crescentic in form and white in colour, modified, however, by the dark-coloured body contents, which show through the almost transparent body wall. As the larva feeds and grows it enlarges the cavity in which it dwells, and, at the same time, the larval castings are spread thickly over the walls of the cavity, and, becoming firmly compacted by the frequent turning of the grub, form a cell in which, after the third moult, pupation takes place. The pupa (fig. 4, B) is creamy or pearly white in colour, gradually becoming darker as the adult stage is neared. When the final moult is about to take place, the pupal skin splits open over the head and slips down over the proboscis and thorax, but it adheres to the antennæ and tip of the proboscis, till the back has been laid bare and the legs kicked free. Then the skin is violently pulled with the fore legs, and so the tip of the snout and the antennæ are freed; finally, with the hind legs, the shrunken and crumpled skin is kicked off the tip of the abdomen. The whole operation lasts for about half an hour. The newly emerged adult is soft, helpless, and quite unable to walk, so it remains for a time within the cavity where it emerged. It is light coloured, the proboscis, which is the darkest part, being yellowish brown, and the elytra or wing cases pale yellow. After about two days the beetle (fig. 3 ) has become hard and more active, and has also attained its normal colouring, so it escapes from its voluntary prison by cutting with its mandibles a hole just the size of its body. The coloration and size of the adults vary considerably. As a general rule, the greater the supply of larval food, the larger the size of the adult, and the larger the adult, the lighter its colour. The largest 

adults are light yellowish brown, and the smaller ones are much darker in colour, whilst weevils that have hibernated are darkest of all.

This, in short, is the life-cycle of the weevil, but, before dealing with the exploits of this pernicious pest in the cotton-fields, it may be of interest to deseribe the process of oviposition in the words of the actual observers, Messrs Hunter and Pierce. They say that, "while engaged in making egg punctures the favourite position of the weevil is with its body parallel to the long axis of the square and its head towards the base. 'The tip of the weevil's body is thus brought near the apex of a medium-sized square. It may be that the position described is especially favourable for obtaining a firm and even hold, and this may have something to do with the regularity with which it is assumed. Having selected their location, the female takes a firm hold upon the sides of the square and completes her puncture while in this position. The female begins drilling a hole by removing with the mandibles a little flake of the outer epidermis. Then, with her feet strongly braced by gnawing and pushing with an auger-like motion, she thrusts her back into the tender portion of the square. At the bottom of the puncture she makes a small cavity by gnawing, at the same time moving about the hole with the beak as a pivot (fig. 5). Withdrawing her beak, she turns about with the centre of her body as a pivot. This places the tip of her abdomen directly over the puncture, into which she thrusts her ovipositor. The ovipositor is protruded to the bottom of the cavity, in which it appears to be firmly held in position by the two terminal papilla and the enlarged terminal portion. Slight contractions of the abdomen occur while this insertion is being made. In a few moments much stronger contractions may be seen, and often a firmer hold is taken with the hind legs as the egg is passed from the body, and its movements may be seen as it is forced along within the ovipositor down into the puncture. Only 
a few seconds are required to complete the deposition after the egg enters the opening to the cavity. Having placed the egg, the ovipositor is withdrawn, and just as the tip of it leaves the cavity a quantity of mucilaginous material, usually mixed with some solid excrement, is forced into the opening and smeared around by means of the tip of the abdomen. This seals the egg-puncture, and the act of oviposition becomes complete. Sometimes the weevil fails to locate the puncture immediately with her ovipositor. In this event she searches excitedly, moving the tip of the abdomen about, feeling carefully over the surface of the square. In this search, however, she never moves her front feet, apparently using the position of these as a guide to the distance through which she should search. Failing to locate the puncture in this way, she again turns around and searches for it with her beak and antennæ. When the cavity has been found again the female invariably enlarges it before turning again to insert the ovipositor. If the search with the antennæ does not prove successful, the female generally makes another puncture in the same manner as at first. The usual habit of the female in puncturing through the calyx enables it to seal the wound more thoroughly because of the healing power possessed by the calyx tissue. Punctures made in the corolla must remain open, or are closed only by the slight filling of mucilaginous excrement by the weevil. Punctures through the calyx will, in most cases, be healed by the natural outgrowth of the tissue so as to completely fill the wounds in a manner analogous to the healing of wounds in the bark of a tree. The custom of the weevil in sealing up its eggpunctures with a mixture of mucous substance and excrement is of great advantage and assistance to the plant in the healing process. While undoubtedly applied primarily as a protection to the egg, it seems to keep the punctured tissue from drying and decay, and this promotes the process of repair. As a result of the growth thus stimulated in 
the calyx, the wound is healed perfectly in a short time, and a corky outgrowth appears above the general surface plane. This prominence has been termed a 'wart.' The healing is completed before the hatching of the egg takes place, and thus both egg and larva partake of the benefit of its production. Occasionally warts develop from feeding punctures which were small, but the exact conditions under which this takes place have not been determined. Nevertheless, the presence of warts is the most certain external indication of oviposition in squares. In a series of observations they were found to follow oviposition in eighty-four per cent. of the cases."

An important factor in the development of all economic insects is their capacity for rapid development. And an interesting experiment has been carried out to test the powers of the boll weevil in this direction. A hibernating weevil, laying one hundred and thirty-nine eggs by 10th June, would probably bring half that number, say seventy, to maturity by 29 th June. There are at least four generations in a season, and, allowing for the same rate of increase in the succeeding generations, the second generation would number about two thousand four hundred and fifty; the third eighty-five thousand seven hundred and fifty; and the last and final generation, three million one thousand two hundred and fifty, or a total of three million eightynine thousand five hundred and twenty individuals, as the progeny of a single pair of weevils and their descendants in one season. Put in other words, the progeny from one fertile hibernated female might, in the course of four generations, that is to say in a single season, number one weevil for every square foot of area in a seventy-five acre field. As over fifty per cent. of the weevils are destroyed by natural conditions, it is doubtful if the actual increase in one season, from a single pair, ever exceeds two millions. Alarming figures in all conscience!

The Mexican cotton-boll weevil is a strong flier, therefore 
its rapid distribution is not the cause of wonderment even to the least observant, as is the case with those essentially stationary insects the coccids, or such semi-stationary ones as the gipsy moths. A certain amount of dispersion takes place in the spring and summer, but it is in the autumn that the more or less annual advance over the cotton belt takes place. The dispersion may be put down as an overflow from territories so overcrowded that there is a scarcity of food, and no opportunities for breeding, combined with a strong instinct to invade new regions. The direction of this great autumn flight is usually governed by the prevailing winds, and the distance travelled is regulated by the occurrence of uninfested cotton. If the first short flight reveals cotton as yet unattacked, the weevils will settle there; if, on the other hand, infested cotton is found or none at all, a series of flights will take place, till the beetles find the cotton they are seeking. Sometimes these flights will carry them as far as forty miles. In the cotton-fields the boll weevils are well protected from their enemies by their colour, which harmonises well both with the dry cotton squares and the soil on to which they frequently fall. When the plant on which the weevil is feeding is disturbed, or even if a large object moves in its vicinity, the insect becomes all attention, remaining motionless, with its antennæ raised. If the disturbance continues, the weevil falls to the ground, withdraws its antennæ against its beak, which, together with its legs, are drawn close to its body. Thus it remains "shamming dead" for some time, unless further disturbed, when it will take to its legs and run a short distance before repeating the performance.

It is only natural that a considerable amount of attention has been paid to the control of such a pest as the boll weevil has proved itself. Climatic conditions have, so far, proved the most effective agency in keeping the insect within anything approaching reasonable bounds. Winter cold and summer heat alike are injurious to the insect, the 
former, by directly reducing its vitality, resulting eventually in death; the latter, achieving the same result indirectly, by interfering with the fruiting of the cotton plant and so depriving the weevils of food; but winter cold is, on the average, twice as effective as summer heat.

With regard to parasitic and predatory enemies of the Mexican cotton-boll weevil in the United States, the American entomologists say that "it is known to be the host of twenty-nine species of parasites, of which four are mites, twenty-one belong to the order Hymenoptera, and five are parasitic flies. In addition to these true parasites, there are six predators which kill the adult boll weevils, and twenty-two predators which attack the immature stages. These include a mantis, a predatory bug, eight beetles, a leaf-feeding eaterpillar, and seventeen species of ants. In all, the boll weevil is known to have fifty-eight speeies of insect enemies, and probably many more species will be found as the weevil enters new regions." A goodly host of enemies, it must be admitted; but the weevil apparently thrives, despite them all. Space permits the mention of one only of these weevil foes: the moth, Alabama argillacea, known in America as the cotton-leaf worm. For many years the larvæo of this moth did an enormous amount of damage among the American cotton-fields; in fact, in some parts, it attracted almost as much attention as the boll weevil does now. Changes in the cotton cultivation and the use of an effective insecticide-Paris green-have combined to reduce the damage done by this insect, and it is one of the most extraordinary coincidences in the history of eeonomic entomology, that this formerly dreaded pest is now regarded by farmers, in weevil-infested regions, as decidedly beneficial. The cotton-leaf worms defoliate the cotton plants, thereby checking their growth, with the result that the opportunities for the breeding of the weevils are lessened, and, as a consequence, their numbers are much reduced at the end of the season. Again, after depriving 
the plants of their leaves, the caterpillars often devour the squares and small bolls in which the immature stages of the weevil occur. Furthermore, the defoliation of the leaves allows the sun to exert its full force on the fallen squares, thereby withering them up, together with their contained weevil larvæ and pupæ. At the present time, as the result of the beneficial work of Alabama argillacea, farmers in infested regions are rapidly giving up the practice of poisoning the formerly much dreaded caterpillar. Will the Mexican cotton-boll weevil ever come to be looked upon as beneficial-who knows?

It must not for a moment be imagined that the American cotton crop was free from serious pests before the advent of the Mexican cotton-boll weevil ; indeed, we have mentioned one enemy of this useful plant, in the shape of Alabama argillacea. A more widespread and destructive pest is the so-called cotton-boll worm, Chloridea obsoleta; in fact, till the weevil went north from Mexico, this so-called worm, which is in reality the larva of a moth, of the family Noctuidoe, was the chief destroyer of cotton in the United States. So nearly cosmopolitan is this insect, that it would be easier to detail the countries where it does not occur than to mention the places where it is found; its origin is obscure, but in all probability its original home was somewhere in the New World. Though we are here only considering Chloridea obsoleta in the light of a cotton pest, it is equally destructive to maize, tomatoes, and tobacco, and, in its wild state, has been known to feed on seventy different plants, a number that is materially increased if we add a considerable number of other plants on which it has been artificially fed.

As a rule, these insects only turn to cotton when the maize begins to harden; then the moths feed on the nectar secreted by the flowers, and lay their eggs indiscriminately over the plants. The amount of damage done to the cotton plants depends on the age of the maize in the 
neighbourhood; if all the crops of maize ripen simultaneously, then Chloridea will migrate en masse to the cotton-fields, but, so long as there is maize to feed on, damage to the cotton crops will be relatively light. Careful computation puts the annual toll of the boll worm, in the cotton-fields of the United States, at four per cent. of the value of the crop.

The female moth lays from five hundred to three thousand eggs, usually on cotton or maize, sometimes on tobacco or tomato, and the early evening is the most favoured time for so doing. In favourable weather, only two or three days elapse before the larvæ emerge; in order to escape from the shell, the larva bites vigorously at the hard membrane of the egg, till it has weakened a spot sufficiently to get its head through. When once this is accomplished the hole is quickly enlarged to allow the larva to crawl out. The whole operation takes about a quarter of an hour. A very constant and curious habit of the newly emerged larvæ is worthy of mention. Unlike the majority of caterpillars that have just come into the world, the young boll worms do not immediately seek out food, at least not vegetable food; they turn their attention to the shells they have just left, and begin once more to eat them. Sometimes the entire shell is eaten, at other times only a portion; but, whatever the extent of this curious habit, it is uncertain what benefit is derived from it by the caterpillars. When replete, after their initial meal, the larvæ wander afield in search of more nutritious food; should ill success attend their efforts and food be scarce, the caterpillars, becoming cannibal, will eat any, as yet, unhatched eggs which they may encounter. When first hatched the larvæ are about one and a half millimetres in length, and by a series of from four to six moults, when they again show their cannibalistic natures by eating their shed skins, they attain their full growth and a length of over forty-two millimetres. The most remarkable feature. 
of the full-grown larvæ is their wide colour variation, even when they have been reared under similar conditions; some are quite dark brown, others of a rose shade, and larvæ of yet a third type are green.

We have mentioned that the young boll worms are cannibalistic; but the habit is not confined to the early larval stages, for when half grown, or rather older, they are exceedingly vicious and are always ready to attack one another. If the paths of two larvæ, feeding in proximity to one another, accidentally cross, they become irritated and snap at one another. The larger one usually kills and eats the smaller one, but if they are of approximately the same size, both may be mortally wounded. With rare exceptions, whenever larvæ meet accidentally on a food plant they fight, though their antipathy to their fellows does not go so far as to cause them to hunt one another out with evil intent. "The boll worms appear to relish the bodies of their unfortunate fellows, but soon sicken and die if compelled to subsist for a long time on this sort of food."

When full grown, the larva leaves its food plant for the soil, in order to pupate; when on the ground it at once proceeds to work its way below the surface, pushing its head against the soil, and, swinging it slightly from side to side, it throws up a pile of loosened earth. The hole (fig. 6) is about twice the diameter of the larva, though it rapidly becomes filled with soil particles. The time required to burrow beneath the surface depends largely on the texture of the soil, and varies from five minutes to nearly an hour. When buried, the larva still burrows, in a slanting direction, to a depth of from one to seven inches, then it turns upwards and forms a curved tunnel, with smooth walls which it coats with silk. About an eighth of an inch below the surface of the ground the tunnel stops abruptly, and the larva, its burrowing operations completed, pupates in the tunnel with its head towards the surface. 

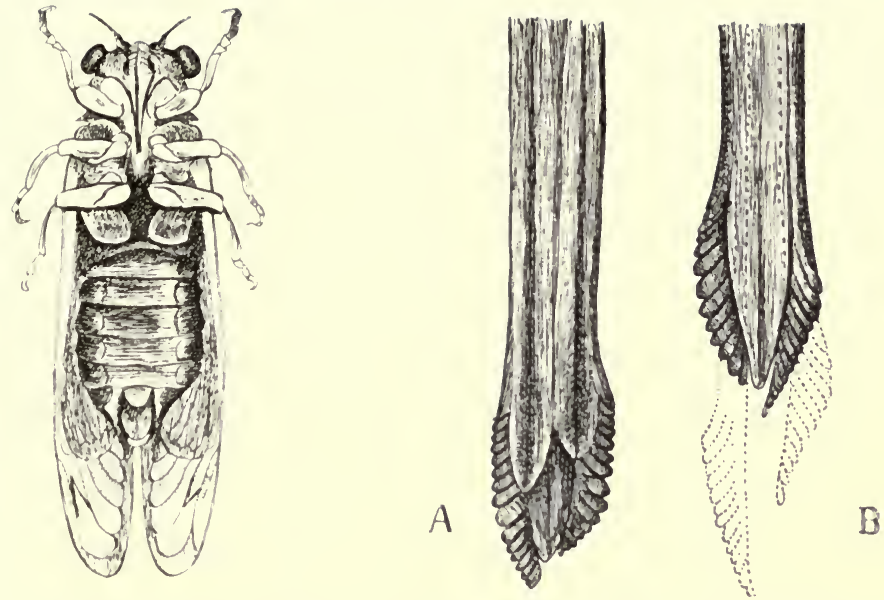

FIG. 7. THE P'leRIOI)ICAI. ('IC MHA, Ciada seplendicille

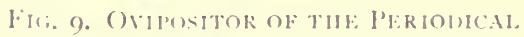

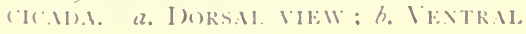
IIEW

A
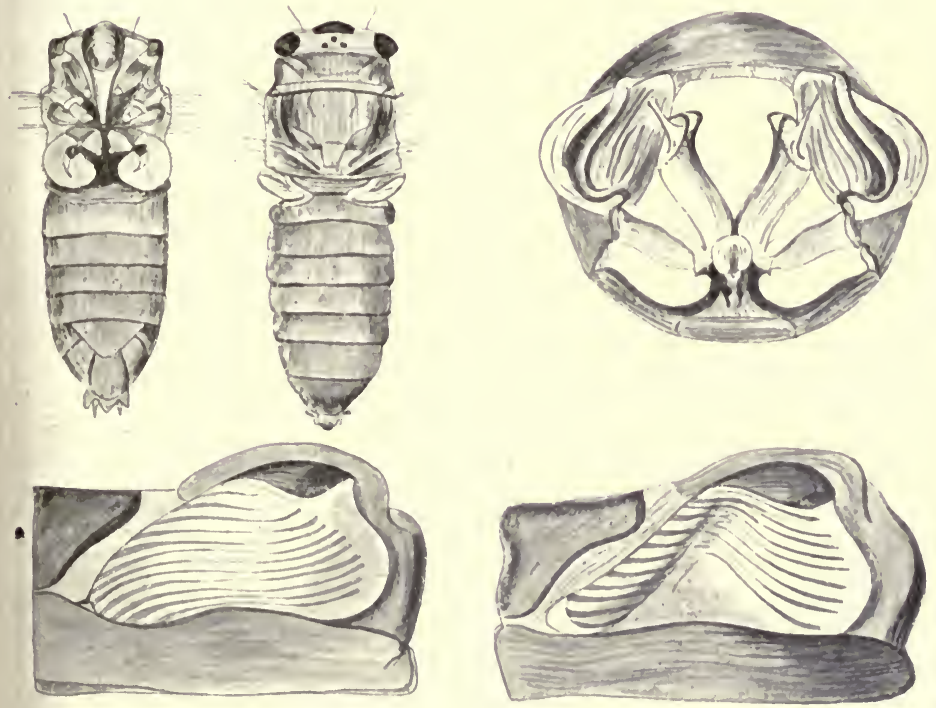

$\mathbb{D}$

E

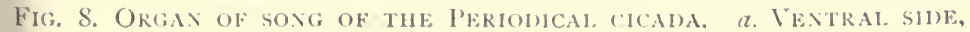
SHOWING I.IGHT-COLOUREI) PIATES COIERIN(; SOUNINA; DISCS; h. DORSAI, SIDE, SHOWING I.ICHT-COLOURED TIMBAI.S ; C. SECTION OF BASE OF ABHOMEN, SHOWING ATTACHMENT OF I.ARGE MUSCIES TO TIMBALS; $d$. ENLARGIFD TIMBAI, NORMAI, POSITION; $e$. ENI.AKGEI) TIMBAI, IRAWN IN FORCIBLY BY THE ACTION OF THE MUSClES, AS IN SINGING 

It is of interest to note that in dry sandy soils the tunnels pass much deeper into the earth than in clay soils; also, in the autumn, the insects which are destined to winter as pupæ pass considerably further into the ground than their relatives earlier in the season: by doing so they are protected against frost.

The duration of the pupal stage varies from rather more than ten days, in the summer, to over six months in the case of the individuals which hibernate as pupæ. When emergence takes place, the moths push aside the layer of earth at the top of the silk-lined burrow and come to the surface with their wings still unexpanded; although unable to fly for several hours, they are able to run with considerable agility. In colour they are even more variable than the larvæ, and no good purpose would be served in attempting to deseribe all the varieties. During the day the moths rest with their wings folded tightly over their backs and never move from their position unless disturbed, when they usually fly rapidly to another resting place and quickly seek cover.

Feeding and oviposition rarely take place by day; it is not till about four o'clock that the adults begin to become active, and often they are not on the wing till much later. In the case of the females, it appears to be absolutely essential for them to feed before they are in a condition to oviposit. Anthonomus grandis, Chloridea obsoleta, and Alabama argillacea are a notorious trio, but, with them out of the way, the cotton plant would not be immune from insect attack; what, for want of a better term, may be styled pests of second rank, in the shape of the cotton stainer, Dysdercus suturellus; the eotton-leaf bug, Calocoris rapidus; and the cotton-square borer, Uranotes melinus, do an incalculable amount of damage to this essential plant.

The periodical cicada, Cicada septendecim, is "undoubtedly the most anomalous and interesting of all the insects peculiar to the American Continent." The most re- 
markable feature about this remarkable insect is the extraordinary duration of its immature stages. From the time the larva emerges from the egg to the time the perfect insect appears, no less a period than seventeen years elapses-in one race it is thirteen years. During the whole of this time the very existence of the insect is unsuspected and unindicated. No less remarkable is the regularity with which, at the end of every generation, millions of individuals attain maturity at practically the same moment. "Without warning this cicada suddenly emerges over greater or smaller areas, filling the ground from which it issues with innumerable exit holes, swarming over trees and shrubs, and making the air vibrate with its shrill, discordant notes. During its short aerial life it leaves very decided marks of its presence in the egg slits which thickly fill all the smaller twigs and branches, the killing or injury of which causes some temporary harm and a sort of general twig pruning not especially injurious to forest trees, but more so to fruit trees, and very undesirable and disastrous to young trees and nursery stock."

"Following briefly the history of the insect, the young ant-like larva, hatching from the eggs a few weeks later, escapes from the wounded limbs, falls lightly to the ground, and quickly burrows out of sight, forming for itself a little subterranean chamber or cell over some rootlet, where it remains through winter and summer, buried from light, air, and sun, and protected in a manner from cold and frost. It lies in absolute solitude, separated from its fellows, in its moist earthen chamber, rarely changing its position, save as some accident to the nourishing rootlet may necessitate its seeking another. In this manner it passes the seventeen or thirteen years of its hypogeal existence in a dark cell in slow growth and preparation for a few weeks only of the society of its fellows and the enjoyment of the warmth and brightness of the sun and the fragrant air of early summer. During this brief period of aerial life it attends 
actively to the needs of continuing its species, is sluggish in movement, rarely taking wing, and seldom, if ever, takes food. For four or five weeks the male sings his song of love and courtship, and the female busies herself for a little longer period, perhaps, with the placing of the eggs which are to produce the subsequent generation thirteen or seventeen years later. At the close of its short aerial existence the cicada falls to the ground again, perhaps within a few feet of the point from which it issued, to be there dismembered and scattered about, carpeting the surface of the ground with its wings and the fragments of its body. Such in brief is the life round of this anomalous insect. . . . If we cannot satisfactorily explain the reason for the long larval life of the periodical cicada or the conditions which led to the origin of this peculiarity, assuming it to be abnormal, we can at least see certain advantages coming to the species therefrom. Among these are the protection from attacks of parasitic enemies, since we can hardly conceive of a parasite limited to this cicada which could possibly extend its existence over an equal term of years. Its occurrence, also, in overwhelming numbers at almost the same moment everywhere within the range of the brood prevents its being very often seriously checked on its aerial existence by the attacks of birds and other vertebrate enemies, which fatten on it in enormous numbers. For this species this is a most important consideration, for it is naturally sluggish and helpless, and seems to lack almost completely the instinct of fear common to most other insects, which leaves it an easy prey to insectivorous animals. The almost entire absence of fear and consequent effort to save itself from danger by flight or concealment is apparently a consequence of the long intervals between its aerial appearances."

The clearing of woodlands and the increase of settlement acts as a serious check on the insect, and the writer, whose words we have already quoted at length, continues: "To 
the lover of nature there is something regrettable in this slow extermination of an insect which represents, as does the periodical cicada, so much that is interesting and anomalous in its habits and life-history. During the long periods of past time the species has recurred with absolute regularity, except as influenced by notable changes in the natural topographical conditions and the despoliation of forests which has followed the path of white settlement. It is interesting, therefore, taking as time measures its periodic recurrences, until in retrospect it is possible to fancy its shrill notes jarring on the ears of the early colonists or listened to in the woodlands bordering the ocean by the still earlier discoverers and explorers. Still more remotely one can picture its song causing wonderment to the savage Indians, who attributed to it baleful influences, and yet, less dainty than their white followers, used the soft, newly emerged cicadas as food; or further back in time, when it had only wild animals as auditors. With these long-time measures our brief periods of days, weeks, months, and years seem trivial enough."

The early study of this peculiar insect was one of great difficulty, till it was discovered that two distinct races existed: the one, limited to the northern half of the range of the species, with a seventeen-year developmental period; the other, hailing from the southern half, with a developmental period of thirteen years. The latter race has been called Cicada tredecim, and, by many, it is considered simply as the seventeen-year form with an accelerated metamorphosis, owing to more favourable atmospheric conditions. In colour, form, and habit, in fact in every respect, except for the length of the developmental period, the two resemble one another. In both races, however, there are two distinct types: a large form, comprising the majority of each brood, and a rarer, small, or dwarf form. The large form (fig. 7) measures about one and a half inches from the head to the tip of the closed wings, which have an 
expansion of three inches. The under side of the abdomen is a dull orange colour, and, in the male, four or five of the segments on the upper side are of the same colour. The smaller form is about two-thirds the size of the larger, and it appears and disappears some ten days later in the season than its larger brethren.

It may reasonably be inferred that, early in its existence, the periodical cicada of America was represented by a single brood; in that event, it would have appeared everywhere over its range at the same time. In the long course of ages this original brood would have become broken up, with consequent divergence of the dates of appearance, so that, at the present time, practically every year has its brood or broods, upwards of twenty having been differentiated, studied, and recorded, with the result that the American Bureau of Entomology can foretell when and where a brood may be expected to appear.

The periodical cicada belongs to the order Rhynchota and the sub-order Homoptera, therefore it is closely related to the scale insects and aphides; they are the largest and most striking insects of their sub-order, and, because they possess the power of "song," have been invested with great popular interest since the time of Homer. Black in colour, for the most part, it has beautiful orange-red eyes and limbs, and the principal veins of its four, almost transparent, wings are similarly coloured.

Contrary to our usual practice, we will give some attention to the structure of two of the insect's organs, viz., the organ of song and the ovipositor, for they are of special interest. With regard to the organ of song possessed by this insect, it is curious and interesting to note that the fullest and most accurate description was given by Réaumur as long ago as 1740, in his Histoire des Insectes, and although the organ has been studied by many later entomologists, little has been discovered that escaped the notice of the celebrated French naturalist. 
The organ of song (fig. 8) is found in the male insect only, "and the true sound apparatus consists of two small earlike or shell-like inflated drums situated on the sides of the basal segment of the abdomen. These drums are caused to vibrate by the action of powerful muscles, and the sound is variously modified by adjacent smaller discs-the socalled 'mirrors' or sounding boards - and issues as the peculiar note of the species, which, once heard, is never likely to be forgotten, or, if heard again, mistaken for that of some other insect. The true sound organs are entirely exposed in the seventeen-year-old cicada, except for the covering afforded by the closed wings of the resting insect. In other cicadas these drums are usually protected by overlapping valves or expansions of the body wall. The sounding drum, or 'timbal,' as Réaumur termed it, of the periodical cicada is a tense, dry, crisp membrane numerously ribbed or pleated, with the convex surface turned outward. The ribs are chitinous thickenings or folds in the surface of the parchment-like drum, and strengthen the drum, while perhaps rendering it at the same time more elastic. The sound is produced by the rapid vibration, or undulation, caused by the springing or snapping in and out of these corrugated drums. Two powerful muscles of very peculiar structure situated within the base of the abdomen set these drums in motion, producing the rattling, so-called song of the cicada, very much, as has been suggested, as sound is produced by pressing up and down the bottom of a tin pan which is somewhat bulged. Beneath each 'timbal' in the base of the abdomen of the insect is a large sound or air chamber, and a third occurs in the thorax joining the first two. These are closed by the body walls and membranes, and the two abdominal ones beneath by the very peculiar 'mirrors' or 'spectacles'-the tense, mica-like membranes situated at the base of the abdomen and protected and covered by the semicircular rigid discs projecting from the thorax. These transparent membranes are often mistaken 
for the true sound organs, but they are rather sounding boards, or drums, to inerease and transmit the sound vibrations induced by the play of the timbals. That they are not essential to the production of sound can be shown by slitting them or removing them altogether without there being any cessation of the note. Much more important modifiers of sound are the semicircular dises projecting from the thorax over the 'mirrors,' which, if closed artificially or by the insect, deaden the sound very much, or, if opened or cut off, allow it to escape in greater volume. In singing also the insect modifies its song notes and their volume by raising and lowering the abdomen, thus opening and closing these dises; and the act of singing is also accompanied by a sort of trembling of the thorax. The position assumed by the male when singing is always with the head upward. The abdomen is then elevated and apparently inflated, and with the beginning of the sound is slowly brought down against the limb, when the note ceases. After a rest of a few seconds this operation is repeated. These abdominal movements vary in different species of cicada and determine in a measure the peculiar notes of each." Each species has a distinctive note, so that anyone used to the song of these insects can at once recognise their note as we can recognise the song of certain birds.

The ovipositor (fig. 9), as its name implies, is the organ for depositing eggs; but in the periodical cicada it serves another purpose as well -it is a boring organ,-for the eggs are always laid in the twigs and younger shoots of trees. When at rest, this organ is almost concealed by the overlapping sides of the eighth abdominal segment; it is also protected by two valves, which form a sort of sheath or scabbard. Within this sheath is the ovipositor proper, a very tough, spear-shaped instrument serrated at the extremity, and consisting of three pieces, also a back portion which acts as a support for the lateral blades. These blades slide up and down, alternately, on tongues projecting from 
the supporting piece, and their serrated edges are the chief agents in piercing the twigs preparatory to oviposition. The blades are operated by powerful muscles, in making incisions in the twigs, and the eggs pass through the tube formed by the three pieces of the instrument, till they reach their resting place in the twig.

The act of oviposition may easily be observed in these insects; when about to oviposit, the female always takes up a position with her head towards the end of a branch, of such a size that she may firmly clasp it with her legs. The ovipositor is brought into operation at an angle of about forty-five degrees, and it is thrust slowly into the bark and wood. When fully inserted, the ovipositor is raised upwards, in order to prise up little wood fibres, which form a sort of covering for the egg-fissure. Space is made to hold ten to twenty eggs; then the female returns to the starting point and inserts the eggs in the twigs, in pairs, separated by a tongue of wood which has been left undamaged. The whole operation of filling a double nest lasts about fortyfive minutes. As many as fifty egg-nests may be found on a single twig; in fact, the female continues making the nests till she has exhausted her store of eggs, which may number from five to six hundred, then, worn out with her exertions, she falls to the ground and dies. The eggs are exceedingly delicate and slightly curved; so thin and transparent is the shell that, before hatching, the larva can be plainly seen within. A certain amount of nourishment is absorbed by the eggs from the juices of the plant cells, resulting in an increase in size. In about six or seven weeks the larva (fig. 10, A), by dint of much wriggling and twisting, frees itself from its shell and a delicate membrane which covers it, and then, after the manner of an ant, runs rapidly about the tree. Before long it deliberately loosens its hold of the branch, and, being very light, falls to the ground as gently as a feather and receives no injury. "The peculiar instinct which impels this newly hatched larva to thus precipitate 


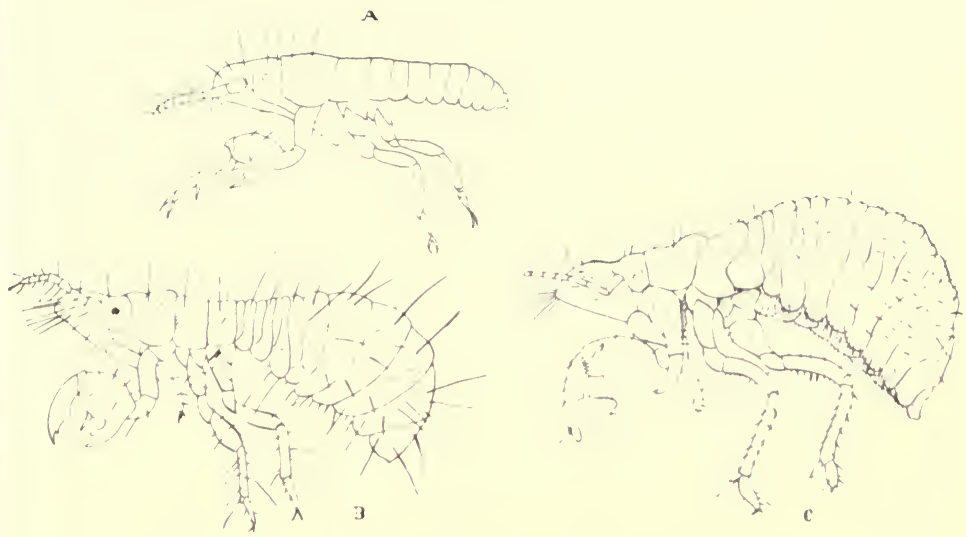

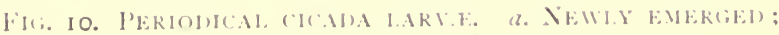

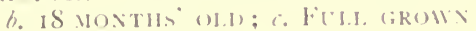

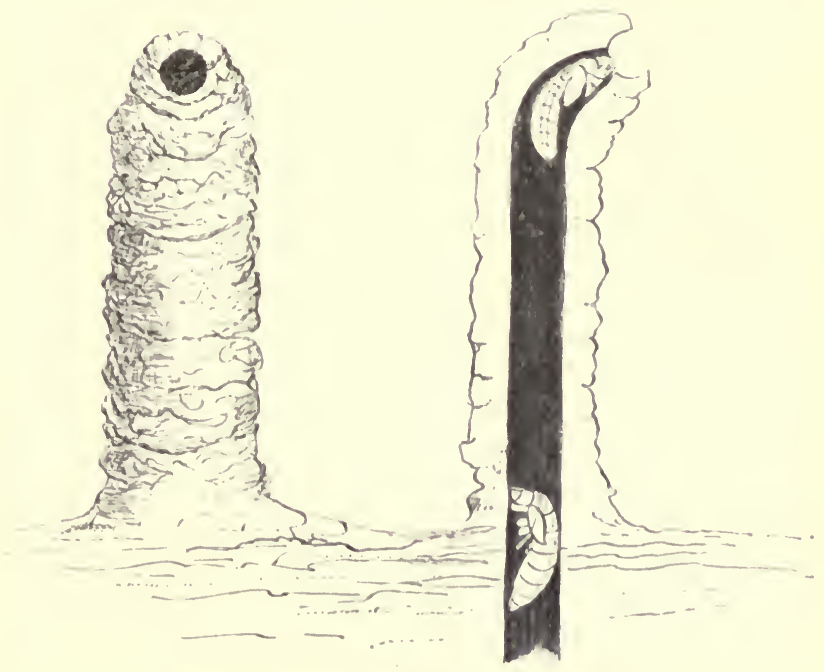

FI(. 11. PERIOI)ICAL (JCAI)A CONES OR CHIMNEYS 

itself into space without the least knowledge of the distance to the ground or the result of its venture has been often commented upon, but it is not more remarkable than other features in the life-history of this species." At this stage the insect is yellowish white in colour, except the eyes and claws of the anterior legs, which are reddish; its total length is about one-sixteenth of an inch, and it is chiefly remarkable for the structure of its lobster-like front legs. On reaching the ground, the larva at once enters some crack or fissure, passes from sight, and begins its long subterranean existence. Concerning this underground life, we can only give the veriest outline. There are four larval stages, and by the time the fourth stage is reached the insect has completed its eighth year; from three to four years are passed in this stage, which is succeeded by two pupal stages. All the time the insect is below ground it dwells in a little earthen cell, which encloses some portion of a root, from which nourishment is derived; in the early stages these cells are very small, but the larvæ enlarge them as they grow. When the time has almost come for the emergence of the adult insects, the pupw usually burrow upwards till they are just below the surface of the ground, though sometimes they come out of the ground and hide under stones, etc. Sometimes, too, when they reach the surface of the ground before they are prepared to leave it, they build huts or cones (fig. 11), little chimneys of earth above the surface of the soil which form continuations of their burrows, though with what object is doubtful: from the top of these cones they emerge in due course.

When the time for transformation arrives, one of the most remarkable events of the whole life-cycle occursafter seventeen years of waiting these pupæ emerge from the ground with remarkable unanimity, and make a beeline to the trunk of the nearest tree, covering the ground so thickly that it is impossible to walk without treading on them. Once on the tree, they crawl out on to all the 
branches and transform to the adult stage. Professor Riley says: "There are few more beautiful sights than to see this fresh-forming cicada in all the different positions, clinging and clustering in great numbers to the outside lower leaves and branches of a large tree. In the moonlight such a tree looks for all the world as though it were full of beautiful white blossoms in various stages of expansion." The adult stage only lasts for a period of about six weeks, and, as a rule, their disappearance is as sudden as their appearance. In this short period, however, the females contrive to do a considerable amount of damage to various trees, by reason of their peculiar egg-laying habits, oak, hickory, and apple being especially favoured.

The gipsy moth, Porthetria dispar, is an insect that is worthy of mention wherever the subject of economic entomology is mooted, not so much on account of its doings in its native country or countries, but because of the enormous havoc it has wrought in the land of its adoption -America. Well known in Central and South Europe, the range of this moth also extends over the temperate regions of Asia to Japan. Though rare in England, it is a serious pest in some parts of France, Germany, and Russia; its southern limit seems to be Algeria, where no doubt it has been introduced from France. As a forestry pest the insect is notorious, and as long ago as 1720 it and its injuries were well known.

The history of the introduction of this moth into America, especially in the light of subsequent events, reads more like some wild romance than the entomological tragedy which it was. In 1869, Professor L. Trouvelot was connected with the astronomical observatory at Harvard University, and he combined with his astronomical pursuits a taste for entomology, his special hobby being the cultivation of wild silkworms. At that time the silkworm disease, known as pébrine, was decimating the inmates of the sericulture establishments of Europe, and the Professor, by 
cross-breeding of allied species, hoped to produce an insect that would be more resistant to disease. His charges embraced a variety of species from many countries, and among them the European gipsy moth. According to one version, the eggs of one of these moths were blown from his study window. Another account says that the caterpillars crawled out. Whatever may be the correct story matters little, the tragedy lies in the fact that Porthetria dispar was at large in the woodlands neighbouring on Medford, Massachusetts. Though the accidental introducer of a very serious pest that eventually cost his country thousands of dollars, in an attempt at eradication, credit must be given to the Professor for his foresight in at once giving notice that a dangerous insect was at large; but his warning fell on deaf ears. Probably the people took no notice, because, at first, the insects were seldom seen; they increased very slowly by reason of the fact that they were accommodating themselves to the severe climate to which they were unaccustomed. Porthetria dispar remained very much in the background, or apparently so, for about a dozen years, when some of the trees about Medford were defoliated by caterpillars, whose identity was not at the time revealed. An energetic but unavailing onslaught was made on the pest, for, by the summer of 1889, "it had multiplied to such an extent as to become a notorious pest. Its numbers were so enormous that the trees (woodland and fruit) were completely stripped of their leaves; the crawling caterpillars covered the side-walks, the trunks of the shade trees, the fences, and the sides of the houses, entering the houses, and getting into the food and into the beds. They were killed in countless numbers by the inhabitants, who swept them up into piles, poured kerosene over them, and set them on fire. Thousands upon thousands were crushed under the feet of pedestrians, and a pungent and filthy stench arose from their decaying bodies. The numbers were so great that in the still summer nights the sound of their feeding 
could be plainly heard, while the pattering of their excremental pellets on the ground sounded like a shower of rain. . . So great was the nuisance that it was impossible, for example, to hang clothes upon the garden clothes-line, as they would become covered with caterpillars and stained with their excrement. Persons walking along the streets would become covered with caterpillars spinning down from the trees. To read the testimony of the older inhabitants of the town . . . reminds one vividly of one of the biblical plagues of Egypt."

At this time the insect was thought to be a native American species, but Mrs Fernald recognised the caterpillars from a description in a European book, and announced that the insect was none other than the noxious gipsy moth. During the ensuing ten years every effort was made to eradicate the pest, and a sum of $\$ 1,175,000$ was spent in the attempt. During these years the affliction remained a local one, and legislators, in districts where the moth had never been encountered, combined successfully to put a stop to further expenditure. This-the greatest tragedy of all in the history of the gipsy moth in Americasaved the situation as far as the insects were concerned, for, unharassed by man, and free from attacks by the parasites and predatory insects which had kept them in check in Europe, the moths had, by 1906, multiplied and spread to such an alarming extent that $\$ 75,000$ was voted at once, and $\$ 225,000$ in 1907 , in "frantic attempts to overcome the results of those five years of rash idleness." What was formerly a local pest had now spread throughout New England, and to-day the expenditure of millions of dollars and vast amounts of time and energy are rewarded, solely, by the belief that the advance of the pest has been checked, and that the infestation of new territory has become preventable.

It has been mentioned that the gipsy moth caterpillars are inveterate enemies of trees, and they show a partiality 
for apple trees, oaks, willows, and elms. The eggs, each of the size of a pin's head, are laid in masses of about six hundred, during July and August. Each cream-coloured egg-mass is covered by yellowish hairs from the abdomen of the female, and has the appearance of a piece of sponge. The caterpillars emerge in May, and, at first, are salmoncoloured, becoming darker as they grow older; when fullgrown they are soot-coloured, and their heads are conspicuously marked with yellow. On their backs are a double row of blue spots and a double row of red ones, and from these spots arise greyish and yellowish hairs. In July, by which time the caterpillars are fully developed, they spin a silken cocoon, within which they change into chocolate-coloured pupre. 'Towards the end of July and the beginning of August the moths emerge, and the two sexes are so dissimilar that they would never be taken for the same species by the unentomological. The male, about thirty-eight millimetres long, is of a general brownish colour, the darker brown upper wings being marked with still darker brown and black, whilst the lower wings are paler brown and unmarked. Owing to its peculiar jerky flight, the male has received the popular name of "zigzag." The female (fig. 12) is nearly twice the size of her partner, being about sixty-two millimetres long; in general colour she is creamy white, and the upper wings are marked with sinuous brown lines. Possessed of a large and heavy abdomen, the female is unable to fly, her aerial locomotion being limited to a few struggling flaps which serve to break her fall when she finds herself, probably accidentally, falling to the earth from one of the upper tree branches where she first came into the world. Flight is not the only function denied to the females, for they are unable to eat, and after laying their quota of eggs they die.

The American naturalists have, not unnaturally, been somewhat puzzled to account for the rapid spread of the gipsy moth, since its introduction into their country. 
Were the females blessed with the power of flight, their distribution over large areas would follow, as a matter of course; but, as they are practically confined to the spots where they are born, the question of their travels has been the subject of much experiment. Into the details of all these researches we cannot enter, but one of them, at least, is of special interest; it concerns the caterpillar in the first stage of its existence, that is to say, before the first moult. In 1893 two Austrian scientists, Wachtl and Kornauth, published the results of some experiments they had carried out regarding the distribution of the first-stage larvæ of the nun moth, Psilura monacha, and, at the same time, they described some peculiar hairs to be found on these caterpillars, and stated that similar ones were to be found on first-stage gipsy moth larvæ. These hairs only occur on the earlier stages of the caterpillar, and, as they are furnished, near the base, with globular enlargements, which were supposed to be filled with air or gas, they were called aerostatic hairs, and the globules were called aerophores. Experiments conducted in the forests of Austria showed that the nun moth larvæ were carried long distances by the wind, and, by analogy, it was assumed that the gipsy moth larvæ, being similarly furnished, would be carried like distances. Microscopic examination of a first-stage larva revealed two kinds of hairs, arising from each of the tubercles which are arranged along the body (fig. 13). Of these hairs a few are slender and nearly half as long as the caterpillar, and a considerable number of much shorter ones are furnished with globular swellings near the base. Whether these aerophores actually assist the young larvæ in their distribution, by making them more buoyant, is not actually known, but experiments in America show that the larvæ can be carried, by the wind, a third of a mile, from a point less than six feet above the ground, and that the most favourable time for the dispersion is when the temperature is above sixty-five degrees 
. 
and the velocity of the wind over fifteen miles an hour. In gusty weather one may observe leaves caught by the wind and carried several hundred feet into the air; there they may be, and often are, brought into contact with the strong currents of the upper air and carried several miles before falling to earth. Observers are agreed that the same thing occurs to the first-stage larvæ, when they are suspended froin the trees by the silk which they spin, though actual proof is wanting. If the surmise is correct, it would account for the, at present, unaccountable spread of the gipsy moth to new territory.

Though probably every family of insects contains one or more species that have earned an unenviable notoriety, on account of the havoc that they cause, either among man's crops or his livestoek, certainly none contains so many injurious species as the family Coccide, or seale insects, the most notorious member of which is the San José seale, Aspidiotus perniciosus. Although of Chinese origin, as we shall see later, this insect was first encountered in America, at San José, California, in the early 'seventies. In less than twenty years, from the time of its first appearance in Western America, it had spread to the Atlantic seaboard and into Canada, and there are now very few fruit-growing districts in the North American continent, within the climatic range of the insect, where it has not gained a permanent foothold.

With the thoroughness that is characteristic of the Americans, in all matters appertaining to economic entomology, it was decided to discover, if possible, the original home of the seale with the object of finding some control insects, either parasitic or predatory. Suspicion having fallen on Japan and China, Mr C. L. Marlatt, of the United States Bureau of Entomology, decided to visit these countries in 1901. Japan was first explored, and in spite of the fact that practically every house in that country has a little garden in which are single examples of cherry, plum, or 
peach trees, and the roads, temple grounds, and streets are lined with cherry and plum trees, planted for their blossom and not for their fruit, no San José scale occurred, except where recent stock had been imported from America.

An extensive exploration showed that Japan could not be considered responsible for the scale; accordingly the investigator's attention was turned to China. After various detours Pekin was reached, and, as this city is the centre for all the region lying to the north and west, the streets devoted to the sale of fruit proved of considerable interest. All the fruit is brought into Pekin in little two-wheeled carts, or on camel back, and in the markets there is always a representative collection of the fruits of Northern China, principally from the hill region leading up to the mountains separating China from Mongolia and Manchuria. Great quantities of these fruits, native apples, pears, and a little haw apple were examined-peaches were out of season,and a scanty but general infestation of San José scale was discovered. As no foreign stock had been introduced, the presence of the scale indicated that it was of native origin, and its scattered nature pointed to the probability of its being kept in check by natural enemies. Further investigation showed that the special region where the scale thrives is a region leading up to the mountains, comprising the northern and north-eastern frontiers of China, and bounded, on the north and north-east, by the vast Desert of Gobi, and, on the south and east, by the great alluvial plain of the Yellow River, where only cereals are grown. The region, it will be seen, is much shut off, a fact that probably explains why the scale has not become a worldwide pest ages ago. It is thought that the insect was introduced into California on the flowering Chinese peach, probably imported from the nurseries of Dr Nevius, a missionary who introduced apple-growing into the province of Shantung.

A tree badly invested with San José scale appears to be 
covered with a greyish, rather rough, scurfy deposit, or an equally good description is to say that the tree appears to be coated with ashes, stem, branches, and fruit alike attacked. The leaves also are not immune, but on them the tendency is for the scale insects to arrange themselves in two or more quite regular rows on either side of the midrib. A characteristic feature, though one which occurs sometimes in other scales, is a peculiar reddening effect which it produces on the skin of fruit and tender shoots; in fact, the quite young scales would be most inconspicuous, when present in small numbers, were it not for the striking reddish-purple circling ring around each one. The scale insects pass the winter in a half-grown state, so small as to be only just visible to the naked eye, the male scales preponderating to the extent of ninety-five per cent.

Early in April, in America, the winter males (fig. 14) pupate and emerge; being winged, they are able to travel from tree to tree, and mate with the winter females, after which they disappear, for their work is done. About a month later these females begin to produce living young, and in this respect they differ from most other scale insects which deposit eggs. The production of the new generation extends over a period of six weeks, when the winter females die. The newly arrived, orange-yellow, six-legged larva is at first soft, and remains stationary, with its legs and antennæ folded against its body ; soon, however, it hardens, escapes from its mother's protecting scale, and runs about the plant, on which it finds itself, in search of a suitable place to settle (fig. 15, A). When the resting place is selected, the larva works its sucking beak through the bark, and folds its legs and antennæ beneath its long ovoid body, which then becomes nearly circular in outline (fig. 15, в). Very minute fibrous, waxy filaments are then secreted all over the body (fig. 15, c), and, as they become more and more dense, the insect, within two days, becomes entirely concealed by a pale grey shell or scale, with a 
prominent central nipple or tuft (fig. 15, D). This scale is formed by the matting and fusion of the waxy filaments. Twelve days after the larva has emerged the first moult takes place, and, up to this time, the males and females are exactly similar to one another in size, colour, and shape. After the moult an examination of the insects, beneath the scale, shows that both sexes are light lemon yellow and devoid of legs and antennæ; but, whilst the males are elongate and pyriform and possess large purple eyes, the females have lost their eyes and are almost circular, being in fact practically flattened sacs, each with a long sucking bristle springing from the central ventral surface. Eighteen days from birth, the males change to the first pupal stage and assume an elongate oval form, characteristic of the sex. The legs and antennæ reappear, together with two wing pads. Two days later, the true pupal stage is reached, and the shed skins are pushed out from beneath the scale. In four to six days more, or from twenty to twenty-six days from birth, the mature males make their exit backwards from the rear end of the scale, beneath which they have rested for a day or two before emerging. To return to the female scale, we find that she moults, for the second time, in about twenty days, and with each moult the cast skin is retained within the scale, the upper half adhering to the scale and the lower half forming a kind of subsidiary scale, next to the bark. Thirty days from birth the females are mature (fig. 16), and if they have then mated, embryonic young may be seen within their bodies, each one enclosed in a membrane. At the thirtythird to the fortieth day the young larvæ appear. The whole life-cycle of this insect is passed beneath the scale, with the exception of a few hours' active larval life and an equally brief existence of the fly-like, orange-coloured male.

Fortunately for fruit-growers, considerable headway against the San José scale has been made by artificial 


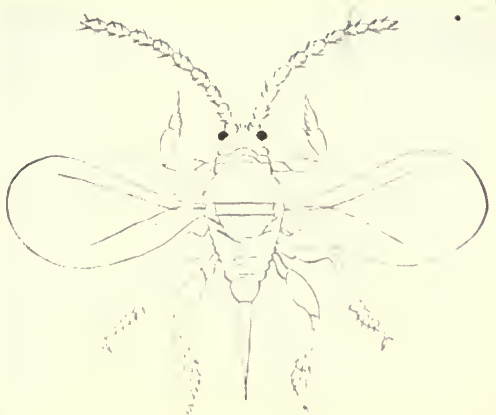

Fig. 14. SAN José SCAlE (MALE), Aspidintws perniciosus

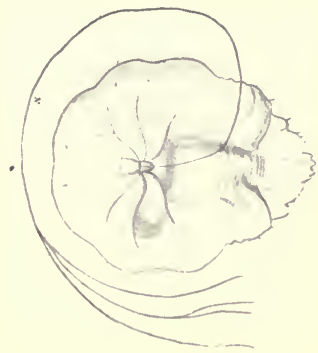

FIC. I6. SAN JOSE SCALE (FE.IALE) BEFORE INEVEIOI'MENT OF EG(i), SHOWINi VERY 1.ONG SUCKING SETAE

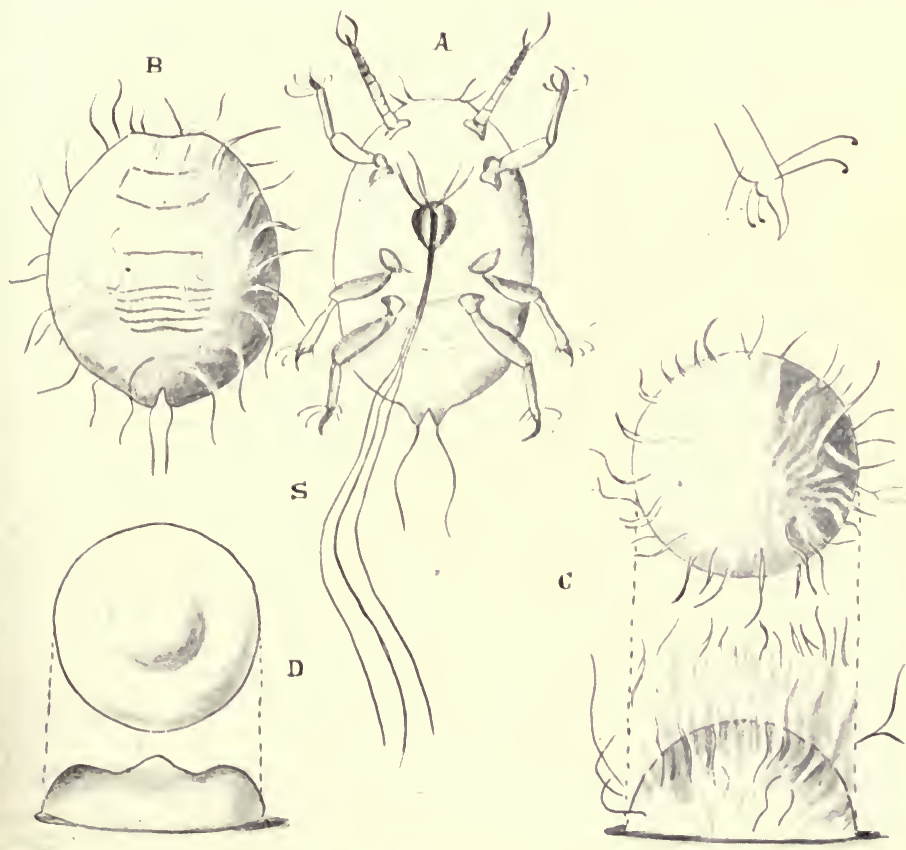

FIg. I5. SAN José SCALE, Aspidiotus perniciosus, young laRVa aNI) DEVELOPING SCALE. $a$. VENTRAL VIEW OF LARVA SHOWING SUCKING BEAK $(\mathrm{s}) ; b$. DORSAL VIEW, SOMEWHAT CONTRACTED WITH FIRST WAXY FILAMENTS APPEARING ; $c$. DORSAL AND LATERAL VIEWS OF THE SAME, STILL MORE CONTRACTED, SHOWING FURTHER DEVELOPMENT OF WAXY SECRETION; $d$. DORSAL AND LATERAL VIEWS OF LATER STAGE, SHOWING: MATTING OF WAXY SECRETION AND FIRST FORM OF YOUNG SCALE 

means-by various washes and insecticides,-and this fact has led to less attention being paid to natural methods of control. Eight species of true parasites are known in America, and of predaceous insects, practically all the native ladybirds devour the scale.

One species of ladybird was introduced from China and Japan by Mr Marlatt, and, although he imported a large number, all but two died on the voyage or during the first winter. The two survivors, however, nobly rose to the occasion, and, during their first summer in America, rewarded their sponsors with a brood of five thousand individuals, a sufficient stock from which to rear colonies for despatch to various states in the three succeeding years. A small colony, sent to Georgia in 1902, increased to a number estimated approximately at forty thousand by the following summer, and, incidentally, materially lessened the numbers of the San José scale: a consummation not to be wondered at, for although the adult Chilocorus similis, for that is the ladybird's name, feeds actively on the scale, its larvæ are apparently never satisfied, feeding incessantly. Five or six scale insects a minute is what may be termed the eating rate of a Chilocorus larva, and an average of only one a minute would give a total of one thousand four hundred and forty a day. Chilocorus similis, however, was not destined to repeat the triumphs of its Australian relative, Novius cardinalis, against the cottony cushion scale. The success of artificial remedies against the scale placed Chilocorus in an invidious position, and, as if that were not sufficient, a native parasite arose, after its first year in America, and practically exterminated it in some parts.

\section{Codling Moth}

Wherever apples are grown-and where in the temperate regions do they not occur?- "wormy apples" are known. They and their contained grubs are familiar to everyone, 
but how many know the history of these destructive little maggots, which are more serious enemies to this fruit than all the other apple pests combined? The familiar maggots are the larvæ of the codling moth, Carpocapsa pomonella, whose popular name is derived from the old English word "querdlying," which means an immature or half-grown apple. The original home of this moth probably coincides with the original home of the apple, that is to say, SouthEast Europe ; it is now almost cosmopolitan, having been recognised in America in 1819, Australia in 1855, in Tasmania about 1861, New Zealand in 1874, South Africa about 1885, and South America in 1891. Needless to say, it has spread all over Europe and even into Siberia.

In many fruit-growing districts the codling moth causes an annual loss of from forty to seventy-five per cent. of the crop. Although the apple is the most infested fruit, pears are also attacked, and, to a lesser extent, peaches, prunes, plums, cherries, quinces, and apricots. No insect of economic importance has received so much attention from entomologists; it has been studied in nearly every country in the world, and boasts a literature far beyond its deserts, yet, in spite of all, there are one or two points in its life-history that remain undetermined.

Although the codling moth was mentioned by Goedaert in his Metamorphosis Naturalis so long ago as 1635, it is a remarkable fact that the eggs were never accurately described and figured till almost two hundred and sixty years later. In size about the dimensions of a pin's head, the egg is oval-shaped and flat, with a surrounding flange; its surface is much ridged, the ridges forming a network of varied mesh, being smaller towards the centre and more open towards the edge. The eggs, which are glued to the apple fruit or leaf by the mother moth, are pearly white when first laid, becoming darker with advancing age; they possess a peculiar power of reflecting light, which renders them somewhat conspicuous. In many countries where 
the codling moth abounds, there are two broods in each year; when this is the case, the majority of eggs of the first brood are laid on the upper surface of the leaves, whilst the greater number of the second-brood eggs are to be found on the fruit. The number of the eggs laid by each female moth is a debatable point, but they probably average about thirty-five, deposited over a period of four or five days. After about ten days, under favourable circumstances, the larvæ emerge.

At first they are semi-transparent and whitish in colour, marked with regularly arranged rows of dark spots, from which a few hairs arise. Their heads are large, black, and shiny. When they attain their full grow th, the caterpillars measure nearly three-quarters of an inch in length, and, on their dorsal surface, at any rate, have changed to a pinkish colour. The spots, which were conspicuous when they first emerged from the eggs, are now a little darker than the body, their heads are brown and armed with conspicuous mandibles, whilst below the lower lip may be seen the spinneret from which silk is drawn. Of the five pairs of fleshy legs, the first four pairs are provided with circles of minute hooks, and the last pair have semicircles of hooks. When the larvæ are hatched on the leaves, they probably feed, for a time, on the leaf tissues, though the point is one that requires further observation; at any rate, the majority eventually reach the fruit, which they enter, for the most part, by way of the calyx, and sometimes near the stalk, or where there is a scar, or even where two fruits touch one another.

The second generation, which, as we have stated, mostly come into the world on the surface of the apple, enter the fruit at the side; in fact, they may often be seen crawling rapidly about the fruit, seeking for some rough spot, or, better still, a scar. The reason for this eager search is that the caterpillar's jaws can make little impression on the smooth apple skin. To help in bringing about this con- 
summation the insect spins a silken web as it wanders over the fruit, and, using this as a foothold, it is able to make some impression on the skin. When once the skin is broken, progress is more rapid; chip after chip of apple is bitten out and dropped into the web, till the larva is partly hidden, then it backs out of its burrow, bringing pieces of apple out with it. This process is repeated till the insect is quite hidden, when, turning round, it spins a silken door over the hole. Unless the larva has partaken of a leaf diet, its first meal is eaten when hidden within the burrow, for none of the fruit is eaten during the tunnelling operations. By the time it is a week old, the larva has reached the core. As it travels towards this point, it pushes its excrement and frass through the entrance hole, and the brown powdery mass which gradually collects there is characteristic of infested fruit. When nearly full-grown, the caterpillar tunnels its way out of the apple, travelling as a rule away from the entrance hole, then, leaving the fruit, it usually crawls along the branches to the stem, where it spins its cocoon beneath some rough bark, or in a convenient crack, if one be at hand, or, should the tree have a smooth bark, it passes to the ground and pupates beneath some hiding place at its foot. Occasionally, though this is not the normal procedure, the larvæ will lower themselves to the ground by means of a silken thread; this probably only occurs when the larvæ slip from the fruit by accident, in which event the thread is spun to save themselves in falling. Should the apple be on the ground before the caterpillar is ready to pupate, it will, on leaving the fruit, simply crawl into the nearest hiding place to spin its cocoon. Whatever the method selected by the insect, one thing is certain, and that is, that after abandoning the fruit it wastes no time in spinning its cocoon. If the larva is one of the first brood, it changes into a pupa in about six days, and about three weeks later the adult moths emerge. If, on the other hand, it is a second-brood larva, 
no immediate change into a pupa takes place; in fact, the insect passes the winter as a hibernating caterpillar, hidden from inclement weather and its enemies by its silken cocoon. Within this cosy shelter the insect remains about eight months, very solicitous the while for its own safety and comfort; for, if the cocoon be broken, it is at once repaired by the ever-vigilant larva.

The moths are variable in size, but never exceed threequarters of an inch from tip to tip of their wings. In general colour they are greyish brown, of a shade that renders them particularly inconspicuous against the bark of apple trees, on which they are fond of resting. The front wings are marked with two irregular rows of metallic, copper-coloured scales, which, in certain lights, appear as if formed of pure gold; a very dark brown, somewhat triangular-shaped band also crosses each wing, the remainder of whose surface is traversed by irregular light and dark bands. The greyish-brown hind wings have fringed margins-at the base of the fringe is an unbroken black line, whilst from this line towards the body, the coloration gradually becomes more and more pale, so that the lightest portion is nearest to the body. These moths, although so destructive, are not scen very frequently, unless in exceptionally badly infested orchards. They spend most of their time resting, either on the leaves or tree trunks, against which, as has been remarked, they are almost invisible except to the trained eye. When disturbed, their flight is so rapid and erratic that it is almost impossible to observe them.

For an insect, the codling moth is particularly fortunate in having few enemies. This is largely accounted for by its habits, for practically the whole of the larval stage is passed within apples or other fruit; the pupa is well protected by its silken cocoon, and the moths are strong fliers, and, when at rest, their protective coloration causes them to be easily overlooked by marauding birds and insects. 


\section{Hessian Fly}

One of the most destructive insects, if not the most destructive, taking all the world over, is the Hessian fly, Cecidomyia destructor. A noted pest of wheat, this minute gnat-like insect, less than one-tenth of an inch in length, does not disdain rye and barley when wheat is not to be found. In America alone, it takes toll of the cereal crops, in some parts, to the extent of fifty per cent., and, in 1900 , its total damage in that country was estimated at $\$ 100,000,000$. In England this destructive pest is not unknown, but is fortunately rare. Its debut in this country occurred, in 1886, in Essex. The name Hessian fly was given to Cecidomyia destructor in America, because it was thought that it had been introduced, during the war of the Revolution, by the Hessian soldiers, and the belief was probably well founded. Its European range extends from France to Russia, and from Norway to Italy. In 1888, too, it spread to New Zealand. How, one may ask, can such a minute and apparently helpless insect reach America and New Zealand, separated as they are from Europe by thousands of miles of ocean? We shall see that the pupæ of this fly, popularly called "flax seeds," are deposited on wheat, which may eventually be converted into straw and used as bedding for horses, or packing for merchandise. The Hessian troops landed near New York in 1776-77, used straw as bedding, and, as the introduction of the fly took place at the same time, it is highly probable that the flax seeds found their way into the country on this bedding. Similarly, it is believed that the pupæ were conveyed into New Zealand on straw used as packing material, which was carelessly scattered, instead of being destroyed.

The fly (fig. 17) belongs to the order Diptera, or twowinged flies, and to the family Cecidomyidoe, or gall gnats, so called because the majority attack living plants, with the consequent formation of galls. The female fly is 


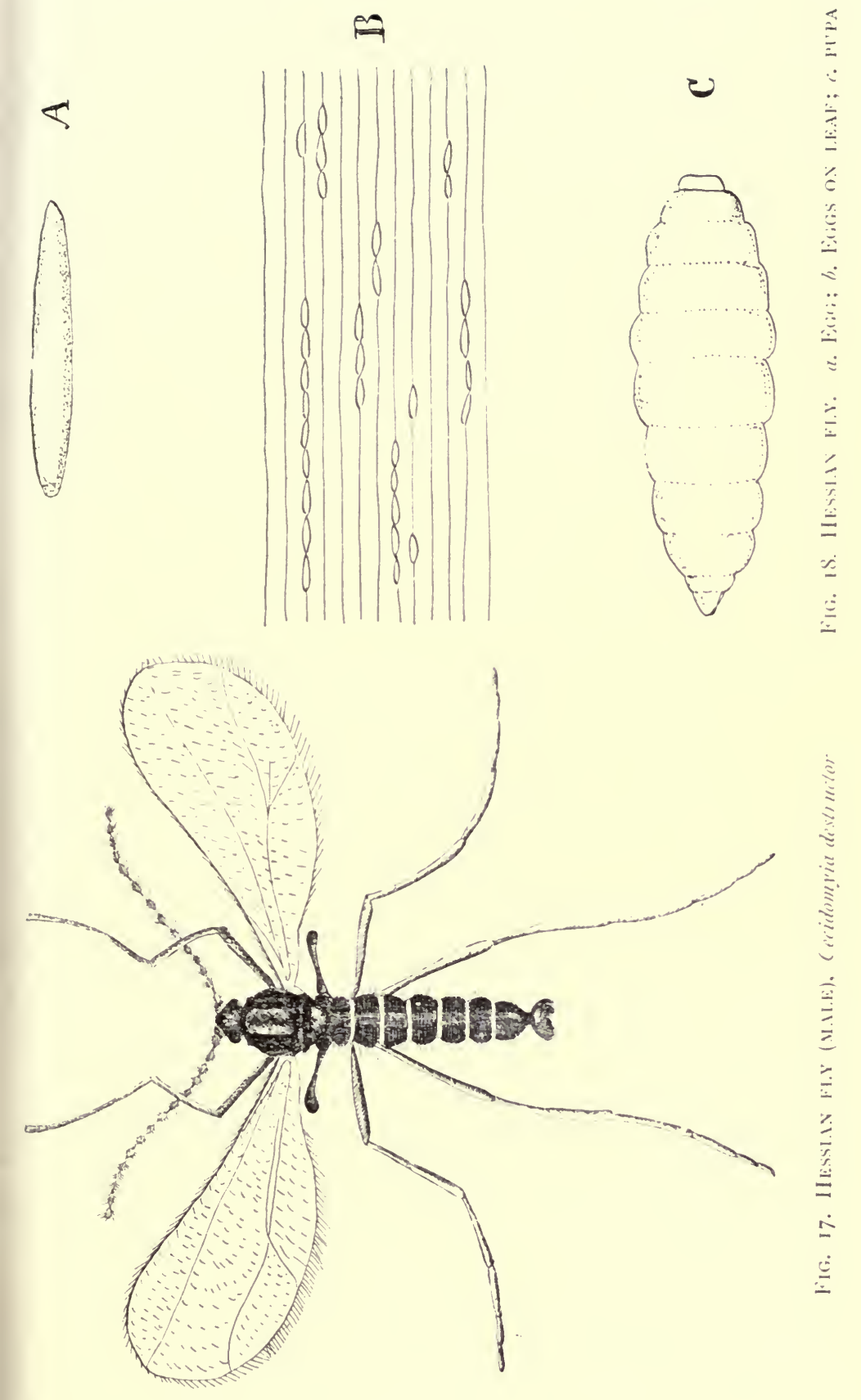



slightly longer, stouter, and lighter-coloured than the male. The abdomen of the female is black, banded with red ; the thorax is provided with two rows of long bristles, curving backwards; the legs are long, and the wings are smoky black. The males, in addition to the differences already mentioned, have larger antennæ than the females. According to Herrick, the female lays her eggs "in the long creases or furrows of the upper surface of the leaves of the young wheat plant (fig. 18, B). While depositing her eggs, the insect stands with her head toward the point or extremity of the leaf, and at various distances between the point and where the leaf joins and surrounds the stalk. The number found on a single leaf varies from a single egg up to thirty or even more. The egg is about a fiftieth of an inch long (fig. 18, A), cylindrical, rounded at the ends, glossy and translucent, of a pale red colour, becoming in a few hours irregularly spotted with deeper red. Between its exclusion and its hatching, these red spots are continually changing in number, size, and position; and sometimes nearly all disappear. A little while before hatching, two lateral rows of opaque white spots, about ten in number, can be seen in each egg. In a few days, more or less, according to the weather, the egg is hatched." When the larva emerges from the egg it travels down the leaf, then, passing within the leaf sheath, it takes up its position near the base of the culm, a position that varies according to whether the infested plant is spring or autumn wheat. If the former, it will be above the first or second node; if the latter, close to the root and probably below the surface of the ground. When the larva has taken up its position, it moults and passes to its second stage, a sedentary, feeding form, with a definite feeding period, during which it takes up all the nourishment necessary for growth. After about twenty days the larva shrinks in size; its outer skin forms a rigid sheath, within which it assumes the third larval form. This last-mentioned change is quite foreign 
to most members of the family, and is probably an adaptation to varying climatic conditions. No nourishment is taken during this stage, but moisture is absolutely necessary. Within the third-stage sheath or puparium, the larva turns into a pupa (fig. 18, c), and remains as such for a variable time, depending on the temperature. When the adult is about to emerge, the end of the puparium is forced off, and the pupa, by active wriggling, not only frees itself from its covering, but also from the leaf sheath, and almost immediately the pupa case splits and the fly appears. The length of life of the adult stage is one of hours rather than days, lasting only so long as is necessary for mating and the deposition of eggs.

The accurate study of the life-history of the Hessian fly presents many difficulties - few insects show such variations during the life-cycle; and this is not to be wondered at, for it is rare to find an insect so well able to adapt itself to varying climatic conditions. Its annual broods vary from one to six, depending on the latitude, and, in addition, it possesses the power of acceleration or retardation, according to the conditions of the year, sometimes appearing early, sometimes late.

The Hessian fly is extensively parasitised, a fact which of course tends to keep it within reasonable bounds, in most seasons. Curiously enough, its most deadly enemy, a minute Hymenopteron called Merisus destructor, occurs naturally, both in Europe and in America, that is to say, it is not a species that has been introduced with the object of controlling the fly, and it is usually when the Hessian fly reaches a new wheat-growing district ahead of its parasites, so to speak, that the greatest damage occurs.

\section{Mediterranean Fruit Fly}

Why are so many of the insects, described in this chapter, either native or introduced American species? The question is sure to be asked, so let us answer it now. The reason 
is that a great many insects, like far more highly developed animals - mankind - have discovered that America is a country of huge possibilities. We in Britain have our insect pests, it is true, and very annoying and, at times, exceedingly destructive they prove to be ; but, at the worst, they are a mere drop in the ocean compared to the countless hordes of six-footed beings that lay waste the crops of the United States. In these pages we recognise no horizon, so our examples have been chosen with the object of showing that man's conflict with the insect world is a stern reality, and no better means are available for so doing than by laying bare some of the insect problems of the great American Continent.

In conversation with an American scientist some few months ago, the writer, commenting on the fact that far greater strides had been made in economic entomology in America than in this country, was told that the science had been forced on the American Government from very urgency. In 1904, and the case is more desperate at the present time, a writer in the Year-book of the United States Department of Agriculture said: "In no country in the world do insects impose a heavier tax on farm products than in the United States. The losses resulting from the depredations of insects on all the plant products of the soil, both in their growing and in their stored state, together with those on livestock, exceed the entire expenditure of the National Government, including the pension roll and the maintenance of the Army and Navy." Seven years later the same writer stated, in the Journal of Economic Entomology, that " very careful estimates, based on crop reports and actual insect damage over a series of years, show that the loss due to insect pests of farm products, including fruit and livestock, now reaches the almost inconceivable total of $\$ 1,000,000,000$ annually." Small wonder, then, that we turn to such a country when we wish to study these economic questions in their most acute form. 
It is small consolation to the Americans to know that most of their worst pests have been accidentally introduced, and so effectually have they taken the lesson to heart, that the most stringent quarantine regulations are enforced to prevent the introduction of other world-famous, or, better, notorious insect pests, and against none are these regulations more earnestly directed than the Mediterranean fruit fly, Ceratitis capitata. This insect is one of a number of twowinged flies, or Diptera, which prefer fresh fruit to a diet of decaying vegetable matter, or of fresh or putrid animal substances. Its original home is probably Spain, though it was first recorded in 1826, when it was brought to London, in the larval stage, in some oranges from Azores. Though widely distributed, being found in the Mediterranean regions, including Malta; in the Azores, Canary Islands, Natal, Cape of Good Hope, Bermuda, Australia, the Hawaiian Islands, China and Brazil, it is very rare in England, and as yet unknown in the United States. The English specimens have probably all been brought into the country in foreign fruit. The insect is catholic in its tastes, such diversified fruits as peaches, limes, figs, mangos, avocado pears, guavas, and tropical almonds being relished by the larvæ. In Europe, at any rate, peaches, nectarines, and apricots appear to be the favoured plants, so much so that their cultivation has been abandoned in Spain, solely on account of the ravages of this fly.

The destructive stage of this insect occurs, as is so often the case, from the time of the hatching to the pupation of the larvæ. The female fly is furnished with a long, needlelike ovipositor, with which she pierces the fruit, thus making a small chamber within which she lays eggs, varying in number from one to over forty. Sometimes the fruits are "stung" by the ovipositor, without the deposition of eggs, with what object is unknown. After oviposition, the mother fly secretes, over the eggs, a substance having the property of converting the surrounding tissues of the 
fruit into a brown jelly which often exudes from the puncture and hardens. This, at least, is the usual happening, though all fruits are not similarly affected: green oranges ripen prematurely around the puncture, but, in some unripe fruits, the secretion of the female fly prevents further ripening around the puncture, with the result that a depression is formed on the exterior of the fruit.

Swift retribution sometimes overtakes the mother fly, for she is not always able to withdraw her ovipositor from the fruit; then she falls an easy prey to marauding lizards, or, worse case still, she dies of starvation. The duration of the egg stage varies, according to whether oviposition has taken place in ripe or unripe fruits; in the latter event the eggs take longer to hatch. Sometimes, too, the eggs hatch, but the larvæ promptly succumb to the effects of the acids in the fruit juices; this is the case in the Chinese banana, whose unripe juices are rich in tannic acid. In the event of no such fate overtaking the maggots, they bore their way into the pulp of the fruit, which begins to decay and eventually falls to the ground. After a variable number of days spent in the fruit, the maggots eat their way out of the rotting fruit and enter the ground to pupate. The period of the larval stage varies with the temperature, moisture, kind of fruit, its hardness, rate of decay, and acidity. The pupal stage lasts for rather more than a fortnight, after which the adult flies emerge. Egg-laying does not begin at once; a period of ten or twelve days is necessary for the adults to attain maturity, and during that time they subsist on various sugary substances.

Whilst America is indebted to Europe for a large number of her most destructive insect pests, accounts have been somewhat balanced by the introduction of the grape vine phylloxera, Phylloxera vastatrix, from the United States. This noxious insect. is a native of the United States, east of the Rocky Mountains, where, for years, it had lived almost unnoticed on the wild vines. About the year 1859 
the pest was accidentally conveyed to France on some rooted vines, and commenced activities in its new home at two points, near Bordeaux and near Gard. Unfortunately, the nature of the mysterious failure of the vines was not understood for some years, with the result that the insect spread rapidly in all directions, and, by 1884, nearly two million five hundred thousand acres, or more than one-third of the French vineyards, had been totally destroyed, and all the others were more or less affected. In many places the vines, which had once yielded so rich a harvest, being reduced to stumps, were used for firewood.

Measures taken to eradicate the pest have not proved very effectual, so that, to-day, there is no vine-growing district of any importance in Southern Europe that is exempt from Phylloxera; furthermore, it has spread through South Russia to the adjoining countries in Asia, to Algeria, South Africa, and New Zealand. About 1874 it was introduced into California, on vines imported from France, where it wasted little time in destroying thirty thousand acres of vineyards. Here we come to a very interesting and important point with regard to this insect_-its behaviour and mode of life differs according to whether its food plant is the American or European vine. Phylloxera exists in four forms; one of these forms is found upon the leaves, another on the roots. The leaf form, though causing considerable disfigurement to the plant, is not of great importance in itself; but the root form, working unseen, is the really harmful stage, rendered the more so because its presence may never be detected till the plant is killed; in fact, during the first year, the vine may be apparently benefited, as we shall see later. For some unexplained reason, the leaf form is found, for the most part, on American vines, and the root form on European ones-a fact which amply explains how an unconsidered insect, in its native home, became a great pest in Europe.

The life-history of this dreaded vine pest is exceedingly 


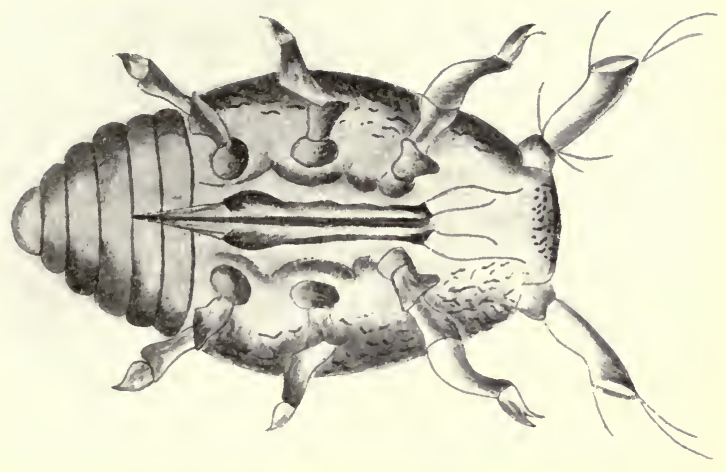

Fig. 19. P'ivlloxera, I'hylloxe'a z'astatrix, LARIA

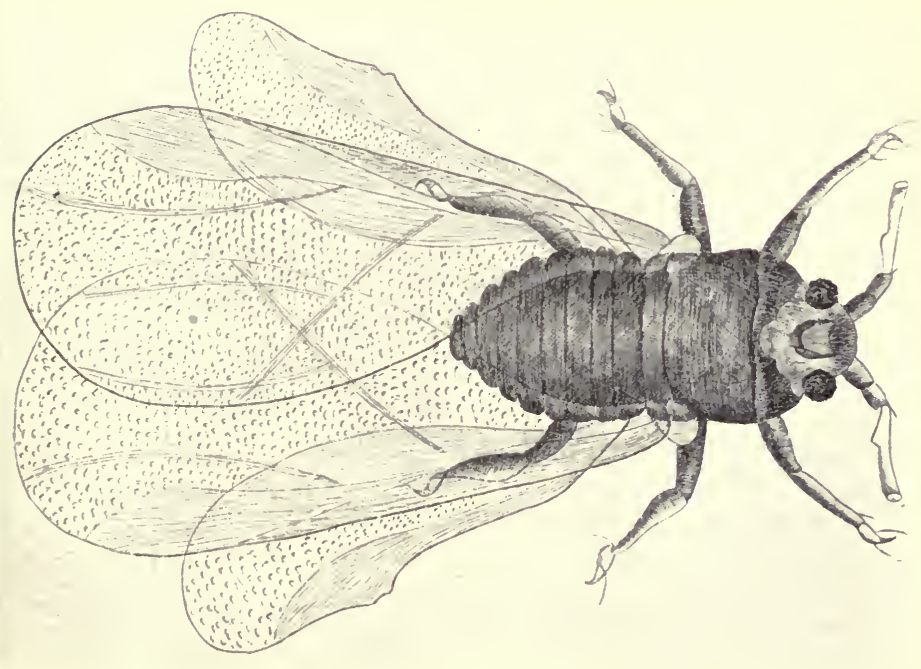

Fir. 20. Phylloxera, Wingen aidet 

complicated, and was only fully worked out, after years of painstaking study, by French and American entomologists. During the winter the eggrs may be found singly on old wood, etc., and, from these single eggs, the young insects hatch in the spring: in every case they are females, provided with sucking mouths. The newly emerged young at once proceed to the vine leaves, into the tissues of the upper surface of which they insert their beaks and begin to imbibe the plant juices. The injury to and irritation of the leaf results in the formation of a hollow sac, which almost encloses the insect and appears on the under surface, like a small tumour-a gall, in fact. In about fifteen days the female is full-grown. She is a wingless, plump, orangeyellow creature, and is able to produce her eggs parthenogenetically, that is to say, without recourse to a male, and this she does to some purpose, filling the little leaf sac, in which she dwells, with minute yellow eggs, and then she dies. In a little more than a week these eggs hatch, producing, in every case, females only, which promptly find their way from the gall and infest other parts of the leaf, or other leaves, in exactly the same manner as their parent. This process is repeated again and again, six or seven times during the summer, till the leaves become thickly studded with galls: always the eggs are laid parthenogenetically, always the young are females, and this form of Phylloxera has been called the form of multiplication. When winter approaches, the insects pass down the vine stems to the roots, where they remain dormant till the spring, then they awaken to activity and begin what is termed the form of devastation (fig. 19). Attacking the roots, as they did the leaves, with the formation of galls, irreparable damage is done to the vines. At first the attack has the same effect on the plant as root pruning, and, as a result, a very large crop of grapes may be produced. The continued root injury, coupled with the strain of bearing an exceptionally heavy crop, tells its tale on the plant-its leaves turn yellow, and 
death ensues. Before the death of the host plant takes place, however, considerable progress has been made in the life-cycle of Phylloxera. During the late summer and early autumn of the second year, some of the eggs, laid by the root insects, give rise to winged females (fig. 20), in place of the wingless forms that had been thus far produced. These winged females find their way to the surface of the ground and then fly to neighbouring vines-that they are carried by the wind would be a more correct statement, perhaps, for they are frail creatures, and their powers of flight are feeble in the extreme. They are short-lived: in two or three days their mission in life is accomplished, and they die. Their one object is to lay eggs, and this they do like their mother, parthenogenetically; there the resemblance ends, for, instead of depositing a large number of eggs, they lay at the most two to four beneath the loose bark on the old vine wood. Now we arrive at one of the most curious phases in this wonderful life-history. The eggs laid by the winged females are of two sizes; the smaller ones, which, by the way, are in the minority, give rise to males, whilst the larger and more numerous produce females, and this stage, which is sometimes termed the stage of regeneration, is the only one in which males are produced. In about ten days the two sexes emerge. Both have rudimentary mouth parts and take no food; their sole mission in life is, probably, to imbue their progeny with renewed vigour. How far this stage is necessary to the continuance of the race is a debated point, for all the while the root forms continue to exist and carry out their destructive work; and that they can do without help from their sexually produced relatives for at least four years has been proved. But to return to the sexual forms; after mating, the body of the female is rapidly occupied with a single egg of relatively enormous size, and this winter egg, which is laid within three or four days, completes the lifecycle. These changes, as described, extend over a period of 
two years; but, in exceptional circumstances, all the stages may be completed in a single year. Possibly, too, the young insects do not all await the approach of winter before passing to the roots, but continue to do so throughout the summer. One fact, however, has been definitely proved, that the young from the leaf galls may easily be colonised on the roots; but the process is not a reversible one, for the insects have never been observed to pass from the roots to the leaves. 


\section{III}

\section{INSECTS AND HUMAN DISEASE}

ONLY insects that are closely associated with man, and normally have every opportunity to suck his blood repeatedly, can be considered as potential disease-carriers. The fact that a species occasionally bites man is not sufficient. Take the case of forest mosquitoes; they may bite an infected person, but the chances are remote that they will survive to develop the blood parasites and then have an opportunity of biting and infecting another person. By the same line of argument, most mosquitoes, also the gadflies, or Tabanidoe, and the buffalo gnats, or Simulida, and many other blood-sucking insects may, probably, be dismissed from consideration as disease-carriers. Most of these insects, too, appear only for a time each year, so they would have to survive long intervals, when there could be no propagation of disease.

All insects that have been found to transmit human blood parasites are closely associated with man, and habitually suck his blood. Two tropical mosquitoes, Stegomyia fasciata and Culex quinquefasciatus, have only become effective transmitters of yellow fever and filariasis respectively by a combination of circumstances. They are always closely associated with man, and prefer his blood over other food ; they are abundant and comparatively longlived; their meals are taken at frequent intervals, and, as breeding is practically continuous, individuals are always present to act as intermediary hosts for the blood parasites. Under these conditions, the chain in the life-cycle of the 
parasite is continuous and the result is an endemic disease. A second, and more striking example, is afforded by the large Brazilian bug Lamus megistus, which transmits a dangerous human trypanosome disease. It is the only American member of the genus which shows a close association with man. It lives in houses, lays its eggs there, and never, naturally, occurs apart from man, on whose blood its young feed from birth. A curious circumstance is, that nearly all the wild species of the genus to which this disease-carrying bug belongs have very painful bites, but this species is specially adapted for giving such painless bites that they will not awaken a sleeping man.

At first sight the malaria mosquitoes do not appear to fulfil this condition of close association with man. A study of the habits of the various species of Anopheles, however, reveals the fact that they differ widely, and that, whilst some species do not habitually seek man's blood, for other species it appears to be a necessity; moreover, it is only those species which habitually associate with man, "domestic" species they have been called, that transmit malaria. Let us consider the mosquito question in the tropics, and see how much more dangerous, from a health point of view, the "domestic" species of mosquitoes are than the wild ones. In the Isthmian Canal zone of Panama, we have a country eminently suited to a mosquito fauna, as is evinced by the fact that no less than one hundred and twenty-five species are found there. This district is characterised by a typically tropical climate, high humidity, a short dry season, and a rich virgin soil, clothed with dense, luxuriant vegetation. Under these favourable conditions the mosquitoes breed continuously throughout the year, oviposition taking place whenever opportunity, in the shape of water, is to be found. Of the economically important mosquitoes to be found in this region are nine species of Anopheles, Stegomyia fasciata, 
and Culex quinquefasciatus. Stegomyia is exceedingly domestic in habit, and is never found, except by accident, away from man's dwellings. Anopheles albimanus is the most abundant of the Isthmian species of Anopheles, and it shows greater persistence in biting man and entering his houses than any other species. Needless to say it is a vector of malaria; in fact, it has been shown that a greater percentage of the females of this species become infective, and capable of transmitting the malaria blood parasite, than do those of any other species. Another mosquito of similar habit is Anopheles tarsimaculata, and it, also, is a transmitter of malaria. Anopheles pseudopunctipennis is not so common as albimanus and tarsimaculata, nor is it so closely associated with man; it is, however, a malariacarrier, though experiments have shown that, under similar conditions, only one individual of this species becomes capable of transmitting malaria, to five of albimanus.

It will be gathered that considerable effort is required to keep this host of disease-carrying insects under control in the Canal zone. The work is carried out by the Division of Sanitation, by whom a chief sanitary inspector and his assistant, three division inspectors, and twenty-five inspectors are employed and apportioned among seventeen districts. "Each district inspector is held responsible for the physical condition of his station as it affects the breeding of mosquitoes, and indirectly for the 'malarial rate,' or cases of malaria occurring each week as expressed in terms of percentage of population." A regular programme of oiling is drawn up by him, and executed by the foreman of oilers; native and American towns are inspected for Stegomyia and Culex breeding places, and most detailed reports are forwarded to headquarters each week. It was not till the Americans began the cutting of the Panama Canal that the work of controlling and eradicating the twin pests of tropical America-yellow fever and malaria-was taken in hand. At the time of 
the French work in this district, the discovery of the relations existing between these dread diseases and mosquitoes had been made known, and were certainly not generally available. The American efforts were at first directed against the yellow fever mosquito, and, when it had been practically eradicated, attention was turned to the malaria mosquito, with equally successful results. But a permanently mosquito-free territory, through artificial means, is impossible in such a climate as that of Panama. "The battle with nature is unending, and the slightest relaxation means reversion... Special and exceptional problems are being constantly presented, due in many instances to the engineering work connected with canal construction. Swamps of large area are sometimes unavoidably created, and before drainage can be effected, breeding of Anopheles has assumed formidable proportions. ... The great Gatun lake, with its approximately two hundred square miles of area and hundreds of miles of rugged shore line, bids fair to offer many problems as its level continues to risc. In the sheltered bays and indentations of its shore line, aquatic vegetation riots, and, as the waters inundate the tropical forest, a condition is created, ideal for the most prolific breeding of Anopheles and other mosquitoes: a tangle of living and dead vegetation, with floating debris from the dying trees, among which water plants flourish. A large part of the breeding areas formed will probably affect only scattered habitations and ranches, but, wherever settlements and towns are contiguous to the permanent shore line, correction of these conditions will be imperative. It is obviously impracticable to thoroughly clear and control square miles of territory, covered with heavy timber, and soon to be buried beneath the waters of the lake, but until the permanent level is reached the uncleared and shallow margins of the lake will supply myriads of mosquitoes to the adjacent regions." 


\section{Three Diseases transmitted by Mosquitoes}

There is one family of insects, a large and cosmopolitan family certainly whose members, collectively and individually, have probably done more than any other group in the animal kingdom to impede man's progress in the universe, have certainly brought upon man more illness and disease than any other insects, and have actually "held up" some of the greatest human undertakings. The mosquitoes, for these are the obnoxious individuals, belong to the family Culicidoe which, it is almost unnecessary to state, is one of the families of the order Diptera, or two-winged flies. All the mosquitoes, with the exception of the members of two genera, are provided with piercing mouths; and every female mosquito, with the exceptions mentioned, is probably a sucker of blood; certainly the majority imbibe this food, whilst the males subsist on plant juices. Here, again, we appear to be faced with an exception, for in Stegomyia - the yellow fever mosquito-both males and females are said to suck blood, but as a matter of fact only the females do so. Let us consider, for the moment, what crimes must, of a certainty, be attributed to the mosquitoes or gnats,--the names are synonymous, though this is not generally known. As a matter of fact, every mosquito should be eyed with suspicion, though, as yet, only a comparatively small number of species are proved disease-carriers, but this small percentage is responsible for the spread of such terrible and widely distributed diseases as malaria, yellow fever, and filariasis.

Many parts of the tropics have been and are practically uninhabitable by civilised man, owing to the ravages of malaria, and this is especially the case in West Africa and parts of India. Sir Patrick Manson, to whom medical entomology owes so much, says that in the tropics " malaria causes more deaths, and more predisposition to death, by predisposing to other affections, than all the parasites affect- 
ing mankind together." Sir Ronald Ross says: "Malaria fever is important, not only because of the misery which it inflicts upon mankind, but because of the serious opposition which it has always given to the march of civilisation in the tropics. Unlike many diseases, it is essentially endemic, a local malady, and one which unfortunately haunts more especially the fertile, well-watered, and luxuriant tractsprecisely those which are of the greatest value to man. There it strikes down not only the indigenous barbaric population, but, with still greater certainty, the pioneers of civilisation-the planter, the trader, the missionary, and the soldier. It is therefore the principal and gigantic ally of Barbarism. No wild deserts, no savage races, no geographical difficulties have proved so inimical to civilisation as this disease. We may also say that it has withheld an entire continent from humanity - the immense and fertile tracts of Africa. What we call the Dark Continent should be called the Malarious Continent; and for centuries the successive waves of civilisation which have flooded and fertilised Europe and America have broken themselves in vain upon its deadly shores." Creighton, in the Encyclopoedia Britannica, says that malaria "has been estimated to produce half the entire mortality of the human race." The disease has devastated Mauritius and Réunion.

Turning from the tropics to Europe, we find that the industrial and agricultural development of Italy is hindered by the presence of malaria in the southern half of the peninsula and in the Po valley; and, in 1900, owing to this disease, five million acres of Italian agricultural land remained very imperfectly cultivated. The depopulation of the Roman Campagna, too, was probably due to the sudden introduction of malaria by the mercenaries of Scylla and Marius.

Greece, too, has paid its tribute to the ubiquitous mosquito, and, in this respect, we cannot do better than quote from Sir Ronald Ross's address on malaria in Greece, 
delivered to the Oxford Medical Society on 29th November 1906. In the course of this address he said: "Now what must be the effect of this ubiquitous and everlasting incubus of disease on the people of modern Greece? Remember that the malady (malaria) is essentially one of infancy among the native population. Infecting the child one or two years after birth, it persecutes him till puberty with a long succession of attacks, accompanied by much anæmia. Imagine the effect it would produce on our own children here in Britain. It is true that our children suffer from many complaints_-scarlatina, measles, whooping cough,-but these are of brief duration and transient. But now add to these, in imagination, a malady which lasts for years and may sometimes attack every child in a village. What would be the effect on our population-upon their numbers and upon the health and vigour of the survivors. It must be enormous in Greece. . . . We now come face to face with that profoundly interesting subject, the political, economical, and historical significance of this great disease. We know that malaria must have existed in Greece ever since the time of Hippocrates, about 400 B.C. What effect has it had on the life of this country? In prehistoric times Greece was certainly peopled by successive waves of Aryan invaders from the north,-probably a fair-haired people-who made it what it became, who conquered Persia and Egypt, and who created the sciences, arts, and philosophies which we are only developing further to-day. That race reached the climax of its development at the time of Pericles. Those great and beautiful valleys were thickly peopled with a civilisation which in some ways has not been excelled. . . . Lake Kopais, now almost deserted, was surrounded by towns whose massive work remains to this day. Suddenly, however, a blight fell over all. Was it due to internecine conflict or to foreign conquest? Scarcely; for history shows that war burns and ravages, but does not annihilate. Thebes was thrice 
destroyed, but thrice rebuilt. Or was it due to some cause, entering furtively and gradually sapping away the energies of the race by attacking the rural population, by slaying the new-born infant, by seizing the rising generation, and especially by killing out the fair-haired descendants of the original settlers, leaving behind chiefly the more immunised and darker children of their captives won by the sword from Asia and Africa?.. Causes such as malaria, dysentery, and intestinal entozoa must have modified history to a much greater extent than we conceive. Our historians and economists do not seem even to have considered the matter. It is true they speak of epidemic disease, but the endemic diseases are really those of greatest importance. . . . The whole life of Greece must suffer from the weight which crushes its rural energies. When the children suffer so much, how can the country create the fresh blood which keeps a nation young?"

Not health alone, but man's very pockets are affected by this overmastering incubus. The mosquito plague has been responsible for arresting the development of the whole state of New Jersey: real estate has fallen in value, on account of the depredations of these insects; milch cows have been so worried by their attentions that their milk yield has been seriously impaired; horses at work in the field have to be covered with sheets, lest the attacks of innumerable gnats should drive them to distraction; in fact, without wishing to be facetious, it may be said that they anticipated the grandmotherly efforts of the American Government in attempting to put a stop to horse racing by making a whole-hearted attack on the race-horses at the Newmarket of America-Sheepshead Bay,-resulting in so impairing the condition of the valuable animals trained there, that thousands of dollars were spent in efforts to abate the pest.

Malaria is a country, rather than a town disease. It was once supposed to be caused by dwelling in damp and 
marshy places, and even now the belief dies hard in the minds of many people, but it has been proved beyond dispute, as we shall see later, that by the bite of infected mosquitoes, and by that means alone, can this dread disease be transmitted from man to man. In studying the lifehistory of the malaria mosquito we shall see that pools of still water are an essential to the insect's existence, hence the association of malaria with ill-drained districts. A humid atmosphere, of itself, can no more introduce the malaria parasite into one's system than can an evil odour infect one with the germs of typhoid fever; nor, for that matter, can healthy mosquitoes, even malaria mosquitoes, infect their victims with malaria, unless they have previously sucked the blood of a malaria patient.

We have mentioned that malaria is not a city disease; nevertheless it does, at times, occur in certain cities. In such cases it will usually be found that the town or city is situated on the borders of a so-called malarial belt, that is to say, a marshy district where malaria mosquitoes breed. Even then, the prevalence of the disease in the urban districts depends largely on the direction and force of the prevailing evening breezes of the summer season; depends, in short, on whether the mosquitoes are carried towards the town by the wind when they become active at nightfall, for all mosquitoes avoid the sunlight and heat of the day as much as possible. Washington is a case in point. At one time malaria, though essentially a rural disease, was rife in the city; to the south lay a marshy area of considerable extent, known as the Potomac Flats, where malaria mosquitoes abounded. During the summer the prevailing night breezes were southerly, so that here were found all the essentials requisite for the spread of the disease in the city. The mosquitoes on the Flats, hungry for human blood, and rendered energetic by the relative coolness of the evening air, were gently wafted towards the sleeping people of Washington. Some, perchance, took 


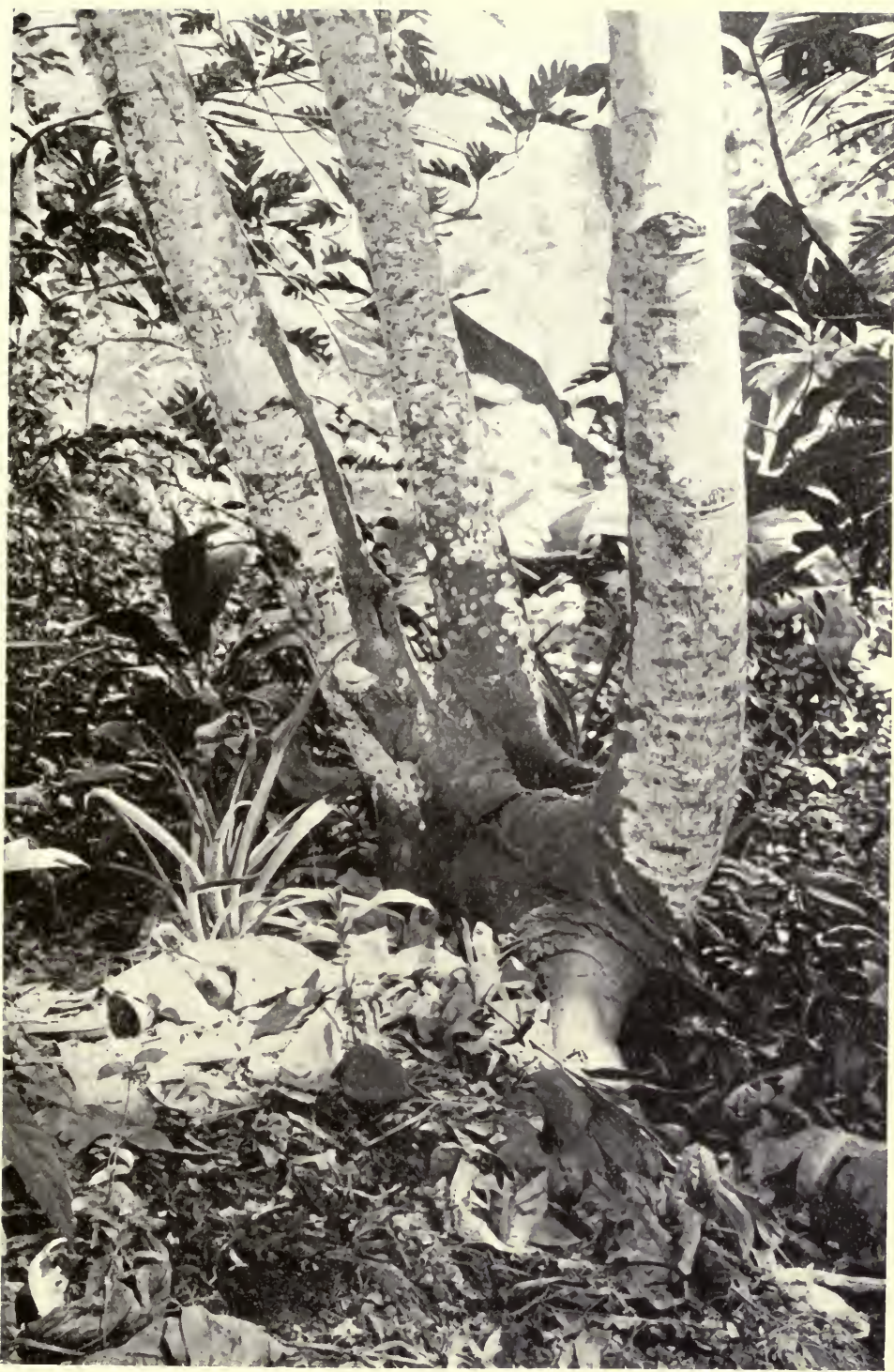

PLATE III

Hollow in a Breadfrútt-Tree. A favourite breeding-place of the Yellow fever Mosquito 

their fill of healthy blood and did no harm; although it does not require the imagination of a Jules Verne to conceive that they caused their quota of annoyance, as anyone who has ever provided a meal for even one hungry mosquito will readily believe. Others, perchance, alighted on someone harbouring blood parasites of malaria, some traveller, maybe, who had contracted the disease in the country and returned to the town to be nursed back to health and strength. Woe betide the individuals who later on fell victims to the "bites" of the latter insects, for, after a developmental period, each mosquito would spread infection at every stab of its lancet-like mouth parts. All this is history now ; for with the reclamation of the Potomac Flats, Washington, figuratively speaking, shook itself free from the disease.

Before proceeding to the study of the malaria mosquito, let us make a few observations on the breeding habits of mosquitoes in general. Certain mosquitoes may be aptly termed pool mosquitoes; these are the individuals responsible for the spread of malaria. They breed in ditches filled with herbage, in muddy, slime-covered water-holes, in abandoned clay pits, which become waterlogged in winter, and other similar situations, as often as not in the neighbourhood of villages. Other mosquitoes breed in marshes of larger area, and they, as befits their more lofty tastes with regard to their breeding places, are relatively large mosquitoes ; they are named Mansonoides, after Sir Patrick Manson. Other mosquitoes, again, like brackish water, and seek their breeding places in crab-holes and similar situations: these, too, are annoying, but the majority are harmless, as far as disease-carrying is concerned. The only other mosquitoes which we need mention breed in domestic utensils such as rain-water tubs, cisterns, old cans in which rain water has collected, and broken bottles-anywhere, in fact, where even a temporary puddle can be found (Plate III.). As may be surmised, these mosquitoes 
frequent inhabited places; in fact, their name Stegomyia is derived from two Greek words meaning, collectively, a house fly. As carriers of yellow fever they are of the utmost importance, but we shall deal with them later.

Into the clinical aspects of malaria in its three forms, malignant, quartan, and tertian, we cannot enter here, but a few words concerning the blood parasite causing the disease may make the rôle of the malaria mosquito a little nore easy to understand. Let us suppose that a female malaria mosquito has just imbibed a drop of blood from an infected man: along with the blood, and in the blood corpuscles, several exceedingly minute structures, known as gametocytes, pass into the stomach of the insect (fig. 21, A). These blood parasites are not all of the same size, the smaller ones, called microgametocytes, carry out male functions, whilst the larger macrogametocytes may be regarded as females. Numerous other forms may be taken up along with the blood, but, as they perish, we will dismiss them for the moment. The female parasite undergoes various changes, which we need not detail, and eventually sends out a small bud-like structure, in which is enclosed some of the original cell contents : at this stage the organism is ready for fertilisation (fig. 21, c o). The male parasite, meanwhile, has also undergone changes, resulting in the formation of several thread-like outgrowths (fig. 21, c ई), which eventually become free and wriggle about actively. One of these free-swimming thread-like bodies, microgametes, fuses with the female parasite (fig. 21, D), and the resulting body is an active organism, with worm-like movements, hence called a vermiculus (fig. $21, \mathrm{E}$ ). The vermiculus penetrates the wall of the mosquito's stomach and passes to the external muscular layers, where it becomes stationary, but grows rapidly, and its nucleus becomes much divided (fig. 21, G), so that eventually the whole structure is filled with a large number of somewhat rodlike bodies known as sporozoites. These sporozoites are 


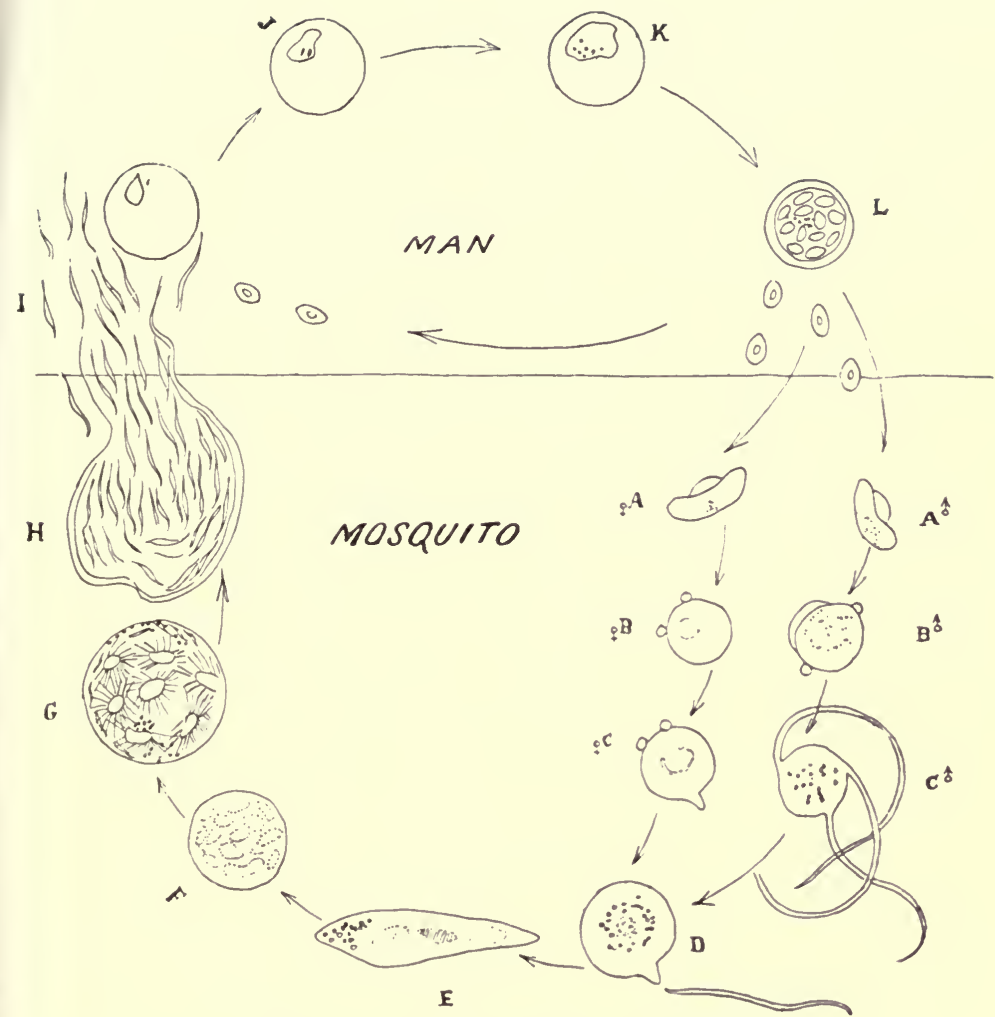

Fig. 2I. BIOOI PARASITE OF MALARIA
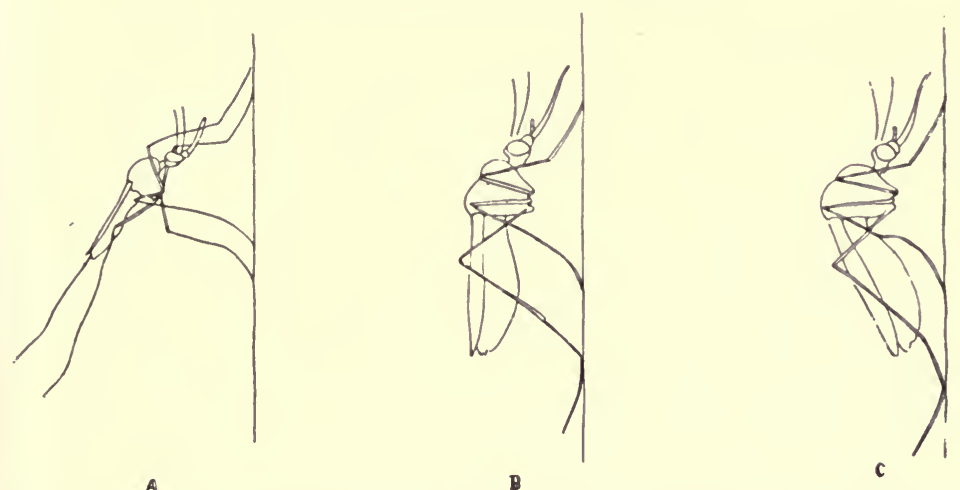

Fig. 22. Resting positions of mosquitoes. a. Anopheles sp; $b$. Culex sp 

liberated into the mosquito's body cavity by the bursting of the envelope in which they were formed (fig. 21, H), and about ten days after the meal of infected blood, they find their way to the salivary glands of their host, which is now in a position to infect the first human being on which it feeds. With the first puncture of the human skin, countless numbers of the sporozoites are injected into the wound along with the mosquito's saliva. Each sporozoite enters a red-blood corpuscle, loses its elongate form, and assumes a "signet-ring" form (fig 21, J). After various changes, accompanied by a deepening of colour, the parasite appears to have assumed the form of a rosette within the blood corpuscle (fig. 21, L); in reality, the original organism has divided up into a number of sinaller ones, known as merozoites. At this stage the wall of the corpuscle bursts once again, setting free the parasites in the blood stream. Not long, however, do they remain at liberty; they soon attack healthy red corpuscles, and the process is repeated, further rosette formations appear, and further organisms are set free, as the parasitised blood corpuscles burst.

Only when a large number of blood corpuseles have been destroyed does the patient feel any ill effects; the intervening period is the incubation period of the disease. Eventually this form of increase by division, asexual reproduction, as it is called, gives place to sexual reproduction, and this can only take place in the body of a mosquito, and a malaria mosquito at that. If no mosquito of the requisite species comes along to taste the blood of the malaria patient at this stage, the parasites perish, as they do, too, if imbibed by some non-malarial mosquito. The sexual changes of the malarial blood parasite can only take place within the bodies of certain mosquitoes, though why they should not be able to live within every species of blood-sucking mosquito has never been satisfactorily explained. It is one of nature's secrets, destined some day, perhaps, to be learned as a result of careful research, or 
maybe by lucky chance. At any rate this cursory consideration of the malarial blood parasite shows us that two hosts are essential to its well-being-a human host for its asexual forms, and a mosquito host, of the sub-family Anopheles, for its sexual forms. We learn, too, that the malaria mosquitoes cannot, at once, infect mankind; after a meal of infective blood, ten days or so must elapse before they are able to do so-till the sporozoites are formed.

We will not attempt to detail the classification of the mosquitoes, for the subject is one of great complexity, a state of affairs that is not made easier by the fact that the classification is at present undergoing revision. All the malaria-carrying mosquitoes, however, belong to the sub-family Anopheles, a name that means harmful, though certain mosquitoes of the genus Stegomyia are equally noxious. Approximately, twenty species of Anopheles are known to transmit malaria from man to man: four species are European, two North American, two tropical American, one Australian, four tropical African, while no less than eight species hail from Southern Asia. It is cold comfort, perhaps, to know that the members of the sub-family Anopheles are, in many ways, the most easily recognised of all the mosquitoes. Let us compare a typical malaria mosquito with, say, the common gnat of this country, Culex pipiens. At rest, these two mosquitoes may be easily distinguished. Anopheles assumes an attitude with its head and beak in the same plane as its body, and its hind legs often stretched straight out, either stationary or gently waving to and fro (fig. 22, A). Culex, on the other hand, shows a hunch-backed silhouette; its head and beak are not in the same plane as its body, and its hind legs rest on the support (fig. 22, B). The resting position of mosquitoes forms a ready means of rough distinction. Some Anopheles, when resting on a wall, project almost at right angles; other genera lie nearly parallel to their support; others again, like Culex, appear 


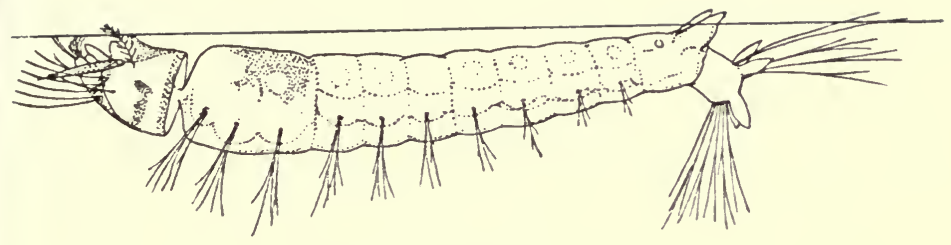

FIs. 23. tnopheles LARVA

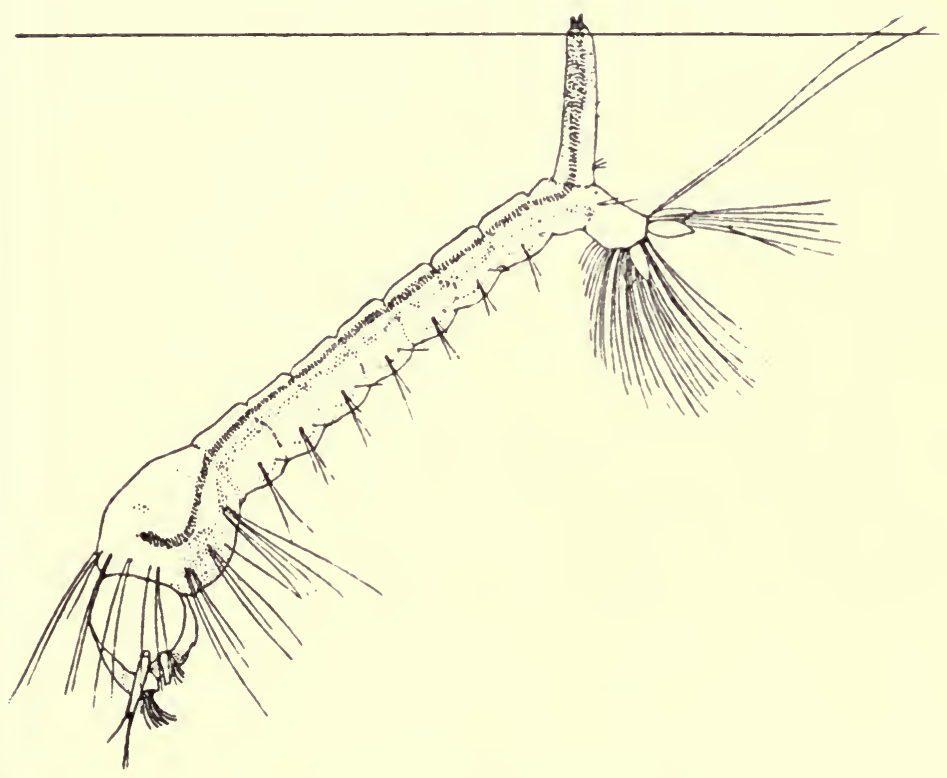

FI(. 24. Culex I.ARva 

hunch-backed. The wings, too, show mork a differences, those of Anopheles being more or less spotted, and in Culex they are clear. But it is in the egg and larvæ that the most striking differences are observed. Anopheles lays its eggs singly and often, as will be described later; they take up almost geometrical positions on the surface of the water. Culex, on the other hand, lays groups of eggs glued together to form rafts. The Anopheles larva, when undisturbed, lies almost parallel with the surface of the water (fig. 23), whereas the Culex larva hangs head downwards, almost at right angles to the water level (fig. 24). There are other important differences, of course, but we have quoted sufficient to show how the ordinary observer may recognise the two mosquitoes.

The life-histories of all mosquitoes are of the greatest interest. The mother insects lay their eggs on or at the edges of water, or sometimes on floating objects; the larval and pupal stages are spent in water, and the adult stage only is passed away from this element. The eggs of all mosquitoes, when first laid, are white in colour, but in a short time they change to dark brown or black. When laid upon water some provision is always made for keeping the eggs afloat, for if they become submerged they fail to hatch. The malaria mosquitoes (Anopheles), and some species of the yellow fever mosquitoes, lay their eggs in piled-up masses on the surface of the water, or on floating substances, whilst the eggs of the common gnat are laid on the water, in groups of from two hundred to four hundred, cemented together in such a manner that each egg floats perpendicularly with its broader end pointing downwards, the whole mass forming an oval-shaped raft.

Let us examine these eggs and egg masses in some detail. When the Anopheles egg mass is laid on the surface of water the eggs separate, and, on account of purely physical causes, assume at times very regular and beautiful patterns; sometimes they are arranged in star- 
shaped groups, sometimes in equilateral triangles, and at other times in regular rows. If the water in which these free-floating eggs are found be disturbed, their arrangement is of course upset, but, when the surface is once more quiet, they will re-arrange themselves in the original designs. With one exception, the eggs of these malaria mosquitoes are boat-shaped-their upper surface is flat, and the lower one deeply convex. Running round the margin of the upper surface is a gleaming white frill, forming, as it were, the gunwale of the boat; whilst, on either side of the egg, there is a remarkable structure, oval in shape, and transversely corrugated; this structure contains air cells and acts as a float (fig. 25, A). We have mentioned that the eggs of one Anopheles species differ from the typical form. In this species the eggs are devoid of floats and exhibit only a rudimentary frill; they are always deposited on floating objects, never on the water; in fact, if they accidentally fall into the water they sink and perish (fig. 25, B).

From the larval stage we pass to the nymphs. They have relatively large globular bodies made up of head and thorax with small tails; roughly, they are comma-shaped (fig. 26). From the globular part of the body-the thorax, to be exact -two breathing tubes arise, and the shape of the orifices of these tubes forms the easiest means of distinguishing our examples. Those of Anopheles have square, truncated ends; in Stegomyia they are broadly triangular; and in Culex, in addition to being longer and narrower than in the other species, they have slit-like openings. The differences between the nymphal stages of the various mosquito species are not nearly so marked as they are in the egg and larval stages. The nymphs, when undisturbed, like the larvæ, lie with their breathing tubes out of water; on the slightest alarm they rapidly dart away from the surface, but they do not stay away from it for long. Some of the darker-coloured nymphs are less active than the others, 


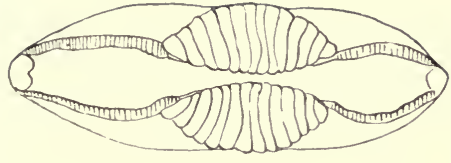

A.

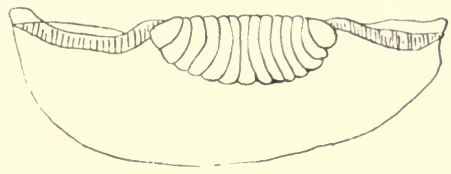

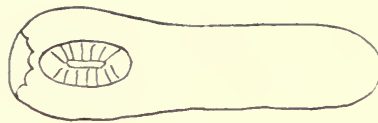

B

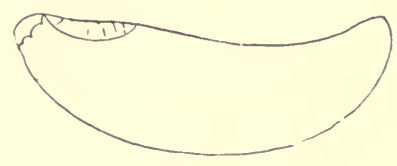

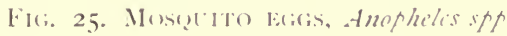
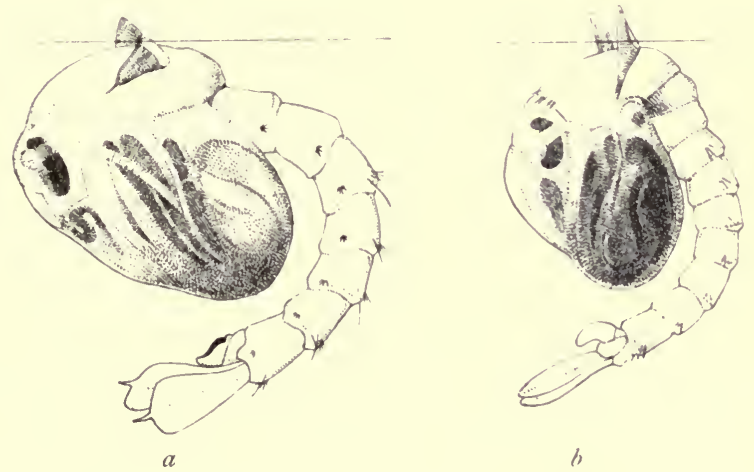

Fin. 26. Pur.t: or a. Anopheles: h. Culex 

their tails are more extended, and they exhibit silvery markings, due, in reality, to air beneath the nymphal skins. When they stretch their tails out in a straight line, or nearly so, the skin splits down the back and the perfect insect emerges (figs. 27 and 28). Unlike some small flies, the Simulidce or buffalo gnats, for instance, the adult mosquitoes do not at once fly away, but rest for a while on the floating nymphal skin, till their legs and wings are dry. When able to fly, they at once turn their attention to the increase of their kind. In the case of the malaria mosquitoes, it is necessary for the females to have a meal of blood before" they can lay fertile eggs. Observations show that they feed every night, chiefly in the early night, and just before dawn, their stomachs never becoming empty, and, as the length of life of the adult may extend to several months, it is clear that these insects are an intolerable nuisance to mankind, quite apart from their disease-carrying propensities.

The eggs of the yellow fever mosquito (Stegomyia) form an intermediate stage between the ones just described and those of the common gnat. Sometimes, as in the case of Anopheles, they are laid singly, and at other times, as in the case of Culex, they are laid in rafts (fig. 29). Each egg is of an irregularly oval shape, somewhat like a minute hen's egg, and its surface is much corrugated. In the corrugations are entangled numerous air bubbles, which keep the egg afloat. As in the case of Anopheles, these eggs, at times, assume varied patterns on the surface of the water. The egg rafts of the common gnat are from one-fifth to one-third of an inch in length, and are roughly boat-shaped. If a single egg be detached from the mass, it will be seen that it is devoid of floats, or any other contrivance to keep it on the surface of the water, a condition of affairs that continues only so long as the eggs are glued together to form the raft. One end of the egg is much thicker than the other, and to this end is attached a trans- 
parent globular body; the thick end floats downwards in the water, and through it the larvæ emerge.

So much for the eggs; and now, turning to the larvæ, we shall see that they also show striking differences. With anatomical details we are not concerned, but we may mention that each larva is composed of three parts, a head, thorax, and abdomen, divided into segments, at the tail end of which is a tuft of gills; and there may, or may not, according to the species, be a breathing tube. The larva of Anopheles is easily distinguished from all others, because, when at rest, it lies flat along the top of the water, and some of its hairs actually pass into the air, so that the larva appears as though it had its back out of water. The reason for this position is, that Anopheles has no breathing or "spiracle" tube, respiration taking place through a pit, on the eighth abdominal segment. With one exception, it is only when about to pupate that the Anopheles larvæ forsake their horizontal resting position for a more vertical one; the exceptional species is the one whose eggs are unprovided with floats, and these larvæ, although they rise to the surface in a horizontal position, then slowly sink till their tails alone touch the surface. As in the egg, so in the larval stage, the yellow fever mosquito (Stegomyia) exhibits an intermediate structure between Anopheles and Culex. The former has no siphon tube; the latter has a relatively long one, whilst Stegomyia has a short, thick one. When at rest, at the surface of the water, this larva assumes an almost vertical position, hanging head downwards, with the tip of its siphon tube projecting into the air. Unlike the majority of mosquito larvæ, however, it spends a considerable time at the bottom of the water, and then it usually lies horizontally. The gnat larva at rest does not assume quite such a vertical position as the preceding example, nor is it so long and worm-like, although provided with a longer siphon tube. A word may here be said about these structures. 


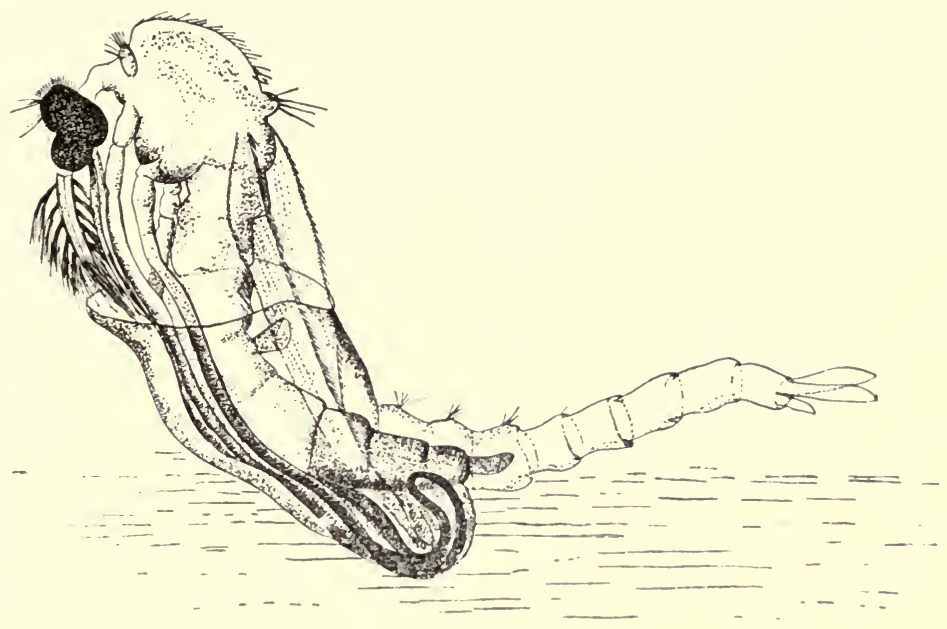

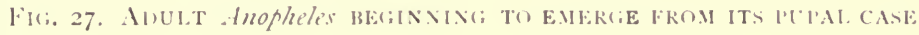

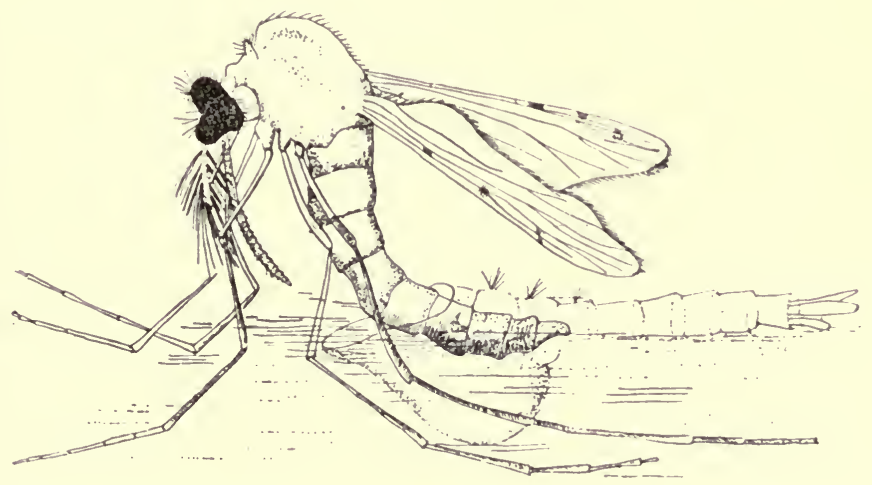

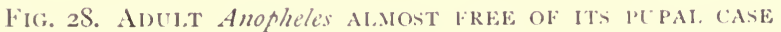



Insects do not breathe by means of lungs, like the higher animals, nor even, in the adult stages, at any rate, by means of internal gills, like the fishes, or external ones, like the tadpoles, but by means of a network of fine tubes called tracheæ, which ramify within their bodies. The siphon tube of a mosquito larva is composed of a cylindrical piece of chitin, a very tough and resistant substance, of which the hard parts of insects are composed; within the tube are the starting points of the two main tracheæ. The tracheæ, as we have said, are tubes, and they have no power of opening and closing; how then do the larvæ, which always forsake the surface of the water when disturbed, prevent themselves from being choked? When a seal or sea-lion is about to go beneath the surface of the water, its nostrils are always carefully closed, to prevent the ingress of any liquid to its respiratory organs; in a similar manner, when the mosquito larva leaves the surface, flaps of chitin close up the end of the siphon tube, thus serving the same end. Though the functions of the chitin flaps are similar to those of the specially modified nostrils of the seal, anatomically, of course, they bear no relation to one another whatever.

We have said that malaria can only be contracted as the result of a bite by an infected mosquito. Certain Italian physicians, by name Bignami, Bastianelli, and Grassi, had shown this, but, from one reason and another, their findings did not carry conviction to the world at large. In 1900, at the instigation of Sir Patrick Manson, and with the assistance of the Colonial Office, two strictly scientific experiments were carried out, with the object of proving the truth of the mosquito malaria theory, in the most striking manner possible. In brief, for one experiment, two men who had never suffered from malaria were to live in a severely malarious region, throughout the fever season, taking no measures against the disease, except protection from mosquito bites. For the other experiment, 
two men who had never suffered from malaria, nor been out of England, were to be bitten with infective mosquitoes, sent from abroad.

The Roman Campagna, "a district so well known as the classic land of malaria, not only on account of the ravages of the endemic, but also because of the noble work accomplished by the Romans during their long struggle with the disease," was selected, and, by the middle of July 1900, the two scientists entrusted with the experiment, Drs Sambon and Low, together with Signor Terzi, were ensconced there in a mosquito-proof hut, of which more anon. The actual site chosen was at Fumaroli, in the district of Ostia, on the low, swampy, alluvial soil at the mouth of the Tiber, and noted for being intensely malarious ; so much so, that it has been said "that it is sufficient to sleep one single night in Ostia, during the fever season, to contract the disease." The district has no indigenous population; agricultural labourers arrive in the midde of October, but depart again in June, before the malarial season begins; their place is taken by other workers for the wheat harvest, who in turn are succeeded by the maize harvest workmen, in September; these peasants suffer very severely from malaria.

In describing the experiment to the writer, Dr Sambon said : "We not only intended to corroborate a fact already scientifically demonstrated, but also to overthrow a number of fallacies and prejudices which prevented the full appreciation of the new discoveries in malaria, and impeded the advantages which would undoubtedly accrue from their practical application. The routine of our life in the Campagna was therefore greatly influenced by the object the experiment had in view. We had to prove that malaria was not carried by a vitiated condition of the air, as the name of the disease implies, and therefore we always slept with our windows wide open, although the stench of the decaying vegetation and putrefying animal matter 


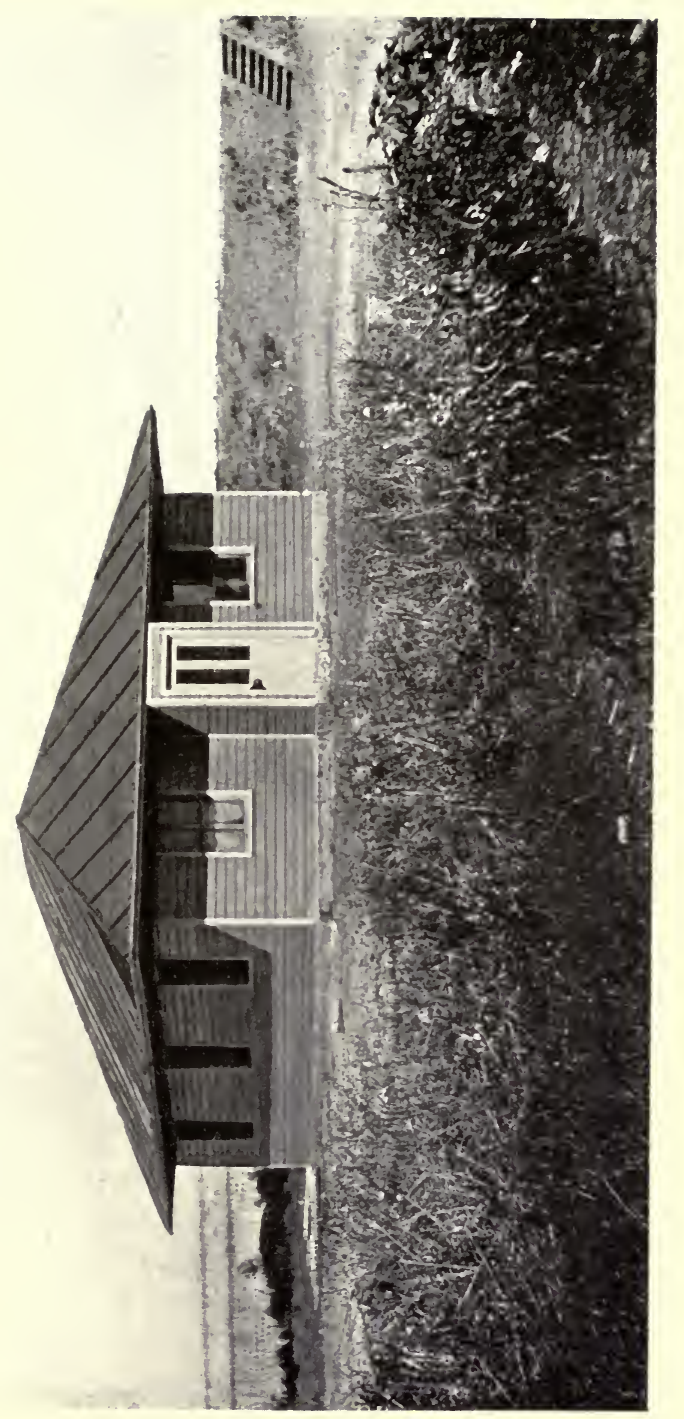

के

\&ั

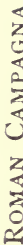

要

근

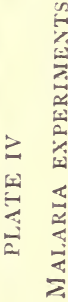

ㄱ.

空

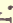

5

\begin{tabular}{l}
5 \\
0 \\
0 \\
0 \\
0 \\
0 \\
6 \\
0 \\
0 \\
0 \\
0 \\
0 \\
\hline
\end{tabular} 

from the drying-up canals was very unpleasant at times. The people of the neighbourhood were greatly amazed at what they considered our temerity in exposing ourselves freely to the night air, and many in Ostia who heard of our mode of life would not believe it, until they had seen it with their own eyes. The habit of the Romans of sleeping with hermetically closed windows probably originated on account of malaria, and is, of course, a perfectly consistent one, especially if viewed in the light of our present knowledge of the atiology of this disease.

"Our food came chiefly from Rome, with the exception of bread, eggrs, and sometimes milk and fowls, which were obtained in the neighbourhood. The people of the Campagna attach great importance to the food question in regard to malaria, and therefore it was not to be regretted that the difficulties of our commissariat obliged us to partake of a fare very similar to that of our malariastricken neighbours.

"We never took quinine, arsenic, or any other kind of remedy which might be considered prophylactic as regards malaria.

"The turning up of the soil is another condition which has been looked upon as a source of malarial infection, on the erroneous supposition that the germ is capable of saprophytic life. The soil all round our hut was constantly being turned over for a number of reasons, amongst which was that of a possible archæological find. We were encouraged in this hope by the fact that while digging for the foundations of the hut we had come upon a tomb of the time of the Roman Einpire. It was formed of large terra-cotta slabs, and contained the skeleton of a young woman. Close to the base of the skull was a coin of the Emperor Commodus, evidently toll-money for the passage of the Styx, which the old Romans used to place in the mouths of their dead.

"Our neighbours were certainly surprised at our im- 
munity and good health, and they watched our experiment with keen interest; but when we advised them to adopt our simple and easy method of protection, they shook their heads and invariably answered, 'Wait till the rains come.' The poor creatures spoke from cruel experience, because a drenching is always followed by relapse in those who have latent malarial organisms. More than once we were thoroughly soaked by torrential showers, but no fever ensued, because we had no malarial parasites in our system that a chill might rouse into activity.

"Long experience in the Roman Campagna and in other malarial regions of Southern Europe has taught that the most dangerous time for contracting malaria is during the evening twilight and at dawn. This fact agrees perfectly with the feeding habits of the mosquitoes of the genus Anopheles peculiar to these regions. We proposed therefore to retire an hour before sunset, and not again to leave our mosquito-proof hut until an hour after sunrise. But we very soon found that it was not necessary to retire so soon as an hour before sunset, because the Anopheles appeared very punctually a few minutes after sunset and disappeared again a few minutes after sunrise."

During the whole of this time the two scientists and their companion remained in perfect health; by day they went about the country quite freely, but always retired to their hut in the evening, before the mosquitoes became active. The hut (Plate IV.), which was made of yellow fir, consisted of five rooms, one of them serving as laboratory and mess room. The windows and double door were protected with copper wire gauze, whilst the whole of the interior was painted white, so that stray mosquitoes could be easily detected; as a further precaution, each bed was provided with mosquito curtains.

So much for the proof of the mosquito malaria theory by negative inference. With regard to the direct positive proof, Dr Sambon says that "the mosquitoes were collected 


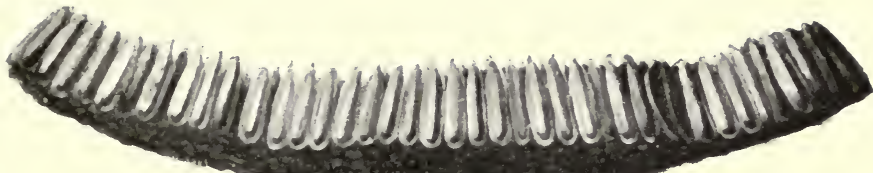

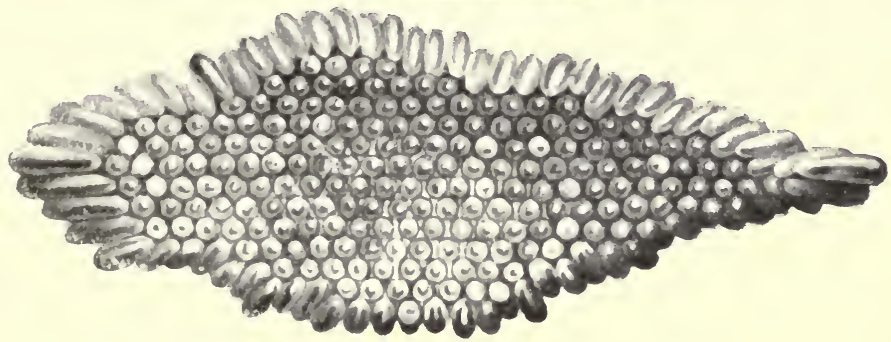

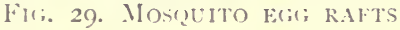

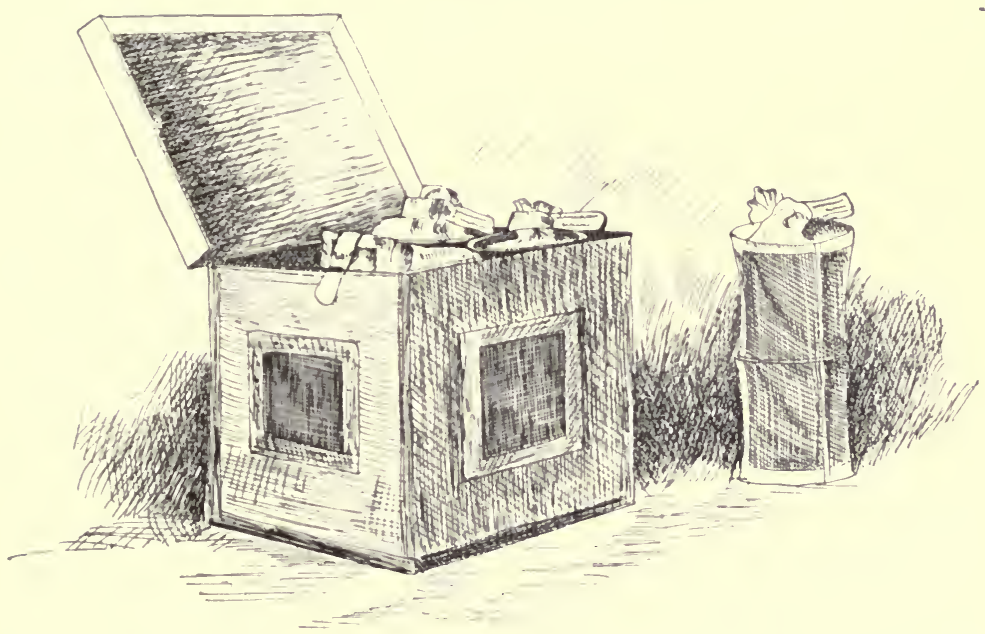

FI(3, 3O. BOX DESIGNED BY DR. L. SAMBON FOR THE TRANSPORT OF MOSQUITOES 

on the margins of the Porto Swamp, which had been at one time the famous hexagonal dock, built by the Emperor Trajan. They were all specimens of Anopheles maculipennis, and were carefully examined to see that they had only just emerged from their pupal cases and had not yet fed. They were then infected on cases of tertian fever, this type of malaria being selected because it offers no real danger, and is easily cured by quinine. The patients employed were very carefully and repeatedly examined, so as to absolutely exclude the possibility of their suffering from any other type of malarial disease.

"'The transmission of the infected mosquitoes from Rome to London was a matter' of some difficulty. 'The journey from Rome to London lasted about three and a half days. So many unfavourable conditions of temperature, shaking, etc., having to be experienced on the journey, it was necessary to devise some apparatus that would obviate these risks as much as possible. I noticed in my visits to the houses and stables of Ostia, that the Anopheles there collected very often, and seemingly by preference, rested on the old cobwebs, and maintained their position on these delicate structures with ease, even while the latter were wafted about by fairly strong currents of air, so I tried to reproduce a similar condition as far as possible in my arrangements for transmission. Mosquito netting was loosely applied round a framework of tinned wire, so as to form a cylinder eight and a quarter inches long, by three and a half inches in diameter, which might be closed at both ends by means of strings. Four such cylinders were placed within a square wooden box to protect them from damage (fig. 30), to render them more portable, and to keep the insects in a state of semi-obscurity. On each one of the sides of the box an opening, three inches square, was made, covered with wire netting, to allow of the transmission of air, and also to prevent the mosquitoes escaping should the cotton netting in any way get torn. By means of this 
method of packing, with very few exceptions, most of the mosquitoes arrived in London alive and in good condition. All the mosquitoes that chose were allowed to feed again on the day of departure, so as to keep them in as good a state of nourishment for the journey as possible. As a precautionary measure, especially for those that had not fed on the day of departure, thin slices of water-melon or other fruit were placed on the floor of the box beneath each cylinder, in such a way that the insects might, if they chose, suck up the juices through the meshes of the netting.

"On their arrival in London, the infected mosquitoes were set to feed on Dr P. T. Manson and on Mr G. Warren, both of whom had volunteered to be inoculated. For this purpose the closed cylinders containing the infected mosquitoes were placed over the hand or arm of the subject, and the insects allowed to puncture through the meshes of the netting. Shortly afterwards (about eighteen days in one case, fourteen in the other) both subjects developed characteristic tertian fever, and tertian malarial parasites were found in abundance in their blood both at the time and on the occurrence of the several relapses of malarial fever from which they subsequently suffered." Thus terminated one of the most picturesque, and withal, farreaching experiments in the annals of medical entomology. The doubting Thomases were silenced, once for all; the means for the amelioration and even eradication of malaria was made clear to all who cared to profit by the lesson; and Sir Patrick Manson's prophecy, made when the experiment was first mooted, that the scientists in the Roman Campagna would suffer no harm, and that those bitten, in England, by infected mosquitoes, would contract malaria, was vindicated in no uncertain manner.

\section{YeLLOW FeVER}

Yellow fever, that dread disease of the tropics, is carried from man to man by a mosquito, Stegomyia fasciata (fig. 31), 


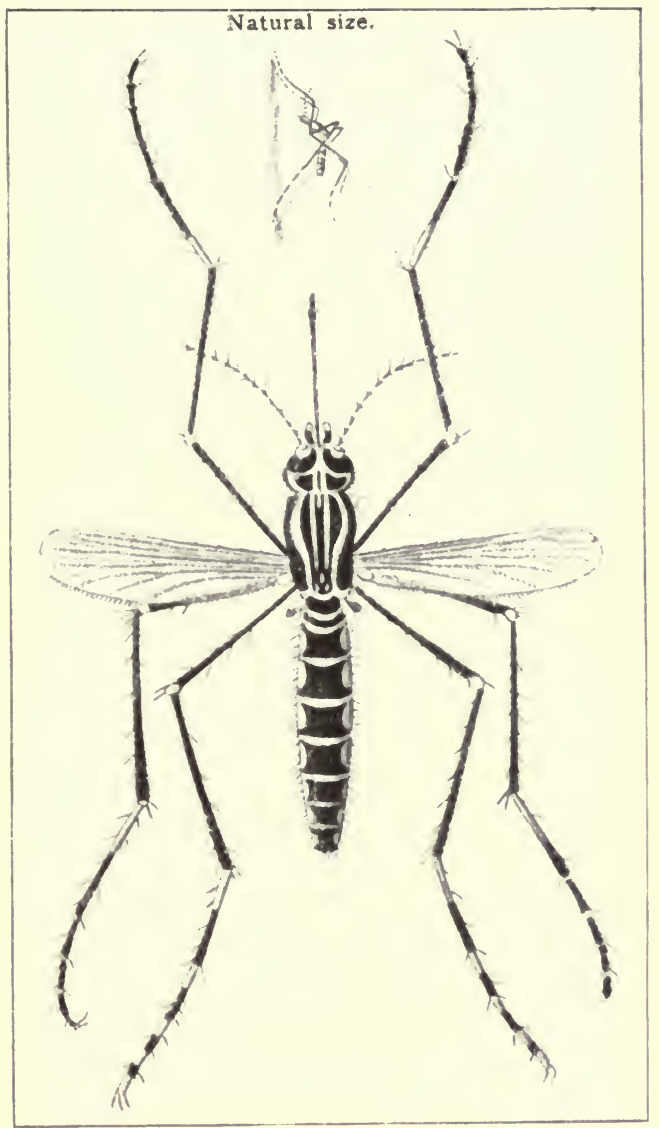

Fil: 3I. THE YELLOW FEVER MOSQUTO (FEMALE) Stesomyia fasciata 

and by that means alone. In connection with the mosquitoborne diseases, it is interesting to note that, although filariasis was first actually proved to be transmitted by these insects, more than one observer, at a far earlier date, had a shrewd suspicion that yellow fever was likewise transmitted. Surgeon-General Blair hinted as much, and Dr Beauperthuy, in 1853, actually accused Stegomyia of being the carrier; and so far he was right, though his belief that the insect obtained its poison from the soil was, as we shall see presently, far from correct.

Yellow fever is probably one of the oldest diseases of mankind; it was known to the Aztecs, and Humboldt inentions its occurrence in the eleventh century. It caused enormous mortality among the followers of Christopher Columbus; it decimated the Mexicans in the sixteenth century, and the inhabitants of Martinique at a later date. Originating probably in Brazil, the disease has spread along trade routes to Central America, the Southern United States, and the West Coast of Africa. It was not till 1881 that Dr Finlay enunciated the theory that the disease was carried from man to man by Stegomyia; and about that time a host of observers took the field; many of them succumbed to the disease they had come to study, and although they were unable to actually find the parasite causing yellow fever, they proved that neither the persons, clothing, nor excretions of patients suffering from the disease are infective. They proved, too, that a patient's blood only contained the virus five days after infection, and that then, if bitten by the mosquito Stegomyia fasciata, and by this species alone, the insect would, after a lapse of time, itself become infective and capable of transmitting the disease. These discoveries "swept away as if by magic the traditional views, which filled very many volumes, as to the nature, origin, and prevention of yellow jack." The disease had been attributed to "droughts and to floods, to the pestilential 'mangrove swamp,' to high temperatures, to 
fæcal matters, to combinations and concatenations of atmospheric circumstances, to stone ballast, hundreds of tons of which have been disinfected or thrown into the sea."

The fight that man has made, in recent years, against yellow fever, or rather against the transmitter of yellow fever, is such a striking example of prophylaxis that some mention must be made of the work done and of the results obtained. Six great yellow-fever campaigns have been carried out, and, in every case, the honours have been with man. The first campaign took place in Havana, when the Americans took over the administration of Cuba. Between the years 1853-1900 the number of deaths in Havana alone had averaged two a day. Colonel Gorgas, whose name will always be writ large wherever mosquito control is the subject of discussion, took the work in hand so vigorously and successfully that, in 1907, only one case of yellow fever was reported in Havana: one case in a city whose yearly average of deaths from this disease had been, only a few years previously, seven hundred and fifty-four. In July 1905 yellow fever broke out among the Italian colony of New Orleans, in the dirtiest and filthiest part of the town; the disease had become firmly established before it was notified, but, when once the danger was realised, a most thorough and scientific campaign was set on foot. By 12th August the disease was at its height, and in three weeks from the first notification the fever was under control, and "an outbreak which in previous years would have developed into the usual awful epidemic was in a few weeks at a comparatively small cost completely stopped, and that in the face of a dense population, open drains, and a sultry summer." That this statement is no exaggeration is shown by a comparison with a previous yellow fever outbreak in the same city. In 1878, when the population of New Orleans was only 191,418, there were 4,046 deaths, whereas, in 1905, when the population had increased to 325,000 , the deaths totalled the comparatively small number 
of 460. Other campaigns have been carried out in Honduras, Brazil, and the West Indies with equally gratifying results, and, most striking and dramatic of all, in the Panama Canal zone.

The Panama Canal forms the centre of a strip of land 10 miles wide by 45 miles long; its population consists of some 50,000 labourers and their families, scattered over an area of 500 square miles. As in Havana, so in Panama, the inhabitants depend on rain-water for domestic purposes, with the result that, adjacent to every house, there is some vessel for catching and storing water. The climate is favourable for continued breeding of mosquitoes all the year round, and by Stegomyia fasciata, the yellow fever mosquito, some domestic utensil containing a little water is the most favoured breeding place. Small wonder, then, that this district was once a hotbed of yellow fever and malaria, and the failure of the Canal work, during the French occupation, was largely due to the enormous mortality of Europeans in the zone. In 1904, the American Sanitary Department took upon its shoulders the seemingly impossible task of rendering the Canal zone healthy and habitable. The whole region was divided into districts, bodies of men worked at mosquito extinction in each district, and an inspector was put in charge of each of these bodies, to see that the work was carried out in a scientific manner. Primarily, operations were directed against the yellow fever mosquito, but the malaria mosquito did not by any means escape from the campaign unscathed. It is impossible to detail all the antimalarial measures that were undertaken in the zone-all the breeding places of the mosquitoes were destroyed as far as possible; bottles, old cans, etc., in which Stegomyia might breed were cleaned up, and ditches, etc., within a hundred yards of any dwelling were cleared so as not to afford a home to Anopheles larvæ; protection for the adult mosquitoes in the shape of rank grass was also burned or 
destroyed around dwellings; habitations were screened to keep out mosquitoes, and breeding places that could not be destroyed or drained were treated with crude paraffin, whilst people who neglected to cover their water tubs or allowed water to stand about their dwellings were fined. Over 1,200 men were employed in the work, at an annual cost of $\$ 2,000,000$ per annum; in fact, the total expenses of the Panama Canal Sanitary Department have been estimated at a little more than five per cent. of the total cost of the Canal.

What is the result of this work, taken in hand in 1904? Yellow fever is practically unknown; there was not a single case between 1905 and 1910, and the number of malaria cases has been materially reduced. By the courtesy of the Panama Canal Commission we are enabled to reproduce three photographs illustrative of mosquito control. Plate V. represents the burning of grass near the haunts of the malaria mosquito; as the adult insect is not strong on the wing, it is partial to places where a luxuriant undergrowth will afford the necessary shelter. Plate I. shows one of the coloured workers of the Sanitary Department treating a ditch-a likely mosquito breeding place-with crude oil from a knapsack sprayer, in order to kill the larvæ. The same end is attained in a different manner by the apparatus shown in Plate VI. A metal container is fixed on supports above some waterway where the mosquitoes abound; crude oil drops slowly from the container to the water below, thereby rendering the place unsuitable for mosquito breeding and killing any larvæ that may be present.

Of Stegomyia fasciata itself, we have already given some details in our account of the malaria mosquito, by way of comparison with that insect. Although what may be termed a coastal mosquito, it readily spreads into the interior of the countries where it is found. Unlike the malaria mosquito, Stegomyia is essentially a town insect; in fact, it has been called the "cistern mosquito." It has 


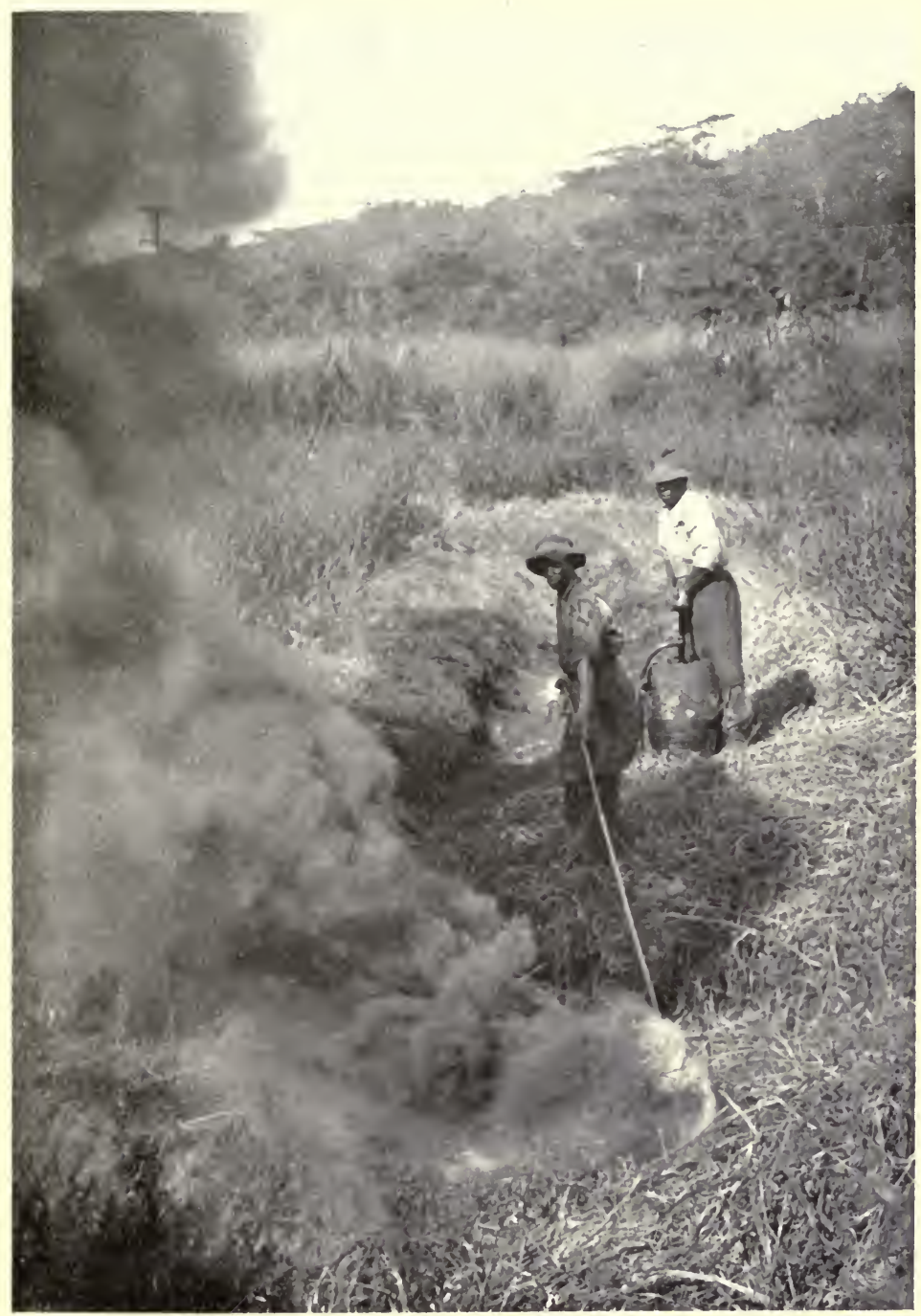

PLATE V

BURNiNg UNDERgRowTh IN Which Mosotitos take Shelter, Panama CaNal ZoNe 

also been called the "tiger mosquito," because its legs and abdomen are striped with white, whilst in the upper surface of the thorax there is a white lyre-shaped pattern. Only the females imbibe human blood, and they feed both day and night. The males have been accused of blood-sucking, but this erroneous notion has probably arisen from the fact that they settle on man for the purpose of imbibing perspiration. Each female lays between twenty and seventy-five eggs, and in this stage the insects are able to tide over the winter when the weather is severe, for their fertility is not destroyed by freezing. Under favourable conditions, however, the eggs hatch in from ten hours to three days; the larval period extends from six to eight days, and the pupal stage may last less than two days, so that the whole life-cycle may be completed in a little over nine days, under favourable circumstances. We have called the yellow fever mosquito a town insect; it is more, it is a domestic insect-"as domestic as the flea, bug, and cat." In its choice of breeding places, too, it haunts man's dwellings; it has been said that it never breeds in any water with a natural earth bottom, but always in artificial water containers, and not necessarily water containers by design, for the females will oviposit in a few teaspoonfuls of water in the hollow base of an inverted bottle (Plate VII.). And if the water evaporates and the eggs are left high and dry, they will retain their vitality for at least six months-till more rain falls.

Whether the opening of the Panama Canal will result in the transport of yellow fever to Asia, time alone can show. Stegomyia occurs in Asia in plenty, but so long as the disease itself or infected mosquitoes are not carried to Asiatic ports all will be well, for non-infective Stegomyia is as harmless as the common British gnat.

The common gnat, Culex pipiens, of this country is an annoying insect, though one of little economic importance. Its near relative, Culex fatigans, however, is notorious 
as the transmitter of a tropical and semi-tropical disease known as filariasis. The disease, which in one form also goes by the name of elephantiasis and Barbados leg, is of a distressing nature, and manifests itself in enormous swelling of the afflicted organs; its cause is a worm which occurs in the blood and lymphatics.

So long ago as 1863, Demarquay had discovered the immature forms of the parasitic worm, and later, Bancroft brought to light the mature form, which was known as Filaria bancrofti. The discovery of the transference of these blood parasites from man to man by the aid of mosquitoes, in itself of the greatest importance, became doubly important, because it paved the way to similar discoveries with regard to malaria and yellow fever.

The discoverer, Sir Patrick Manson, described his work at a meeting of the Authors' Club, in 1909, in the following words: "Let me go back to my early years of tropical experience. I was then in the island of Formosa. I took a great interest in the diseases of the people. One disease had a special fascination for me-elephantiasis. I puzzled over what might be the cause of this disease, but without finding a satisfactory solution. Later I went to Amoy, a large town on the coast of China, where I saw many more cases and many more forms of the same disease. Still I failed to find an explanation.

"In 1874 I came to London, and there for the first time I heard that Timothy Lewis, who had done so much in the study of tropical diseases, had discovered that in the blood of a proportion of the inhabitants in certain districts of India there was to be found an organism which he called Filaria sanguinis hominis. This is a microscopic animalcule, eel-shaped, and enclosed in a loose sac, or sheath, within which it wriggles about in the blood very actively. It is sometimes present in enormous numbershundreds in every drop of blood. These parasites Lewis had found in more than one instance in association with 

elephantiasis or elephantoid diseases. On my return to China in 1876 I endeavoured to ascertain if these parasites occurred also in China. I discovered that they were present in some districts in ten per cent. of the population; in other districts they were present in fifty per cent.; while in other places they were not found at all. One thing was certainthat this little organism was not a mature animal. It showed no evidence of growth while in the blood, or of any organs such as would leave one to suppose that it was capable of reproducing itself. The inference was therefore that it was the young of some other animal. For this I searched many times, and at last found such to be the case, although my discovery had been anticipated by Bancroft and by Lewis himself.

"The parental worm was quite a big animal, from about 3 to 4 inches in length, of a thickness of a strand of fishing gut. It lay in the lymphatic vessels. But between this mature animal and its young, actively wriggling progeny in the blood no intermediate form could be discovered. The problem naturally suggested itself, How does this parasite contrive to pass from one human being to another?

"Now it occurred to me that if it could not pass by virtue of its own effort from one human body to another, and if such a passage were necessary, as it obviously is, some other agent must intervene, and that that other agent must be one which is capable of piercing the skin of the human body, and also one which absorbs the blood of the human body, and with the blood the little wriggling parasite which it contains. Such translation was, in my opinion, a first and necessary step for the parasite to take when it would quit one human body and get into another. Now, the agent which occurred to me as being the most likely to effect the necessary step in the translation of the filaria was the mosquito."

Whilst in Amoy, Manson examined the blood of over a 
thousand Chinamen, and discovered that the number of filariæ in the blood increased during the night. Was this development of the blood parasite, during the night, an adaptation to the nocturnal habits of the mosquito? Manson decided to test the matter, so he dissected mosquitoes that had just fed on the blood of a Chinaman known to be afflicted with the parasites. "I shall not easily forget the first mosquito I dissected so charged," he said. "I tore off its abdomen, and by rolling a pen-holder from the free end of the abdomen to the severed end, I succeeded in expressing the blood the stomach contained. Placing this under a microscope, I was gratified to find that, so far from killing the filaria, the digestive juices of the mosquito seemed to have stimulated it to fresh activity." This was an epoch-making discovery, but Manson was not content; further research showed him that the filariæ became exceedingly active in the stomach of the mosquito, and that they passed through the wall of this organ into the abdominal cavity, and from thence into the thoracic muscles. He discovered, too, that during this passage the parasite increased in size from a length of $\frac{1}{100}$ of an inch to a length of $\frac{1}{16}$ of an inch, and that in doing so it developed an alimentary canal and a mouth. "Manifestly it was on the road to a new human host."

At the time of these discoveries, Manson concluded that the filariæ then reached the blood of man through drinking water, having reached the water owing to the death and decay of the mosquito. Later work, however, led to the discovery that the parasites eventually left the thoracic muscles of their insect host and travelled to its labium or proboscis, there to await an opportunity of passing into the blood of a human host, an opportunity which came on the next occasion that the mosquito took a meal of man's blood. We have mentioned that a near relative of the common gnat is a frequent vector of filariasis, but at least seven species of Anopheles, and many 


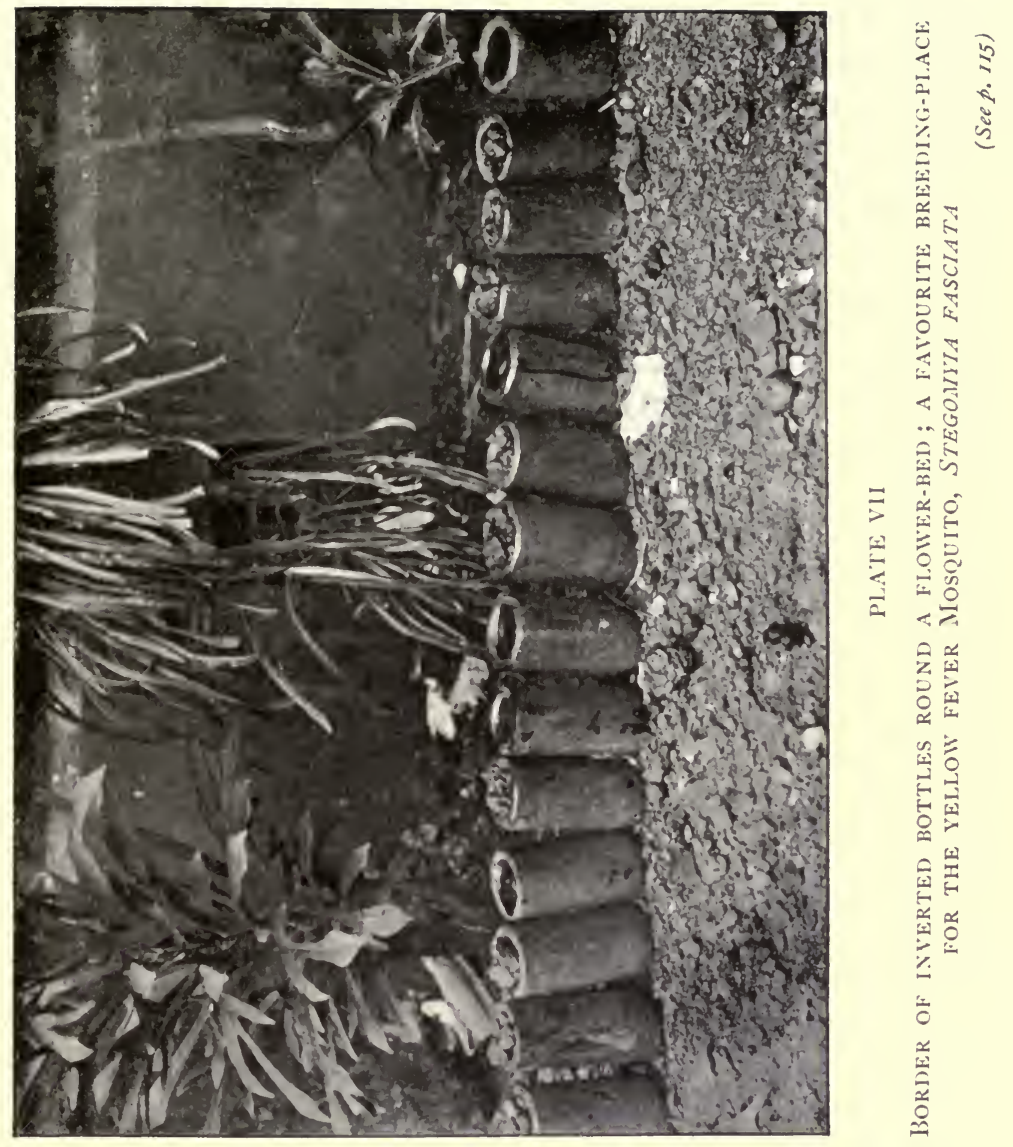



species of Stegomyia, are also known to transmit the disease, as do other mosquitoes. This is in marked contrast to the behaviour of the blood parasites of malaria and yellow fever, which are only transmitted by Anopheles and Stegomyia respectively; it resembles these parasites, however, in that the mosquito is absolutely essential for its complete development.

"A most interesting fact with regard to this association between Filaria bancrofti and its mosquito intermediary host is that the larval filariæ are found only at night in the general or peripheral circulation, hiding during the day in the vessels of the lungs and other internal organs. If the blood of the patient is examined during the day, the young parasites are rarely seen, or not at all. As evening approaches, the tiny larvæ begin to enter the peripheral eireulation in greatly increasing numbers. The swarm goes on increasing until about midnight, at which time it is not unusual to find as many as three hundred, or even six hundred, in every drop of blood. This uncanny swarming of the larvæ of Filaria bancrofti in the peripheral circulation becomes at once comprehensible when connected with the nocturnal habits of their liberating agent, the mosquito. The young filariæ may persist for months in the blood of man, and no further development is possible, unless they reach their necessary intermediary host, and this is why they swarm into the peripheral circulation at the time when mosquitoes bite. There are a large number of similar correlations in Nature."

\section{House Flies and Disease}

As disease-carriers, the house flies, Musca domestica, stand in a class by themselves. The belief that they disseminate infective diseases is not new. "Mercurialis (1577) considered that they carried the virus of plague from those ill or dead of plague to the food of the healthy. Sydenham 
(1666) remarked that if swarms of insects, especially house flies, were abundant in summer, the succeeding autumn was unhealthy. A number of authors, e.g. Crawford (1808), might be cited who refer in a general way to insects, especially to house flies, as carriers of infection. Moore (1853) refers to flies as possible carriers of cholera, typhoid, tuberculosis, anthrax, and leprosy; Leidy (1872) refers to flies as carriers of the infection of hospital gangrene and of wound infection, . . . but none of these authors do more than offer surmises regarding the part played by flies in the spread of disease."

To avoid any misunderstanding as to the part played by house flies in the transmission of disease, we may state at once that their work is purely mechanical, though none the less deadly on that account. Their mouths are not adapted for biting, and they are quite unable to pierce the human skin, or any skin for that matter, if they would. "They are a disgusting pest which feed and wallow in filth of all sorts, and when their proboscides and legs are covered with germs which are growing and living in such filth, they proceed to our food and to the food of our children and contaminate it. This infected food we human beings eat and drink, and in this way disease is kept circulating from one person to another in a never-ending cycle, the flies carrying disease from one sick person to the food of others and perhaps to and from animals besides." In time of war the house fly has proved more deadly than the enemies' bullets. During the Spanish-American war more than eighty per cent. of the deaths were due to typhoid; during the Boer war the number of deaths brought about by the agency of the house fly are impossible to compute.

The disgusting habits of these insects have been mentioned in another place, how they swarm on all manner of filth and garbage and fly direct therefrom to our food and persons, which they soil with their excrement and vomit, in addition to carrying oddments of the 


\section{INSECTS AND HUMAN DISEASE}

decaying matter over which they have walked and dropping it as they go. The deplorable number of deaths from typhoid that took place in the Spanish-American and Boer wars focussed the attention of entomologists on the house fly. A Government report concerning the conditions of the former war states that: "It was impossible to keep the flies from the already cooked food, even if a man kept one hand over his plate and ate with the other"; whilst the American Army Medical Department, in a circular showing that flies were probably carriers of typhoid, states that: "They swarm about fæcal matter and filth of all kinds deposited on the ground or in shallow pits, and directly convey infectious material attached to their feet, or contained in their excreta, to the food which is exposed."

During the war an Army Typhoid Commission was instituted, and its findings made it more and more clear that house flies were responsible for the spread of typhoid. Dr Vaughan, who drew up a report for the Commission, laid especial stress on three points: that flies pass direct from fæcal matter to food, as was plainly shown, when lime had been recently sprinkled over the contents of the pits, by the fact that insects whitened with lime were seen on the food; that the officers suffered less in proportion than the men-their mess tents were effectually screened; that with the approach of the cold weather and the consequent reduction in numbers of the flies, typhoid gradually decreased. The report continues: "It is possible for the fly to carry the typhoid bacillus in two ways. In the first place, fæcal matter containing the typhoid germ may adhere to the fly and be mechanically transported. In the second place, it is possible that the typhoid bacillus may be carried in the digestive organs of the fly and be deposited with the excrement."

During the Boer war matters were no better. Tooth and Calverley, writing of typhoid during the war, state that "in a tent full of men, all apparently ill, one may almost 
pick out the enteric cases by the masses of flies they attract. This was very noticeable at Modder River, for at that time there were in many tents men with severe sunstroke who resembled in some ways enteric (or typhoid) patients; and it was remarkable to see the insects hover round and settle on the enterics. The moment an enteric patient put out his tongue a fly would settle on it. . . . At Bloemfontein the flies were a perfect pest; they were everywhere, in and on every article of food. It is impossible not to regard them as important factors in the dissemination of enteric fever. Our opinion is further strengthened by the fact that enteric fever in South Africa practically ceases every year in the cold weather; and this was the case at Bloemfontein." So clearly did the evidence point to house flies as carriers of typhoid during the war, that numerous investigators took up the matter and proved conclusively that they were very efficient vectors of the disease, even after a lapse of twenty-three days from the day of infection.

Another disease, with a higher death-rate than typhoid, and, like typhoid, carried by house flies, is infantile diarrhœa, or enteritis. "In London, during the year 1910, there died of this disease 1,811 infants under two years of age; and during 1911, which had a hot summer, the infantile deathrate rose to even greater proportions. But in Bombay, during 1910, 2,263 died, and in Paris this disease killed 1,152 infants; in New York, 5,649; Chicago, 3,384; Rio de Janeiro, 2,692." As a final example we read that: "During the hot weather at Cairo in 1909 it killed 3,000 children in less than two months." At the Lister Institute in London, Dr Morgan carried out a series of researches on this disease from 1905 to 1908, and succeeded in isolating a germ which he called Morgan 1. Rats fed on the bacillus died of enteritis; monkeys, too, subjected to the same test, died exhibiting all the symptoms usual in children. The researches were continued, but attention 
was turned to house flies, and in the bodies of many of these insects, taken from houses where there were children ill with infantile enteritis, the germs of the disease were found.

"But because infected flies were found after the onset of the cold weather in the autumn, and because some infected flies were found in a house in the country where no child suffering from the disease happened to be discovered, and because some doctor's believed that the fly curves and the disease curves do not correspond, this research seems to have been relegated into the background. It should have been named as one of the most important investigations of the present century. Flies may live for weeks in the cold weather-in fact, we know they do; but the majority die. And there may be enteritis-carriers, as we know there are typhoid-carriers, who appear apparently healthy and who have had but mild attacks of the disease." So little notice, however, was taken of the established connection between house flies and disease that in the summer of 1911 infantile enteritis broke out again nearly all over England; thousands of pounds were spent in a vain attempt to stem the tide of mortality, flies were everywhere, thriving in the decaying organic matter which the hot weather made plentiful, yet no one, apparently, gave any thought to a campaign for stamping them out and so mitigating the evil. In America, bacilli were discovered, similar to those discovered by Morgan, and equally pathogenic.

Various estimates have been made as to the number of bacteria that may be carried about the body of a single healthy, active fly; one investigator, Torry, puts the number at twenty-eight million in its intestine, and four and a half million on the outer surface. Esten and Mason, by careful experiment, found that the number of external bacteria varied from five hundred and fifty to over six and a half million; other observers have put the number as high as five hundred million per fly. The numbers seem 
incredible; that one house fly can carry about its body as many as five hundred million germs is almost beyond belief, yet the estimated number is not the result of guesswork but of careful experiment. Looking at the matter from the most favourable point of view, and supposing each fly to carry only five hundred and fifty bacteria from place to place, the supposition is not pleasant. A goodly number of these bacteria would assuredly be pathogenic, or diseaseproducing, and a fly, laden with only fifty typhoid germs, and making an attempt on its life in a jug of milk, is an obvious source of danger, for these germs increase with surprising rapidity in such a favourable medium as milk. Speaking of the house fly, or, as it is called in America, the typhoid fly, Howard says: "And as for the typhoid fly, that a creature born in indescribable filth and absolutely swarming with disease germs should practically be invited to multiply unchecked, even in great centres of population, is surely nothing less than criminal."

"Moore (1853) drew attention to the necessity of guarding food against flies, because, he supposed, they might disseminate cholera, adding: 'Flies in the East have not far to pass from diseased evacuations or from articles stained with such excreta, to food, cooked and uncooked.' Nicholas (1873) writes that in 1849, when cholera prevailed at Malta: 'My first impression of the possibility of the transfer of the disease by flies was derived from the observation of the manner in which these voracious creatures, present in great numbers, and having equal access to the dejections and food of the patients, gorged themselves indiscriminately and then disgorged themselves on the food and drinking utensils. In 1850 the Superb, in common with the rest of the Mediterranean squadron, was at sea for nearly six months; during the greater part of the time she had cholera on board. On putting to sea the flies were in great force; but after a time the flies gradually disappeared, and the epidemic slowly subsided. On going 
into Malta harbour, bui without communicating with the shore, the flies returned in greater force, and the cholera also, with increased violence. After more cruising at sea, the flies disappeared gradually, with the subsidence of the disease.' Various experiments and observations in more recent times, notably those of Macrae and Buchanan in India and Tsuzuki in China, present convincing evidence that the house fly plays an important part in the dissemination of cholera.

"The earliest experiments with anthrax in relation to flies are those of Raimbert (1869), who placed house flies and meat flies on infected material and afterwards tore off their appendages and inoculated them, with positive results, into animals. Experiments of a somewhat similar nature were made by Celli (1888), Sangree (1899), and Buchanan (1907), and they 'all agree in demonstrating that flies pick up anthrax bacilli when they walk about and feed on infected material. It remains to be determined how long flies may harbour the bacillus on its spores, and whether the virulence of the bacillus in the vegetative stage is modified by passage through the intestines of flies.'

"The part played by non-biting flies in the spread of ophthalmia is well recognised to-day. Budd, as early as 1862, considered it was fully proven that flies serve as carriers of Egyptian ophthalmia. Laveran (1880), writing of Biskra, says the same. Howe (1888) stated that (1) the number of cases increases rapidly from the moment when flies are present in large numbers; (2) eye trouble occurs in the same places where flies are numerous (Delta of the Nile); where there are a few flies (the Desert) there are also a few cases of illness; (3) natives, and especially children, are remarkably indifferent to the attacks of flies: they allow the flies to settle in crowds about their eyes, sucking the secretions, and never think of driving them away; (4) examination of the flies captured on diseased eyes revealed bacteria on their feet which were similar to 
those found in the conjunctival secretion." Other authors are agreed that the evidence regarding the spread of Egyptian ophthalmia by flies is conclusive.

"The first to investigate the house fly in relation to the possible dissemination of the tubercle bacillus were Spillman and Haushalter (1887). These authors found tubercle bacilli in the intestinal contents and dejections of flies which had fed on tubercular sputum. Hofmann (1888) carried out observations under natural conditions by examining flies captured in the room of a phthisical patient. He found tubercle bacilli in four out of six flies examined, and also in the excreta of flies scraped from the walls, door, and furniture of the room. Celli (1888) has reported experiments by Alessi in which the latter fed flies upon tubercular sputum, and subsequently inoculated the flies' dejections into rabbits, thus causing the latter to become tuberculous." Later experiments by Hayward (1904) and Buchanan (1907) showed that, without a doubt, flies are capable of spreading tuberculosis. The cup is not yet full, for the ubiquitous house fly has also been accused, and not without reason, though the proof is not yet forthcoming, of spreading diphtheria, dysentery, yaws, plague, tropical sore, small-pox, and swine fever.

We have stated in another place that, normally, the food of adult house flies is taken up in liquid form. In this connection some interesting experiments by Grassi (1883) and Stiles (1889) are of importance. Grassi showed, when flies sucked up water in which the eggs of parasitic worms were floating, that they were absorbed with the liquid and passed away unaltered in the insects' dejections. Stiles placed house-fly maggots with the female of another parasitic worm, which they devoured, together with the contained eggs. Both the maggots and the adult flies were found to contain the eggs of the parasite. "The experiment being made in very hot weather, the eggs developed rapidly, and were found in different stages of development 
in the insects, thus proving that the latter may serve as disseminators of the parasite. Providing that the eggs attain the proper stage of development, the fly, acting simply as a carrier, might convey the parasite to man by falling into or depositing its excreta on his food."

Various non-pathogenic, and therefore relatively unimportant, bacilli are carried from place to place by flies; one species in particular, known as Bacillus prodigiosus, is frequently found on food. "Although the organism is quite harmless, it has arrested attention because it produces blood-red colonies upon the substances on which it grows. 'The miracle of 'the bleeding host' in the middle ages has been attributed by modern writers to the development of prodigiosus colonies upon the wafers in damp churches. Because of the characteristic pigment which it produces, Bacillus prodigiosus has been a favourite organism in experimental work. 'Thus, as early as 1875, Otto Helm experimented with Monas prodigiosa, and stated that the slimy masses containing the bacillus are easily conveyed by flies from one food substance to another." The story might be continued ad nauseam; we have said enough, however, to show beyond doubt that, as a disseminator of disease, a carrier of unpleasant parasitic worms and of bacilli, which, though non-pathogenic, ruin man's food, the ubiquitous house fly is without a compeer.

A prevalent disease of children in Scandinavia, Germany, and America, known as infantile paralysis or acute epidemic poliomyelitis, was first recognised in 1840 by Heine, a German surgeon. Since that time the disease has made considerable headway in Europe and America, and has also spread to Australia, the West Indies, and other parts of the world. For several years there has been a growing suspicion amongst those familiar with the disease that it is insect-borne. Sporadic cases occur in such a way as to render it unlikely that they have been contracted by personal contact. The disease almost disappears in winter 
and reaches its maximum in the height of the summer; it is also a typically rural or semi-rural disease. All these facts point to a probable insect vector.

The seasonal distribution of poliomyelitis puts out of count fleas, lice, and bed bugs, for they are nearly as prevalent in the winter as in the summer. Suspicion can hardly fall upon mosquitoes, for they are so generally abundant and so persistent in their search for human blood, that diseases borne by them usually develop into extensive outbreaks, and this is never the case with infantile paralysis. Ticks and Reduviid bugs, both of which are known to transmit human diseases, are unlikely rectors in this case, because their attacks leave considerable wounds, which are easily observed. Various Diptera have been suspected from time to time, but, with one exception, they may all be dismissed-the gadflies are rare in inland rural communities; the closely related Chrysops does not occur in the latter part of the summer, when the disease is most prevalent; the buffalo gnats, too, are most abundant in the spring.

The only insect which cannot be dismissed for any reason whatever is the stable fly, Stomoxys calcitrans. This fly has bloodthirsty habits which render it a probable vector of disease; its seasonal abundance is closely correlated with the incidence of the disease; its geographical distribution agrees with that of poliomyelitis; it is a rural rather than a town-frequenting insect; and in a very large number of cases the children had played about stables, etc., where Stomoxys was abundant. Experimentally the bites of infected stable flies have produced poliomyelitis in healthy monkeys, so there is every reason to believe that they may spread the disease naturally, and that probably some domestic animal acts as a reservoir for the virus.

The stable fly resembles a stoutly built house fly, grey in colour, and with a resting position, with wings somewhat spread, which distinguishes it from the house fly. Its 


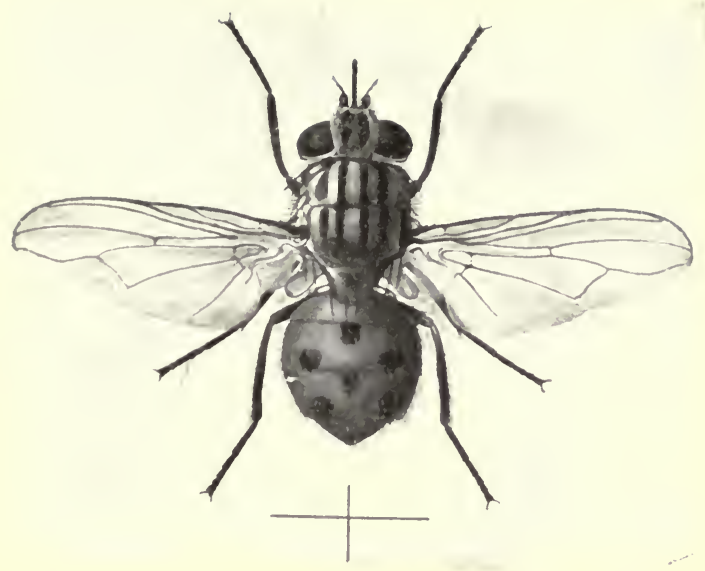

Flli. 32. THE stabie Fiy, Stomoxy's calcitrans

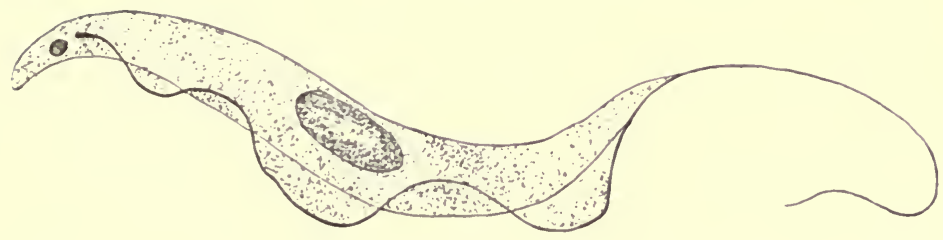

FIC. 33. A TRYPANOSOME 

proboscis, when at rest, is carried in a forward position (fig. 32); and the presence of this awl-like piercing organ renders confusion with the house fly, with its soft, sucking proboscis, impossible. Common in Europe, the Americas, and parts of Asia and Africa, this insect is almost as widely distributed as the house fly. Both males and females attack men and animals and suck their blood. The eggs, to the number of about sixty, are laid on stable manure and hatch out in two or three days, whilst the larvæ, which feed on the nidus, are full grown in about a fortnight. They closely resemble house-fly maggots, but may be distinguished by their having quite cireular spiracles on the posterior segment. The pupa, which is reddish brown and tub-shaped, elosely resembles that of the house fly.

\section{T'Tetse Flies and Sleeping Sickness}

Sleeping sickness is one of the most appalling diseases carried from man to man by the agency of insects. It has been known to exist on the West Coast of Africa for more than two hundred years, but not till 1901 did medical men know that it was eaused by a trypanosome, which its discoverer, Dr Dutton, named Trypanosoma gambiense; and two years later it was proved that a tsetse fly, Glossina palpalis, acted as the carrying agent. As trypanosomes are responsible for some of the diseases of live stock, which will be considered in a later chapter, it is as well to describe the organisms briefly, without attempting to distinguish between the various species causing different diseases. Detailed descriptions can be found in many works on tropical medicine, of which a list is given in the bibliography. Trypanosomes are very minute Protozoa, that is to say, animals consisting of a single cell or a small collection of similar cells; they belong to the class of flagellates, so called because they are provided with a fine thread-like structure, known as a flagellum (fig. 33). An 
examination of a stained trypanosome, under a high power of the microscope, shows that it is a single-celled organism, pointed at either end, and possessed of a membrane extending the whole length of the cell. This membrane terminates at its anterior end in a flagellum, arising from a minute structure known as a blepharoplast. During life the organism is exceedingly active, wriggling about in the liquid portion of the blood, the plasma, by means of its flagellum, which lashes like a whip and is controlled by the blepharoplast, the while the membrane undulates, after the manner of the dorsal fin of certain fishes. Some trypanosomes are harmless, or, at any rate, are not the cause of disease; they simply live as parasites in the blood of certain hosts; others are the cause of tsetse-fly disease, or nagana, surra, dourine, and mal de caderas in cattle, and to all these diseases, whether in man or animal, the general term trypanosomiasis is applied. Sleeping sickness, with all its distressing symptoms of lassitude, paralysis, and eventual coma, is, in reality, the final stage of human trypanosomiasis.

As the African Continent was opened up for trade, sleeping sickness spread over the tropical area from west to east, like an all-embracing octopus. In 1908, the first cases were reported from Nyasaland, and, in the following year, Rhodesia came under the fatal spell; its appearance in the latter colony caused considerable astonishment to the medical profession, for the vector, Glossina palpalis, had never been found in that part of Africa. The blood of an European patient was examined, and was found to contain, not Trypanosoma gambiense, which up to that time had been looked upon as the sole cause of the disease, but a new organism which was named Trypanosoma rhodesiense, after the colony where it first came to light. The discovery was startling in the extreme, and of such importance that Drs Kinghorne and Yorke were at once dispatched to North-East Rhodesia, by the Liverpool School of Tropical 


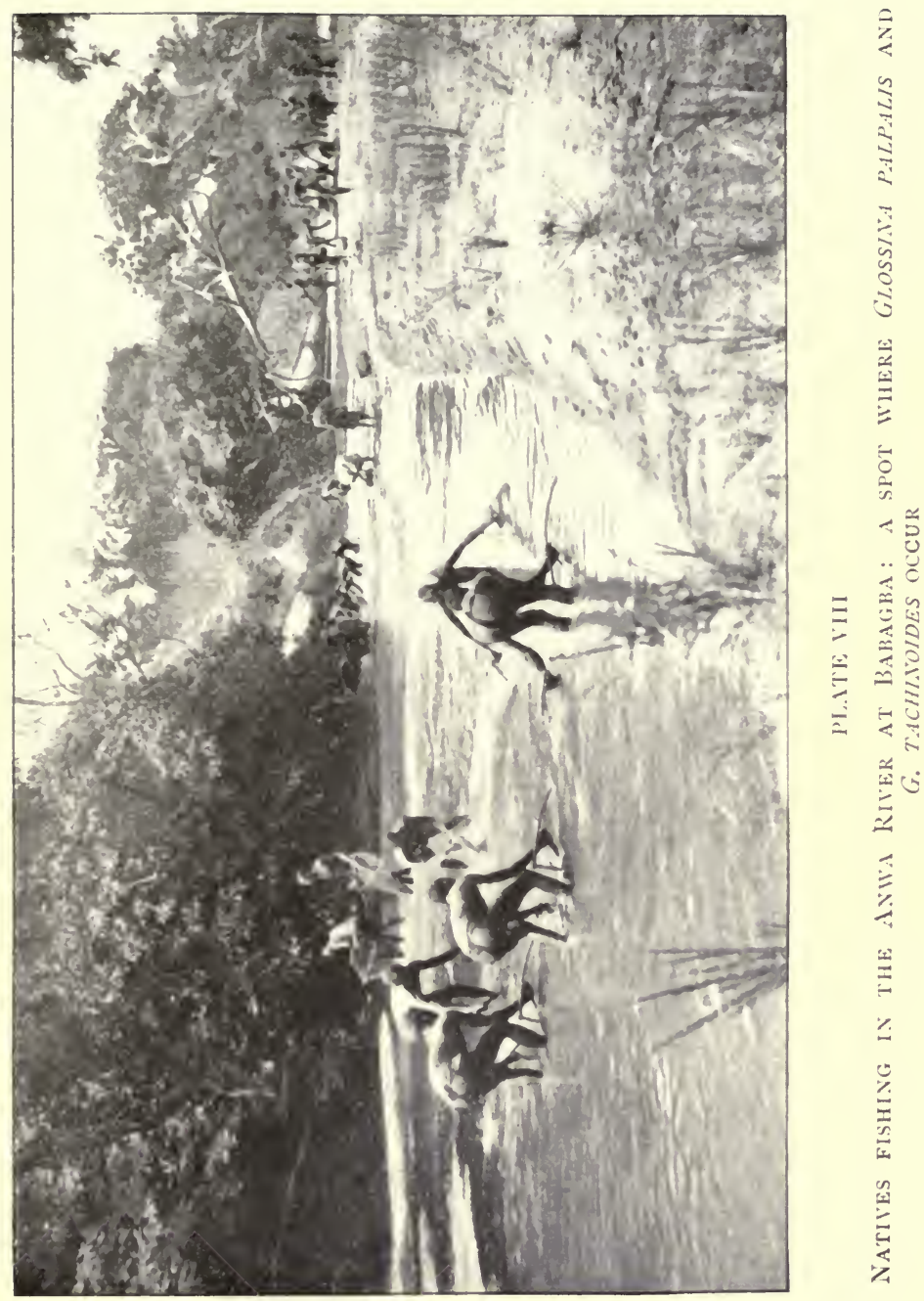



Medicine, to study the disease on the spot. These two scientists, to whose discoveries much of our present knowledge of sleeping sickness is due, established themselves at Nawalia, in the Luangwa Valley, which runs north to south through the middle of North-East Rhodesia. The valley has an evil reputation, and is closed to Europeans on account of sleeping sickness, whilst natives may neither enter nor leave it. In this lonely spot, cut off from all civilisation, these two men, at imminent peril to themselves, spent eighteen months, working to discover why sleeping sickness was spreading in districts where Glossina palpalis was unknown. Although Nawalia is the site of an old government station, no palatial dwelling or well-equipped laboratory was vouchsafed the scientists; simply wattle and daub structures sufficed : they were "glorified native huts." Even their ordinary wants were at times in jeopardy, for, as Dr Yorke said, in describing his work, "All our stores had to be carried by natives from Fort Jackson (120 miles distant), a procedure which at times resulted in a certain amount of exasperation. For example, on one occasion we sent in an order for a hundred pounds of flour and a six-gallon tin of paraffin oil. After about three weeks the carriers returned with a note and an empty oil tin. In the letter was written, 'Sorry no flour, herewith the oil.' On the way back the natives had perforated the paraffin tin, either accidentally by letting it down suddenly on a sharp stone, or designedly to render the load lighter." The domestic stock in the valley was decimated by trypanosomiasis, and many of the natives employed by the commission died of sleeping sickness.

The headquarters had scarcely been established before Drs Kinghorne and Yorke announced an epoch-making discovery. Luangwa Valley was reeking with sleeping sickness, yet not a single tsetse fly, of the species that was believed to be the only carrier of human trypanosomes, could be found. An allied species, Glossina morsitans, 
present in enormous numbers, was spreading disease far and wide among the cattle, and was soon proved to be also a vector of sleeping sickness. The importance of this discovery is apparent, when the habits of the two tsetse flies are taken into consideration. Were the disease carried by Glossina palpalis alone, there might be some hope of its ultimate eradication, or of its being kept well in hand; for palpalis has a limited distribution, and is never found far from water, either river or lake; in short, it frequents well-marked "fly belts," and excellent results have been attained in Uganda by a wholesale removal of the native population from the watercourses and lake shores, and so out of the "fly belt." Glossina morsitans is not confined to the neighbourhood of water, or even to low-lying ground, being found even at elevations of five thousand feet. It is, however, confined to somewhat arbitrary boundaries or "belts" though why this should be so is curious, for it is absent from many topographically and climatically similar stretches of country. It is the most widely distributed of all the Glossina species, extending from Senegambia to Abyssinia, and as far south as Zululand. So that now whole districts, which only a few years ago were considered unlikely to be visited by this disease, are obviously liable to come under its fatal spell. Indeed, although these two flies are the only two proved carriers of sleeping sickness, all the species of Glossina must be viewed with suspicion. Glossina fusca and Glossina pallidipes have been artificially infected with the trypanosome: time alone can show whether they, or their relatives, transmit it naturally. A word or two concerning the transmission of sleeping sickness may not be out of place. When one of the species of Glossina in question bites an infected patient, that is to say, a man harbouring in his blood the trypanosome responsible for sleeping sickness, it is in a position to transmit the disease; and this may take place in one of two ways, either mechanically or by reason of the fly itself becoming 


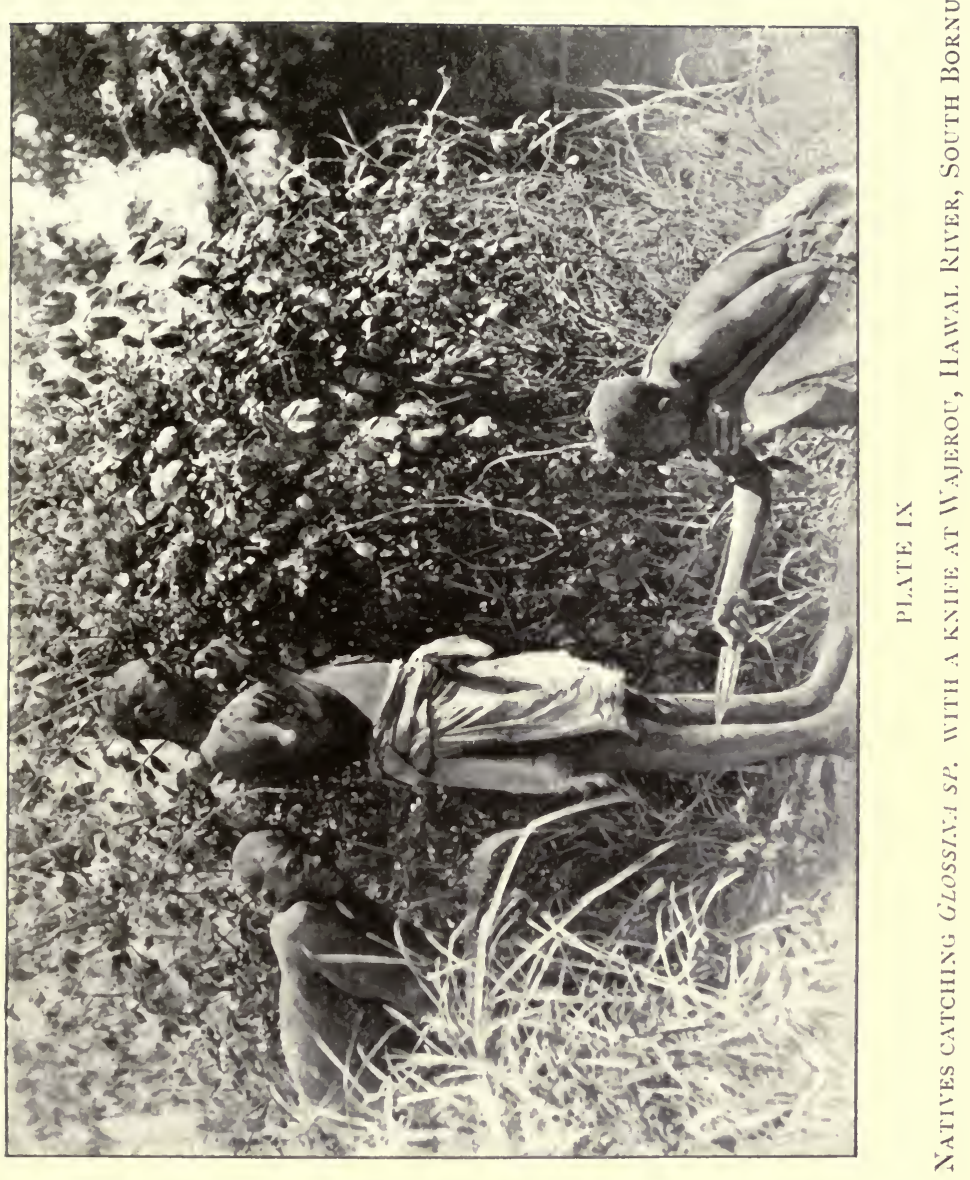



infective. Should the infected fly bite a healthy person within twenty-four hours, mechanical transmission takes place; the trypanosomes adhering to its mouth parts are simply transferred to the blood of the new host and sleeping sickness ensues. At the end of twenty-four hours there is no fear of mechanical transmission; from this time till some days after the infective meal, further bites are harmless, even to a healthy person. During this time the trypanosomes taken into the system of the Glossina are undergoing development in its gut-an incubation period, in fact. Eleven to fifteen days after the fly has had its infective meal, it is again able to infect those whom it bites, this time with the organisms it has harboured in its body, provided that the atmospheric temperature has been fairly high; for it is a curious fact that only under such conditions do the parasites develop within the tsetse flies, but, once infective, they may remain so for sixty days. So much for the transmission of sleeping sickness from man to man. But man is not the only host; the trypanosomes are to be found in the blood of domestic animals and a number of wild animals. Trypanosoma gambiense is said to exist in the blood of cattle without detriment to health, but Irypanosoma rhodesiense, on the other hand, is the cause of enormous mortality in horses, donkeys, goats, and dogs. Six hundred and ninety-eight animals were examined at the Nawalia laboratory, including elephant, rhinoceros, hippopotamus, lion, buffalo, caracal, galago, squirrel, hunting dog, giant rat, wild rabbit, fourteen different kinds of antelope, twenty-five monkeys, thirtyfive head of domestic stock, one hundred and forty-two wild rats, and fifteen mice. Approximately, the percentage of infected big game was fifty, being very high among the antelopes, of which waterbuck, haartebeeste, reedbuck, and duiker have been proved dangerous neighbours to man. Big game are the reservoirs of the trypanosomes of man and domestic animals. Frequenting the fly belts, and 
apparently unharmed by the trypanosomes, they form an inexhaustible source, from which Glossina morsitans may become infected. For when once a fly has bitten an antelope whose blood harbours the parasite, it becomes, after a developmental period, a source of infection to man.

This, then, in brief, is the present state of our knowledge of sleeping sickness. Either Glossina palpalis or Glossina morsitans may carry the disease, the former in the shape of Trypanosoma gambiense, the latter as Trypanosoma rhodesiense. Whichever trypanosome is introduced into the human system, the result is the same; the clinical manifestations of disease, caused by the two parasites, are practically identical, though Trypanosoma gambiense is probably more virulent. Some excellent results have been obtained in the control of the disease, as transmitted by Glossina palpalis, owing to its habit of never leaving the neighbourhood of water. What can be done with Glossina morsitans and its limitless living reservoir of Trypanosoma rhodesiense? This is a problem which has excited, and is exciting, considerable controversy. Suggestions have been made for wholesale slaughter of big game and for driving them back far from the limits of human habitation, in the hope that the flies, deprived of their source of infection, may ultimately become non-infective. Into the ethics of the controversy it would be out of place to enter, rather let us turn to the flies themselves and learn something of their life-histories.

Glossina palpalis (fig. 34) is a bluish or olive-grey fly with brown markings; its abdomen is brown, and on the first segment is a light-coloured triangular area with the apex pointed posteriorly. The second segment has a similar, though smaller, triangular mark, and it is continued as a pale stripe down the abdomen to the end of the fifth segment. Its geographical distribution is confined to the areas drained by the Senegal, Congo, and Niger, and it frequents districts where forest trees provide the shade it loves, 


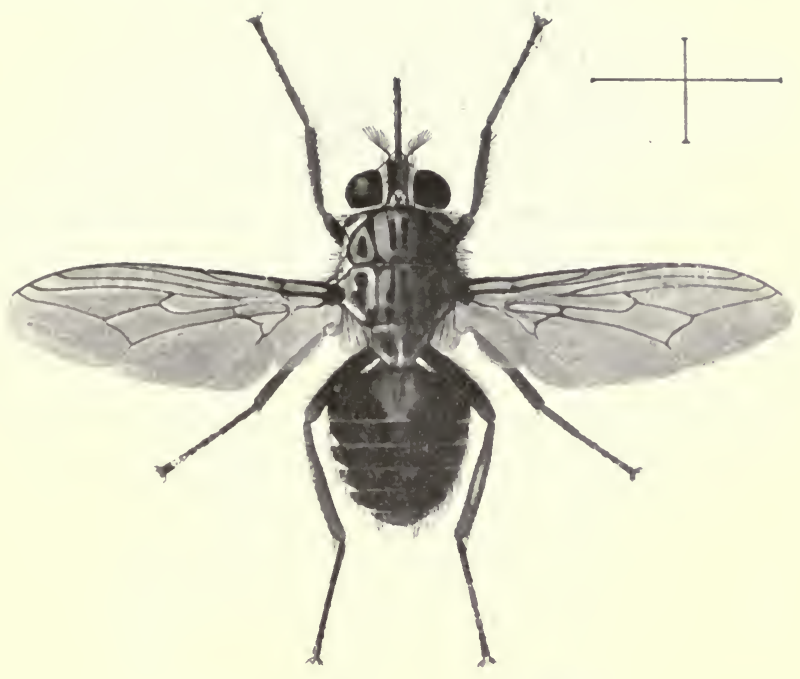

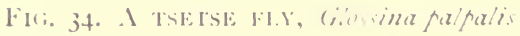

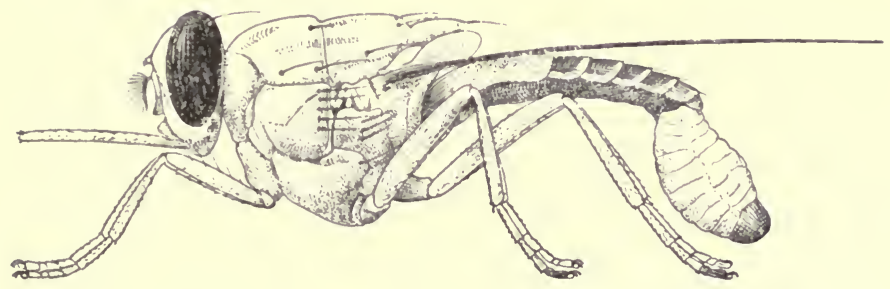

FIG. 35. A TSETSE FHY IN THE ACT OF GIVING BIRTH TO A LARVA 


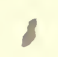


and where there is reasonable, though not excessive, moisture. As in other species of Glossina, the larva emerges from the egg within the body of the mother fly; in fact, it undergoes three moults before it is born (fig. 35). When full grown, it consists of thirteen segments, is from six to seven millimetres in length, and of a dirty white colour, with the exception of the posterior end, which is black. Each female fly, during a life of about three months, gives birth to eight or ten larvæ, at intervals of about ten days. Immediately it is born, the larva seeks a suitable hiding-place where it can pupate, and it usually selects a well-drained site, such as dry sand, or beneath leaves or debris; after approximately five weeks the adult flies appear.

Glossina morsitans has a light grey thorax and a buffcoloured abdomen with a brown spot at the lateral margins of the second segment. Segments three to six have brown transverse bands which do not reach to the middle line; in short, the fly is so distinctly marked that it cannot be mistaken for any other species. It is widely distributed in Western and Central Africa, much more so than palpalis. For many years this fly has been associated, by Europeans and natives, with nagana, a disease of domestic stock, and recently, as our notes have shown, it has attained further notoriety as the transmitter of sleeping sickness. Palpalis and morsitans are rarely found in the same locality; the latter fly frequents more open country and is not nearly so closely associated with water as its congener. Little is known of the life-history of this fly; in fact, one puparium only had been found up to 1910, and from then, till the sleeping sickness commission under Drs Kinghorne and Yorke reached Luangwa, no further finds were recorded. Of a number of pups that were then discovered, the majority were closely associated with trees, either in hollows at the roots, or in crevices in the trunk itself, and often at some distance from water. The duration of the pupal stage, in the laboratory, was found to vary from twenty-one to 
eighty-eight days, according to the temperature; in nature the warmth of the sun probably shortens the period.

\section{Two more Diseases transmitted by Flies}

Working in Malta, many years ago, Pym described an obscure fever whose origin remained a mystery till 1908, when Doer in Hertzegovina showed that it was caused by a so-called sand fly, Phlebotomus papatasi (fig. 36). Doer's experiments have recently been confirmed by Birt and others, and the disease is now known as Phlebotomus fever. In the family Psychodidoe there are hairy, moth-like flies, called owl midges, and blood-sucking insects, known as sand flies. Phlebotomus papatasi is a very minute, pale yellowish fly, rendered conspicuous by its very long legs, which enable it to hop like a flea. It is somewhat widely distributed, being found in Malta, South Europe, North Africa, America, and North India. 'The female, which, by the way, is the blood-sucker, for the males do not bite, lays about forty of her translucent eggs in caves and cracks in walls; after a few hours the eggs lose their translucency and become shining, dark brown, and marked with longitudinal, slightly raised, black wavy lines. In about nine days the larvæ emerge; they resemble small greyish-white caterpillars, with dark heads and two stiff tail bristles, which become four when the larva is full grown. The pupa is a curious object with a triangularly shaped head, which, viewed end on, resembles a ram's head in miniature, the antennal sheaths appearing like horns; in colour it is yellowish buff.

Various experiments have been carried out in London and Malta, with a view to obtaining data as to the diseasecarrying power of these flies. They show that a person suffering from Phlebotomus fever carries the virus in his blood during, at least, the first day of fever, and that a sand fly, having partaken of a meal of infected blood, remains infective for from seven to ten days.

All the insects considered in this chapter, with one excep- 


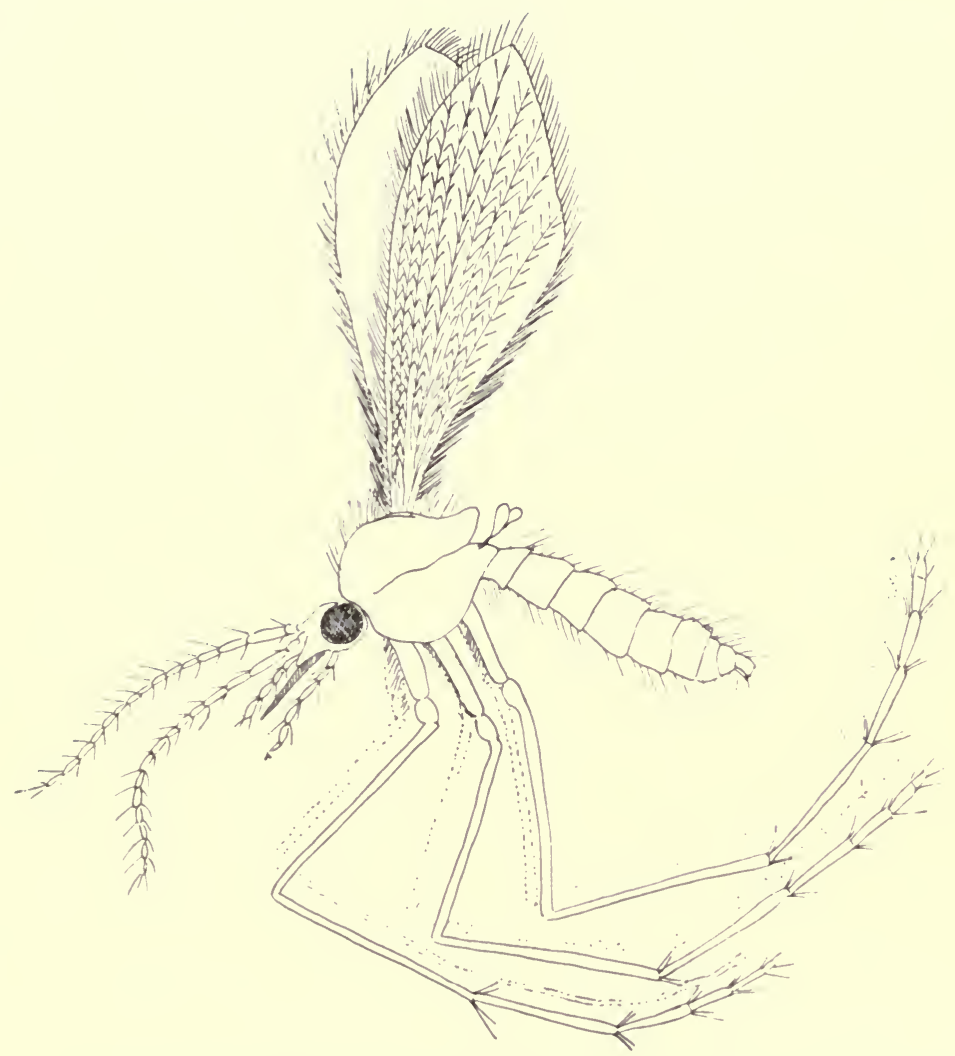

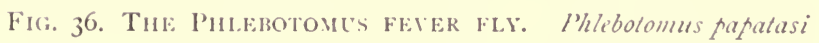




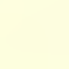


tion, have been proved, beyond a doubt, to be the carriers of the various diseases with which they are associated. There remains one important problem which deserves mention, namely, the probable transmission of pellagra by one or more species of Simulium, popularly known as buffalo gnats, or by some other closely related biting flies. The history of pellagra and its probable connection with insect life is of interest, quite apart from the question of what insect will ultimately be proved to be the vector. Pellagra, like malaria, yellow fever, and sleeping sickness, is essentially an endemic disease; it is invariably associated with the same ecological conditions. Just as malaria is associated with stagnant water, so is pellagra linked to rapidly running streams.

The disease itself was first recognised in Spain in $\mathbf{1 7 3 5}$ by Dr Casal, and was then called mal de la rosa; it affects the skin and nervous system, causing, as its early name inplies, a red rash on the affected parts, the hands, neck, etc., and often terminating fatally. It is probably rare in England, but is endemic in the eastern districts of Scotland, north of the Forth, and in the Shetland Islands, where it was known as long ago as 1863 . Till quite recently it was thought that pellagra was contracted by eating maize that had become stale and attacked by a fungus; despite the brilliant work of Dr L. Sambon, who first drew attention to the fact that pellagra is probably carried by insects, and despite the fact that pellagra occurs where maize is not eaten, many still adhere to this belief. In certain districts of Italy the disease is rampant, whole populations being affected in some cases; in America it is spreading to an alarming extent.

As the connection between insects and pellagra is at the moment theoretical, with, it must be admitted, a strong bias towards the probable, it is of interest to read Dr Sambon's observations in the Venetian lagoon: "Venice, with its urban population, is, as in the case of all towns, entirely free from pellagra. The island of Lido, 
just opposite, is also immune. Murano, close by, with its industrial population of world-famous glass-blowers, is also quite free. The islands that harbour pellagrins are Pellestrina and Chioggia between Lido and the mainland to the south, where the Brenta and the Adige flow out into the sea, and the group of islets formed by Burano, Torcello, Mazzorbo, S. Erasmo, etc., between Lido and the mainland to the north about the mouth of the Piave. Both the Pellestrina and the Burano group of islets are inhabited principally by fishermen, who fish in various parts of the lagoon, and not infrequently, especially in the spring, for weeks together, along the mainland coast. Burano is a small islet entirely covered by closely clustered houses. As a town one would naturally expect it to be entirely free from pellagra, just like the neighbouring Venice and Murano, yet many of its inhabitants are pellagrins. But whilst on the neighbouring mainland and in all pellagrous districts throughout the world the disease is, as a rule, more prevalent among women than men, the Burano pellagrins are almost exclusively men. Moreover, whilst on the mainland the disease is especially common in very young children, in Burano it has never been known to occur in any girls, and only very rarely in boys, and not before their tenth year. Another interesting and telling fact is that, whilst the disease is very common amongst the fishermen, it has never been seen in any of the Burano artisans who go every day to work at the Venice arsenal. It is obvious, therefore, that Burano is not an endemic centre, and that its fishermen, who are very heavily taxed by the disease, contract it whilst fishing along the mainland coast, and especially near the mouths of the Brenta and other streams flowing into the lagoon, when they are at times greatly molested by swarms of small biting flies. This explains why, contrary to the general rule, the disease in this island is restricted almost entirely to adult males and to the older boys who go out fishing with their 


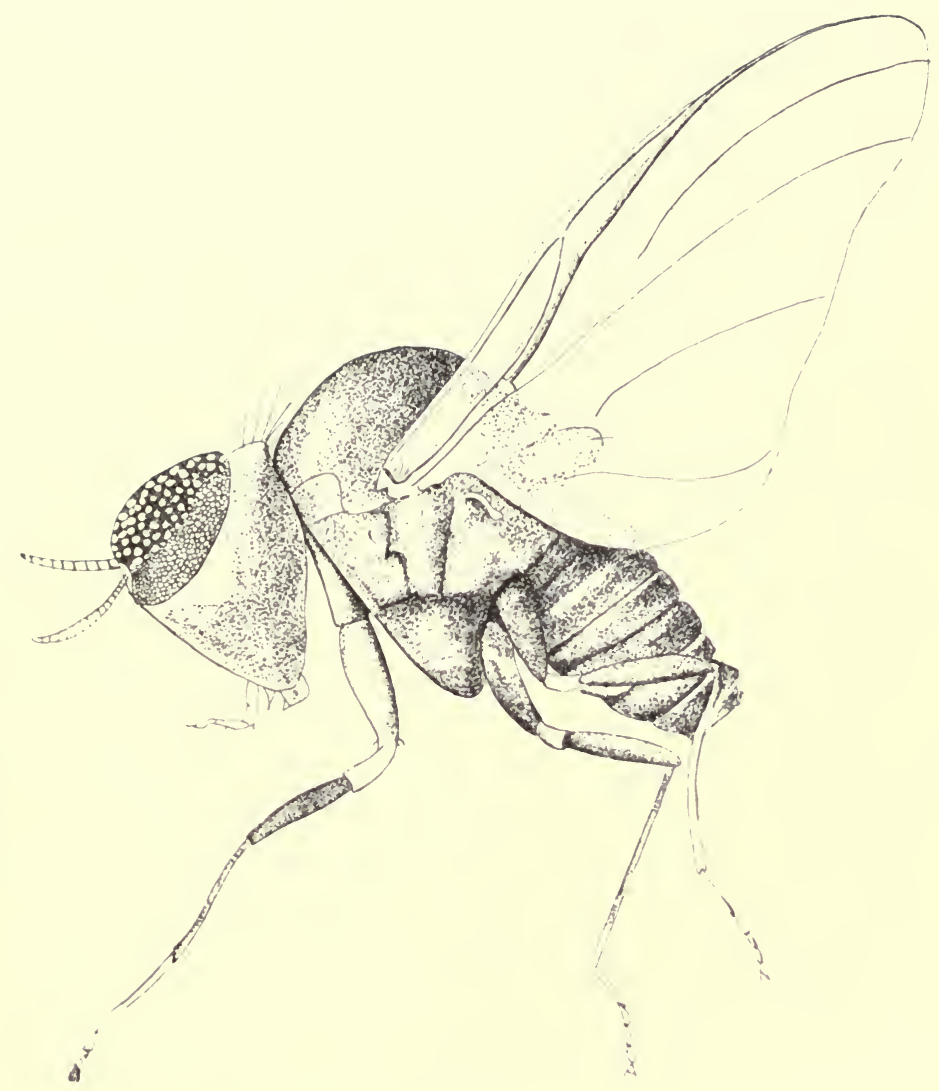

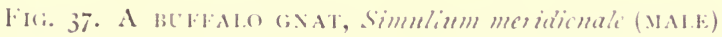




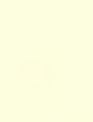

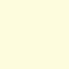

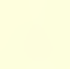


relatives and often sleep on the mainland. It explains the immunity of the men permanently employed at the Venice arsenal. It explains the immunity of the Burano women and girls who remain continually on the island to work at that wonderful needle-made lace, the 'punto in Aria,' for which the island is famous. It explains the exceptional occurrence in the very few women who go to work in the fields of the neighbouring mainland." The conclusions from these investigations alone seem reasonably obvious, but, taken in conjunction with Dr Sambon's later work in the Americas and the West Indies, his theory appears incontrovertible. Pellagra occurs in districts where maize is never eaten, but, with one exception, the Nile delta, it is always found in association with buffalo gnats. In the delta pellagrins are found, but despite the most diligent search no species of Simulium has been discovered, though another fly, Leptoconops, is much in evidence. Perhaps it too is a vector of pellagra. ${ }^{1}$

The Simulium (fig. 37) is a very small fly, one to four and a half millimetres long, usually black or dark brown, its long legs often banded with white, its transparent wings relatively large and broad; whilst its arched, hairy thorax, and short, stout antennæ have earned it the name of buffalo gnat, from a supposed resemblance to the buffalo. It is cosmopolitan, and the common British species are Simulium lineatum and Simulium reptans. Like many other biting flies, the female alone is the culprit, the male being inoffensive. Unlike other flies, however, the so-called bite is not brought about by piercing the skin but by a continued scraping till blood flows-natural vaccination, in fact. All the stages, except the adult, are passed under running water. The female fly oviposits in the evening; flitting along the water with a peculiar darting flight, she holds on

${ }^{1}$ Since the above went to press, Dr Hunter has announced, in an American journal, that he has succeeded in infecting monkeys with pellagra by means of infective Simulida. 
to a rock or other support, just above the water, the while the tips of her wings and abdomen vibrate in the water. The eggs, to the number of two hundred, are laid in patches, and adhere to some submerged support by means of a gelatinous covering. After about a week, the time depends on the temperature of the water, the larvæ (fig. 38) emerge. They are usually greenish brown in colour, and of a peculiar club shape. Their chitinised heads are furnished with two fanlike appendages, each composed of about fifty filaments, attached to a stalk, which, by continual expansion and contraction, draw food, consisting of minute aquatic plants, into the gullet. Just below the head is a conspicuous proleg furnished with a sucker, whilst at the posterior end there is a large terminal sucker, by means of which the larva remains attached in an upright position to some support. But its habitat is below swiftly running water, and a false step would mean destruction; so absolute reliance is not placed on the sucker: a silken thread is spun and affixed to some support, a life line, if you will, by means of which the larva can remain at anchor. In two or three weeks, or perhaps only after several months, depending on the temperature and rapidity of the water, the larva spins a characteristic silken cocoon in the form of a pocket, open at its larger end (fig. 39). In this curiously shaped dwelling it pupates, holding to its silken home by means of abdominal spines. The head of the pupa, which protrudes from the open end of the cocoon, is furnished with a pair of tufted breathing filaments which float about in the water. Towards the end of the second or third week, a bubble of air gradually collects within the cocoon, the pupa case splits, the fly emerges, and, rising within the air bubble, reaches the surface of the water without wetting its wings. Once in the air it darts away immediately; there is no wait for wings to dry or expand, no hesitation, only an eager search for blood of man or beast. 


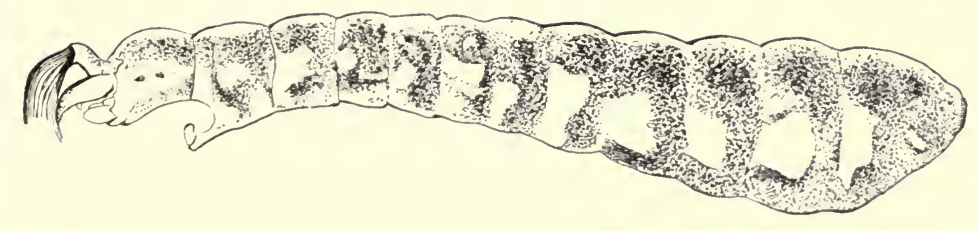

Fig. 38. LARVA OF Simulium meridionale

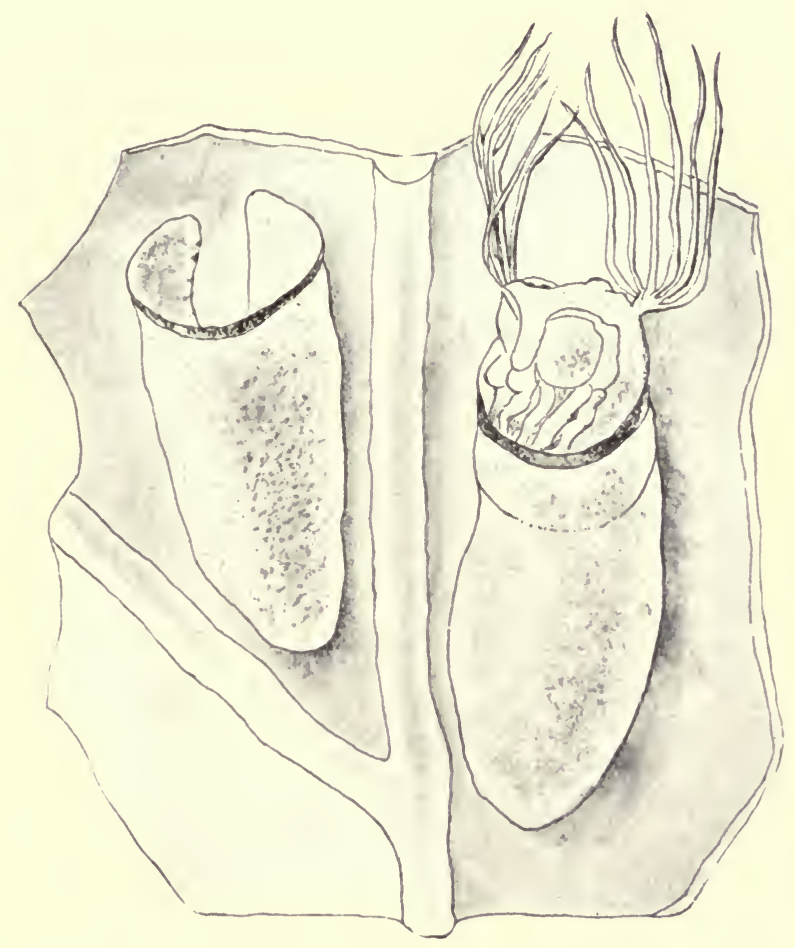

Fig. 39. PUPA ANI) "pockers" or Simulium meridionale ATTACHEI TO A LEAF 



\section{'Ticks and Human Disease}

That ticks, by their bites, could cause disease in human beings has been known for more than two hundred years. Drury, in an account of a visit to Madagascar, 1702-1720, said that very few people would enter the dwellings of the Vazimbas because of an insect called "Poroponjy" by the natives. This insect, which resembles a cattle tick, was only found among the Vazimbas, who held it in some esteem, because the fear of it prevented a neighbouring tribe, the Sakalaves, from entering their dwellings. A bite from this tick entailed an illness of six weeks to two months' duration. Livingstone first described "human tick disease" in Portuguese East Africa, and at the present day tick fever, clinically identical with relapsing fever, occurs in the Oriental province of Congo Free State, and is well known and feared by the natives.

The actual cause of the disease is a spirochrete, that is to say, an exceedingly minute, spiral, thread-like organism. When spirochætes are numerous, they can easily be seen in rapid motion in a blood preparation from an infected patient. These blood parasites are transmitted by a tick known as Ornithodorus moubata (fig. 40), which the natives call "Kimputu." Concerning them, Livingstone says: "Before the Arabs came bugs were unknown. .. . One may know where these people have been by the absence or presence of these nasty vermin." The explanation is probably that the natives live in mere temporary abodes, and for varied, and often trivial reasons, they will strike camp and found a village elsewhere, whilst the Arabs, on the other hand, construct more substantial dwellings and live in permanent villages. In these houses the ticks are to be found in the cracks of mud floors, in odd corners where dust has collected, in thatched roofs, near the hearth, and especially just inside the doors where the natives are in the habit of sitting. The ticks have entered the Oriental province with 
the Arabs from the East Coast, and with traders from the Southern Portuguese territory, where they existed in Livingstone's time; they occur all along the trade routes, and in many villages along the Congo between Kasongo and Ponthierville, though in the native villages an hour's walk inland they are quite unknown.

Ornithodorus moubata passes through an interesting life-cycle, differing in many respects from that of the other ticks described in this book. The adults are capable of rapid locomotion, though their feeding is slow; a wellgrown female, for instance, will feed continuously for three hours, becoming distended with blood to the size of a cherry before dropping off. It is obvious that only sleeping people can be attacked with any degree of satisfaction to the ticks, and, to that end, they are nocturnal. When disturbed they will pretend to be dead for hours at a stretch, curling up their legs and remaining motionless. The bite of one of these ticks is very painful and unpleasant, quite apart from the probability of infection. When about to partake of a meal, which may take place at any part of the body, the tick first sees that its forelegs have a firm hold, then, lifting up its hind quarters, it literally buries its mouth parts in its host's flesh. While feeding excrement is voided, a filthy habit common to many ticks, but important, as will be seen later. At the same time a considerable quantity of a clear fluid often oozes from glands opening between the bases of the first and second pair of legs.

The adult female tick is of a dark brown colour, blotched irregularly with yellow; when gorged with blood and about to oviposit it measures approximately $12 \times 10 \times 7$ millimetres. The number of eggs laid by each female depends, to some extent, on the amount of blood she has imbibed; the greater the amount of blood food, the larger the number of eggs, about one hundred and forty being the average (fig. 41). The eggs are golden brown in colour, and they 

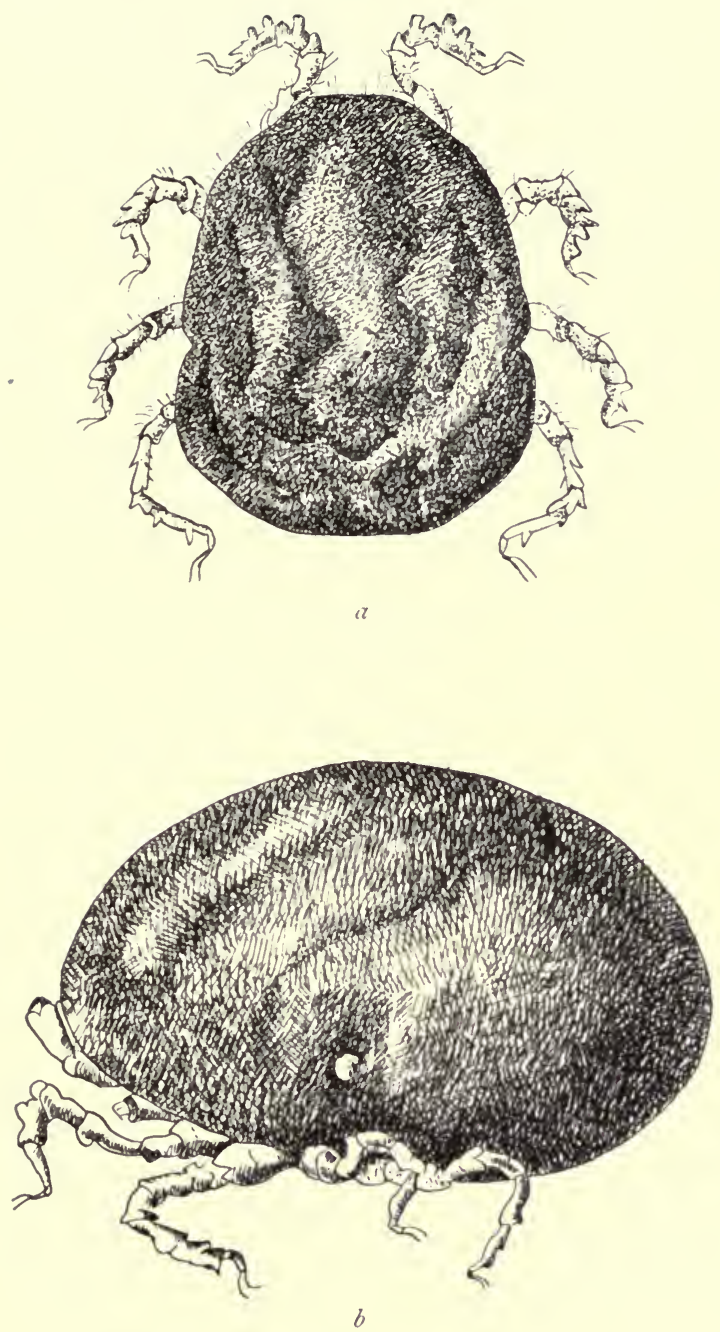

FIs. 40. ThE FEVER TI(K. Ornithoionus mouhata (FEMALE) a. CNENGOR(IEI) ; $b$. EN(;OR(IED) 

adhere to one another, so that, when magnified, they resemble miniature bunches of grapes. They are ovoid in shape, and each egg has a smooth, soft, and highly refractile covering. The average time for ineubation is twenty days. At the end of seven days the egg changes its shape, becoming more ovoid and transparent, so that the larva can be seen within the shell. On or about the thirteenth day the shell splits and discloses a six-legged larva which is incapable of locomotion, despite the fact that it can move its legs freely. Then a very peculiar thing happens : instead of the larva emerging from its covering, as is the usual case, it remains within its shell, beneath which air enters, so that the young tick appears of a dull white colour. A close examination at this period will show that the dull purplish-brown larva is about to moult, and, within its skin, the eight-leggred nymph may be seen. Eventually the yellowish-coloured nymph crawls backwards from the combined egg shell and larval skin. Nymphs do not feed for three or four days, but when once they have started to feed they grow quickly, if they are provided with a plentiful supply of food. After three moults the adult stage is reached, when, despite the absence of eyes, no time is lost in seeking human blood.

It has been shown by experiment that an unfed female weighing · 0270 grm. will weigh $\cdot 2602$ grm. after a meal, an increase of approximately ten times her original weight. Remarkable as this may seem, it is by no means a record, for the gorged females of some species of ticks increase to thirty times their original unengorged weight. Imagine a hungry 10-stone man weighing 300 stones after a single meal, or even after many meals! Ornithodorus moubata transmits relapsing fever by reason of its feeding habits; the spirochretes are not found in the tick's salivary glands, but are voided in the excrement at the time of feeding, and so pass into the wound, and infection takes place. The process is not merely mechanical, for a developmental 
process on the part of the parasites takes place within the tick's body, and, moreover, a tick once infective remains infective for the rest of its life, which lasts for some years, and transmits the infection to its offspring through the eggs. It is interesting to compare the transmission of relapsing fever by Ornithodorus moubata with the transmission of plague by the plague flea, and it is some consolation to know that the tick has deadly enemies in the shape of ants and rats.

Relapsing fever is not the only tick-borne disease of mankind. For many years, probably even before the settlement of white man, a disease, transmitted by ticks, and known as spotted fever, has been recognised in the Rocky Mountain region of the United States. Indians warned the first white settlers that they ran considerable risk of contracting a very serious disease if they established themselves in certain localities. It is in Idaho and Montana, and especially in the Bitter Root Valley of the latter state, that Rocky Mountain spotted fever is particularly prevalent at the present day. A most remarkable fact is that different degrees of virulence exist in different localities; in Idaho the fatalities from this disease amount to from five to seven per cent., whilst in the Bitter Root Valley they reach the formidable total of seventy per cent.

As regards the carriage of infection in the blood of man, the conclusions are merely theoretical; it is not known how long the blood of an infective person remains infective, though the period probably extends for some time before and after the fever has reached its maximum. In certain diseases, such as splenetic fever of cattle, which is, in many respects, similar to Rocky Mountain spotted fever, the disease organisms may remain in the blood for many years without causing any ill effects, but all ticks drawing blood from these apparently immune animals can and do transmit the disease in an acute form to other animals. There is only one tick in the Bitter Root Valley that attacks man, 
and it is known as the Rocky Mountain spotted fever tick, Dermacentor andersoni (venustus). Both males and females can act as vectors, and an infected adult may pass on the germs of the disease, through its egg, to the next generation, so that they also become capable of transmitting spotted fever. The larvæ and nymphs too may become infected and retain the disease germs through all their moults, with the result that, when adult, they can transmit the infection to another host.

The spotted fever tick is the only known natural vector of the disease, from which it derives its name, and the area over which spotted fever is rife coincides with the range of the tick, just in the same way that the presence of malaria and yellow fever is coincident with the distribution of their mosquito vectors. The tick occurs at various elevations, ranging from five hundred feet to nearly nine thousand feet above sea level. Favourable or unfavourable local conditions for the creature's development alone regulate its prevalence or searcity in a given locality. The abundance of these ticks depends largely on the amount of vegetation, which acts as a protection for the developmental stages when the ticks are not upon a host; small and large mammals are also necessary adjuncts of this tick, the former to act as hosts for the immature stages, the latter for the adults.

Dermacentor andersoni (venustus) has such a peculiar life-history that it is well worth considering in some detail. Oviposition in the female extends over some thirty or so days, and during this time small ovoid brownish eggs, to the number of about four thousand, are laid. After sixteen to fifty days, depending on atmospheric conditions, small, brown, active, six-legged larvæ emerge. Before the larvæ or "seed ticks," as they are often called, are able to grow they must partake of a feast of blood, and, usually, they affix themselves to some small mammal, such as a ground squirrel, and remain attached and feeding for from three to eight days, by which time they have become engorged. 
During this time they increase in length from one-thirtyseventh to one-eighteenth of an inch and change in colour to slate grey. After engorgement they drop from their host and seek some hiding place in the undergrowth where they can continue their development. Repletion has rendered them less active, and so they remain more or less inert till, at the end of from a week to three weeks they shed their skins and appear in a new guise, as eight-legged nymphs, and hungry withal. As more blood is necessary for further development, the nymphs, now about oneseventeenth of an inch in length, emerge from their hiding places and once more become attached to some hapless mammal, for a period of three to nine days, during which time they feed on its blood, and increase in length to about one-sixth of an inch. After feeding, the nymphs fall to the ground, hide once more and become inactive; their sexual organs are formed during this period, and, after a second moult, they appear as mature male and female ticks.

At first the adults of both sexes are somewhat inactive and rather soft in texture; almost similar in size, they may be distinguished by the fact that the male has a plate or shield, decorated with a complicated pattern of white stripes, entirely covering his back. The female too has a shield, but behind it is her soft, elastic, usually wrinkled, reddish-brown body. Before the adults can proceed to the business of increasing their kind another substantial meal of blood is a necessity for both sexes: this is usually derived from some large domestic animal. On cattle, the dewlap and between the fore and hind legs, and on horses, between the fore and hind legs, and sometimes on the mane, are the most favoured spots.

The change of hosts from small mammals, such as squirrels, in the larval and nymphal stages to the larger domestic animals in the adult stage is a firmly fixed habit of this tick, and it is due, no doubt, to the fact that the 


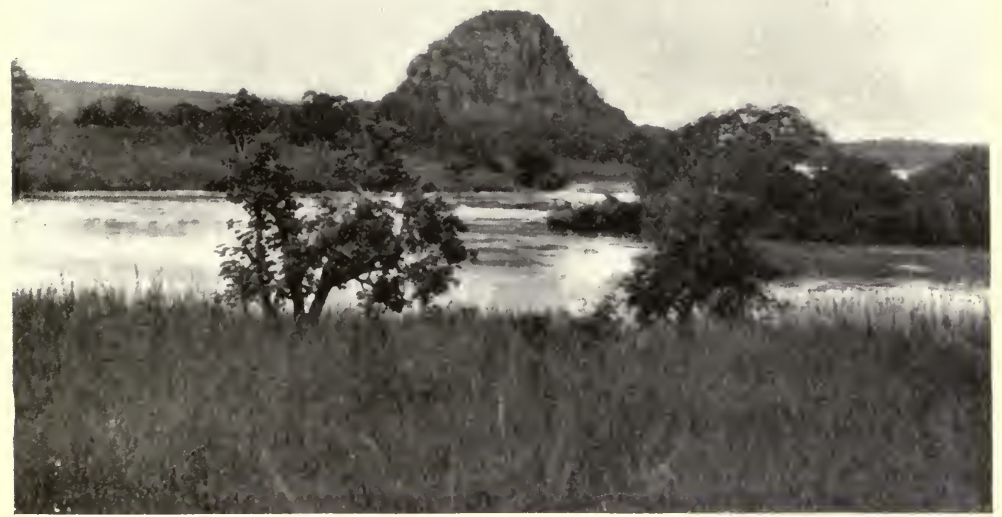

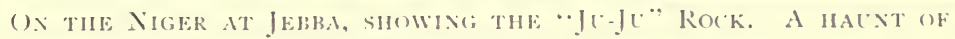
GLOSSI.I:I P'.1LI'.1LIS

(Si'p. 1.35)

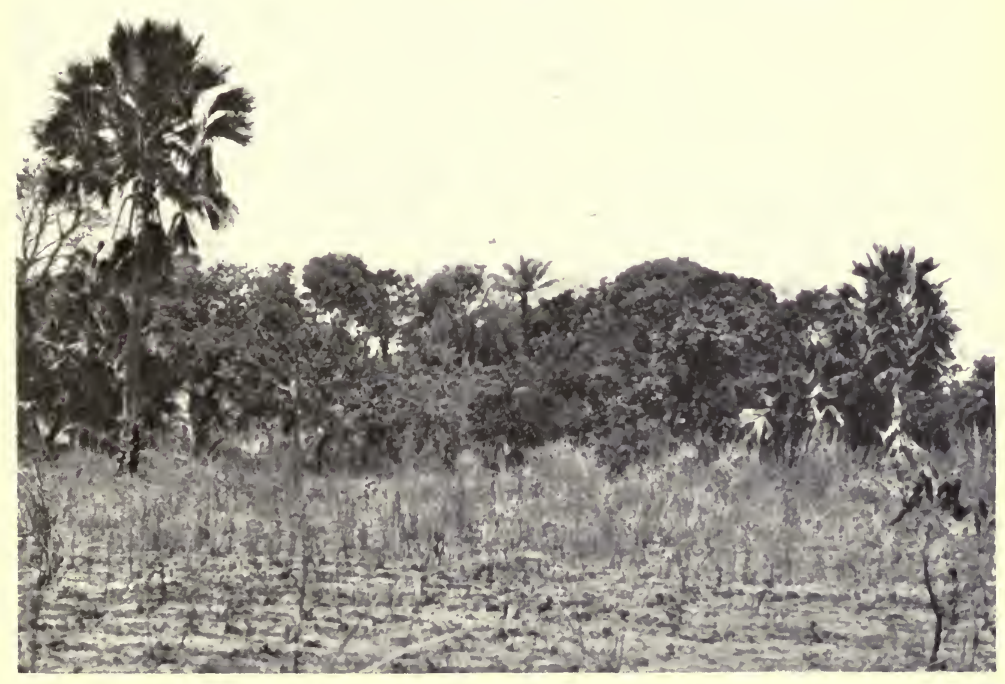

PLATE X

VIEW XEAR BAKAU SHOWING OPEN FOREST bEIT WITH OH, ANI BORASSUS Palms. A maUnt of GLOSSIAA MORSITAIS 

adults are of such a size that they could easily be removed by the smaller animals. Attachment is effected by means of a spiny beak, through which blood is drawn. The male feeds for a period of four days; fertilisation takes place on the host, and, in a week to a fortnight, after attachment, the female, being filled with blood, falls to the ground and seeks a hiding place where she may lay her eggs. As showing the great extension of which the body of the female tick is capable, it is of interest to note that, prior to feeding, its dimensions were one-sixth of an inch long by one-tenth of an inch wide, whilst, after feeding, the measurements had increased to half an inch long by onethird of an inch wide, with a thickness of a quarter of an inch. In fact, the distension is often so great that the head and legs become very inconspicuous. The males do not increase in size to nearly the same extent. During oviposition, the female shrinks in size, shrivels up and changes from a bluish-grey colour to a mottled yellow, and eventually dies.

The chief hosts for the larval and nymphal ticks are the Columbian ground squirrel, Citellus columbianus, the pine squirrel, Sciurus $h$. richardsoni, and the yellowbellied chipmunk, Eutamias b. luteiventris; and for the adults, horses, cattle, mules, asses, the mountain goat, and the brown bear. The adult is the only stage that nor mally attacks man. The mountain goat is probably the natural reservoir of the virus of Rocky Mountain spotted fever, and the immature stages of the tick are probably carried by ground squirrels from the higher altitudes, where the mountain goats feed, to the lower levels, where the cattle graze.

In addition to the Rocky Mountain spotted fever, the New World is responsible for another disease of mankind, probably carried by ticks, and known as verruga fever; to be perfectly honest, ticks have not been actually proved to be the vectors, but many things point to the probability 
of their being so. Verruga exists to-day in certain valleys on the Pacific slope of the Peruvian Andes; its origin is a mystery, but it is no new-comer, for, at the time of the Spanish conquest, it was more widespread than at present; in fact, certain reliable authorities maintain that the disease has existed in the quebradas of the Rimac from the most remote times. When the Spaniards came to Peru, verruga extended from South Central Peru to Northern Ecuador. Four centuries ago, the armies of Huayna Capac were decimated by a disease, probably verruga; for small-pox, which, by some, is considered to be a more likely disease to decimate an army, was unknown at the time in these regions, having been introduced by the Spaniards at a later date.

As we shall see later, the disease exists in two stages or phases, a fever phase and an eruptive phase, and at least nine different names have been applied to each of these two stages. No purpose would be served by giving a complete synonymy, but special interest attaches to the names Carrion's grave fever and mule warts for the fever and eruptive phases respectively. Localities where the disease may be contracted are invariably situated in or near deep narrow canyons with luxuriant vegetation and great summer heat, combined with little ventilation. Dr Ernesto Odriozola, senior member of the Lima Faculty of Medicine, who has made a special study of verruga, says that all ages and races of men are susceptible, as well as certain domestic animals. The fact that mules often exhibit eruptions similar to those found on human patients has given rise to the name mule warts for the eruptive phase of the disease. All degrees of intensity may be exhibited, the most serious form being called Carrion's grave fever, on account of the fact that, in the 'eighties, an investigator named Carrion "vaccinated" himself with blood from a verruga tumour, thereby proving, at the cost of his life, that transmission by inoculation is possible. 
The disease is characterised by fever, anæmia, and prostration, the anæmia is always rapid and profound, the reduction of the red blood corpuscles being almost incredible, and accompanied by a corresponding increase of the white corpuscles. In certain severe cases, patients become perfectly indifferent and immovable, and the slightest movement produces vertigo. Unless the disease ends fatally at an earlier date, the high fever lasts from fifteen to thirty days; after that it falls, and the eruptive phase begins. Although verruga is caused by a blood parasite, the only organisms found in the blood of patients are exceedingly minute, rod-like structures, called Barton's $x$-bodies or Bartonia bacilliformis, after their discoverer Dr A. L. Barton of Lima. Continued observations of the blood of sufferers from verruga show that, if the patient is destined to recover, the $x$-bodies will become distorted, break up, and ultimately disappear, and that their disappearance coincides with the outbreak of the eruption; should the $x$-bodies reappear, the disease terminates fatally.

As showing the virulence of this disease, we may quote two examples from the pen of $\mathrm{Mr}$ C. H. T. Townsend, entomologist to the Peruvian Government: "In 1906, at San Bartolome, which is in the verruga district, on the Central railway, two thousand men were employed in tunnel work during the year. Among these there occurred two hundred known deaths from verruga, and it is practically certain that still further deaths occurred among the many labourers who left the works and whose history was not followed up. The general experience with labourers on the Central railway has been that five or six nights passed successively within the verruga district causes the fever to appear in seventy-five per cent. to eighty per cent. of the workmen in a camp. In a week or so nearly all are certain to contract the disease. No animals of any kind were employed by the labourers in any of this work. Mosquitoes and buffalo gnats (Simulidoe) in abundance, as 
well as bed bugs and fleas, occur at Chosica and throughout the greater part of the verruga districts.

"During the early stages of the work in the building of the Central or Oroya railway up to 1876 , when the road was completed into Chicla, thousands and tens of thousands of labourers were employed, largely strong healthy Chilians, as many as eight thousand being carried on the pay roll at one time. During this period the recorded mortality from all causes-disease and accident-was some seven thousand. A large majority of these deaths were doubtless due to verruga, the result of carrying the road through the verruga district of the Rimac which has given its name to Verrugas Bridge" (Plate XI.).

It has been shown that verruga cannot be transmitted by mere contact, so long as the skin remains whole, nor can it be contracted through the respiratory or alimentary tracts, under normal conditions. It is a blood disease, and, like all other diseases of this class, can only be transmitted by inoculation. The only way for such inoculation to take place, naturally, is through the bites of some blood-sucker, and to Dr Julian Arce of Lima belongs the credit of first propounding this theory with regard to verruga. As in the case of yellow fever, the causative organism of the disease is unknown, though Barton's bodies are undoubtedly related to the fever phase of the disease, during which phase, by the way, verruga cannot be transmitted by inoculation. In other words, cultures made from blood containing these bodies fail to produce verruga on inoculation, so it is probable that they are merely the visible results of a non-infective stage of the organism, which changes to the infective stage, just beneath the skin, thereby giving rise to the eruption. Now we will endeavour to see by what agent verruga is carried from one patient to another. In all such diseases there occurs some natural reservoir for the disease germs; sometimes, as in malaria and yellow fever, the reservoir is man himself; 

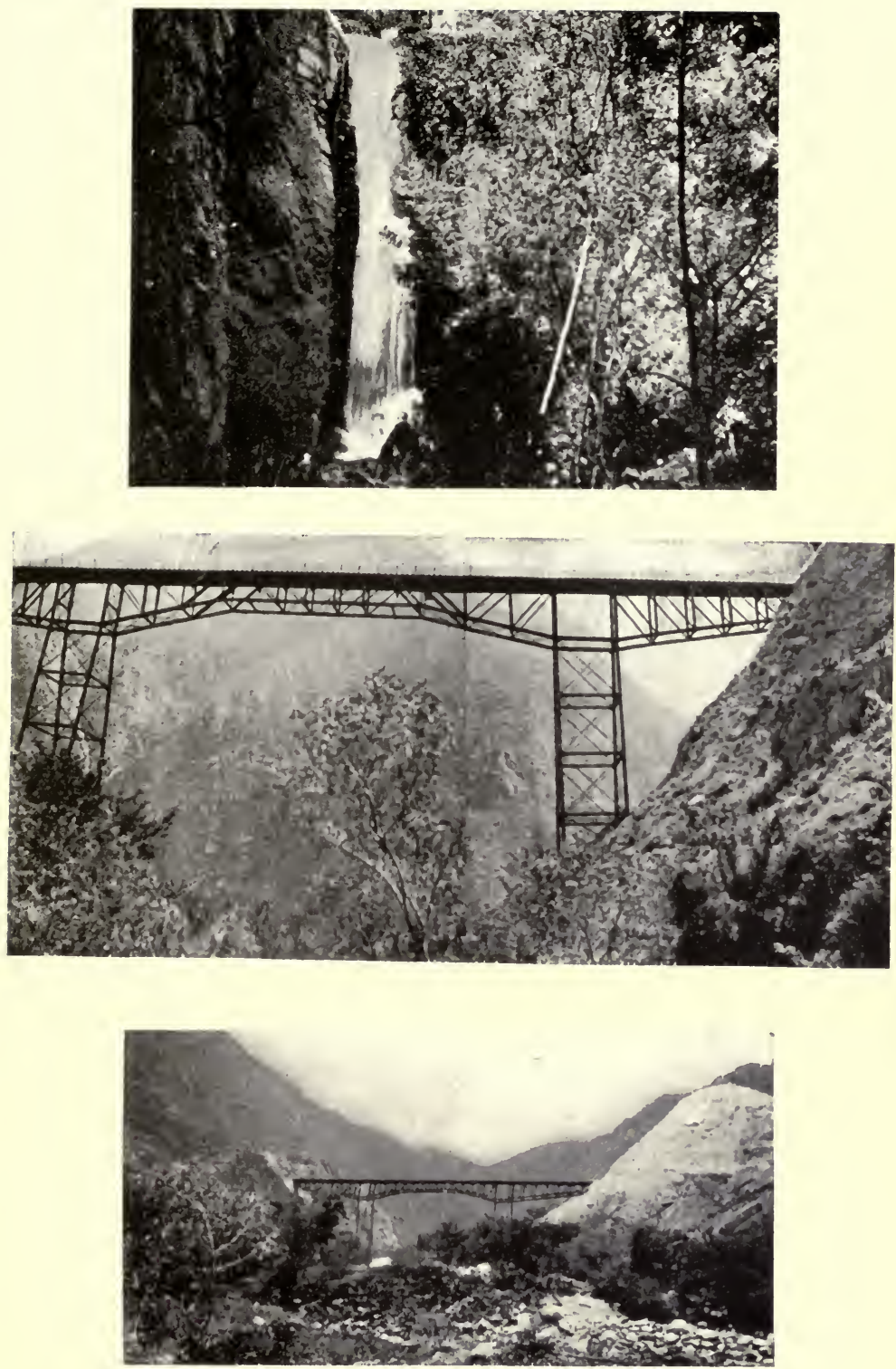

PLATE XI

Verrugas Bringe of the Central, Railway, across

Verrugas CANYoN 5,840 FEeT, THE bUILIING OF WHICH COST THE I.IVE OF THOUSANIS OF WORKMEN BY VERRUGA

Lower figure: From the mouth of the Canyon Central figure: From up the Canyon

Upper figure : First waterfall above the bridge 

at other times, as in sleeping sickness, the native fauna act in this capacity. That the native fauna and not man himself must be blamed for the survival of verruga is shown by the fact that the disease may be contracted in localities uninhabited by man. What blood-sucking animal, then, under these circumstances, is most likely to be the vector? Men suffering from the eruptive phase of verruga - the infective stage-are continuously encountered in the coast regions of Peru, where, however, the disease does not spread, so we may at once dismiss fleas and mosquitoes, which are prevalent in these parts, as well as in the verruga districts; but the disease does not spread with them. For the same reason, Simulida or buffalo gnats and horse flies may be excluded, as may also bed bugs and lice. As the chain of evidence is gradually forged the guilt falls more and more upon the invertebrate blood-suckers, the ticks, or upon one of the remaining families of Diptera. Investigations show that the disease is usually contracted at night-time, and ticks bite day and night; they are so large as to be observed and avoided in the day-time, but at night, while man is aslcep, they can feed on his blood for hours without molestation. Again, although the disease may be contracted at almost any season of the year, it is most prevalent in March and April, at the end of the warm, rainy season, and this is the time when the adult ticks are washed down the slopes by the rains, and are found in large numbers, looking for hosts on which to engorge.

Parasitologists are agreed that the blood parasites causing verruga are allied to Piroplasma, micro-organisms of which some account is given in the chapter on diseases of live stock. All the known species of these blood parasites are transmitted by Ixodine, that is to say, ticks with hard bodies, as opposed to the Argantince, or softbodied ticks. It will be seen that there is a close parallel between verruga and Rocky Mountain spotted fever, and 
it is probable that both diseases are bizarre forms of piroplasmosis. Both diseases consist in the breaking up of the red-blood corpuscles during the fever stage, with resultant anæmia; both are confined to certain restricted valleys in mountainous regions; both cause swelling and congestion of the liver and spleen; both may be contracted in places uninhabited by man; the primary reservoir of infection, in both cases, is to be found in the native fauna; and both show every indication of being transmitted by ticks.

When disease-producing organisms pass into the gut of a tick along with the blood of the host, some travel to the salivary glands and some to the ovaries. Those organisms in the salivary glands escape during the next feeding of the tick and so transmit the disease; those in the ovaries are transmitted through the eggs to the next generation of ticks, where they pass to the salivary glands, in readiness to infect a new host, when feeding takes place. The guilt has not yet been laid upon any one species of tick; in fact, a fly is now also suspected of being the carrier; but Margaropus annulatus australis, from the bodies of cattle, and Ornithodorus megnini, from the ears of horses, cattle, and sheep, both of which occur in the verruga locality, may be dismissed, because they pass all their stages, including engorgement, on the same host. It is to ticks of the genera Dermacentor, Amblyomma, Rhipicephalus, and Homaphysalis, which live on small hosts during the larval stage, and drop to the ground during the nymph stage, to seek new hosts when they become adult, that we must assign the probability of the transmission of this fatal disease if it be tick-transmitted. And the natural reservoirs of the disease organisms will probably, eventually, be shown to be the Octodontidoe and Cricetina, relatives of the pocket and grasshopper mice.

As recently as October 1913, a scientist, working in the verruga district with a view to discovering its means of 


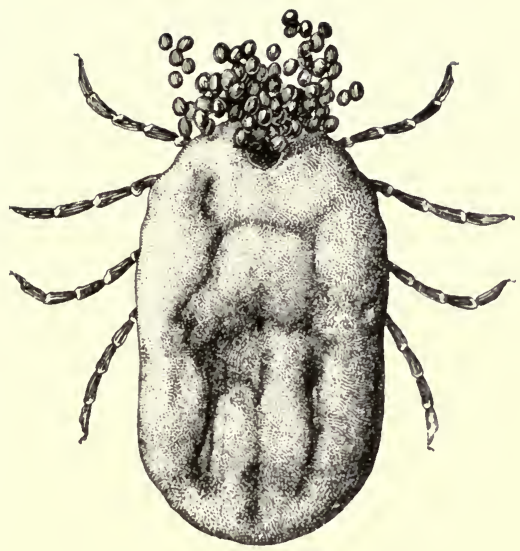

FIli, 41. A THCK LAYING EGris

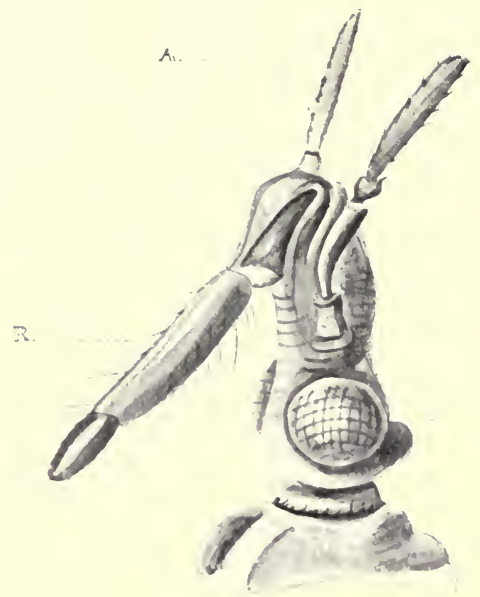

Fuli. 43. HeAl OF Lallus metistu a. INTENAA ; $九$. EVE; , ROSTRl'

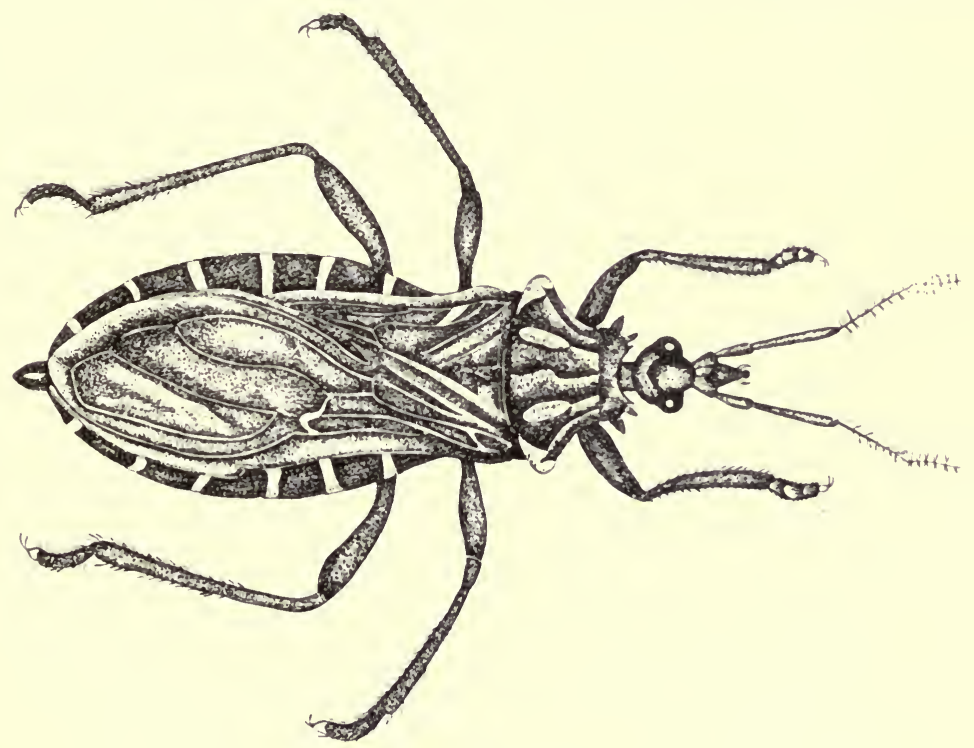

Ful: 42. Lamus megistus 
. 
transmission, was bitten one night no fewer than fifty-five times by a Phlebotomus fly, and, as a sequel, he contracted the disease. The disease has also been transmitted to a dog and a monkey by the same species of fly which is now known as Phlebotomus verrucarum, so that it, at any rate, must be looked upon as one of the vectors of the disease.

\section{A Disease-Carrying Bug}

The Indian bed bug is strongly suspected of being a disease-carrier, but another member of the order, Rhynchota, has been recently proved so. The insect in question is the South American bug, Lamus megistus, known as "Barbeiro" in the states of Minas Gaeras, Motto Grosso, and Sao Paulo, and "Chupanca" in the extreme south of Motto Grosso, and as the wall insect, "bicho de parede," in the north of Brazil ; it also occurs in British Guiana. The bug (fig. 42) is dark brown, with conspicuous black markings, and is about thirty millimetres long. It is the carrier of a blood parasite, Trypanosoma cruzi, from man to man, and the ensuing trypanosomiasis is of a fatal nature; in Minas Gaeras whole populations are at times attacked, when the children either die off or the disease assumes a chronic form.

As is invariably the case with disease-carrying insects, this bug is domestic in habit, frequenting inhabited houses and quickly forsaking empty ones. It lives in holes and cracks in the walls, where each female lays about five hundred creamy-white eggs, in batches of eight to twelve. The eggs resemble those of the bed bug in being rounded at one end and flattened at the other. In from twenty-five to forty days the larvæ emerge; at first they are light coloured, but they become darker as they grow older : they are ready for their first feed of blood in about a week, and the second, in a fortnight to three weeks after their first appearance. The larvæ pass through five moults before 
the adult stage is reached, the first taking place in about six weeks from emergence; the second, during the second or third month; the third, from the fourth to the sixth month; the fourth at about the ninth month; and the final moult, six weeks later. The penultimate stage is the critical one, many of the bugs dying before they reach maturity. A week after reaching the adult stage, the insects take a meal of blood, and, in the ordinary course of events, the females begin egg-laying eight weeks later.

The complete life-cycle, under favourable conditions, takes nearly eleven months. Metamorphosis is incomplete, that is to say, there is no resting stage, and the immature forms are active throughout life, but their wings do not develop till they are adult. Being wingless, the young bugs are only able to attack people sleeping in beds; as a consequence, hammocks are much in favour, despite the fact that they entail no immunity from the strong-flying adults. Feeding takes place at night; the rostrum or beak (fig. 43) is plunged into the flesh and blood is imbibed. Curiously enough, the so-called bite is painless and leaves no scar.

In this connection it is of interest to read Darwin's remarks in his Journal of a Naturalist; speaking of the bites of a closely related bug he said: "We slept in the village of Luxan, which is a small place surrounded by gardens, and forms the most southern cultivated district in the Province of Mendoza; it is five leagues south of the capital. At night I experienced an attack (for it deserves no less a name) of the Benchuca, a species of Reduvius, the great black bug of the Pampas. It is most disgusting to feel soft, wingless insects about an inch long crawling over one's body. Before sucking they are quite thin, but afterwards they become round and bloated with blood, and in this stage are easily crushed. One which I caught at Iquique (for they are found in Chili and Peru) was very empty. When placed on a table, and though surrounded 
by people, if a finger was presented, the bold insect would immediately protrude its sucker, make a charge, and, if allowed, draw blood. No pain was caused by the wound. It was curious to watch its body during the act of sucking, as in less than ten minutes it changed from being as flat as a wafer to globular form. This one feast, for which the Benchuca was indebted to one of the officers, kept it fat during four months; but after the first fortnight it was ready to have another suck."

\section{Fleas and Plague}

The most dread disease that has ever attacked mankind is the bubonic plague, and it is also probably the oldest of all known diseases. It is caused by a bacterium known as Bacillus pestis, which produces an epizootic in rats, and is carried to man by fleas. One of the most curious and interesting facts in connection with plague is that, although the causal agent has only been discovered within the last quarter of a century, its association with rats dates at least from Biblical times, and probably earlier. In the first book of Samuel, the reference to emerods and mice of the field undoubtedly refers to plague; Sennacherib's army was attacked by a disease in the spread of which rats played a part; whilst in a fragmentary writing of Rufus of Ephesus, a contemporary of 'Trajan, in the third century B.c., we find the first mention of the disease, though its association with rats does not appear to have been recognised at this early date. In the sixth century, during the reign of Justinian, plague reached Europe; beginning at Pelusium in Egypt, in 542, it reached Constantinople during the next year, and there was responsible for ten thousand deaths in a single day; in the same year it also spread to Italy, and three years later it reached France, whilst England came under the fatal spell in $664,672,679$, and 683 , and its ravages continued unabated for nearly two hundred years. 
In the eleventh and fourteenth centuries further outbreaks occurred, and throughout the sixteenth century it was a permanent disease on the European continent. The last appearance of the dread disease, in epidemic form, was "the great plague" of 1665, when seventy thousand persons succumbed in London alone, and it spread throughout the country till 1679, when it suddenly died out. Historians tell us that the great fire of London put an end to the disease in our capital, but bills of mortality of the time show that it was practically extinct before the fire broke out.

En passant, we may mention that the word quarantine, now so thoroughly assimilated into our language, had its origin during the plague outbreak in Venice, in 1403. The Venetians isolated all persons who had been exposed to infection for a period of forty days, and incidentally laid the foundations of modern preventive medicine. To state that cats and plague are in any way connected may appear farcical, but it is well known that the ancient Egyptians revered the cat as a demi-god, and the reason, according to several reliable authorities, was because, even in those early days, the people were well aware that the presence of numerous rats portended an outbreak of plague and that no creature could so well rid the land of the rodents as the cat, hence the high favour in which it was held. The explanation may not be the correct one, but, at any rate, it bears the stamp of probability.

After this digression let us return to our brief history of plague. Anything like a complete narrative of the various epidemics and pandemics of the disease is impossible here; a very full account is given in the eleventh edition of the Encyclopadia Britannica, and to that work the reader is referred. We may mention, however, that a severe outbreak occurred in China in 1894, and spread from Kaochao to Canton and Hong Kong, and from thence to Bombay and the greater part of India. It. is with Hong 
Kong that we are mainly concerned, for it was here that a Japanese physician named Kitasato discovered Bacillus pestis to be the cause of the disease, and a little later Yersin confirmed his discovery. The bacillus is very minute, nearly as broad as it is long, and when stained its median portion appears as a clear area; it occurs in great numbers in the swollen lymphatic glands.

The incubation period of plague varies from twelve hours to fifteen days, but the usual period is three or four days. Sometimes the onset is sudden; the patient falls as if shot, and dies after a few convulsive gasps. Usually the lymphatic glands of the thigh, groin or armpit, and more rarely of the neck, become swollen and painful, producing the characteristic "buboes," hence the name bubonic plague; in the severer septicæmic plague the buboes have no time to form, but extensive hæmorrhage takes place, the skin becomes mottled with dark patches, and on this account the disease has been called the black death. The most fatal form is pneumonic plague, which attacks the lungs, and the least fatal the ambulatory plague. Fortunately, only two and a half per cent. of the cases are pneumonic, which spreads from man to man by bacilli in the air, but the bubonic and septicæmic forms are only spread from rats to man by the agency of fleas, as was suggested by Ogata in 1897, and shown by Verjbitski and Simond at a later date.

The home of plague is Central Asia, where it is endemic mainly in the Kurdistan Hills and about the Himalayas. Its spread is little influenced by climate, and in no wise by soil. In Asia, at any rate, the black rat, Mus rattus, is the means of spreading the disease; as this animal is the true ship rat, it is easy to understand how easily plague is carried from port to port. That its connection with these rodents was known to the ancients has already been mentioned, and, as further evidence, we may remark that the ancient Greeks in Asia Minor worshipped Apollo as 
"the god whose arrows spread the plague," and, at the same time, as "the destroyer of rats." On monuments this divinity was represented treading on a rat. Again, Dr Sambon, an authority on the history of plague, has described to the writer a coin of Lucius Verus, struck at Pergamum during an epidemic of plague. It represents Esculapius, the god of medicine, with a rat at his feet, and near by is a small naked figure with arms outstretched, in an attitude of fear or worship. Defoe, writing of the great plague, said: "All possible endeavours were used to destroy the mice and rats, especially the latter, by laying ratsbane and other poisons for them, and a prodigious multitude of them were also destroyed."

We now have absolute proof that when an epidemic of plague breaks out, it first of all spreads from rat to rat and then from rats to man. Coastal towns are the first affected, and those who have had dealings with a ship from an infected port are usually the first attacked. Whilst rats are the chief source of plague, mice, cats, squirrels, monkeys, and other animals may also become vehicles of infection.

The plague flea, that is to say the flea most usually associated with the transmission of the disease, is known as Xenopsylla cheopsis (fig. 44); it is sometimes called the Oriental rat flea. Its original home is the Nile valley, but it has now been distributed all over the warmer parts of the world by rats; it cannot, however, stand cold weather. In colour it is lighter and in size smaller than the human flea, Pulex irritans, which, by the way, is also capable of spreading plague, as is the European rat flea, Ceratophyllus fasciatus, and the Californian ground-squirrel flea, Hoplopsyllus anomalus. When a rat or other host infected with plague dies, its fleas abandon its carcass and seek some other warm-blooded animal. Often these insects literally swarm during plague epidemics, and, at Sydney, during an outbreak, the labourers on the wharves used to tie strings 


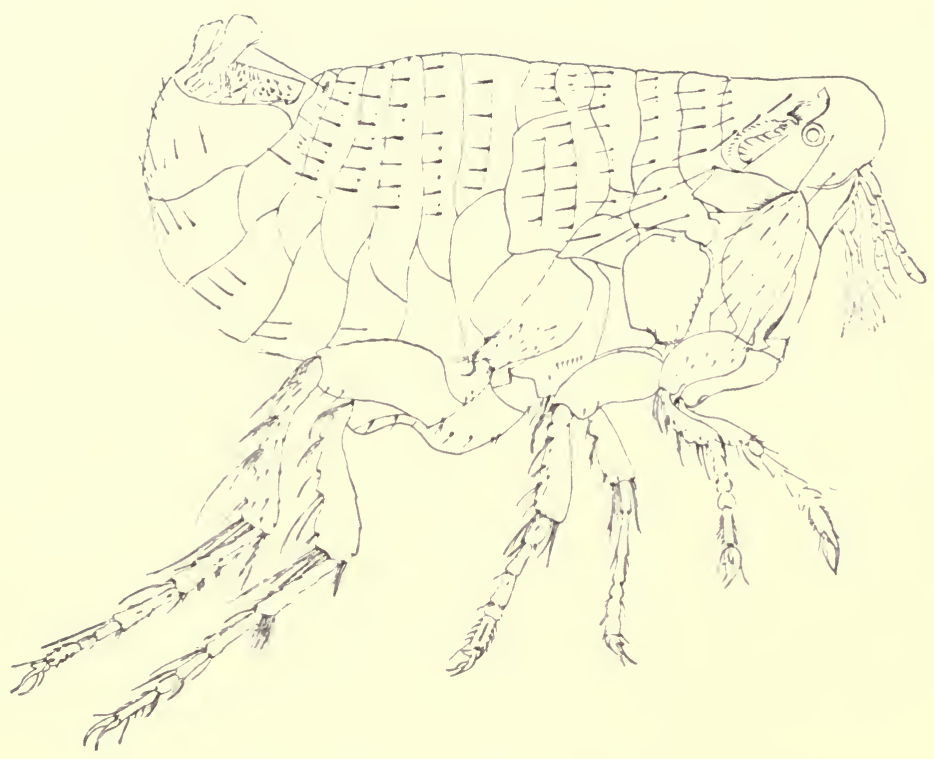

FII. +t. A MALE ILACIUE FIAS 

round the bottom of their trousers as a precaution against being bitten.

The disease begins with a small blister, as the result of a flea bite, from whence the bacilli make their way to the lymph glands; and when persons are bitten on the legs the buboes usually appear in the groin. Indian women, on the other hand, usually suffer from buboes in the arm-pit, the reason being that they sweep their floors with their bare hands. It has been proved that male and female fleas can transmit the disease, but the exact method of infection is not perfectly clear. Experiment shows that the blood of a plague flea may contain 100,000,000 bacilli per cubic centimetre, and, as a flea's stomach will hold half a cubic centimetre of blood, it follows that after engorgement on a plague-stricken rat each flea may contain 5,000 bacilli; moreover, they have the power of multiplying within the insect's body. Into the various theories of the actual infection of man we cannot enter, the most generally accepted is that the fæcal matter, which the flea always voids while feeding, as we have explained elsewhere, is carried to the wound made by the insect's bite on the nails of the person bitten. This fæcal matter, in an infected flea, is always teeming with Bacillus pestis; the flea bite sets up irritation, as a relief scratching is resorted to, and, as a result, unconscious infection takes place.

We have mentioned that the human flea is capable of transmitting plague, and the fact has been proved experimentally. Whether it does so naturally is highly improbable, because the degree of septicæmia in man before death is so much less than it is in rats, that the probability of a human flea imbibing a single bacillus from a plague patient is remote. In the Middle Ages, when the septicæmia was probably much greater, it is possible that the human flea frequently carried the disease from man to man. 


\section{INSECT ENEMIES OF LIVE STOCK}

\section{Ticks and Disease}

THE ticks are of primary importance as vectors of disease; no less than ten distinct human and animal diseases are known to be transmitted by these creatures. Apart from their disease-carrying propensities, ticks are of the greatest importance. As external parasites, the constant irritation caused by their attacks, combined with the serious drain on the host's system, occasioned by considerable loss of blood, leads to an emaciated condition and general want of tone.

In order that ticks may reach maturity and increase their kind, it is essential for them to suck blood, and, to do this, they must become attached to some animal; unless they are able to find a host within a reasonable period, they starve. This fact has been utilised in America, by establishing a rotation system of farming, in order to starve out Margaropus annulatus, a tick responsible for Texas fever in cattle. In brief, the life-history of every tick consists of egg, larva, nymph, and adult, and, in nearly every case, engorgement must take place just prior to oviposition, though the spinous ear tick, Ornithodorus megnini, drops from its host as an engorged nymph, moults to the adult form, and deposits eggs without any further engorgement. In the genus Argas, or shining ticks, the nymph engorges twice before moulting. Behaviour at or after oviposition also varies considerably; in some species the females die immediately after depositing their quota 
of eggs; in other species engorgement is repeated and followed each time by further oviposition. In all the genera of ticks, the females differ strikingly in appearance in their gorged and unengorged states; so marked are the differences, in some cases, that individuals of the same species have often been taken for females of different species: in the males the differences are not nearly so striking, because they engorge on serum rather than blood. In the nymphal stage there is no genital pore, and this serves to distinguish the nymphs from the adults; the sexes, with few exceptions, can only be distinguished after the final moult.

The ticks fall naturally into four separate classes, according to their moulting habits. (1) Both moults, that is larval and nymphal, take place on the host: in this class are certain ticks of the genus Margaropus, and the tropical horse tick, Dermacentor nitens. (2) Larval moult takes place on the host, but nymphal state off: examples may be found in the spinous ear tick, Ornithodorus megnini, in Rhipicephalus bursa, and Rhipicephalus evertsi. (3) Both moults take place off the host, as in the castor-bean tick, Ixodes ricinus, and the fever tick, Ornithodorus moubata. (4) Larval moult off' the host, but nymphal moult during attachment, as in the "bont" tick, Amblyomma hebrcum. At first glance this purely artificial classification of the ticks may not appear of much inportance, but, from the point of view of disease transmission, it merits some attention. Ticks of the first class pass the whole parasitic period of a generation on a single host, and, as a consequence, they exhibit a rapid rate of reproduction and assume importance as external parasites, as far as the removal of blood is concerned, for they are continually imbibing the blood of the same animal. Individuals of classes two and four may attach to two hosts during a generation, and those of class three to three hosts. When it is essential for a tick to find three separate hosts in its 
life-cycle, the chances of its reaching maturity are much lessened, for at any stage starvation may be the result of the non-appearance of the host within a reasonable period. To some extent this disadvantage is overcome by the superior powers of resistance possessed by all ticks belonging to this class; they are less affected by heat and cold than other ticks, and they are able to withstand prolonged fasting.

The majority of ticks favour certain hosts, hence the popular names, sheep tick, dog tick, etc. ; they may, however, attach to other hosts, on occasion; in this event, one animal is called the usual and the other the accidental host. A very curious example of this host relationship is exhibited by the Senegal tick, Hyalomma agyptium. In its larval stage it attaches to fowls and cannot be made to feed upon any mammal; while attached to its avian host, it undergoes its first moult. The second moult takes place while unattached to any host; then, when the adult stage is reached, the tick will attach to almost any mammal, except the dog.

As we have already remarked, all ticks must find hosts and attach to them at least once, sometimes as often as four times, during their life-cycle. The result is that they show very special adaptation of structure and function for attachment. In the family Ixodidoe, for instance, the larvæ or "seed ticks" use their front legs in a very peculiar manner-standing erect, on some elevated support, they wave their anterior legs in the air whenever a likely host approaches, and, when once these legs come in contact with anything of a solid nature, they cling most tenaciously, as anyone may prove by passing a finger over a cluster of "seed ticks." In this case, the larval legs are used solely as sentinels and grappling irons for attachment.

Structure may also be adapted for protection, as exemplified, to some extent, in the sub-family Ixodince, or hard ticks, which have mouth parts of such formidable 

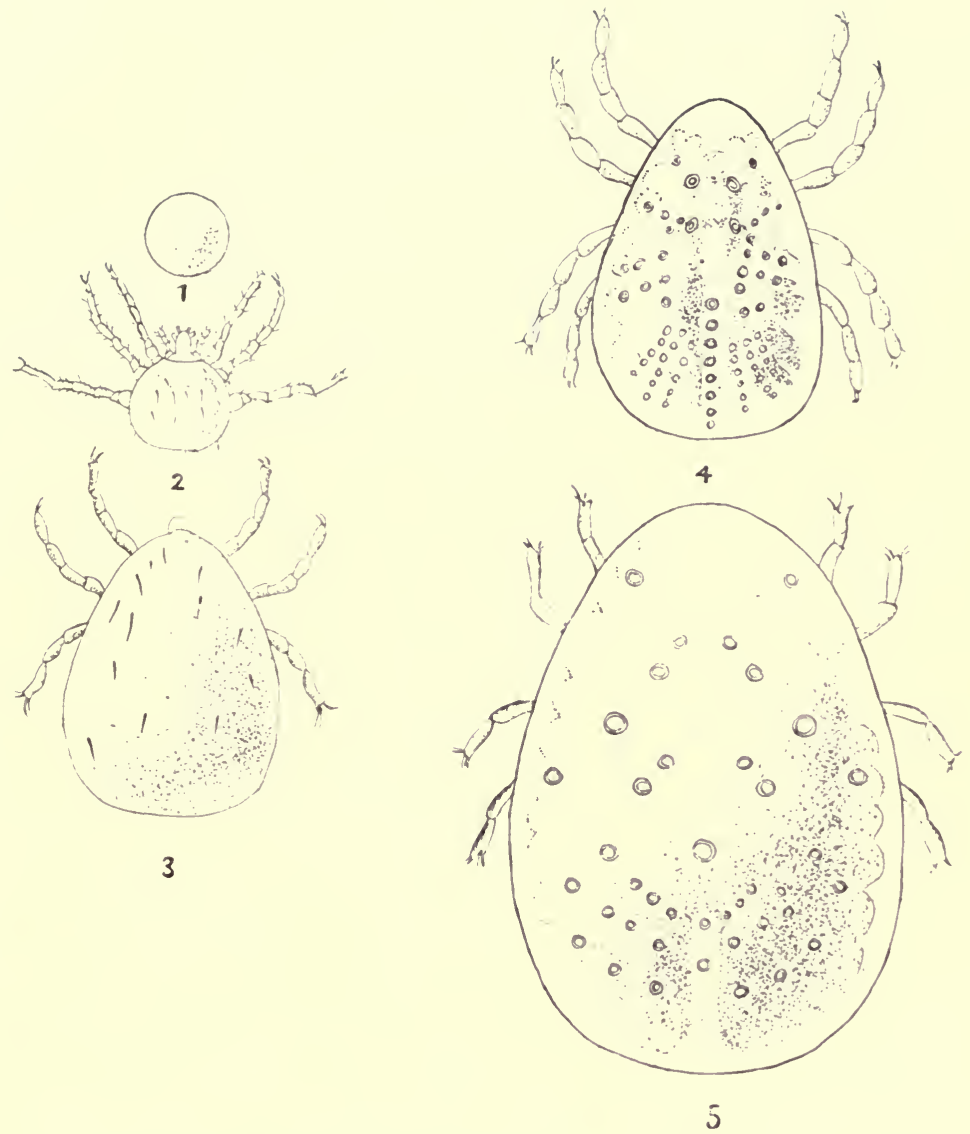

Fig. 45. EYOlution OF THE FOWL TICK. Atras fersicus. I. EGa; 2. LARVA; 3. LARVA (;ORgeI) ; 4. YOUNG NYMIII ; 5. GOR(iEI) NYMIII 

build that they are not easily removed from a host, when once attached. A more striking protective adaptation is seen in the fowl tick, Argas persicus. The larvæ of this tick feed upon domestic fowls, becoming attached in positions where they are with difficulty reached by their host. During the greater part of the time they are attached, their shape is globular (fig. 45), but, just before dropping from the host, they become flattened, assuming the typical adult shape. There is good reason for this abrupt change: in their new form they are able to crawl into cracks and crevices out of reach of the fowls, which eat them with avidity whenever they catch them.

Adaptations of habit, favourable to attachment and protection, form still more striking illustrations of the process of natural selection. The habit of dropping from the host to the ground, to moult, necessitates long periods of waiting for a new host, and occasions considerable mortality. This disadvantage is overcome, in certain species, by the acquired habit of moulting on the host, or, as in the case of the spinous ear tick, by passing the first moult on the host and then becoming so engorged as a nymph that, after the second moult, which takes place off the host, no further engorgement is required before oviposition.

The adaptation of tick habits to the habits of hosts is a most interesting study. Rabbits, as is well known, pass most of the day in their burrows and only become active towards evening-the rabbit tick, Hamaphysalis leporis palustris, has adapted itself to this habit to such an extent that it only drops from its host during the day-time, in order to undergo a moult. By so doing, it is practically assured of being able to find a host, when one again becomes a necessity. Conversely, the fowl tick, Argas persicus, drops from its host for moulting purposes at night, during roosting time; departure from the host during the day, when fowls are active, would give the ticks but a poor chance of being able to re-attach to their host. The adults 
of the fowl tick also exhibit another acquired habit: they become engorged at night and rest by day. When fowls are roosting, the ticks can take their fill of blood in peace; by day, their hosts are not above making a meal of such unwelcome visitors. Other ticks again exhibit the protective habit of only attaching to inaccessible parts of their host; the usual feeding position of the spinous ear tick, Ornithodorus megnini, within the external ear of cattle, horses, etc., is a case in point. Certain species of the genus Homaphysalis have, as hosts, quails and larks, but they only engorge upon the birds' heads, where they are out of danger. As a final example of protective habit, we may mention that accelerated engorgement may be observed in certain species of ticks; in this way, the period of exposure to enemies is much reduced.

What, it may be asked, is the origin of tick-borne diseases? On the discovery of Texas fever in America in 1795, it was noticed that when cattle from the south were brought north, in summer, all the northern cattle along the route sickened and died, whilst northern cattle taken south also became diseased; but the southern cattle, for the most part, remained healthy, for they had been used to tick infection from birth and had become immune, although those raised in non-tick-infested districts were as susceptible to disease as the northern animals. Similar diseases of cattle occur in most parts of the world, but, in different countries, very similar diseases are carried by very different ticks, a fact which shows that the diseases have not originated in the ticks. Probably all the species now carrying disease to certain hosts were originally confined to other hosts, to whom they were innocuous. Certain organisms were probably transferred by other ticks to other hosts, of the same kind, without ill effect. But when a tick, after imbibing the blood parasites of its natural host, became attached to a new and different kind of host, then the blood parasites, transferred to this alien blood, would quite probably origin- 


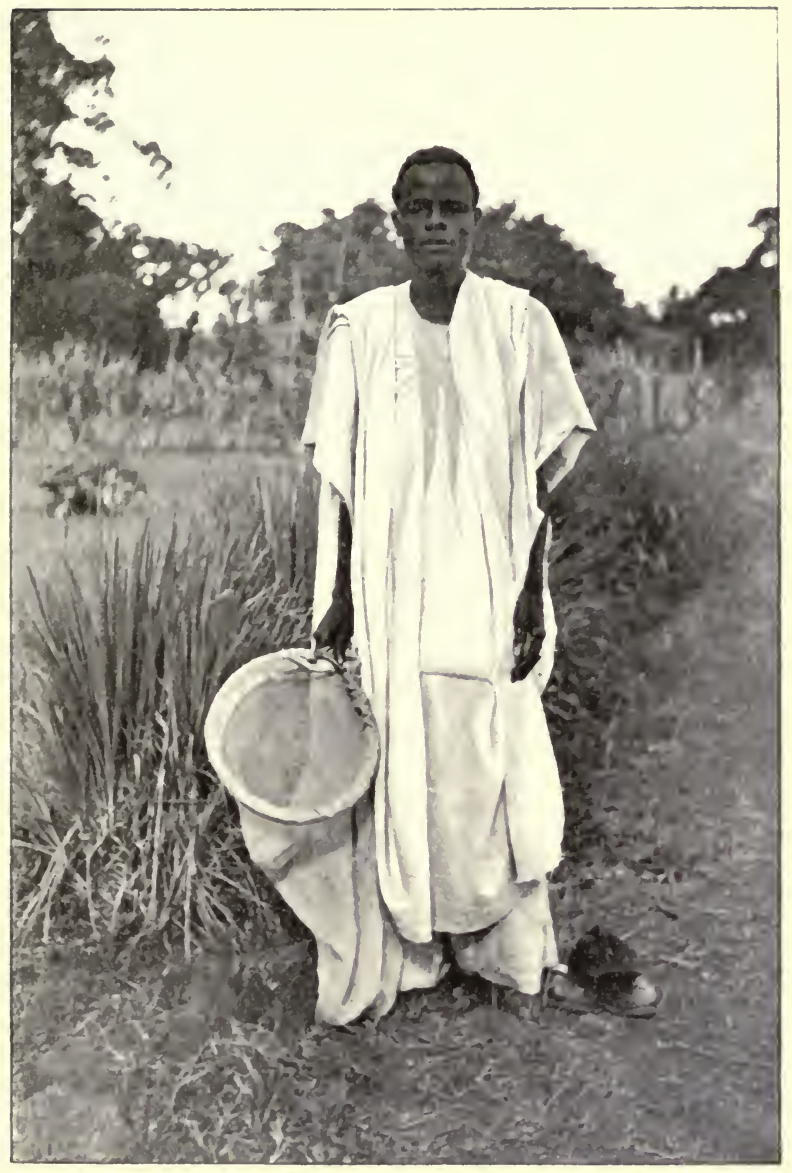

PIATE XII

A Native Colmector 

ate a disease. The march of civilisation has probably in many cases well-nigh exterminated the ticks' natural hosts, with the result that they have turned their attention to domestic animals, giving them these blood parasites and, in many cases, setting up disease. Ticks are absolutely essential to the blood parasites, for in some, and probably in all, the sexual stages in the life-history of the organism can only be completed within the tick. On this account alone, all ticks must be looked upon with suspicion, for they may, at any time, change from a wild to a domestic host, and in doing so set up a new disease.

\section{Piroplasmosis}

In our chapter on human diseases conveyed by insects, a considerable space was devoted to malaria, for it is one of the greatest scourges of mankind in many parts of the world. To state that animals, as well as man, suffer from the disease would be hardly accurate; still, the cattle disease we are about to describe has been termed bovine malaria, and certainly the two diseases are comparable in many ways. There is a group or series of diseases, technically known as piroplasmosis or babesiasis, and caused by a micro-organism, known as a piroplasma or babesia. There are four distinct diseases of cattle, sheep, dogs, and horses, transmitted by a round dozen of ticks, and named respectively, Babesia bovis, or piroplasmosis of cattle; Babesia ovis, or piroplasmosis of sheep; Babesia canis, or piroplasmosis of dogs, and Babesia equi, or equine piroplasmosis. All these diseases are transmitted by ticks, twelve at least being implicated in the work, and, as they resemble one another very closely, we will rest content with a description of bovine piroplasmosis and the method of its transmission, pointing out, as we proceed, when the allied diseases vary from our type.

Piroplasmosis in cattle is a very wide-spread disease, and has received various popular names in different countries. 
Africa, Australia, North and South America, and many districts in Asia know the disease, as well as Russia, Roumania, Finland, Central Europe, Sardinia, Germany, Holland, Belgium, Ireland, Scotland, and more rarely England. In England and Ireland the disease is known as red water or red murrain; in Scotland it is called moor ill or moor evil; Australia has given it the name of tick fever; bovine malaria is its name in the Argentine, and Texas fever in the United States. The name matters little, for the disease is the same all the world over, although various ticks are concerned in its transmission.

Red water in cattle, to give the disease its popular name, which is derived from the red colour of the urine, owing to the parasites carrying the disease having destroyed the red-blood corpuscles, was, at one time, thought to be caused by some irritant taken by cattle during feeding, and to be especially prevalent in marshy districts. In 1888, however, Babes, when examining the blond of some Roumanian cattle attacked by red water, found therein some shining round bodies of whose purport he was unaware. In the following year an American scientist, Theobald Smith, also discovered micro-organisms in the blood of cattle suffering from Texas fever; these parasites were eventually called Piroplasma bigeminum. Following on this discovery came reports of the disease from practically all over the civilised world, and, in every case, the parasite was found in the blood of the afflicted animals.

Before proceeding to a description of the ticks conveying bovine piroplasmosis, a word or two concerning the parasite itself may not be out of place. It is hardly necessary to remark that the blood of cattle resembles human blood, in that it is composed of a liquid plasma in which float redblood corpuscles; it is in these corpuscles that the majority of the parasites occur, though a few may occasionally be found in the plasma. In outline, Piroplasma bigeminum may be pear-shaped or circular; often two parasites are 
joined, and appear like two diminutive pears, joined by a common stalk, or they may lie in opposite directions, and sometimes they appear almost as a straight line; the varied shapes denote stages in their life-history. The microorganisms multiply by division, so that, at times, four of them may be found in one blood corpuscle. All the time the parasites are within a blood corpuscle they show amœboid movements, that is to say, they move about after the fashion of an Amceba, a very diminutive and lowly animal, resembling nothing so much as a tiny globule of living jelly, and not only do they move, but they eventually break up the blood corpuscle within which they have been enclosed, setting free the red colouring matter which is execreted with the urine. Normally, a cubic millimetre of bovine blood contains some seven or eight million redblood corpuscles, but, in a severe attack of piroplasmosis, the number may be reduced to below a million. Einaciation, loss of appetite, and, eventually, coma and death may follow these internal changes.

In some parts of the United States, where Texas fever is rife, the death-rate of cattle brought into the afflicted area exceeds ninety per cent. When recovery takes place it is very protracted, and sometimes development is permanently arrested. Quite apart from the fact that they carry disease, the ticks are a severe drain on the animal economy, as the figures of the following experiment show. A steer, badly attacked by ticks, was losing weight, so it was freed of these animals by dipping, and weighed, turning the scale at $730 \mathrm{lbs}$. In two months' time the animal, still tickfree, was weighed again, and scaled 1,015 lbs., a gain of 285 lbs. in two months, or 42 lbs. a day. The feeding was the same as before in quantity and quality, a fact that shows clearly that a largely increased amount of food is required by tick-infested cattle to make up for the loss caused by the parasites; flesh is put on slowly, or not at all, and the milk production is greatly diminished. 
But we are here concerned with the ticks as diseasecarriers, and it is by their agency alone that piroplasmosis in cattle is spread from host to host; without the ticks there would be no red water, Texas fever, or tick fever, call it what you will; a tick of some species or other is as necessary in the propagation of the disease as mosquitoes are essential to the spread of malaria or yellow fever. Realising the importance of this fact, the American Bureau of Animal Industry, by vigorous eradication work, for the six years 1906-1912, rendered 162,648 square miles tickfree, which is equivalent to saying that this enormous area was immunised from Texas fever. The total annual loss, due to ticks, has been estimated, in America alone, at from $\$ 40,000,000$ to $\$ 100,000,000$, and is comprised of direct loss by death of cattle suffering from tick fever, losses owing to arrested growth of infected animals, which lessens beef and milk production, expenses of fighting the fever-bearing tick, etc. In short, these ticks have a detrimental effect on the whole of the agriculture of the Southern United States.

In America the tick, Margaropus annulatus, is the vector of piroplasmosis in cattle; in Australia the vector is Margaropus annulatus australis (fig. 46); and in Africa Margaropus annulatus decoloratus is mainly concerned in the spread of the disease, though two other ticks, Hyalomma coyptium and Homaphysalis punctata, are also responsible for its spread. In Norway, and certain parts of Europe, the tick, Ixodes hexagonus, is an essential factor in the transmission of red water; and in other parts of Europe, including the British Isles, a closely related species, Ixodes ricinus, carries the blood parasite from host to host.

It is hardly necessary to describe all these ticks and their life-histories; systematic descriptions can be found in many books, and the life-histories have, in some cases, not been fully worked out. Margaropus annulatus, however, is practically cosmopolitan, and its life-history may be taken as typical. From what has been said, it will 
have been gathered that cattle form the normal hosts of Margaropus annulatus, but horses, mules, deer, and sometimes even sheep and buffaloes, act as hosts, and, of these, besides cattle, only deer and buffalo are susceptible to red water. They all suffer from the ticks as simple parasites, capable of withdrawing a large amount of blood-it has been estimated that a beast may lose from $200 \mathrm{lbs}$. to $500 \mathrm{lbs}$. of blood in one season,--but as transmitters of disease the ticks are harmless as far as horses, etc., are concerned.

The adult male tick is brown in colour and about onetenth of an inch long; the female is slightly larger, and of an olive-green shade. At the time the female is ready to lay her eggs she has increased enormously in size, because of the blood she has imbibed, being then about half an inch long and very plump. When fully engorged, she leaves the host and drops to the ground, for only part of the development takes place on the host, the other period being spent on grass, etc. Immediately on reaching the ground, a hiding place is found for egg-laying, where the earth is moist, beneath leaves or some other protection against the sun and unfavourable weather conditions. Too high or too low a temperature, alike, are fatal to the eggs; absence or excess of moisture must also be guarded against; enemies, too, in the shape of ants and birds, are less likely to discover the eggs beneath some protective covering. Oviposition usually begins from two to twenty days after the female tick has reached the ground, though, in winter, the period may be protracted to ninety-eight days.

Each mother tick lays from one hundred to five thousand small, elliptical, light-amber-coloured eggs, and, in doing so, shrinks to about a quarter her original size. These ticks are very prolific, and it is estimated that, under favourable circumstances, the descendants of a single male and female tick, hatched in April, will number 6,750,000,000 individuals by the middle of October in the same year. The abovementioned favourable circumstances are, for the most part, 
circumstances of temperature, for a low temperature retards or even arrests egg-laying altogether. In a warm summer the operation is usually completed in four days, and in autumn it may extend over one hundred and fifty days. The eggs, which measure one-fiftieth of an inch in length, soon turn dark brown; they are coated with a sticky secretion which causes them to adhere to one another in clusters, and probably also prevents them from becoming dry. After egg-laying, the female shrivels up and dies. In from nineteen to one hundred and eighty days, depending on the season of the year, a small, sixlegged, oval larva will hatch from each fertile egg. Amber in colour, turning later to rich brown, these larvæ or "seed ticks," as they are called, are somewhat lethargic at first, and spend their time slowly crawling over the empty egg shells from which they have emerged. After a few days, however, the larvæ become exceedingly active, especially in warm weather, and ascend the nearest vegetation, such as blades of grass, shrubs, etc.

As each female lays a large number of eggs, thousands of larvæ collect together, and their instinct of ascending plant stems and even sticks is a very important adaptation for increasing the "seed ticks" chances of reaching a host; in fact, larvæ remaining on the ground would have little or no chance of finding a suitable host. The larval ticks appear to select dried stems in preference to green ones, probably because, on them, there is less chance of being devoured by some passing beast. Once arrived at their vantage point, the ticks assume a "waiting attitude" by grasping the support with the third pair of legs, and waving the first, second, and fourth pairs in the air, so as to catch hold of some passing animal. When undisturbed, their legs are slowly brought down in contact with the support, but even a shadow passing over them will cause them to wave their legs violently in the air, as also will a gentle breeze blowing upon them. 

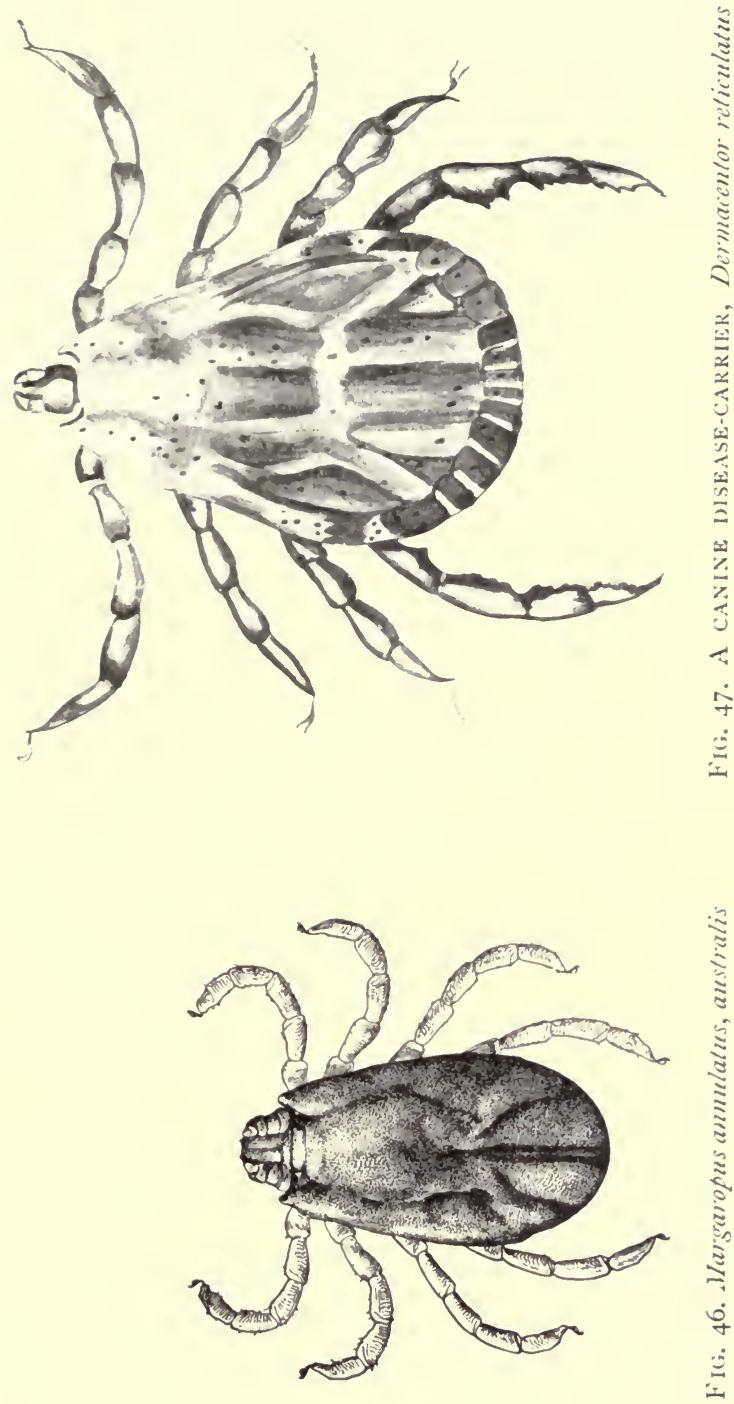

Ticks in a cage, when blown upon vigorously, fall to the ground; and perhaps this happens in nature, when a beast breathes upon the shrub on which the larval ticks have taken up their position, and, by falling to the ground, they avoid being eaten. It is probable therefore that ticks are informed of the presence of their hosts by shadows and by the slight breeze they make in walking along. It is absolutely essential for the larval tick to find a host, for failure to do so means eventual starvation, though a beneficent provision of nature enables them to live for nearly eight months without feeding, if necessary. During the whole of the time spent on the vegetable support, no food is taken by the larvæ, and, as a natural corollary, no growth takes place. When once the host is reached, the larva begins its parasitic life, and, becoming attached to dewlap, inside of thighs and flanks or escutcheon, it immediately starts to draw blood. In a few days the rich brown colour gives place to white, and in five to twelve days the skin is shed, and, instead of a six-legged larva, an eightlegged nymph continues to deplete the host of its blood. In another five to ten days a second moult takes place, and, as a result, the ticks attain sexual maturity.

The male has now attained his full development, but the female is only on the threshold of hers. The male is quite active, and moves from place to place over the host's skin to mate with the female ticks, which, in contradistinction to the males, are exceedingly sluggish, rarely moving from the point of attachment. After mating, the female increases enormously in size, and in from three to nine weeks after first attachment to the host as a seed tick, she becomes fully engorged and drops to the ground to oviposit and start the life-cycle over again.

If, during the life-cycle, any of the ticks become attached to cattle suffering from red water, the parasites causing this disease are taken up by the ticks, along with the blood on which they feed. Within the tick's body the fate 
of the parasite is unknown, though able scientists, aided by most powerful microscopes, have tried to probe the mystery. It is known, however, that these ticks, if transported to another host, can convey the germs of disease; and not only that, but the young generation, hatching from eggs laid by an infected mother, are themselves infective and can carry the disease. From what has been said it is clear that cattle and ticks are necessary, in order that red water may be perpetuated, and, so far as is known, no other animal can replace either of them; in fact, no animals but cattle, deer, and buffaloes can be infected with the disease.

As we have already mentioned, dogs, sheep, and horses all suffer from piroplasmosis, but the disease is peculiar to each species, just as piroplasmosis of cattle is peculiar to oxen and allied animals. For example, piroplasmosis in cattle cannot be transmitted to horses, or vice versa, though the disease can be, and is, easily transmitted from one ox to another, or from one horse to another. The piroplasma is pathogenic for one species of mammal only, and it requires two animals - a mammal and a tick-for its complete lifecycle, just as in the case of human malaria a human being and a mosquito are necessary for the completion of the malarial parasite's life-cycle. The tick Ixodes ricinus, which, by the way, obtains its name from the fact that the engorged female strongly resembles a castor-oil or Ricinus seed, not content with transmitting red water in cattle, is also, along with Dermacentor reticulatus (fig. 47) and Ixodes hexagonus, the European vector of the parasites causing piroplasmosis in dogs. In South Africa this disease is transmitted by the tick Homaphysalis leachi, and in India still another tick, Rhipicephalus sanguineus, carries on the evil work. A closely related tick, Rhipicephalus evertsi, is the African vector of piroplasmosis in horses, and another, by name Rhipicephalus bursa, transmits the ovine disease. In connection with piroplasmosis in sheep and 
the vector of it, Rhipicephalus bursa, it may be of interest to mention that, although in nearly all essential respects the progress of the blood parasite is exactly similar to that observed in bovine piroplasmosis and Margaropus annulcttus, there is one striking difference-the larval Margaropus, emerging from eggs laid by an infected mother, can at once transmit red water to another host; but in the case of Rhipicephalus bursa the larvæ do not possess this power, and the adult stage must be reached before disease transmission can be effected.

\section{MaL DE CADERAS}

The South American Equide, animals of the horse, mule, and ass tribe, are never attacked by nagana, for the simple reason that the flies transmitting the disease do not occur in the American continent. Another trypanosome disease, known as mal de caderas, is epizootic of asses and mules in South America. The trypanosome causing the discase was discovered in 1901 by Dr Elmassian at Asuncion in Paraguay, and was shortly afterwards named T'rypanosoma equinum. Mal de caderas, tumby-baba or tumby-a, as the disease is called in Paraguay and Argentina, or peste de caderas in Brazil, is widely distributed in South America ; presumably imported into the island of Morajo, it spread to the state of Matto Grosso, and at the present time it is known in Brazil, Bolivia, and Paraguay, and in the Argentine territories of Chaco, Formosa, and Misiones, and the provinces of Corruntes, Santiago del Estere, and Catamarca. Since 1860 the disease has caused such ravages in Matto Grosso that there are no horses and mules left; the natives are compelled to use cattle as draught animals, and young bulls are trained for riding purposes; in whatever region caderas occurs, however, it is most prevalent in marshy districts and after rain.

Although sheep, goats, dogs, rabbits, guinea pigs, rats, 
and poultry can all be artificially infected with caderas, naturally, it is almost exclusively a disease of horses; mules and asses are also attacked, but they are more resistant than horses, while cattle are said to be completely resistant. The incipient stages of the disease are accompanied by profuse weeping; later, the most pronounced symptom is that of progressive anæmia, accompanied with partial paralysis of the hind quarters. The disease is uniformly fatal. Although some of the symptoms of nagana and mal de caderas are similar, the two diseases are quite distinct; the morphological differences between Trypanosoma brucei, causing nagana, and Trypanosoma equinum, causing mal de caderas, are constant, and again, horses immunised against nagana are still susceptible to mal de caderas.

The actual vector of the disease is unknown, and, in this regard, it is of importance to remember that the transfer of the trypanosomes may be effected in two ways, either indirectly or directly. Indirect transfer of blood parasites takes place when malaria mosquitoes carry infection, and the process is indirect, because the parasites, perforce, pass through certain developmental stages within the body of the mosquito before they are capable of again producing the disease. Direct transference takes place where the fly simply carries the germs of disease on its mouth organs, and so infects the next host from which it takes a meal, and, in this respect, it is of interest to note that the house fly, which is incapable of biting, can transmit various trypanosomes, and, among them, those of mal de caderas, by alternately sucking sores on an infected and a healthy animal. The house fly, however, cannot be considered as the natural carrier of this disease, but rather must we look to the biting flies, Stomoxys calcitrans and Stomoxys nebulosa, known in the Argentine as " mosca brava" ; indeed, virulent mal de caderas trypanosomes have been found in the stomach of the former fly, after feeding on an infected 

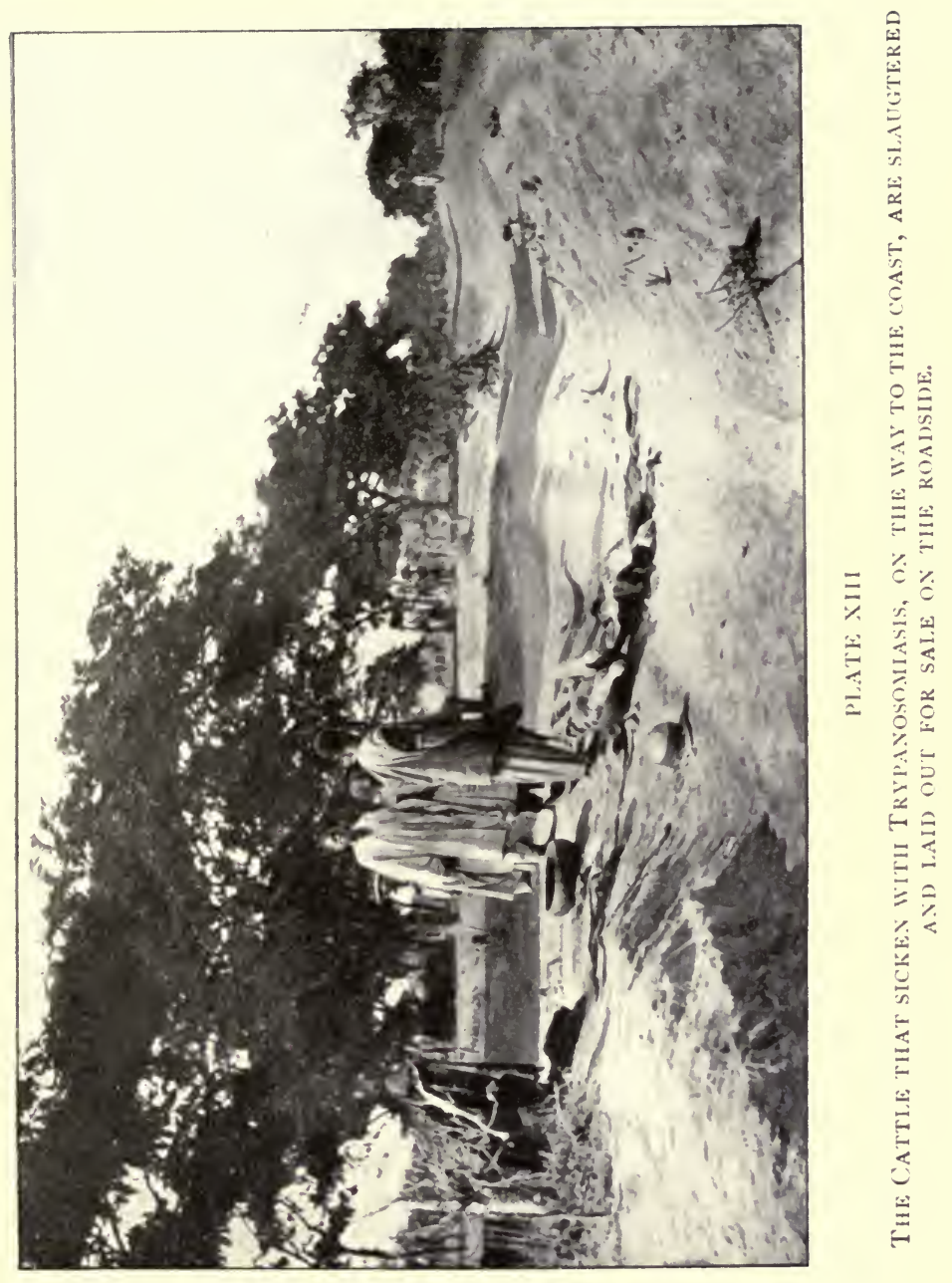
. 
animal. These flies closely resemble the house fly in appearance, but they are outdoor insects, and not "domestic" to the same extent as the house fly. Wherever horses and cattle occur, there the stable fly, for that is the popular name of Stomoxys calcitrans, may be found in plenty.

In general colour the stable fly is brownish, shot with green; the upper side of the thorax is marked with four longitudinal dark stripes, or, looked at in another way, there are three longitudinal light stripes; the central one, which runs down the middle of the thorax, is of a characteristic golden shade at its anterior or forward end. The abdomen is conspicuously spotted with brown. Instead of the sucking proboscis, so well known in the house fly, this insect is armed with an awl-like organ, adapted for piercing and sucking; often this organ projects forward horizontally and is then plainly seen on looking down upon the insect from above. Usually the female fly lays from fifty to seventy white eggs in decaying vegetable refuse, and from them emerge legless larvæ, very similar to those of the house fly, but more shiny and translucent, and differing, also, in the structure of the posterior spiracles. In a fortnight to three weeks the larvæ are full grown and pass to the pupal stage, which lasts from a little over a week to a fortnight, so that the whole life-cycle may be completed in from twenty-five to thirty-seven days.

The means of transmission is a subject of disagreement among the various authorities on the disease, but the identity of the reservoir for the virus is a point upon which there is unanimous agreement. It will be remembered that the big game of South Africa have been shown to act as reservoirs for the blood parasites causing sleeping sickness; in a precisely similar way, the capybara, Hydrochœerus capybara, a large South American rodent, acts as a natural reservoir for Trypanosoma equinum. These animals are common in the streams of the Chaco district of Argentina and Paraguay; at times they are overcome 
by some epidemic and lie along the banks of the streams in a dead or dying state. Whenever the Paraguayans find the dead capybaras, they know that an outbreak of mal de caderas is imminent. "There is a striking analogy between this mortality among the capybaras, which precedes outbreaks of caderas, and that among rats, which precedes epidemics of plague." In 1910 there was a great mortality among the capybaras of Paraguay, in which paralysis of the hind quarters was a well-marked symptom, and the caderas trypanosomes were found in their blood for the first time; as a rule, however, these rodents seem to suffer little inconvenience from the trypanosomes, but, needless to say, the fact that the parasites exist in their blood renders their proximity to horses, asses, and mules dangerous.

\section{Bot Flies}

The bot flies, or OEstrida, are of great importance, on account of their parasitic habits, their attacks being confined to vertebrates and, so far as is known, to mammals. The larvæ are fleshy, headless maggots, composed of twelve rings or segments, which are often spiny, to assist in locomotion. Between the first and second segments two anterior, external breathing organs may always be distinguished, as may two posterior ones, protected by horny plates, on the last segment. They all live parasitically in various parts of the bodies of mammals, such as the alimentary canal, the nasal passages and throat or the subcutaneous tissues. The adults are all heavy-bodied, generally hairy, and are characterised by their small eyes and antennæ, the latter being sunken into pits on the front of the head. Naturally, the habits differ in different species, but, in every case, the eggs are deposited on the animal host, although, in the sheep bot fly, living larvæ may take the place of eggs. All the adults frequent warm sunny spots, and most of them pass through this stage 

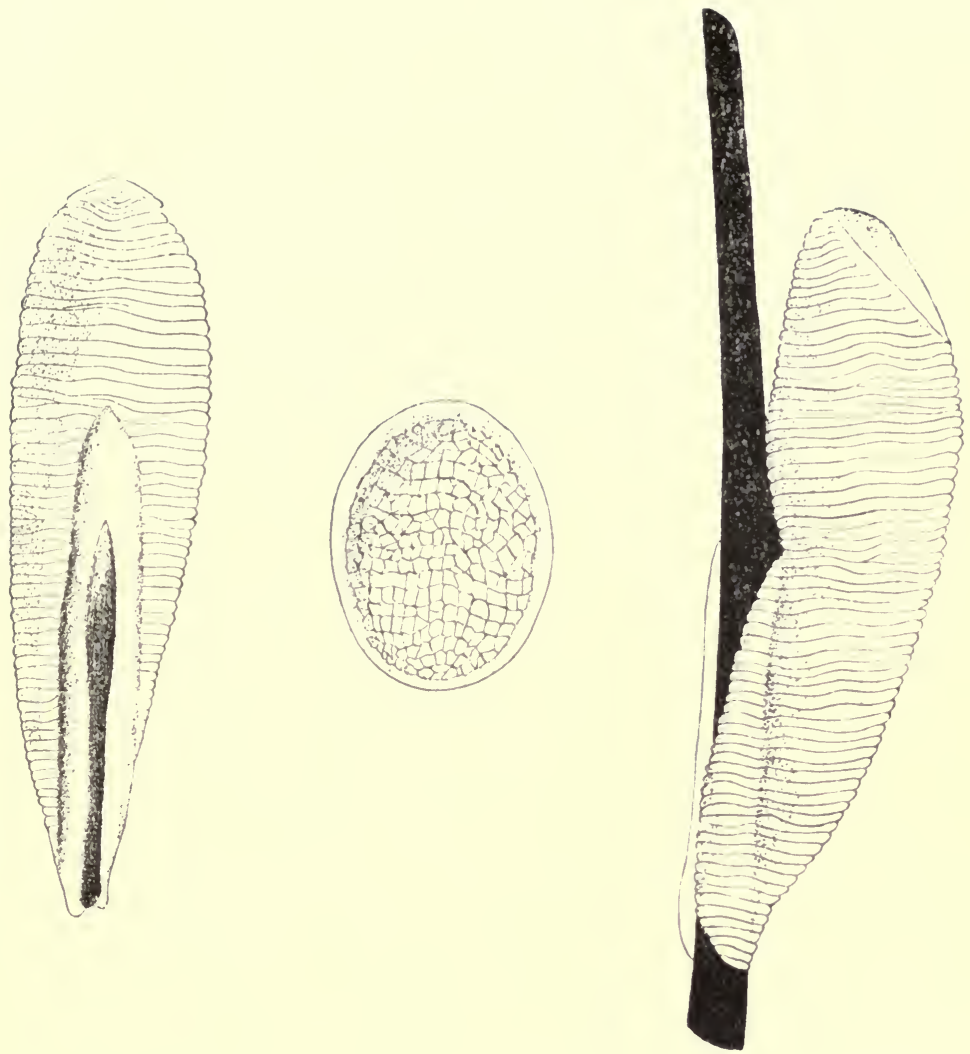

Fin. 48. Egais OF HORSE BOT FIY, Gastrophilus enui 

without food, their mouths being, for the most part, very rudimentary, and in some cases wanting.

The adult horse bot fly, Gastrophilus equi, is about three-quarters of an inch in length; its transparent wings are spotted, in such a way as to give them the appearance of being crossed by an irregular, transverse band. The hairy body is relieved from a uniform brown colour by the whitish front to the head and three rows of blackish spots on the abdomen, though the abdominal colouring is subject to considerable variation. In the male, the abdomen may be light brown, or even quite yellow, with very distinct brown spots; whilst, in the female, the brown segments may have a marginal series of yellow spots.

The female fly, when about to oviposit, hovers near a horse in a nearly vertical position. Then, with a sudden dart, it fixes almost instantaneously a single egg (fig. 48) to a hair, in some place where it may easily be reached by the horse's tongue, and then retreats a yard or two, where it hovers till another egg can be laid. By the repetition of this operation, at short intervals, a large number of eggs are laid. At first they are almost white, but they soon change to pale yellow, and are marked with a series of transverse, raised ridges. Each egg is about 1.25 millimetres long, obliquely truncate at the free end, and bluntly pointed at the other; it consists of two parts, the egg proper, and a pair of lips or valves, which close round the hair and give attachment. The presence of these eggs causes a considerable amount of irritation to the horse, which seeks relief by licking the afflicted parts. The eggs themselves are rarely removed, but the friction and moisture of the horse's tongue, essentials to hatching, cause the lid or operculum, covering the free end of each egg, to open, and the contained larva is carried into the horse's mouth. These larvæ are slender and worm-like, and so transparent that their internal organs may be plainly seen. Growth is rapid, and probably takes place at the expense of the mucus, secreted by 
the mouth and gullet. Soon, however, the maggot passes into its host's stomach and undergoes considerable change in appearance. Near its mouth are a number of hooks: with these it fixes itself firmly to the stomach wall. Its tail end becomes broadened, and the two spiracles, or respiratory organs, which appeared as two flap-like projections in the earlier stage, are drawn somewhat within the body and protected by a horny plate; at the same time the segments become spiny. The larvæ attain their full growth in the spring, and then they are from three-quarters to one inch in length. Their nutriment is derived from the tissues to which they are fixed, and also from the stomach contents, and in this respect it is of interest to note that they are generally found clustered round the opening of the stomach into the intestine, thereby, as it were, damming up the contents, with the object of obtaining more food. When fully grown, the bots relax their hold, pass through the intestine, and escape with the excrement, when they burrow into the ground to pupate. The pupal stage usually lasts from thirty to forty days, and the newly emerged fly at once proceeds to the business of providing another generation.

According to some authorities, the bots do little harm to a horse; others assert that they are very dangerous, by causing great irritation in the stomach and intestines, by absorbing food material, which could be more profitably employed, and by causing an obstruction to the free passage of food along the alimentary canal. Harmful or not, the fact remains that nine-tenths of all horses pastured in the summer become attacked, and the proportion of those in work is somewhat smaller.

The ox warble flies, Hypoderma bovis (fig. 49) and $H y$ poderma lineata, are the cause of extensive loss to stockowners in this country, whilst the latter is a well-known pest in America. The loss in damaged hides alone, in Manchester, Newcastle, and Nottingham, in a single year, was estimated at $£ 33,715$; add to this the loss to the butcher 
on meat that is rendered unfit for human consumption, or at any rate much depreciated in value, and to the dairy farmer in the reduced milk yield of afflicted animals, and we obtain, in England alone, an aggregate loss, caused by warble flies, that has been variously estimated at from $£ 2,000,000$ to

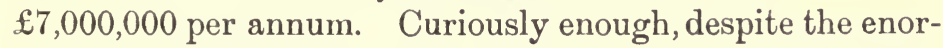
mous loss which these flies entail, there are many points in their life-histories that require elucidation.

Vallisnieri, in 1710 , appears to have been the first observer of warble flies. Little is known of the adult, but its long, elliptical, flattened eggs are white in colour, except for a brown appendage, which serves the purpose of attachment to the hair of the host. Horses, asses, and occasionally men have been attacked. The whitish, transparent larvæ are comprised of twelve segments, and possess a pair of very minute, crescent-shaped mouth parts. They are armed with sixteen short, transverse bands of exceedingly minute prickles, arranged in alternate narrow and broad stripes. At a later stage, in Hypoderma lineata at any rate, the larvæ become quite smooth, except for a few prickles at either extremity, and the mouth parts become more conspicuous. As they become older, they lose their worm-like appearance and become spindle-shaped, with an extensive armature of prickles on the ventral surface and a pair of short, horny, blunt, projecting tubes or spiracles at the hinder end. During the last stage of their development the maggots become oval, compressed, and warty. Their skins are much thickened, and they develop a powerful coat of subcutaneous muscles. The armature of prickles becomes more formidable than ever, and the hard tips to the spiracles, at the hinder end of the body, are replaced by a pair of kidney-shaped structures, sunk in oval depressions.

At one time it was believed that the eggs were always attached to the backs of cattle, on either side of the spine, and that the larvæ penetrated the skin soon after they emerged. Another belief was that the mother fly herself 
pierced the host skin with her ovipositor, and so laid her eggs hypodermically. In reality, the eggs are attached to the hairs of the legs, often at a point just above the hoof, a fact which has earned these insects the name of "heel fly" in America. This probably explains why cattle so frequently stand with their legs in water during the fly season, and so avoid the attentions of this baneful insect. It is thought that, as in the case of horses attacked by the horse bot fly, so cattle lick the eggs on their hair and the larvæ are carried to their mouths, where, being strongly spined, they bore their way into the soft tissues of the throat. Once there, they reach the second or smooth stage and wander through the connective tissues of the host till they arrive just below the skin of the back. At this point a moult takes place; they once more become spiny and bore a hole through the skin, in order to obtain air, and, by so doing, absolutely ruin the hide. ${ }^{1}$

During the last stage the maggot lies head downwards in the subcutaneous cyst, with its spiracles pointing upwards to the air, its presence made evident by the raised lumps or warbles which decorate its host. This is the period of growth, and the maggot waxes fat on the products of inflammation which its presence causes. Lest there be any diminution in the supply of nutriment, the prickles are, from time to time, raised and depressed into the abscess, and the irritation which this entails ensures a copious supply of pus. When fully fed, the larvæ are rather more than an inch in length, and of a yellowish-white colour. They emerge from the warbles, usually in the early morning, and fall to the ground, which they may or may not enter. In either event, they contract and become nearly black in colour as they change into puparia, whence, in from three to six weeks, the flies emerge. The adults of

1 Professor Carpenter has just announced the results of some experiments, which show that the newly emerged larvæ bore directly into the host's skin. 


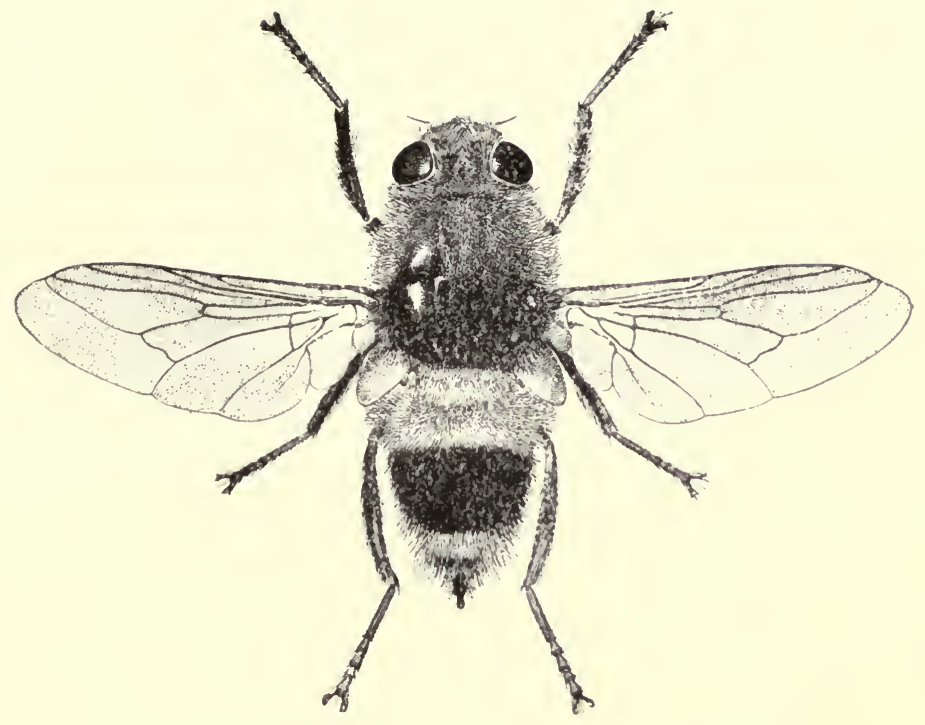

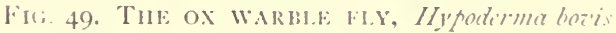

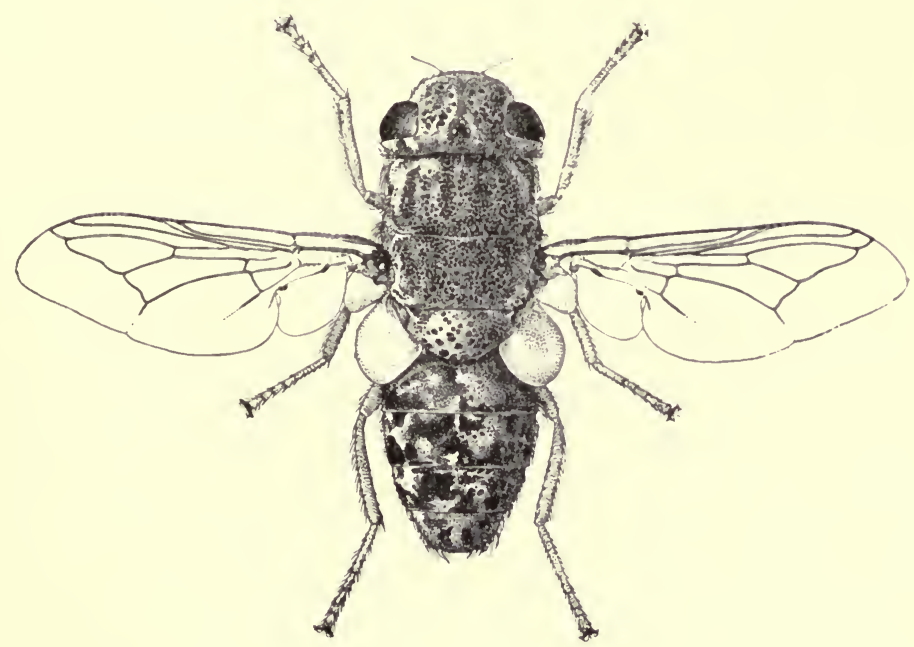

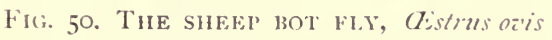



lineata are not unlike honey bees in general appearance, half an inch long, and of a general black colour, furnished with yellowish, reddish, and black hairs; bovis is much larger, and is banded with yellow and black.

Another EEstrid which deserves mention, on account of its peculiar, if repulsive habits, is the emasculating bot fly, Cuterebra emasculator, of North America. The life-history of this fly is but little known. Exactly when and where the eggs are laid is a mystery, but the larvæ develop within the scrotum of grey squirrels, red squirrels, and chipmunks, and, in doing so, destroy the testicles, hence the popular name of the fly. The larvæ, having attained full development during the months of August to October, escape to the ground to pupate, and remain in the pupal stage till July of the following year. The life-cycle, therefore, takes at least two years to complete. The damage done by this fly appears to be somewhat local, but, should it be allowed to spread and increase, the harm done to the fur trade might, conceivably, be considerable.

The sheep bot fly, Estrus ovis (fig. 50), popularly named the nostril fly, has been known for centuries; in fact, it was mentioned by the Greek physician Alexandra Trallian in the year 560. The fly itself resembles a large house fly in appearance. The upper parts of its head and thorax are dull yellow, though they appear brown, owing to being covered with little round spots. The abdomen of five segments is velvety and variegated with dark brown and straw colour above, whilst the underside has a dark spot in the middle of each segment, in place of the variegation. The head, which is white below, is furnished with very small antennæ, purplish-brown eyes, and three small eyelets. There is no mouth, and the only instinct of the adult fly seems to be to continue its kind. It is very lazy, except when attempting to deposit eggs, which it does very soon after fertilisation has taken place.

The characteristic, curved eggs are laid in clusters of 
twelve to eighteen, on the nostrils of sheep, or sometimes having developed within the body of the fly, living larvæ, to the number of five or seven, are deposited in the same position. The cream-coloured maggots at once proceed to work their way up the nostrils and nasal passages, causing intense irritation during their travels, till they reach the frontal sinuses, cavities lying between and slightly above the eyes. These cavities are lined with a membrane, and mucus is always present in them. To the membrane the maggots attach themselves by minute hooks placed on each side of their heads; on the mucus they feed. When fully grown, the larvæ change in colour, becoming darker towards the tail end, so that they show all shades of colouring, from white on the first two or three segments to dark brown on the last segments, whilst a number of minute brown spines, all pointing posteriorly, assist in locomotion. When ready to pupate the maggots pass down the sheep's nasal passages, being materially aided by violent sneezing on the part of their host, and fall to the ground, where they quickly bury themselves; and in forty-eight hours they contract to half their original size, at the same time becoming smooth, hard, and black. The pupal stage lasts from forty to fifty days.

\section{Some more Pests of Sheep}

The nostril fly is not the only British dipterous parasite of the sheep; the green-bottle fly or sheep maggot, Lucilia sericata, and the misnamed sheep tick or ked, Melophagus ovinus, are both of considerable importance from the stock-keeper's point of view. Lucilia sericata is quite common in this country, whilst in Holland it often becomes so numerous as to be a very serious pest. During the warmer months of the year the female lays about five hundred eggs, fastening them in groups of fifty or so to the wool of the host, selecting, as a rule, sheep with 
greasy or soiled fleeces. Lambs, or enfeebled, old, or unhealthy sheep are usually chosen for attack. The larvæ bear a considerable superficial resemblance to those of the house fly; they are pointed at the anterior or head end, and broad at the hinder end, where the spiracles are situated. They are provided with somewhat formidable mouth hooks, with which to tear the flesh of their hosts. In a fortnight the maggots, being full grown and about half an inch in length, change into brown, barrel-shaped pupæ, so common amongst dipterous insects. As the lifecycle is rapidly completed, several broods may occur in one season, and, as sheep once attacked are more liable to future infestation, it follows that considerable harm may be and often is done by these flies.

The sheep maggot flies are, at the present time, the greatest menace to the sheep-raising and wool industry of Australia. The European green-bottle fly, though by no means a recent importation, has, till recently, confined its attentions to dead meat, but now is making its presence felt in no uncertain manner. 'Two blow flies, Calliphora oceania and Calliphora villosa, have, in the past, done considerable damage, but are being rapidly superseded by the metallic blue blow fly, Calliphora rufifacies, which affords an excellent example of a fly, once harmless, taking to evil habits. In 1912, damage, estimated at a million sterling, was done by these flies alone in New South Wales, and as much again in Queensland. The situation became so serious that a sheep maggot-fly experiment station was founded, with the object of working out the life-histories of the insects, and, if possible, of finding a means of eradication.

Calliphora rufifacies, which has long been known to the squatters as the hairy maggot fly, is about one-third of an inch in length, and of a general, deep metallic blue colour, sometimes shading into green on the abdomen; the legs are black, the wings transparent, and the veins black. The space between the eyes is black, with the rest of the 
head dull yellow, but clothed with fine white down. The bristles covering head, thorax, and abdomen are black, with very few upon the dorsal surface of the thorax. The under surface of the fly is clothed with finer downy hairs, which form a grey coat on the thorax and first segment of the abdomen. The maggot, which, when full grown, is fiveeighths of an inch in length, is dull light brown to dirty white; the dorsal surface is the darker, on account of being furnished with a number of minute black spines, arranged in regular bands and patches; there are bands of spines also on the ventral surface The whole larval skin is finely shagreened; the small head is armed with a pair of black hook jaws. The spiracles or breathing pores are on the eighth segment, and the whole maggot is covered with a fringe of fleshy tubercles, hence the popular name of hairy maggot. The pupa is dark brown or even almost black, slightly flattened, and the larval tubercles, which are aborted, form an irregular coat of blunt spines. Often these pupæ are found in the sheep's wool, but, as a rule, pupation takes place in the ground in this species, as with other closely related species.

There is some hope that the hairy maggot fly may not assume such formidable proportions as to get beyond control, for, quite recently, a minute, dull metallic green chalcid, one-twelfth of an inch in length, has been found actively engaged in parasitising the pupæ of this fly. As this chalcid is a native hymenopteron and has been found to increase enormously under artificial conditions, there is every reason to hope that the Australian entomologists will be able to secure a sufficient supply of these useful insects to keep the hairy maggot in check.

The sheep ked (fig. 51), although frequently termed a tick, has no relationship with the true ticks, and, what is more, bears no resemblance to them. Although a fly, like the green bottle, it is more truly parasitic, being wingless, and provided with strong claws, which enable it to cling 
to the wool of its host. Of a general rust-brown colour, with a grey-brown, irregularly spotted abdomen, showing no distinct segmentation, and thickly covered with hair, these insects present a strikingly curious appearance. The female is about five millimetres in length, and the male is smaller, rarely exceeding three millimetres. The lifehistory of the ked is remarkable in many ways, not the least curious fact being that it spends every stage, larva, pupa, and adult, on the host. The female gives birth to four or five creamy, ovoid, shining, slightly flattened grubs ; no egg is laid, hatching and full larval development takes place in the body of the mother fly. The larvæ are fixed to the wool of their host, and almost immediately transform into oval, glistening, copper-coloured pupæ, which rapidly turn almost black and resemble apple pips, though the resemblance is often masked by a sticky white incrustation by which they are fixed to the wool. Keds are provided with sucking mouths which enable them to absorb blood from their host; it is also supposed that they obtain a considerable amount of nutriment from the grease with which sheep's wool is always richly charged. Although these parasites cause considerable annoyance to sheep and goats, when present in large numbers, it is only to lambs that they are likely to cause death.

Several other flies of the family Hippoboscide, to which the ked belongs, are parasitic on domestic animals. On the horse is Hippobosca equina, and, in Brazil, Hippobosca nigra; the former also attacks the ass, mule, dog, cattle, and swine; its varied hosts are probably accounted for by the fact that, unlike the ked, it is winged and is, accordingly, not so strictly parasitic in habit. The camel, in Egypt, has a dipterous parasite in the shape of Hippobosca camelina, whilst Hippobosca rufipes, Hippobosca maculata, and Hippobosca taurina are parasitic on cattle. Maculata, though a native of India, was introduced into South Africa during the Boer War, where rufipes is common; both of 
them are suspected of transmitting a bovine trypanosomiasis, known as galziekte or gall sickness, the pathogenic agent of which is Trypanosoma theileri. Three closely related flies, Lynchia maura, Lynchia capensis, and Ornithomyia avicularia, are parasitic on the pigeon, and, of these, maura, in Algeria, where it is common, transmits a pathogenic blood parasite, known as Homoproteus columbce.

Biting lice, Trichodectes ovis, are common parasites of sheep. Like the keds, they are truly parasitic, and spend their whole existence on their host. Their feet are remarkably well adapted for their mode of living, being armed with powerful claws, which enable their owners to obtain a firm grasp of the wool in which they hide. Their food consists of skin secretions and possibly wool, for though possessed of biting mouths, they lack all provision for sucking blood, thereby differing from the true blood-sucking lice.

The most serious parasitic disease of sheep, known as scab, is caused, not by an insect, but a mite; it is also the oldest known of all diseases attacking this animal. The disease-causing mite is known as Psoroptes communis, and varieties of the same species cause scab in horses, cattle, goats, and rabbits. So similar are these varieties that it is a matter of exceeding difficulty to identify them; but, as the scab mite of one host will not cause scab on a dissimilar host, there is no doubt that the varieties are distinct, and they are known as Psoroptes communis, var. ovis, var. equi (fig. 52), var. bovis, var. caproe or var. cuniculi, according to whether they attack sheep, horse, ox, goat, or rabbit.

Though one of the largest of these mites, the female sheep scab mite is only about one-fortieth of an inch long by one-sixtieth of an inch broad, whilst the male is a little smaller; they are just visible to the naked eye. Apart from a difference in size, the sexes may be distinguished by the fact that in the male only there are a pair of 


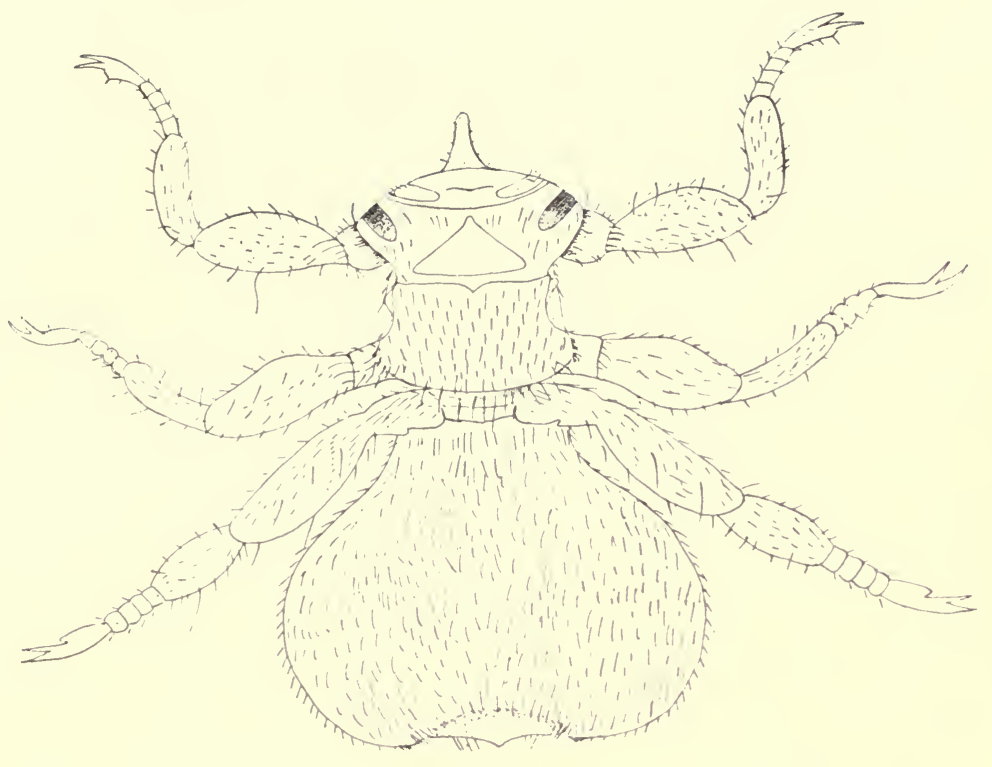

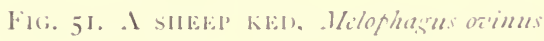

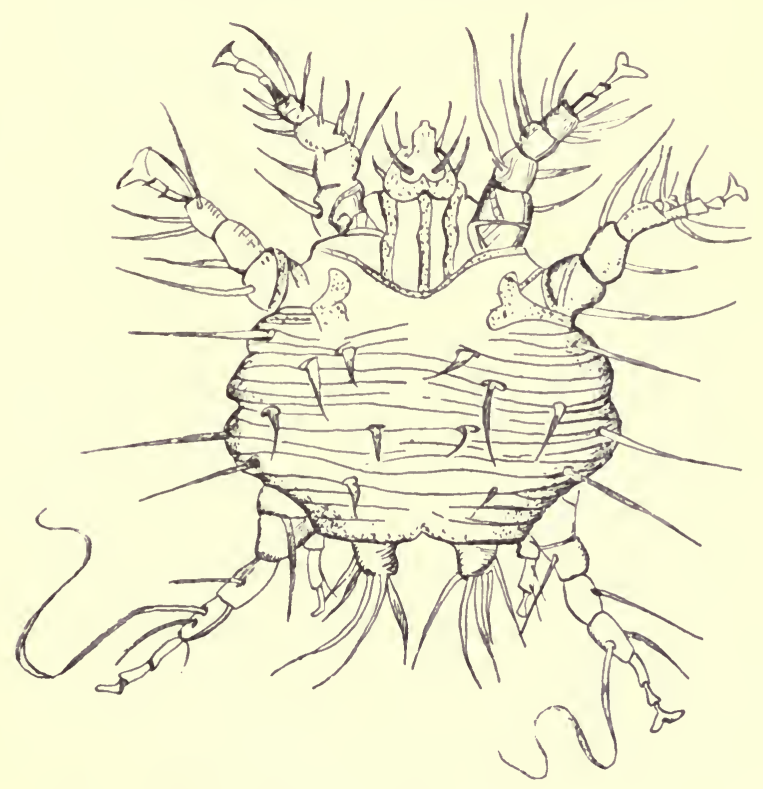

Fir. 52. SCAB mITl, Fsoroptes communis VAR. equi 

posterior processes, each furnished with stiff bristles. Again, the last pair of legs in the male are very short and without sucker feet, whereas in the female it is the third pair of legs that are without sucker feet, and in their place are two very long curved bristles. Wherever the host is thickly covered with wool, on back, shoulders, sides, and rump, there the mites congregate most thickly. With their barbed mouth organs they pierce the skin of their host, and, by working these barbs up and down they cause intense irritation and a flow of blood and matter; this hardens to form a scab, beneath which the mites hide, hence their popular name, scab mites. The damage does not end here, for infected sheep have soiled and matted wool which finally falls off in large patches. The disease is exceedingly contagious, both directly, from sheep to sheep, and indirectly, from fallen wool, rubbing posts, etc.; in fact, healthy sheep have become infected in places where no sheep have been kept for as long as twentyfour months, though how the mites retain their vitality during this period is not known. Birds probably aid in spreading the disease; they constantly settle on the backs of scabby sheep, and, passing thence to healthy animals, they may carry on their feet a tag of wool or even a scab.

The female mite lays about a score of eggs, either near the roots of the host's wool or actually on the skin, and after doing so she dies. From these eggs six-legged larvæ arise, and after moulting they become mature. The duration of the egg and larval stages varies considerably under varying conditions, but, as a rule, the eggs hatch in about six days, and, on the third day of larval life, a moult may occur, when the larva obtains its fourth pair of legs and becomes adult; pairing then takes place, followed by two moults and oviposition. So that the average period for a complete life-cycle is about fifteen days, and, of ten females and five males, "in three months' time the sixth generation 
would appear to consist of about one million females and five hundred thousand males."

British sheep are often attacked by the castor-bean tick, Ixodes ricinus, which is notorious as being the vector of piroplasmosis of cattle and dogs; whilst in Roumania, Italy, Turkey, and France, the tick, Rhipicephalus bursa, transmits ovine piroplasmosis or carceag; and in South Africa the bont or variegated tick, Amblyomma hebrceum, transmits a disease of sheep and goats known as "heartwater."

\section{Some Enemies of Poultry}

The external parasites of domestic fowls belong to many orders and are comprised of various species. In America, for instance, the domestic hen is known to be infested by eighteen species of mites, eight species of bird lice, two species of fleas, and one species each of bugs, ticks, and flies. Add to this, the bird lice found on other domestic fowls, which comprise five species on the goose, four each on the turkey, duck, and pea-fowl, three on the guinea-fowl, and seven on the pigeon, and we get a considerable number.

One of the most striking facts concerning the bird lice, or Mallophaga, as they are called, is that similar species occur on domestic fowls of the Old and New World. Seeing that these insects cannot fly, and can only pass from one host to another when in actual contact, the fact is the more remarkable. Various explanations have been enunciated to account for this phenomenon; according to one author, "the parasitic species have persisted unchanged from the common ancestor of two or more distinct but closely allied bird species." In other words, these species of Mallophaga existed on the ancestors of their bird hosts, and have persisted ever since, without change, although the hosts may have become modified into different species. If this explanation be the correct one, it is easily accounted for by the fact that although the host may change, the 
environment of feathers, skin, and temperature, in which the lice dwell, remains unchanged.

Although the Mallophaga are provided with biting mouths, they do not, according to most observers, suck blood, but sustain themselves on skin scales and bits of feathers. One species, however, lives inside the pouch of the Californian brown pelican, clinging to the pouch walls by its mandibles. What form of nutriment is taken up, in this case, is a debatable point. All the bird lice are provided with sharp claws, and, as they are constantly on the move, they set up irritation in the skin of their host and have an injurious effect on its general health. Sometimes the infestation may be serious enough to set up pruritis, an intense skin irritation which is exceedingly weakening, and, in laying hens, effectually reduces egg production. Infested chicks become stunted and fail to make normal growth, whilst failures in hatching are of frequent occurrence, because the sitting hen is rendered so restless that she breaks many of her eggs. Despite this catalogue of woes likely to befall the louse-infested hen, it must be clearly understood that the parasites are not disease-carriers; the trouble which follows in their wake is purely superficial, though none the less unpleasant for being so.

Though the Mallophaga are known as bird lice, some of them occur on mammals. They are hard, flattened, simple-eyed insects, with strong legs, of which the first two are short, and, after the manner of hands, are used to convey food to the mouth. The female louse deposits its eggs on the hairs and feathers of the host, and the young insects, except for their relatively large heads, resemble their parents, for they do not undergo complete metamorphosis, but grow by a series of moults into adults. The death of the host is followed by the death of its parasites, though they often attempt to reach another host, as is shown by the fact that they crawl towards the head. Being feather-eaters and not blood-suckers, it is 
curious that they should show such anxiety to leave a dead bird, and it is probably due to the falling temperature of the host's body.

Aquatic birds, contrary to expectation, are not free from Mallophaga, and, more remarkable still, their lice are not specially modified to enable them to withstand immersion in water. The explanation for this apparent lapse of nature is probably that sufficient air always remains enitrapped between the feathers of the host to enable them to exist in this unaccustomed element.

Of the other parasites attacking poultry, we need only mention the red mite, Dermanyssus gallince; the chickenitch mite, Sarcoptes nutans; and the fowl tick, Argas persicus. Of these, so far as is known, only the latter transmits disease, but the others do considerable mechanical damage by sucking blood, etc.

Red mites are about one-twenty-fifth of an inch in length, and, except when red after engorgement with blood, they are of a light grey colour. In habit they are particularly stealthy; very active and also voracious, they hide by day, issuing at night to feed on their hosts, and returning to shelter after repletion. These mites can hardly be termed true parasites-semi-parasites is a better term-for their eggs are laid and hatched in their hiding places and not on the host. Their attacks lead to loss of flesh and general want of tone in chickens of all ages, whilst in those newly hatched they cause a mortality often as high as ninety per cent., and their not infrequent attacks on man result in an eczematous skin disease.

The chicken-itch mite, Sarcoptes nutans, causes a serious and common disease in its host. Making its attack between the scales of legs and feet of the chicken, it gives them a tendency to stand up on end and separate, whilst between them a chalky secretion is formed. Beneath these scales and excretions the mites live and breed.

Argas persicus (fig. 53) is a brownish-red tick about eight 


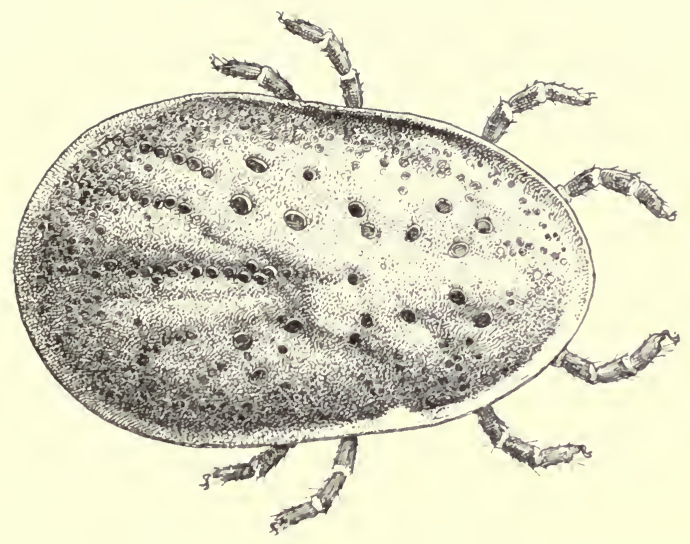

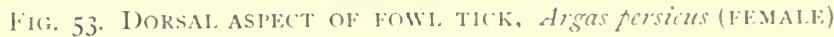

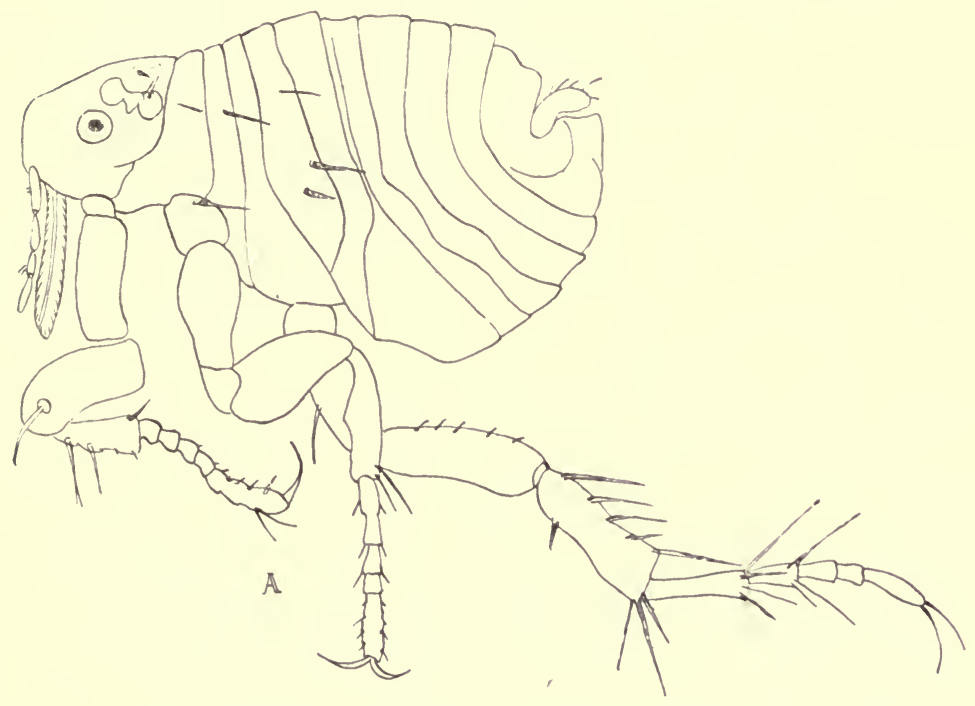

Fig. 54. The hen fleA, Sarcopsylla gallinacea, (MALE) 

millimetres long in the female, and half the size in the male. Its body is pitted in rows and irregularly. In 1903 Marchoux and Salimbini, in Brazil, discovered that the tick, by its bite, transmitted a blood parasite, Spirochata gallinarum, to poultry. These spirochætes, like the organisms causing human tick fever, are spiral, threadlike structures which swim about rapidly in the blood; so rapidly, in fact, that it is difficult to observe them. To geese they are especially fatal, and hardly less so to ducks and guinea-fowls; doves and sparrows are less susceptible, and in pigeons, after they have been bitten by an infected tick, there is no illness, and no spirochætes can be found in the blood. The incubation period is usually four to nine days, and it has been shown that an infective tick ean remain so for five months after its last infective meal. Ornithodorus moubata, the vector of human relapsing fever, can also transmit spirochætosis in poultry. The disease is characterised by diarrhœe, anæmia, pallor of the comb, and such weakness that the infected fowl lies with its head on the ground.

The eggs are laid in the hiding places of the ticks, usually some crevice in the fowl house, and in three weeks the six-legged larva hatches, and at once attaches to a host for the purpose of feeding, and, at the next moult, attains the flattened form typical of the adult, and so well adapted for hiding in narrow cracks, beneath boards, etc.

\section{The Hen Flea}

The hen flea, Sarcopsylla gallinacea (fig. 54), is very much smaller than the human flea, and of a reddish-brown colour. Discovered in Ceylon, it has since been encountered in Turke tan, German East Africa, Cameroons, Cape of Good Hope, Italy, Madagascar, and the Southern States of America. Though its usual hosts are chickens and ducks, it has been known to attack horses, rats, and children. Its 
chief point of interest lies in the fact that it is more truly parasitic than other fleas, with the exception of the jigger flea. It does not bury itself beneath the host skin like the latter species, but it inserts its mouth organs deeply and firmly into the host and there remains affixed. The neck and head, especially the region of the eyes, are the favourite points of attack, and the results are swellings and ulcers, which often result in death to the host.

\section{AIR-SaC Mites}

As long ago as 1858, a German scientist named Garlach, while dissecting some chickens, by chance examined their respiratory organs, and there discovered some whitish, rounded mites, so small as to be only just visible to the naked eye. Our excuse for mentioning these minute parasites is not that they are particularly common, or even specially injurious to their hosts, but because in habit they are dissimilar to other closely related species, which are all external parasites. The creatures, which have been named air-sac mites, and are known to science as Cytodites nudus (fig. 55), normally inhabit the air passages of gallinaceous birds, where they may cause inflammation of the lungs: at times they occur in other organs, and have even been found in the heart, where they set up endocarditis.

Though closely related to the mange mites, Sarcoptes species-in fact Cytodites was at first believed to be an internal form of these mites-it differs from them in many important characters. The mange mites have mouths adapted to cut and tear flesh and so enable them to burrow below the skin: the air-sac mites have tubular sucking mouths, quite incapable of biting or piercingflesh. Although they are unable to rupture even the delicate mucous membranes on which they live, their constant movements over these surfaces set up a considerable amount of irritation, despite the fact that their feet take the form of suckers and are not provided with claws. 
The affection caused by these parasites is a contagious disease, and, once introduced on a farm, will rapidly spread from bird to bird. It has never been shown how and when these mites leave the air sacs, but it has been abundantly proved that they rapidly dry up and die when exposed to the air; they probably gain access to the avian body by entering the nostrils and following the trachea and bronchial tubes till they reach the air sacs.

\section{A Canine Disease}

Filariæ do not confine their attacks to human beings, but certain species are also internal parasites of other mammals and birds. One of the most widely distributed of these parasites is Filaria immitis, the "cruel filaria" of the dog, which occurs in various swampy parts of the world and even of Europe. Sporting dogs, probably on account of their more frequent exposure, suffer more frequently than house dogs.

As in the case of Filaria bancrofti, the causative organism of elephantiasis, the adult parasitic worms occur in the blood vessels; but, unlike bancrofti, the larvæ may be found in the peripheral circulation by day, though they are far more numerous by night. The larvæ collect, for the most part, in the right ventricle of the heart, where at times as many as fifty may be coiled together in a bundle. Weakness and shortness of breath are the result, and violent exercise may cause temporary insensibility, whilst the attacks usually end fatally. Anopheles maculipennis and other mosquitoes of the genera Anopheles and Culex transmit the parasites from host to host. Within the kidneys of the mosquito development takes place, and in about twelve days they pass thence from the insect's mouth parts, and the infection is ready to be passed to another canine host. 


\section{An Internal Parasite of Swine}

A curious disease of swine must be mentioned en passant, not because an insect is the actual cause of the disease, or even the carrier of infection, in the usually accepted sense, but because the manner in which the organism producing the disease enters the bodies of the swine is so peculiar as to merit attention. The disease in question is common in France towards the end of winter, and it is also well known in Germany, Austria, Sicily, Australia, and the United States. Affected swine become uneasy and show loss of appetite; sometimes convulsions ensue, and, to young animals at any rate, the attacks are often fatal. Although swine are usually affected, wild boar, and even man, may fall victims.

The cause of the disease is a parasitic worm, known as Giganthorhynchus hirundaceus, whitish in colour and cylindrical in contour, with a retractile head provided with recurved hooks (see A, B, fig. 56). By means of these hooks it becomes affixed to the membrane lining the intestine of its host, much in the same way as the horse bot-fly larva is attached to the stomach of the horse, and the points of attachment appear as nodules on the exterior wall of the intestine. Into the further progress in the life of the worm and the serious damage it causes it is beyond our sphere to enter; we are only concerned with the part played by insects in the spread of the parasite.

In course of time the worm produces eggs within the intestine of its host, and these pass to the ground with its excrement; there some of the eggs may be swallowed, either by the larvæ of the common cockchafer (Melolontha vulgaris) (see $\mathrm{C}$, fig. 56), or of the rose beetle (Cetonia aurata). Within these intermediate hosts the embryo worms can exist for some time; but such larvæ are eagerly sought by swine, and the eating of them serves to complete the parasitic life-cycle, for, once within the mammalian 


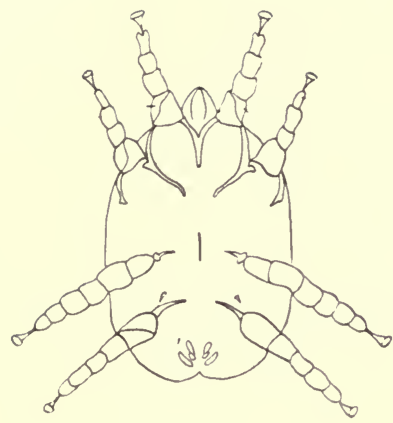

A

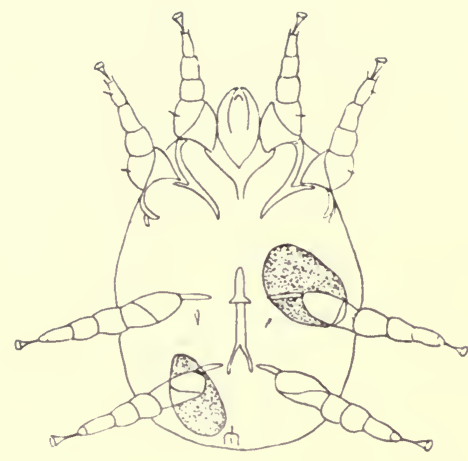

B

Fili. 55. AIR side mTEs, Cyodites munus:

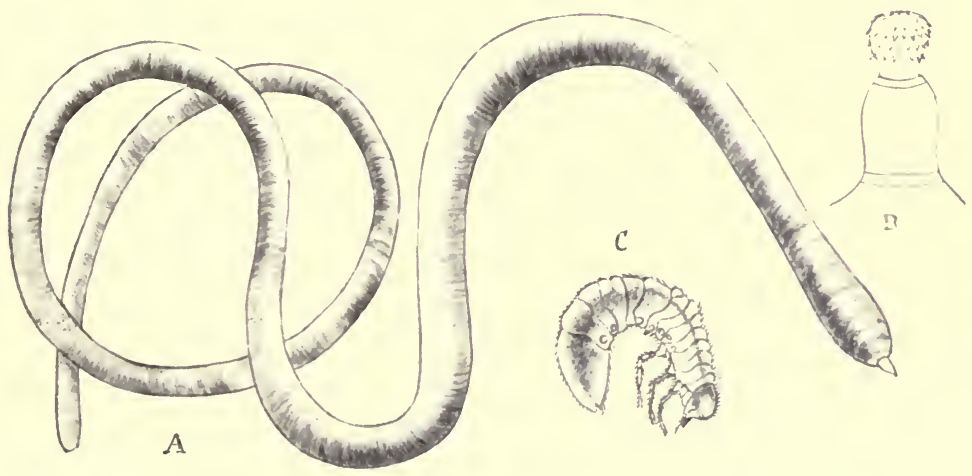

FIn. 56. a. Giganthorhynihus hirnndaces; b. ITS HEAI); $c$. LARVA OF COCKCHAFER 
(2)

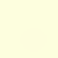

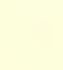


intestine, the embryos become adult. In the United States the cockchafer is unknown, so there the larvæ of a beetle of another genus, Lachnosterna arctuata, acts as intermediate host.

Giganthorhynchus is occasionally found in man, in South Russia, where cockchafers are eaten raw.

\section{Two Diseases of Useful Insects}

In the year 1851 the most important silkworm-rearing centres in France were threatened with almost total annihilation, on account of a mysterious disease of the caterpillars which had made its appearance in the Department of Vaucluse six years previously. In 1856, the total production of silk, in France, had been reduced by seventyfive per cent., and severe losses were also experienced in Italy. In the latter country the disease was called "gattina," and in France it was named "pébrine," from a local name for pepper, because spots resembling pepper grains were often found upon the infected caterpillars, though later researches showed that these growths had nothing to do with the disease. Balbiani discovered that "pébrine" was a parasitic disease, and Pasteur it was who made some startling scientific discoveries, which saved the silk-raising industry from utter ruin.

The disease is eaused by minute organisms, Mixosporidia, to which the name of Nosema bombycis has been given. These organisms are somewhat peculiar, in that they attack practically every organ of the infected insect, even to its silk glands, and they vary in form, according to the organs in which they have taken up their position. Young caterpillars, attacked by "pébrine," become inert, and, in many cases, die in numbers before pupation; those that survive the larval stage spin small cocoons, deficient in silk, and sometimes die in the pupal stage. Those that are destined to survive to the adult stage mate and produce eggs that are infected, so that the next generation comes into 
existence in a diseased condition. This, however, is not the only way in which "pébrine" is spread-the excrement of infected larvæ is charged with parasitic spores, and, falling among the mulberry leaves on which healthy larvæ are feeding, these spores become scattered, and they are eventually devoured, thus setting up the disease in new hosts.

With this double method of infection it is plain to see that hundreds of thousands of caterpillars may be infected in a short time. The fact that the eggs themselves may be contaminated accounts for the rapid spread of the disease to districts where it was previously unknown, for it is in the egg stage that these insects are sold commercially and conveyed from place to place. Thanks to Pasteur's efforts, drastic measures were enforced, and "pébrine" was practically banished. Of remedies there were none, so the parent silkworm moths were sorted out and put into separate breeding cages, a male and female in each. After oviposition, the parents were killed, if not already dead, and their bodies were macerated and examined for Nosema bombycis; if the parasites were found, the eggs were all destroyed, only eggs from healthy parents being allowed to hatch. Great credit is due to the proprietors of the silkworm farms for so faithfully carrying out this crusade at enormous expense to themselves, and, although "pébrine" is now mainly of historical interest, it merits a place of honour in every book on economic entomology, if only as an example of what can be done in the way of stamping out disease, if the findings of scientists are efficiently discharged by those who alone can make them effective-farmers and gardeners.

An allied disease, popularly known as the "Isle of Wight bee disease," because it made its first appearance in that island in 1904, has caused serious losses to bee-keepers in this country. The causative agent is a parasite, Nosema apis. Both parasite and disease have many points in common with "pébrine," though hereditary infection is unknown. 


\section{V \\ BENEFICIAL INSECTS}

\section{BEES}

There are few people who would, or could, omit the bees from any list of useful insects, but most people would so classify them on account of their being manufacturers of honey. Bee culture has become such a specialised branch of husbandry that details can hardly be given in a book of this nature; besides, it is not on account of the honey they provide that these insects are most useful to man. The market gardener, fruit-grower, agriculturist or florist is absolutely dependent on insects or wind for his crops; the former he can regulate to a certain extent, the latter is beyond his control. In the production of a harvest, insects, and especially bees, dwarf all the modern implements of husbandry into utter insignificance, and it is this aspect of bee utility that we shall consider here. To the farmer the work of the bee makes no great appeal, for his cereals are fertilised by wind; but stone fruit, pomaceous fruit, in fact, practically all fruits, could never be formed without the aid of insects. They make the labours of the fruit-grower a certainty, and without them his labours would end in failure; the florist is no less indebted to insects for his crop. Why should bees be so lauded when other insects contribute to the work of fertilisation? Butterflies, moths, and beetles all fertilise our plants, it is true, but they leave behind them whole armies -well-drilled armies - of caterpillars and maggots. These destroy the very fruit their parents fertilised, defoliate 
the trees, cause sickness inducing disease, and eventually destroy the plants. No such indictment can be brought against bees. Again, these marauding insects cannot easily be introduced into a neighbourhood, and when introduced it is still more difficult, should occasion arise, to eradicate them. Bees are domestic and social; their numbers may easily be increased or diminished as occasion demands.

Let us consider, for a moment, how this work of fertilisation is carried out. For a clear understanding of the process it is necessary to know a little about flower structure. The essential organs of a flower are the stamens and pistil, and they are usually found in the same flower; though, in certain cases, some flowers may be provided with stamens and others with a pistil. The stamens may, for our purpose, be considered as the male reproductive organs, and they usually consist of two parts, a threadlike filament and a terminal portion, the anther, which is yellow in most plants; sometimes the filament is absent. The pistil, or female reproductive organ, is composed of three parts, the terminal stigma, the central style, and the basal ovary; but often the style is absent. When the anthers are mature they split open, and pollen, having the appearance of very fine dust, escapes. The pollen is carried by insects, wind, or more rarely by other agencies, to the stigma of another flower, and, after various changes, the little structures, called ovules, contained in the ovary become seeds, and the ovary itself becomes the fruit. In order that good, strong, healthy fruit may be produced it is necessary that self-fertilisation should be avoided, that is to say, the pollen from the anthers of a certain flower should not fall on the stigma of the same flower, though nature often makes provision for self-fertilisation, when cross-fertilisation, as it is called, has failed. Pollen may be red, white, green, or orange yellow-the latter is the prevailing colour. If a piece of honeycomb, containing bee-bread, be cut in two longitudinally, strata of various 
colours may always be seen. The bees knead the pollen into pellets and neatly pack it into their "pollen baskets" on their hind legs. They are enabled to do so because the pollen of insect-fertilised flowers, with the exception of those of the cucumber family, is sticky, whilst that of wind-fertilised flowers, being non-adhesive, cannot be made into pellets.

In order that fertilisation may take place, pollen from a certain species of plant must reach the stigma of the same species; pollen from an apple tree could never fertilise an orange. How, then, is provision made by nature for this essential? Watch a number of bees at work and the answer will be unmistakably revealed. In the spring, bees begin work about sunrise, and if they have selected an apple tree from which to gather stores, they will keep on apple trees or some other member of the tribe for the whole of their outing. Foraging about among the anthers, they gather on their hairs countless grains of pollen; head, thorax, and abdomen are all more or less dusted with them. During the early morning they are solely engaged in collecting pollen; passing from flower to flower and tree to tree, they busily collect their harvest and pack it in their " pollen baskets." Later in the day the stigma becomes receptive, and the bees then begin their search for honey; for nectar, which is not secreted in the early hours, now begins to flow. Anxious to fill their honey sac whilst gathering pollen, the bees enter the flowers and thrust their tongues down into the nectaries; in doing so they brush their bodies to and fro on the stigmas, and so some of the pollen grains on their fur become detached, and, falling on the viscid stigma, are retained. Having commenced working on an apple for pollen, they will not go to a Tropæolum or any other plant for their honey. Apples provided the pollen; apples must provide the honey. Other insects, it is true, visit flowers for pollen and honey, but none work so systematically as the social bees; they make no mistakes. They will carry 
pollen from variety to variety, and sometimes from species to species, but never from order to order, and they never return to their hives from a foraging expedition with different varieties of pollen on their bodies. Where other insects visit a single flower, bees will visit a hundred; and this is important, for flowers mature rapidly, and the vitality of pollen is short-lived. Again, when other insects carry pollen it is entirely accidental; but bees cannot live without it; their young cannot be nursed to maturity without it; they are the only insects having instruments and appliances for gathering, carrying, and storing pollen. Every movement of bees in the direction of fertilisation is a studied one, designed by nature to accomplish the perpetuation of the plants they are at work upon. The anthers of some flowers are so situated as to discharge the pollen only on some particular spot of the external anatomy of the bee, and the stigma is so placed in the flower that only the portion of the bee that has received the pollen would be capable of effecting the purpose.

Only honey bees and humble bees are furnished with apparatus suitable for collecting and carrying pollen from flowers of any and every form or design. The mason and leaf-cutter bees, Osmia and Megachile, are adapted for fertilising broad, flat flowers with protuberant reproductive organs, because the undersides of their abdomens are furnished with long stiff hairs, pointing the "wrong way," which brush the pollen from the anthers. The hairs on the hinder legs of humble bees are distributed in an irregular fashion and are fairly efficient as pollen gatherers; but, in the honey bees, the hairs are arranged in eight or nine regular rows, and this regular arrangement enables them to brush the pollen from the anthers far more effectively than is the case with any other species. Most of this pollen is, of course, transferred to the pollen baskets, but many grains escape, and it is these grains that bring about fertilisation.

Let us consider, for a moment, how well adapted the 


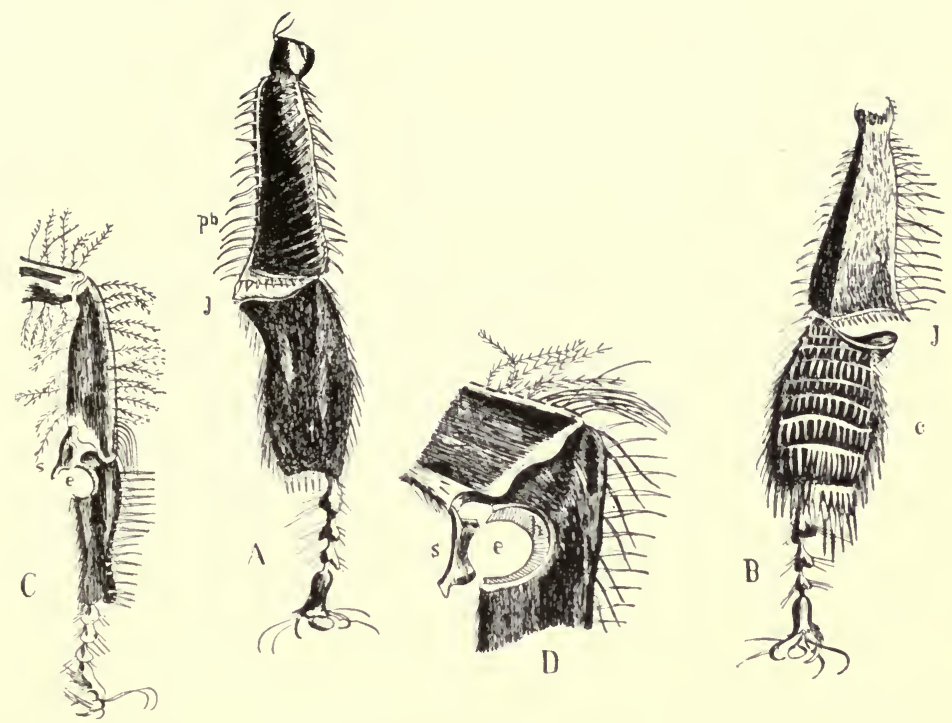

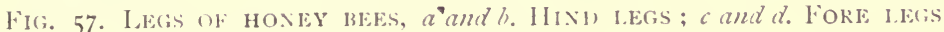

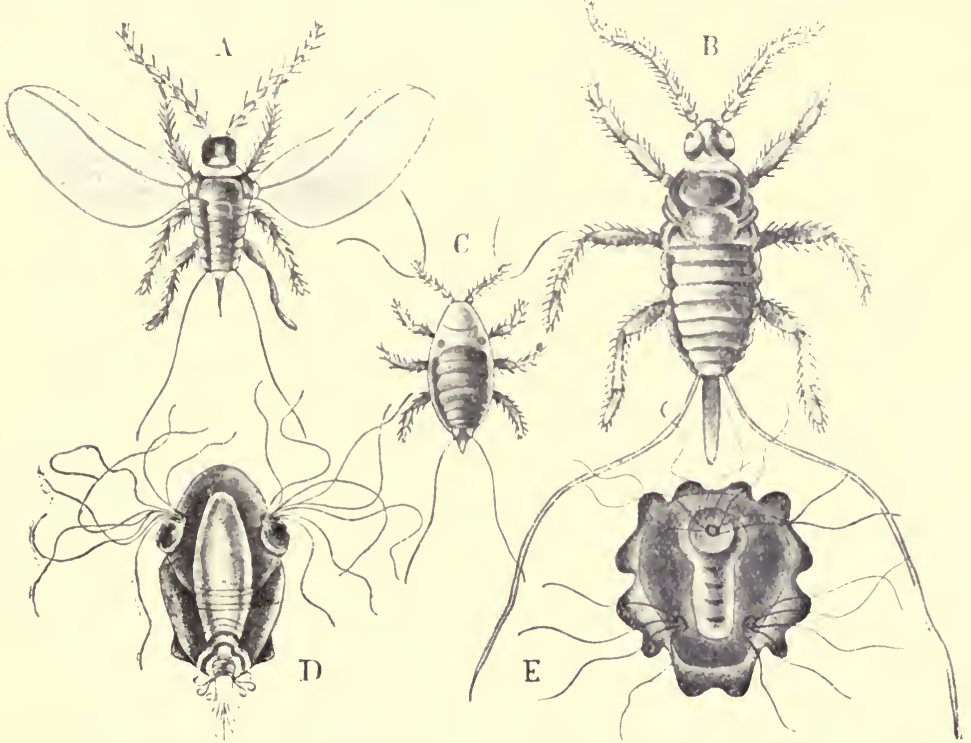

Fig. 58. LaC insects, Tachardia laca. $a$. WingeI Male; $b$. Wingiess male; $c$. LARVA; $d$. Young FeMale; $e$. OLDER FeMAle 

honey bee is for the work it has to perform. A reference to fig. 57 will show that the insect's legs are covered with rough hairs, coarser hairs, and combs, comprised of short spines; each of these hair groups is designed for a special purpose. In A, fig. 57, at $p b$, it will be seen that the $\operatorname{limb}$ is considerably hollowed and is fringed, on either side, with coarse hairs: this is a "pollen basket," and into it the pollen is placed by the bees, after they have kneaded it into little pellets. At $j$, in $\mathrm{A}$ and $\mathrm{B}$, are jaws or pincers, used to gather the wax that is secreted on the ventral surface of the bee, and utilised in forming the comb. At $c$, in $\mathrm{B}$, are rows of combs or spines; these are used to comb off the pollen which collects on the hair of the head, thorax, and legs of the insect, after it has visited a flower. "It is probable, also, that the tongue is an important organ for gathering pollen grains as well as nectar, for it seems to be fringed with fine hair on which pollen dust might readily lodge. Just how the bee cleans its tongue it is difficult to see; but the brushes on the fore legs are evidently designed for the purpose of rolling these grains off, which probably contain a little honey or nectar. In any event, they are transferred to the middle legs from the fore legs, and from the middle legs to the pollen basket, in a way that leaves sleight-of-hand in the shade, unless one watches the whole operation with a powerful glass. The transfer seems to go on in the blossom and even after the insect is on the wing. Dust the bee all over with flour, and it immediately begins the process of brushing its hairs. It will rub the palms of its legs and then begin the work of combing itself, reaching with its middle and fore legs over its back and cleaning its antennæ with its fore legs. All the manœuvres may take place while it rests on some object or while on the wing, but the bee is unable to reach over its entire body, especially the top of its back. After it enters the hive it is cleaned by other bees, when, after a little, it will be brushed and groomed, every particle of 
pollen having been removed." It is essential for the bee to keep its antennæ clean at all costs, and the operation is performed with the aid of the special cleaning apparatus shown at $e$ in $\mathrm{C}$, and, on a larger scale, at $e$ in $\mathrm{D}$. Just over the hollow $e$, which is fringed with stiff hairs $h$, there is a cap or spur $s$, and when the insect's antennæ require cleaning the hollow is passed over the organ, the cap $s$ is pushed over to its place on the open side of the hollow and the leg drawn outwards, so as to clean the whole length of the antennæ. As this cleaning apparatus is situate in the elbow of the fore leg, the antenna is within easy reach. The adaptation of the honey bee for collecting pollen is little short of marvellous.

Why are bees attracted to flowers, in the first place? It is impossible to give a definite answer, for we are not in a position to read their innermost thoughts, but it is no difficult matter to make a shrewd guess: the purpose of their floral visits is, wholly and solely, to obtain pollen and honey. How they are guided to the right flowers is a still more difficult question. Many naturalists have attempted to show that bright colours are attractive, and have gone so far as to call the markings on certain flowers honey guides, and to argue that nature has placed them there to show the bees the way to the nectaries. Bees, however, are too intelligent to require such natural signposts; nor is colour the attraction, as may be seen when these insects are crowding round the lime-tree flowers and paying scarcely any attention to the many brightly coloured garden flowers. If colour is the guide, as some would have it, why do bees invariably pass over the bright yellow Eschscholtzia in favour of the paler yellow Enothera? The one contains nectar; the other does not. Scent is said by other observers to be the bee's sole guide; but it is not the most strongly scented flowers that are most frequently visited by bees; they rarely visit a strongly scented double rose, because it produces no nectar, and, 
having no anthers, supplies no pollen. The subject is interesting and complex, yet a moment's thought, or, better still, observation, will show that not colour and scent alone, but some other force, instinct, sense, call it what you will, guides the bees in their daily work.

\section{Insects as Human Food}

Of all the ways in which insects have been pressed into the service of man, none are more curious, more foreign to the normal man's outlook on these lowly creatures, than their use as food and as additions to the Materia Medica. True, the Israelites were enjoined by Moses to eat locusts, beetles, and grasshoppers, and it is common knowledge that John the Baptist subsisted in the desert on a diet of locusts and wild honey, despite the fact that certain purists have expended much time and considerable ingenuity in attempting to show that the locusts, in this case, were not insects at all, but the fruit of a leguminous tree. Why any such attempt at prevarication should have been made passes all comprehension, for, to this day, these insects are very highly esteemed in parts of Africa, Arabia, and Persia, where they are bought and sold as an everyday article of commerce.

According to Pliny and Herodotus, the Parthians and Nasamones both relished locusts as food, whilst, among Moors of the present day, these insects, fried in butter, form a staple and favourite dish. Many of the North American Indian tribes were in the habit of consuming large quantities of the Rocky Mountain locust, an insect of great economic import, seeing that it greedily consumes every green leaf encountered in its wanderings. When the red man was at his zenith, the Rocky Mountain locust was practically innocuous; since his subjugation, it has increased and spread to such an extent that it has come to be viewed in the light of a serious pest. According to De Smet, the Assiniboine idea 
of luxury was an immense dish of pulverised ants, grasshoppers, and locusts, that had been dried in the sun. The same author and traveller says that the Shoshone relished grasshoppers and crickets, and that they stored up bags of roasted ants for future consumption; in this respect they resembled another tribe, the Soshocs, who were described as miserable, lean, weak, and badly clothed. Their territory abounded in artemisia, a herb much favoured by grasshoppers. A large deep hole was dug in the earth by the Soshocs, who then formed themselves into a ring round the excavation, but at a considerable distance from it, and gradually converged towards it, beating the ground as they went, with the object of driving the insects into the pit, when they were collected and eaten, either as soup, or boiled and made into a paste for future use. The Maidu, a Californian tribe, also relished locusts and grasshoppers.

The literature on the subject is meagre in the extreme, but there is little reason to doubt that locusts have been prominent items in the bills of fare of many races from time immemorial. Grasshoppers were eaten by the ancient Greeks, whilst, to the natives of Uganda, the allied crickets, Curtilla africana and Acheta bimaculata, have a double use, being kept in warm ovens, on account of their musical note, to induce sleep, and, presumably, when the pangs of hunger outweigh the discomforts of insomnia, they are used as food. Dried locusts are said to be a common ingredient of Indian curries, even in Calcutta.

"In some parts of Italy the cricket is looked upon with love and almost veneration. In the city of Florence, on Ascension morning, the pedlars throng the streets with crickets in little painted cages, selling them at from two to five cents, and the air resounds with their cries, as well as those of the captives. You must pick your cricket with care, for his singing powers, or want of them, will decide your destiny for the coming year. An active bright singer 
means good luck; a sluggish silent one the reverse. These caged insects, after being carried about all day, and their respective merits being dilated upon by their owners, are liberated in the evening.

"In the north of Africa the natives in the villages make a regular trade in capturing and caging crickets, which they sell in the towns, where they are kept and fed like cage-birds for their song. In China, another species is often sold in cages; but they are used like game-cocks for their fighting qualities, and sums of money are lost and won on their prowess. In some parts of England it is still firmly believed that if you kill or injure a cricket that has come into the house, its relations will come into the house at night and eat holes in your clothes for revenge."

It is hardly possible to imagine anything less appetising, in appearance, than the larva or grub of a warble fly, yet one species is in great demand as an article of diet with the Dog Rib Indians. These people of Athabascan stock are in the habit of eating caribou, an animal that is much affected by warbles, often several hundreds being found on one individual. This does not appear to trouble the Indians, who never remove the warbles from the meat before cooking; in fact, the grubs are considered a delicacy. Hearn says, of the same tribe: "The Indians, however, never could persuade me to eat the warble, of which some of them are remarkably fond, especially the children. They are always eaten raw and alive out of the skin, and are said, by those who like them, to be as fine as gooseberries."

The butterflies and moths, despite the fact that they include an enormous number of species, have not been very largely drawn upon as food. Pliny, writing of the Roman epicures, mentions that the larva of an insect called Cossus was held in great esteem by them. The grub was very carefully tended, and especially fattened for the table on flour and wine; when ready for eating it was said to 
resemble a substantial prawn.' 'The exact identity of this favoured insect is subject to some doubt. By many it is thought to be the larva of the goat moth, Cossus ligniperda; and as a mature and well-fed goat moth caterpillar agrees closely with Pliny's description, there seems little reason in trying to establish the claims of other insects. It is highly probable that the taste for this dish was an acquired one. To most people the idea of eating an insect is, in itself, sufficiently repulsive ; to those who have handled Cossus ligniperda the act is unthinkable. The grub has none of the beauty possessed by many caterpillars; but its forbidding appearance is as nothing to its foul odour, resembling, as it does, the well-known scent of the billy goat, hence the name goat moth. Whether its taste is akin to its smell, probably few can tell, but the insect is not one to inspire confidence in the heart of a neophyte in gastronomic research. By some it is thought that the Cossus of Pliny was the larva of a stag beetle, Lucanus cervus, or of a Longicorn beetle, Prionus coriarius, though with what reason is hardly apparent. At the present time, caterpillars of various kinds are consumed, in quantity, by the Pai-Ute-Indians. The collection of these larvæ and their preparation for food is an industry of very considerable importance along the Nevada-California line.

The Bushmen of Africa eat the caterpillars of butterflies to some extent, and the natives of Australia a species of moth called bugong, which at certain seasons is found in the greatest abundance in some localities. Regarding the bugong moth, Agrotis infusa, a correspondent of the Agricultural Gazette, New South Wales, who has actually seen the natives devouring the insects, says: "These moths reside in the great fissures in the granite rocks, right on the top of the peaks of the Bugong Mountain, and their numbers are as the sands of the seashore. The moths are a dark yellowish brown or brownish yellow, about an inch long, and very plump and fat in the body, and when 
properly cooked are very palatable and highly nutritious, judging from the condition of the birds that feed on them. 'The mode of cooking adopted by the blacks is primitive, but effective. Our two niggers provided themselves with bags, which were filled with bugongs by simply opening the bag and sweeping thousands of moths into it with their hands. These bags, well filled, were brought down to our camp at the foot of the mountain, a fire was made, and kept up with sticks which burn to a clear white ash, and, when a good heap of white ashes was prepared, a hole was raked in the heap with a stick, and the moths tumbled in out of the bag, and the ashes heaped round them and stirred about with the sticks for several minutes, and when the experienced cook reckoned the cooking was complete, the mixture of the ashes and moths was well scattered about to cool and stop further cooking. When cool enough to handle, the moths' bodies-wings and legs pretty well singed off - were gathered up, ashes and all, and cleaned by simply pouring from one hand to another, and blowing on the falling mixture, by which means the moth's bodies were almost cleaned of ashes; and a little further delicate manipulation by gently rubbing the moths on the leg of the trousers completed the cleaning process, when the delicious moths were eagerly eaten."

According to Kunzé, "the bodies of these moths abound in oil and taste like nuts. When first eaten they produce violent vomiting, but this effect soon passes off, and the natives thrive and fatten on this diet. The flight of these insects is followed up, and at night fires are built under trees on which they have settled. The smoke soon brings the moths down, and their bodies are collected and pounded together into a sort of fleshy loaf. The larvæ of a few other lepidopterous insects are used for food by the natives," those of Euploca hamata being the most favoured.

In China, the pupæ of the silkworm moth, Bombyx mori, after removal of the silk from the cocoon, are considered 
delicacies, as are the caterpillars of a species of sphinx moth. In South India, the pupa of the tassar silk moth, Anthercea paphia, is esteemed.

The lumbermen of Maine are not averse to a meal of large black wood ants. A red ant, Ecophylla smaragdina, though possessed of a pungent flavour, is considered a delicacy in Burmah; whilst Dr A. R. Wallace, in an account of insects used as food by the Indians of the Amazon, says, concerning the red-headed ant, Ecodoma cephalotes: "It is the female of this destructive creature that furnishes the Indian with a luxurious repast. At a certain season the insects come out of their holes in such numbers that they are caught by basketsful. When this takes place in the neighbourhood of an Indian village, all is stir and excitement; the young men, women, and children go out to catch 'saubas' with baskets and calabashes, which they soon fill; for, though the female ants have wings, they are very sluggish, and seldom or never fly. The part eaten is the abdomen, which is very rich and fattening from the mass of undeveloped eggs. They are eaten alive, the insect being held by the head as we hold a strawberry by its stalk, and the abdomen being bitten off. The body, the wings and legs are thrown down on the floor, where they continue to crawl along, apparently unaware of the loss of their posterior extremities. They are kept in calabashes or bottle-shaped baskets, the mouths of which are stopped up with a few leaves, and it is rather a singular sight to see for the first time an Indian taking his breakfast in the 'sauba' season. He opens the basket, and as the great-winged ants crawl slowly out, he picks them up carefully and transfers them with alternate handfuls of farina to his mouth."

" Termes flavicolle, a large 'white ant,' common in the Amazon, is eaten. In this case it is not the winged female that is eaten, but the great-headed, hard-biting worker, and it is by means of his jaws that the creature is entrapped. 
An Indian boy going after 'Cupim' takes with him a calabash or a bottle-basket, and searches about for a nest. He then scrapes away some of the earth, and, taking a long piece of grass, inserts it as far as it will go, and on withdrawing it finds a row of ten or a dozen Termes holding tightly on to it; and he repeats this operation till he fills his basket. These insects are also eaten alive or roasted; but in this case it is not the abdomen, but the enormous head and thorax, which is devoured, as these parts contain a considerable mass of muscular matter. These insects have generally a bitter taste, and are not much esteemed except by the Indians themselves."

The "white ants," Termes arborum, Termes fatale, and Termes smeathmanni, which, by the way, are not ants at all, but are popularly misnamed, supplement the menu in many an Indian and African home. One Hindu and several African tribes eat both the termites and their eggs. In the lake regions of Central Africa the termite mounds are a common feature of the landscape, and a welcome one, too, to the natives, for, when they run short of tobacco, as a substitute they chew the clay of these ant-hills, which they call "sweet earth." The Hindus consider the female "white ant" to be highly nutritious, and they used to be eagerly sought for and forwarded to the debilitated Surjee Rao, Chief of the Mahrattas. In the East Indies, old men eat the queens alive, in order to strengthen their backs. When the native boys of South Africa attain the age of twelve to fourteen years, they are given a termite queen to eat and then compelled to run more than two miles: this procedure is supposed to endow them with wonderful powers of resisting fatigue. Termites are also eaten by the Australian natives.

Next to the locusts, beetles appear to offer the greatest variety of diet to those who appreciate insect food. Elian says that the larva of the palm weevil, Calandra palmarum, was considered an epicurean treat. The grubs are a dirty 
white colour, and about the size of one's little finger. They are known to the natives of the West Indies and Brazil as "Grougrou," and are held in great esteem as food. Armed with a strong knife, the West Indian digs a hole in some cabbage palm that has been attacked by the weevil, till he comes to the pith, and then he is almost certain to find a plentiful supply of grubs, which he devours after a preliminary roasting or frying. Should the supply of these grubs become scanty, the larvæ of another beetle, Stenodontes damicornis, efficiently take their place.

The common cockchafer, Melolontha vulgaris, is not exactly a prepossessing-looking insect, from a gastronomic point of view; its aroma is not pleasant, and its habits are not of the best, but this does not prevent a closely related species, Melolontha hypoleuca, from being much relished in Java, whilst the peasants of Lombardy are partial to the abdomens of another bettle, Rhizotrogus assimilis. In Moldavia and Valachia, the beetle, Rhizotrogus pini, forms a common article of food.

Among certain peoples a considerable degree of plumpness is essential in every woman who would find favour with the opposite sex, and here again insects come to the rescue. The ladies of the Nile Valley wax fat upon the scarab, Scarabocus sacer, a beetle whose outlines are familiar to the most unentomological, for they have been figured on Egyptian tombs and monuments times without number. In Tunis, a species of churchyard beetle, Blaps sulcata, is used for the same purpose, despite the fact that it is possessed of a disgusting odour; whilst in Turkey, the larva of a beetle allied to the meal worm, Tenebrio molitor, is the recognised flesh producer. An aquatic beetle, Eunectes sticticus, in its larval and adult forms is eaten in Burmah.

Beetle fare is by no means confined to the Old World; a favoured dish among Peruvians is largely composed of an aquatic beetle, Elmis chilensis; and the Mexicans, not 
contented with their national beverage, "pulque," prepared from a cactus, manufacture another and no less deadly drink by infusing a tiger beetle, Cicindela curvata, in alcohol.

To Mexico and to the bugs we must turn for the pièce de résistance of all insect food, the Central American counterpart of caviare, so highly prized by the gourmets of the Old World. Three aquatic bugs, Corixa femorale, Corixamercenaria, and Notonecta unifasciata,considerately deposit their eggs in large quantities in the streams, and in due season they are collected and eaten with great relish.

Speaking of the sale of these insects in Mexico City, Froggatt says: "Probably the most curious of the many curious foods on sale in this market were the bags of water-bug eggs, about the size of dust shot. They are obtained in the canals round the city by sinking sheets of matting under water, upon which the eggs are laid in millions. The matting is then shaken over a sheet and all the eggs gathered. These are dried and placed in sacks and sold at so much a pound; they are known as 'ahuahutl,' and are made into cakes and eaten.

"There are also large quantities of two species of waterbugs sold in the same manner in the markets. They are collected like shrimps, with nets, in the swamps and marshes, but they are sold to feed the mocking birds, the common cage bird in the Mexican home. Another interesting insect is a black fly, the larvæ of which swarm in such quantities in the waters of Lake Texcoa, that when they pupate the pupæ are collected in bags and used as manure to fertilise the adjoining lands. At certain seasons these flies swarm out in such clouds that they cover the railway track and stop the trains. Another curious insect food is the caterpillar of a hesperid butterfly, which lays her eggs upon the leaves of the Agave americana. These caterpillars burrow into and feed in the tissue of the leaf, and are cut out, placed in little boxes made out of a section of the thick leaf, and sold as a great delicacy." 
The cicada, described in another part of this book, has long been esteemed as an article of food in America, though its periodical occurrence is too infrequent to make it of any real value. The Rev. Andrew Sandel, of Philadelphia, first drew attention, in 1795, to the fact that these insects were eaten by the Indians; whilst, at a later date, another authority corroborated this and stated that "the Indians make the different species of cicada an article of diet, every year gathering quantities of them and preparing them for the table by roasting in a hot oven, stirring them until they are well browned." In 1885, Dr Howard, Chief of the American Bureau of Entomology, and Professor Riley made some experiments on the use of these insects as food. When writing his experiences later, Dr Howard said: "With the aid of the Doctor's (Riley's) cook he had prepared a plain stew, a thick milk stew, and a broil. The cicadas were collected just as they emerged from pupæ, and were thrown into cold water, in which they remained one night. They were cooked the next morning and served at breakfast time. They imparted a distinct and not unpleasant flavour to the stew, but were not at all palatable themselves, as they were reduced to nothing but bits of flabby skin. The broil lacked substance. The most palatable method of cooking is to fry in butter, when they remind one of shrimps. They will never prove a delicacy." Dr Hildreth, writing in 1830, said that when the cicadas first leave the earth they are so plump and full of oily juices that they are used in making soap.

Non-aquatic bugs, with the exception of the cicada, do not appear to be highly favoured as articles of food, but a large species, Aspongopus nepalensis, is eaten with rice in Assam, and still more curious fare hails from Nyasaland, in the shape of "Kungu," a paste composed of mayflies (Conis kungu) and mosquitoes (Culicidoe).

Bees are rarely eaten, the big jungle bee of India, 
Apis dorsata, being the only one recorded; its larvæ and pupæ supply food to the natives in the wilder parts.

Quoting once more from De Smet, who, relating his experiences among various North American Indian tribes, said: "I have seen the Cheyennes, Snakes, and Utes eat vermin off each other by the fistful. Often great chiefs while they talked to me, would pull off their shirts in my presence without ceremony, and while they chatted would amuse themselves with carrying on this branch of the chase in the seams. As fast as they dislodged the game, they crunched it with as much relish as more civilised mouths crack almonds and hazel nuts or the claws of crabs and crawfishes." Dr A. R. Wallace relates of the Indians of the Amazon that an insect which they eat more as a delicacy than as an article of food is a species of Pediculus, which inhabits the head of that variety of mankind, and is probably a distinct species from that of our own country. The method of capturing and devouring this insect is exactly the same as that which everyone has seen adopted by the monkeys at the gardens of the Zoological Society. A couple of Indian belles will often devote a spare halfhour to entomological researches in each other's glossy tresses, every capture being immediately transferred, with much gusto, to the mouth of the operator.

Biblical students will need no reminder concerning the words that have been written on the subject of manna in the Old Testament. The passage has been the subject of considerable controversy. By some, manna was thought to be a lichen; by others, a vegetable secretion, and as such it was described by an ancient Persian writer under the name of Guezengebin or Tamarisk honey. This writer, however, noticed that an insect was always closely associated with the secretion. An Englishman, Hardwick, while travelling in Persia, discovered the insect, which he called Chermes mannifer; and, a little later, Ehrenberg found the insects on tamarisk, growing near Mount Sinai, and at the same 
time saw their secretion, which closely resembled honey in appearance, and was known to the Arabs as "man." According to the latter authority, the manna insects, which are now known to science as Gossyparia mannifera, infested the smaller branches of Tamarix gallica in large numbers, sucked up sap in quantity, and exuded manna in the form of a sugary secretion which, in the cool of the evening, fell to the ground in solid form, but, after sunrise, melted and percolated into the soil. Little appears to be known concerning this Coccid, for manna is a scale insect, like lac and cochineal; it is mainly of Biblical interest, for nowadays, at any rate, the secretion is not collected in sufficient quantity to make it of any commercial value.

The entomophagous habit, in modern times at any rate, is probably closely connected with the abundance or otherwise of more staple food. In countries or districts where agriculture is practised the habit is either absent, or by no means so prevalent as it is in places where man must perforce rely on an abundant supply of game for his nutriment. This is strikingly illustrated in North America, where the aborigines were insect-eaters, whereas the Indians, living east of the Mississippi, have never been entomophagous, the reason being that agriculture was prevalent to the south of the Great Lakes, and in other regions economic conditions were regulated by the abundance of the game supply, so that in times of famine attention was turned to insects as food.

\section{INSECTS AND MEDICINE}

In the annals of quackery, rather than in the pages of official pharmacopœias, insect remedies figure most prominently; nevertheless, certain species have been pressed into legitimate service from time to time, and they deserve notice in a book dealing with the varied relations of insects and man.

Just as the Coleoptera, or beetles, supply a considerable 
amount of food to entomophagous peoples, so has this extensive order of insects been drawn upon largely by the medical profession, qualified or pseudo, in their search for remedies. Ladybirds were formerly considered a very efficacious remedy for colic and measles, and homœopathy has introduced the seven-spotted ladybird, Coccinella septem-punctata, to the Materia Medica. A mashed ladybird introduced into the cavity of a decayed and aching tooth is stated, by some authorities, to relieve the pain immediately.

The leather beetles are notorious as household pests rather than as contributor's to the Materia Medica. In modern medicine they play no part, but they were much esteemed by the Egyptians. Both Galen and Dioskorides refer to Tomicus typographus as a vesicator. The same beetle, called in Arabic "Dudchabath elsanawbar," is used by the Arab physicians for opening abscesses on account of the fact that the powdered insect will rot flesh which is exposed long enough to its action.

The mandibles of the European stag beetle, Lucanus cervus, under the name of "horns of Scarabæi," were formerly employed in cases of pain and convulsions, whilst an infusion of these beetles is recommended by Schroeder to be dropped into the ears as a remedy for pain in these organs.

The medicinal virtues attributed to the dung beetles are many and varied. Pliny says that the eyesight of those who gaze on the green scarabæus is rendered much more piercing, and that, on this account, the insect is in great demand by engravers of precious stones to steady their sight. According to Schroeder, a preparation of Byrrhus pilula is an efficient remedy for hæmorrhoids and certain eye diseases. A beetle of the genus Copris is used medicinally in China. Mouffet, in his Theatrum Insectorum, describing a scarab engraven on an emerald to be used as an amulet, says: "It keeps away likewise the headache, which truly is no small mischief, especially to great drinkers." 
Oil in which these beetles have been boiled was recommended by Galenus for earache, deafness, and the bites of scorpions, and certain Arabian doctors apply the juice of scarabæus to the eye in the minutest quantity for weakness and blindness.

Pliny recommends decoctions of skipjack beetles for ulcers and malignant growths, and a glow-worm, Lampyris noctiluca, is said to be an efficient remedy for stone.

The Spanish flies, or Cantharido, are the most familiar of all beetles to the present-day physician. Cantharis vesicatoria has earned a widespread reputation as a vesicating agent. In Italy, an allied species, Mylabris cichorii, and in China, Mylabris pustulata, are similarly employed. In earlier times the blistering beetle was held in great awe, and when a Dr Greenfield of London administered some cantharides internally to a patient, in 1698, he was promptly imprisoned, only being released on the publication of his success in using the preparation in certain diseases of the bladder and kidneys. Cantharides is still used medicinally, and is also an ingredient of many hair washes.

The oil beetles, so-called because, when handled, they eject a drop of clear yellow oil from the joints of their legs, are used in some cases as a substitute for cantharides, notably in Spain. They were formerly esteemed in Germany as a remedy for hydrophobia, and in Sweden the oil is expressed from the beetles and used with considerable success as an ointment for rheumatism. By Arabian and Hindu doctors preparations of these beetles, in vinegar, are used against itch and to destroy lice.

In Egypt and the Levant the churchyard beetles, Blaps sulcata and Blaps mucronata, prepared with oil, are used as a remedy against earache and the bites of scorpions and, externally, for all kinds of skin affections.

The weevils appear to contribute but little to the Materia Medica. Professor Gergi of Florence, writing towards the close of the eighteenth century about a certain weevil, 
reported that, if several of the larvæ were crushed between the fingers until sufficient oil had been absorbed, any aching tooth touched with an anointed finger would be relieved of pain. About the same period other weevils were used by the Tuscan peasants against toothache.

The only other beetle that appears to have been used medicinally is a musk beetle, Aromia moschata, which, when dried and powdered, forms a vesicatory as efficient as cantharides.

Of the earwigs, the common Forficula auricularia alone appears to be of remedial value, or supposed value. Oil of earwigs, when rubbed on the temples, wrists, and nostrils, is good to strengthen the nerves.

The Orthoptera are well represented in entomological Materia Medica. In Russia the common misnamed black beetle, Periplaneta orientalis, has long been used in the form of the powdered insect and in other ways as a remedy for dropsy; it is known as Tarakane. In other parts of the Continent the powdered, medicinal form of Periplaneta orientalis is sold, under the name of Pulvis Tarakanæ, as a remedy for pleurisy and pericarditis; the American cockroach, Periplaneta americana, is also used in homœopathy.

Crickets, according to Pliny, possess many medicinal virtues, mainly in connection with disorders of the ears and throat; and, in later times, the ashes of the domestic cricket, Gryllus domesticus, have been used in cases of weak sight and enlarged tonsils.

Although grasshoppers and locusts were used in medicine so long ago as in the time of the ancient Greeks-Locusta africana being a noted remedy against scorpion poison, and the eggs of the Chargol locust being carried in the ears of Jewish women as a protection against earache-their remedial value has not waned. In Sweden a grasshopper, Tettigonia verrucivora, is much prized by the native peasants who suffer from warts. They allow the insects 
to bite their warts, and during the process a black fluid is emitted from the mouth of the grasshopper which is supposed to possess the power of destroying the excrescences. The exuviæ of the Semni grasshopper are preserved and sold for medicinal use in China and Japan. A drug called locusteum was prepared by Dr J. M. Honigberger, by triturating the bodies of Locusta migratoria, minus head, wings, and legs, into a paste and then adding proof spirit. It was recommended for hæmorrhoids and thirst.

The gall flies, belonging to the order Hymenoptera, or membrane-winged insects, furnish galls rich in tannin, and much used in the arts and in medicine. The female of Cynips gallo tinctorice lays its eggs in the tissue of the leaf of an oak, Quercus infectoria, injecting with each egg a fluid which causes a tumour to arise on the leaf to serve as a shelter for the future larva and pupa till transformed into a gall fly, when it eats its way out. The best oak galls come from the Levant, and they are strongly astringent. Another gall fly, Cynips rosce, produces galls on rose trees. These galls, called Bedeguar, are successfully used as remedies against diarrhœa and dysentery, and are also reported to be of use in cases of stone, scurvy, and worms.

The old Spiritus formicarum of the Prussian pharmacopœia was prepared by macerating two parts of bruised ants in three parts of alcohol, thereby extracting the active principle of the insects known as formic acid. Ants found in the wood of pine trees are eaten by the lumbermen of Maine as an anti-scorbutic, it is said with good effect. Schroeder prescribed preparations of ants which he called Formica minor for leprosy and an infusion of Formica major for gout and palsy. In Thuringia a spirit of ants is rubbed into the affected parts in cases of rheumatism; whilst, in Russia, a successful remedy for the same complaint is a vapour bath, prepared by pouring boiling water over ants, thus setting free the formic acid. 
Bees have been used extensively by homœopathists, and the most curious property attributed to them is that, if a powder, prepared from bees, is mixed with unguents, "it will contribute to the growth of hair on bald places." And another of the older writers on medical subjects says that, "If bees, when dead, are dried to powder and given to either man or beast, this medicine will often give immediate ease in the most excruciating pain." In Hindustan and Lahore the native druggists keep Mutilla antiguensis, a beautiful insect, resembling a scarlet wasp and possessed of a very long sting. The insect is officinal, and is used by native doctors against snake bite and colic in horses.

Butterflies and moths contribute but little to the Materia Medica. According to Dioskorides, the caterpillar of the common white cabbage butterfly, Pieris brassica, if rubbed in with oil, is a sovereign remedy against the bites of animals and insects, whilst the caterpillars of the browntail moth, Euproctis chrysorrhoea, and of the procession moth, Bombyx processionea, are ingredients of certain homœopathic tinctures.

The medicinal virtues of the Rhynchota, or bugs, are of greater repute. A Chinese cicada, Flata limbata, secretes a kind of grease on various trees; this hardens into wax, and is collected, melted, and purified, when it becomes white and glossy in appearance. As a native remedy, it is employed in several diseases, particularly as a preventative against palpitations and swooning. The wax is also mixed with oil and made into candles.

Both Dioskorides and Galen recommended roasted cicadas for bladder troubles; whilst for colic, the latter writer advised five or seven cicadas to be eaten with pepper.

The green flies, Aphida, are used medicinally by homœopathists, a tincture being made of the species Aphis chenopodii glauci, which is found on goosefoot.

Females of the scale insects, Coccida, have been used in 
medicine and the arts from very early times. Some species furnish very valuable dyes. One species, Kermes ilicis, infecting the oak, Quercus ilex, a native of the Levant and Southern Europe, when acted upon by mordants of tin and other salts, furnishes a beautiful blood-red dye, which was known to the Phœnicians as Tola or Thola, and to the Hebrews as Zehori. The Arabs received it from Armenia and Persia as Kermes or Alkermes, and the Greeks knew it as Coccus. At a later date this dye was supplanted by another, also prepared from a scale insect, Dactylopius coccus, found on the prickly pear, Opuntia coccinellifera. Cochineal, as the dye is called, once formed a staple article of commerce in South America, Mexico, and the Canary Islands. The dried cochineal insect, resembling a shrivelled silver-grey hemp seed, furnishes the colours known as carmine and lake. But, just as cochineal superseded the earlier pigments, so has it given way to aniline dyes, only being used at the present day to colour foodstuffs and as a dye for soldiers' uniforms, because it stands the weather better than chemical dyes; and the cultivation of Dactylopius coccus, once a flourishing industry, is now in a moribund condition. It is, however, with the medical aspect of the insects that we are concerned here. Both species of coccid have been utilised for various ailments: cochineal is used medicinally by the allopathic and homœopathic fraternity; in the United States Dispensatory it is recommended for whooping cough and neuralgic affections on account of its anodyne properties. According to Dr J. M. Honigberger the Hakims of India consider cochineal as destructive to the generative faculty.

Chinese pela wax, an important article of commerce, known as Schih-Kene-Ming, is the secretion of Ericerus pela. This scale insect is partial to an ash tree, Fraxinus chinensis, and it coats large surfaces of the branches with wax, which is collected for medicinal and other uses.

Bed bugs are well known, by reputation at any rate, in 
all civilised communities. Not so well known, however, is the fact that Cimex lectularius, man's most undesirable bed-fellow, constitutes a medicine of some repute. Pliny says that the bed bug is a neutraliser of the venom of serpents; Guettard, his French commentator, recommends them to be taken internally for hysteria. According to a later authority, their smell relieves those under hysterical suffocation; and also, if given to the number of seven, as food with beans, they help those that are afflicted with quartan ague, if they be eaten before the accession of the fit. Quintus Serenus, in his verses, says they are good for tertian agues, a statement which is confirmed by Gesner, who tried the remedy "among the common and meaner sort of people." The Ancients gave seven to adults and four to children when they were overcome by lethargy. During the later part of the last century the bed bug was given by country people, in certain parts of America, as a cure for fever and ague, and it is highly praised for its remedial properties in homœopathic circles.

Baldness was evidently as common an infliction in ancient times as at the present day, and the remedies, though distinctly quaint, were probably quite as efficacious as some of the much-advertised modern nostrums. Pliny says : "Varro affirmeth that the heads of flies applied fresh to the bald places is a convenient medicine for the said infirmity and defect." Another authority says that gnats, rubbed into the bald places of one's head, will promote the growth of hair, and, curiously enough, the bodies of the same insects rubbed on the eyelids were said to cure ingrown lashes. The larvæ of bot flies have been used as a remedy for epilepsy.

Of lice, the most disgusting remedial agents imaginable, Schroeder, in his History of Animals that are Useful in Physic, says: "They are swallowed by country people against jaundice." Of them, too, Beaumont and Fletcher write: "Die of the jaundice, yet have the cure about you: 
lice, large lice, begot of your own bodies and the heat of the brick-kilns." These insects have also been made use of in cases of atrophy and quartan fever.

Many other insects have undoubtedly paid tribute at the shrine of Hygeia, but the practice of using them as drugs is on the wane. Formic acid is no longer manufactured from ants, but is made artificially. Cantharides has many rivals as a blistering agent. It is in country districts, where old customs die hard, that the remedies of our forefathers are most likely to be encountered. Chemical research and medical science have inflicted other nostrums upon us, though none more efficacious, if we can believe a moiety of all that is claimed for those that have passed.

\section{Some Useful Scale Insects}

\section{The Lac Insect}

Scale insects, as a family, are looked upon with great disfavour by economic entomologists. One member of the family, however, by its general utility, does a little to retrieve the bad name of its relations: the individual is the lac insect, Tachardia lacca. When it is realised that the value of the export of lac from Indian ports, in a single year, has totalled, approximately, thirty-three million rupees, it will be gathered that the cultivation of the lac insect is an important industry. A word or two concerning the origin and nature of lac and some information about the industry itself may not be out of place. Lac is the resinous secretion of a scale insect. Like other scale insects, the lac insect is provided with a sucking beak, which it inserts into the tree on which it lives and from which it draws up the sap. These insects have been likened to animated siphons, in that the imbibed sap, after modification and partial absorption, is given out as a secretion at the anal end of their body. On contact with the air this secretion solidifies, forming the "scale" which is popularly 
known as lac. Owing to the fact that these scales are exceedingly closely crowded together, they form a continuous layer over considerable areas of the tree branches, and are then known as stick lac. From stick lac, "shellac" is manufactured.

The lac industry is one of the most ancient of the minor Indian industries; in fact, it seems to date back for several thousand years, whilst the use of the resin as varnish is mentioned in the Ain-i-Akbari, issued by the great Akbar in 1590. The earliest European writer to mention lac was a Dutchman, who had returned from a scientific expedition on behalf of the King of Portugal about the year 1596, but he was quite ignorant of the origin of lac. Long before the lac resin was imported into Europe, another product of the insect, lac dye, was an article of commerce. This dye, which consists, for the most part, of the substance from which the eggs are produced in the body of the female insect, was once a rival of cochineal, but now both have been superseded by aniline and other synthetic dyes; and while the lac resin industry is a growing one, the dye industry is practically a dead letter.

The best lac, called nagali, is obtained from the Indian Kusum tree, Schleichera trijuga. It is a light golden colour, and from it the valuable orange shellac is made. Another good lac is found on the Dhak tree, Butea frondosa; and it is called baisakh or katik, according to whether it is gathered in the month of Baisakh or Katik. It is darker and not so clear and bright as nagali. Lac may also be obtained from many other trees, but is then of inferior quality, and the two kinds above mentioned are the only ones held in esteem by Europeans. The best lac comes from Bengal and the Central Provinces of India. Lac, in its manufactured state, is, of course, largely used as a varnish and polish for woods and metal, as a stiffening material for hats, an ingredient of lithographic ink, and as sealing wax; it is also in great demand in electrical work, 
and, more recently still, in the manufacture of gramophone records. In India itself this useful product is largely used as a varnish in the manufacture of painted pottery, and in the manufacture of cheap bangles, toys, marbles, imitation fruit and flowers, etc.

The newly hatched larva of the lac insect (fig. 58, c) is orange red in colour and elliptical in shape. Like other similar larvæ, it is six-legged and possesses two eyes and a pair of antennæ, whilst just behind the head are two white, powdery, hair-like filaments, and from the penultimate segment of the abdomen two long hairs arise. These little red insects crawl about over the trees for a time, and then, after inserting their beaks in some of the softer tissues, settle down to a resting period. Sap is absorbed, and, as already mentioned, a secretion is exuded which, on drying, forms the scale, the larger scales being those of the females, and the smaller ones cover the males. The object of these scales, in all insects of the family, is probably protective, for, living a stationary life, they are much more liable to attack than when moving about. The female scales far outnumber those of the males, but both sexes are so closely packed on the stems that the scales fuse to form a thick incrustation. Although the scales appear to be no more than reddish-brown wax to the ordinary observer, structural changes are going on within them, and in two and a half months from the time the larvæ appeared, the males, having reached maturity, push up the lower edge of their scales and crawl out backwards. In appearance (fig. 58, B) they somewhat resemble the larvæ, but are larger, have well-marked antennæ, and four eyes instead of two, whilst on the last abdominal segment there is a beak-like, horny process.

Immediately the males escape they crawl about over the colony and mate with the females, which remain beneath their scales. After pairing, the males die, but considerable changes take place within the females (fig. 58, D and E); the 
ovary, which grows to occupy the greater part of their bodies, becomes filled with a light red fluid, within which the eggs are formed. This red fluid forms the basis of the lac dye. Each female produces as many as a thousand eggs, on an average, and as they mature the mother dies; in fact, by this time she consists of little more than a skin which ruptures and allows the larvæ to escape. There are two generations in the year, and they differ markedly in that the adult males of the later generation are winged (fig. 58, A), probably with the object of ensuring the fertilisation of the females on trees where males are scarce. The time to collect the lac is obviously when the larvæ have left the mother scales, for then the incrustation contains no insects and a minimum of the red coloration, which is somewhat difficult to remove during manufacture, and depreciates the value of the commercial lac.

\section{Cochineal}

The cochineal insect, Dactylopius coccus, is another member of the family Coccide deserving a place among the useful insects; without exaggeration, it may justly be called the most celebrated of all the scale insects. Cochineal, in the larval and female adult forms, is essentially parasitic upon the prickly pear, Opuntia coccinellifera, though it lives equally well on some other allied species. The adult male is very minute, only a millimetre in length, and of a carmine colour, which is intensified on its head and thorax. The wings, which are longer than the body, have only a single bifurcated yellowish-brown vein, and the head is provided with four compound and two simple eyes, whilst from the last segment of the abdomen two long bristles arise. The female is about six times larger than the male, measuring from six to seven millimetres in length; deep red brown in colour and segmented, though the segments are hidden by a white, waxy secretion.

The life-history of this insect is so similar to that of our 
other examples from the same family, the lac insect and the San José scale, that there is no need for reiteration. The winged male dies after mating; the resting female deposits her offspring, according to some authorities, viviparously, according to others, as eggs, but whichever is the method the larvæ are covered by the waxy secretion of their mother, in which, though very active, they remain for about nine days. At first they closely resemble their mother, who, by the way, dies after oviposition; but even at this stage the sexes can be distinguished, for the antennæ of the males are composed of five segments, whilst those of the females have six. In a fortnight, after several moults, the larvæ are full grown. The male during growth surrounds itself with a waxy covering from which it emerges, in the winged, adult form, after the last moult; but the female remains on the spot where she first plunged her larval rostrum into the tissues of the prickly pear.

The commercial history of this insect is, perhaps, of greater interest than its life-history. A native of Mexico, it was known and utilised by the Aztecs before America was discovered by Europeans. Lopez de Gomara, in 1525, first described cochineal, but he took it to be a seed, and it was not till the time of Plumier, in 1666, that its true insect nature was guessed; even then, however, many scientists of that and later times persisted in believing the seed theory, so, in 1729, Melchior de Ruusscher published certain documents he had received from Mexico, which once and for all settled the question.

When the Spaniards conquered Mexico they recognised that the cochineal industry would be a source of wealth, and they at once tried to establish a monopoly, punishing with death anyone detected attempting to take the female insects out of the country. This monopoly was strictly upheld, and, as long as Mexico remained a Spanish colony, cochineal could be obtained through Spain and Spain alone. That the industry was no mean one may be gathered from 
a statement in d'Alembert and Diderot's Encyclopadia, in which they say that eight hundred thousand pounds of cochineal, of the value of 15,500,690 francs, reached Europe in 1734, and in 1760 the insect, to the value of $4,000,000$ francs, reached Marseilles alone, and De Humboldt relates that, at the time of his voyage to America, the annual export of this commodity exceeded 12,000,000 francs.

De Ruusscher gives some interesting details of the cultivation of cochineal, by the Mexicans, at the beginning of the eighteenth century. During the winter the insects were kept indoors, as a protection against inclement weather; but when the warm weather arrived, as soon as they were old enough to reproduce their kind, they were placed, twelve together, in little nests made by the natives out of hay, straw, moss, or, best of all, from the most tender fibres of the cocoa-nut. The nests and their contents were then affixed to the prickly pears, and, in due course, the larvæ emerged from the nests, sought out the greenest and youngest parts of the plants, and collected, for the most part, on the sides sheltered from the prevailing winds. During their growth they were most carefully tended and protected from their enemies, even spiders' webs being cleaned from the prickly pears, lest the precious insects should be harmed; moreover, the wild cochineal insects, which also flourished on the same plants, were considered so objectionable that they were not allowed to mingle with their pampered relatives. There were three harvests a year, and, at the last one, branches, laden with the cochineal parasites, were cut and taken indoors so that they might be protected during the rainy season. The usual method of killing the insects was either by pouring boiling water over them or by roasting them in specially constructed ovens; at times, however, they were roasted on the frying-pans which the native women used for baking their bread, and, in drying, the insects lost one-third of their weight. These cultural methods have changed but little with the march of time. 
Réaumur, the celebrated French scientist, in his writings, predicted that the time would come when cochineal would be smuggled out of Mexico, in the same manner that the silkworm had reached Europe from China. Forty years later, Thiéry de Ménonville, inspired by what Réaumur had written, travelled to Mexico, secured some of the coveted insects and took them to Port-au-Prince; a native insurrection, however, put an end to the venture, which was never repeated. In 1806 the insect made its first appearance in Europe, where its food plant had long been known. At Cadiz, Toulon, in the south of Spain, and in Italy, unsuccessful attempts were made to acclimatise it. In 1810, owing to an insurrection, Mexico was lost to Spain, and seventeen years later further attempts were made to establish the insect in Corsica, Sardinia, and in the neighbourhood of Grenada and Valencia. As before, the attempt resulted in failure, for the climate of Europe was evidently ill suited to so delicate an insect. In the same year, however, cochineal was introduced into the Canary Islands, and a veritable god-send it proved to the islanders. The director of the Botanic Gardens at Orotava, Berthelot by name, received some living specimens from Cadiz, and placed them on the prickly pears in his gardens. So well did the insects thrive that, by the end of the year, he proposed to distribute them over the island to all who had the necessary food plants on their land. His project was received with scant courtesy and almost opposition, so that it also came to naught. Almost at the same time the Spanish Government established a cochineal farm at Santa Cruz, and, despite the fact that those in charge displayed unwonted energy in the matter, sent the insects to the neighbouring islands and used every means to interest the peasant proprietors in the scheme, in less than two years all trace of the industry had vanished. Not so, however, the insects themselves. In the neighbourhood of Orotava, when left to themselves they increased rapidly, so much so 
that in 1833, after an island life of only five years, they threatened to totally destroy the prickly pears which the poorer inhabitants used as food. Measures for the extermination of the insects were set on foot, but, before they had been put into execution, some of the islanders, more far-seeing than their neighbours, took up the cultivation of the prickly pear, and, incidentally, of cochineal, with the result that the once despised insect became the greatest source of wealth that the Canary Islands have ever known. From an export of eight and a half pounds of cochineal in 1831, the Island industry increased by leaps and bounds to a total export of eight hundred and forty-two thousand eight hundred and twenty-seven pounds in 1850 . When we take into consideration that one pound of dried cochineal represents about seventy thousand insects, the insect mortality in these favourable years was beyond computation. During part of this time the vines in the Canary Islands were almost totally destroyed by a fungoid disease, and cochineal, in very truth, saved the islanders from starvation.

In the Canary Islands the insects are cultivated mainly on Cactus tuna and a dwarf species; the former, a large leaved species, is utilised in Teneriffe and the eastern islands; the latter, smaller leaved species finds favour in Las Palmas and the other islands. In the early days of the industry, women were employed to collect the insects from the plants in metal spoons-a slow method that entailed much waste; now, however, a quicker method is used. The branches are gathered and then beaten with small brooms, made of palm leaves, in order to detach the insects. This rough pruning causes the plants to send out the fresh young growth, which is so essential for the cochineal. In order to make certain that the young insects shall be well looked after in early life, the fertilised females, recognised by a reddish posterior spot, are carefully collected, covered with a linen cloth, and subjected to 
a temperature of about $20^{\circ} \mathrm{C}$. This proceeding hastens the advent of the larvæ, which, on their first appearance, show great activity, but eventually settle down on the surrounding linen. The fragments of linen are then carried by night, and fastened to the prickly pears, and without delay the larval insects affix themselves to the plant and begin feeding; the linen, however, is left on the plant for some time, to give shade to the larvæ and to keep them dry. In three months the cochineal insects are fully developed and harvest time is at hand. Women do the work, some breaking off the branches, others brushing them, in order to remove the insects, which are then spread in thin layers and dried in the sun or subjected to a temperature of about $40^{\circ} \mathrm{C}$. After drying, the insects are cleaned from portions of their food plants and other impurities and then are put on the market as plateada or as madres. The former, which are in the majority and therefore cheaper, are the young unmated females; the latter are females which have produced young.

At the present day, the cochineal insect is cultivated mainly in Honduras and the Canary Islands, and, though the industry has languished considerably since the discovery of aniline dyes, its fall is as nothing, compared to the fall in price of the commodity, which at the present day is less than a fifth of what it was in the heyday of the industry. Of the uses of cochineal we have spoken in another chapter, but the least sentimental of us must regret that a beautiful red dye, once universally used and around which hangs such an atmosphere of romance, is now mainly of service in the decoration of fancy cakes.

\section{A Wax Scale}

Under the heading "Insects and Medicine" we have mentioned Pela wax-an important commodity prepared from the scale insect, Ericerus pela. The tawny-coloured male is of relatively large size, and is possessed of 


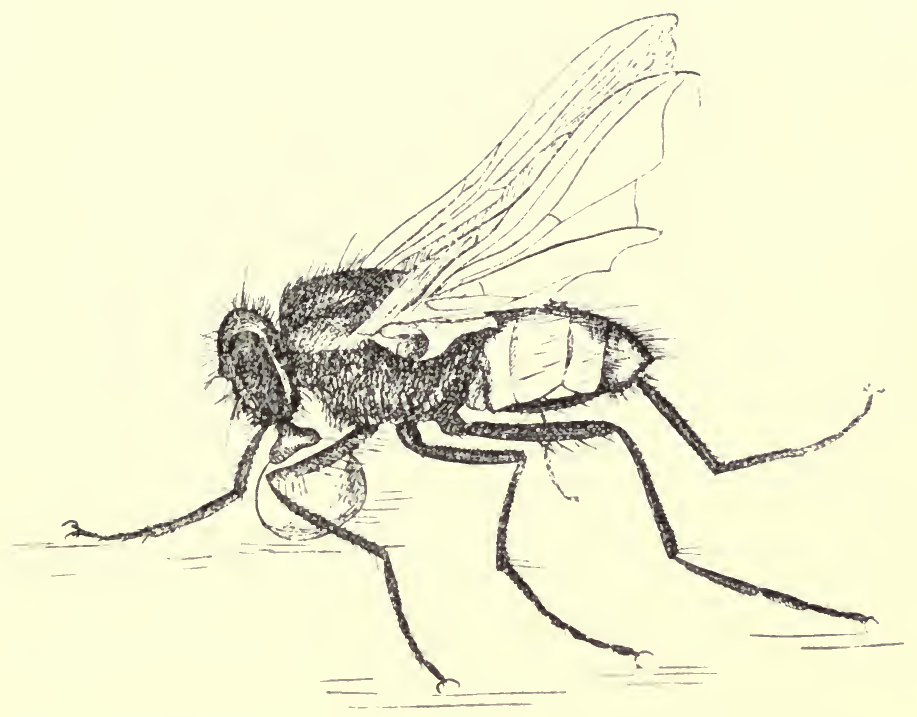

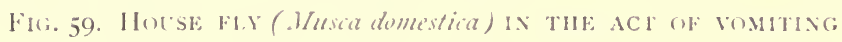

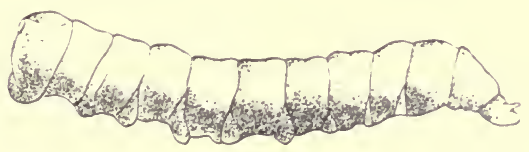

FIti. 6O. HARIA OF HOCSE FIY, Musca domestica 

correspondingly long wings and antennæ: the most remarkable fact in its economy is that it, and not the female, as is usual among scale insects, is responsible for the secretion from which, in this species, Pela wax is prepared.

According to ancient Chinese records, the culture of the wax insect, in that country, dates back to the middle of the thirteenth century, for, about that time, Chinese candles, which had been made of beeswax since the seventh century, were first made of Pela wax. As long ago as 1610, Chinese writers had described the life-history of this insect with remarkable accuracy, which, in all essentials, resembles that of the majority of scale insects. There is considerable difficulty in identifying the various trees on which Ericerus pela lives and secretes its wax, but reliable authorities are agreed that it thrives on Rhus succedanea, Fraxinus chinensis, Ligustrum glabrum, Ligustrum lucidum, Hibiscus syriacus, and Celastrus ceriferus. To all these trees the insect does extensive damage, for, like all members of the family, the wax scale obtains its nutriment by sucking the juices of the host plant. The owners are, of course, recompensed by the value of the wax; but, to prevent total destruction of the trees, the insects are removed to other feeding grounds, after from one to three years, and the trees are given a corresponding rest.

The greater part of the cultivation of Pela is carried on in the province of Sse-tchouen, and Élisée Reclus gives some interesting details of the industry in his Nouvelle geographie universelle, of which the following is a free translation: "One of the most curious agricultural industries of the district is the cultivation of this vegetable wax or peî-la, which can only be carried on by a division of labour between the inhabitants of two remote districts. The insect (Coccus pela) which forms the wax is born and lives upon the leaves of Ligustrum lucidum, in the Kientchang 
country, near Ningyuen. At the end of April the cultivators carefully collect the eggs of this insect and carry them to Kia-ting-fou, fourteen days' march on the other side of a chain of mountains. The route is very difficult, and is accomplished by night marches, so that the eggs may not suffer from the heat; from afar, all the lights which may be seen on the winding mountain road produce a very picturesque effect. For China the unique exception is made of leaving the gates of Kia-ting-fou constantly open during the egg-collecting season. After transportation, however, the most difficult part of the business begins; the eggs have to be detached from the branches on which they have been carried and placed on a tree of a different species, Fraxinus chinensis, where the insects are born and produce the white wax so valued by the Chinese. . . . The total value of the wax harvest in Sse-tchouen is estimated by Richthofen at fourteen million francs. The ownership of the wax-bearing trees is very much split up; usually they belong to other peasants than those who own the ground beneath their shade."

The wax, when collected, is first dried in the sun, and here we may mention that some authorities considered the wax to be a secretion of the insect and others looked upon it as an exudation from the trees; the former, which has always been the Chinese opinion, is the correct one, Pela wax being analogous to beeswax. The dried wax is then placed on a linen sheet over the mouth of an earthenware vessel, which, in.turn, is plunged in boiling water: this causes the finer wax to melt and pass through the linen (which acts as a filter) into the earthenware vessel where it collects. The coarser wax which remains on the linen is put into silken sacks, and thrown into boiling oil, with which it combines and forms a fit substance for the manufacture of candles. The pure wax is used in China much as beeswax is used with us; it is perfectly white, and without taste or smell, not greasy to the touch, and, in the 
mouth, becomes reduced to a dry, non-adhesive powder; it is harder than beeswax, owing to its fibrous structure.

Here we must bid farewell to the useful insects, not because we have enumerated them all, but on account of the exigencies of space. Of bees as honey producers and of silkworms we have made no mention : in general, their utility is known to everyone, and their culture has become so specialised that a very considerable literature is devoted to them. The parasitic and predaceous insects mentioned in Chapter VIII., together with a multitudinous host, not mentioned, are also man's friends. Many insects, which in the main are decidedly injurious, have some points in their favour; the much despised house fly is of considerable utility as a scavenger; cockroaches, despite their loathsome habits, rid our houses of bed bugs, and examples innumerable might be quoted. Though man is very deeply indebted to some few insects, not only for his luxuries but for his everyday needs, it is impossible, despite the wish to do so, to contend that insects on the whole can be considered in any other light than as inveterate enemies. 


\section{VI \\ HOUSEHOLD INSECTS}

The House Fly

There is no insect better known to the world at large than the common house fly, Musca domestica, though, truth to tell, this omnipresent insect is often confused with other house-frequenting flies and with the lesser house fly, Fannia canicularis, in particular. The house fly belongs to the Diptera family, that is to say, to the twowinged flies, its hind wings being reduced to a pair of stalked knob-like structures, known as balancers or halteres. A few anatomical details will render the behaviour and habits of the fly more easy to understand. On either side of the head are the compound eyes, wider apart in the female than in the male, and each composed of about four thousand small eyes; on the top of the head are three simple eyes, arranged in a triangle. The most important organ, from the housewife's point of view, is the proboscis, in reality a modified mouth, terminated by a pair of soft lips, forming a heart-shaped structure, in the middle of which is the aperture through which food is sucked; this fly is absolutely devoid of any structure capable of piercing the skin, though it is often accused of biting, owing to the fact that it closely resembles the stable fly, which has a piercing mouth. From the nature of its mouth organs, all food normally taken up by the fly must perforce be in liquid form. When sugar is the diet, the insect first of all pours upon it a quantity of saliva from its salivary glands, thereby bringing its food into 
solution; having done so, the liquid is sucked up by a powerful pump-like structure, situated just behind the mouth, into the crop, which is really a food reservoir on which the fly may draw when at rest, much as a ruminating animal does when chewing the cud. Frequently the fly regurgitates some of this food and deposits it on the surface where it is resting, in the form of a light-coloured vomit spot (fig. 59), easily distinguishable from the brown excrement spot. Sometimes the regurgitated food is reabsorbed instead of being deposited as a vomit spot.

Known practically wherever mankind exists, the house fly may be said to be truly cosmopolitan, its range extending even to the Arctic and Antarctic circles, though its abundance and activity increases with a rise of temperature. Apart from temperature, the most potent factor in the abundance of these insects is the presence of garbage, for "filth and flies are practically synonymous terms." "As illustrating the abundance of flies in relation to the breeding places, Major Faichne, in India, reared about four thousand flies from one-sixth of a cubic foot of ground from a latrine and as many as five hundred from a single dropping of human excreta. Herms in California obtained ten thousand two hundred and eighty-two larvæ of the house fly from fifteen pounds of samples taken from five different parts of a manure pile after four days' exposure. The whole manure pile weighed about a thousand pounds, and on a conservative estimate it would contain over four hundred and fifty-five thousand maggots. From one and three-quarter pounds of manure collected at random two thousand five hundred and sixty-one pupæ of the house fly were obtained." These data show that the house fly is remarkably prolific, mainly on account of its rapid development and the prevalence of suitable media in which to oviposit.

Heaps of stable manure form the most favoured breeding places for these insects; but if this medium be not available, 
cow or fowl dung, human excrement, straw, sacking, and other manufactured stuffs soiled by excrement, decaying vegetable matter, and even the contents of slop-pails and spittoons may be selected as suitable nurseries for the larvæ. From June to October are the months during which egg laying normally takes place, though in warm kitchens the process may continue during the winter. Each female deposits five or six batches of eggs, each one containing from one hundred to one hundred and fifty oval, pearly white eggs about $\frac{1}{25}$ in. long. Under favourable conditions the larvæ emerge in from eight to twenty-four hours. After two moults, taking place respectively after about twentyfour and forty-eight hours, the larvæ are full grown (fig. 60) and are then about half an inch in length, cream coloured, and legless. The head end of the larva is pointed and provided with a hooked process, which is used in locomotion and in tearing up food; the posterior end, or the thirteenth segment, is furnished with a pair of eye-like spiracles or breathing pores; on the under surface of the sixth to the twelfth segments are pads furnished with recurved spines, also used in locomotion. Almost the whole of the larval period is passed literally within the food material on which the maggot feeds; but, when the time for pupation arrives, a short emigration takes place to some drier situation, the maggot contracts, assumes a cylindrical form, and changes into a dark brown, barrel-shaped pupa, from which the perfect fly emerges in from three to four days. The adult insect is so well known that a description of its appearance ought to be unnecessary; so frequently, however, is it confused with other house-frequenting flies that a brief mention of its more salient characters may not be out of place. The front of the dark head is marked with a black stripe; the prominent compound eyes are wider apart in the females than in the males, as is usual among the Diptera. The grey thorax bears four equidistant black stripes, whilst the yellow abdomen has a medium dark 


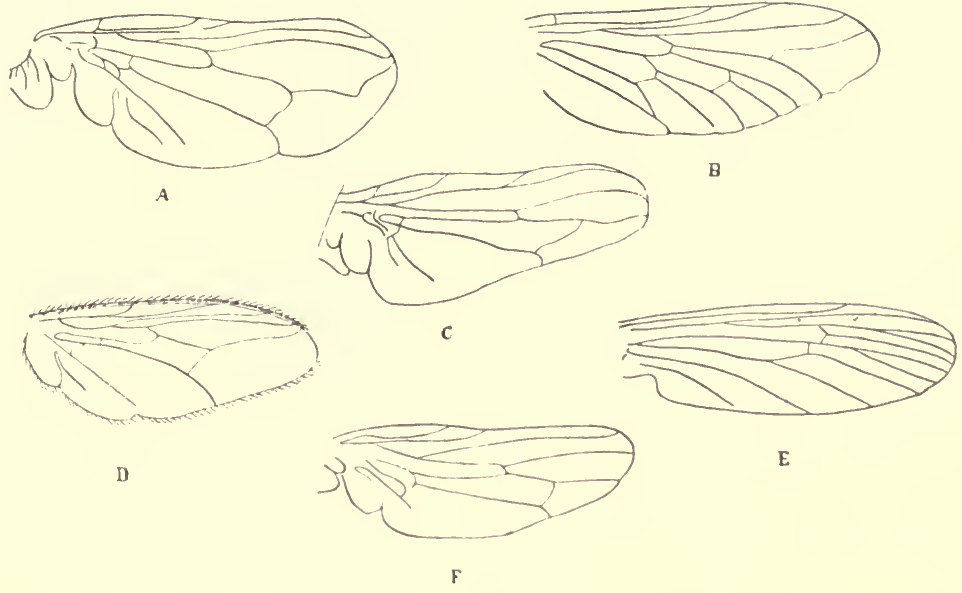

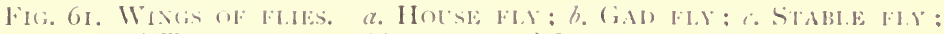
d. TSETSE FI,

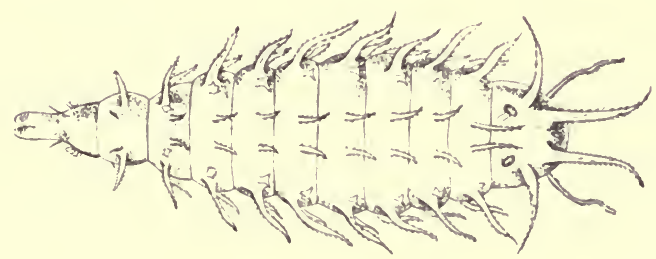

FHG, 62. LARIA OF L.FSSER IIOLSE FIS, Fannia ianicularis 

stripe and a dark tip. The venation of the wing (fig. 61) should be earefully noted, because the course of the fourth longitudinal vein serves to distinguish this insect from other flies. In many towns of Great Britain, and even of other countries, the house-fly population has from time to time been subjected to a census. Taking an average of these investigations in this country, it is found that ninetyfive per cent. are true house flies, Musca domestica, and the balance is composed of the lesser house fly, Fannia canicularis, the blow fly or blue-bottle, Calliphora erythrocephala, the stable fly, Stomoxys calcitrans, the fly which the Americans call the stable fly, Muscina stabulans, and others.

The lesser house fly, Fannic canicularis, so closely resembles the house fly in general appearance, except for its smaller size, that it is popularly considered to be a young house fly; as a matter of fact, the adult fly does not grow; when it emerges from the pupa it has attained its full growth and no further increase in size takes place. Apart from its size, the fact that the fourth longitudinal vein of the wing runs straight to the margin, instead of bending at an angle (tig. 61), serves to distinguish the house fly from the lesser house fly. The thorax, too, is striped with three, instead of four, dark lines, and the abdomen is more pointed than in the house fly. The characteristic, jerky flight of these flies, usually near the ceiling or round a gas bracket, is quite unlike the heavier more laboured flight of Musca domestica. In habits the two flies are somewhat similar. The lesser house fly appears earlier in the year than the true house fly and also disappears earlier. Oviposition takes place either in decaying animal or vegetable matter. The eggs resemble those of Musca domestica, but the larvæ (fig. 62) are quite unlike those of the house fly. About a quarter of an inch in length, considerably flattened, and armed with a double row of spines down the back and a double row down each side of the body, they are quite 
distinct from most dipterous larvæ. The pupa is of the usual brown colour and barrel shape.

The blow fly or blue-bottle, Calliphora erythrocephala, cannot be mistaken for the house flies already mentioned; its larger size, its dark blue colour, and its rapid, noisy flight render it a most conspicuous insect. On occasion, oviposition may take place in excrement and decaying vegetable matter, but it is on meat that the eggs are usually laid. The females are exceedingly prolific, as many as six hundred eggs being deposited by a single fly. In from eight to twenty hours the larvæ, commonly called gentles, emerge; they may be distinguished from those of the house fly by their larger size and by the twelve tubercles on the posterior end. In a little over a week the pupal stage is reached, and it usually lasts a fortnight.

The stable fly, Stomoxys calcitrans (fig. 32), is very closely related to, and often confused with, the house fly. A moment's examination with a lens will reveal the fact that this fly is armed with an awl-like proboscis, which usually projects straight forward from beneath its head, whereas the house fly has a soft sucking proboscis. There are other differences, of course, but, as the stable fly is described elsewhere, we need not enumerate them here. This insect is only an occasional visitor to houses; it is a lover of the sun and open air, and, as its popular name implies, it is usually found in propinquity to horses and cattle.

Muscina stabulans, as we have mentioned, is called the stable fly in America, though the name is a misnomer, for the fly is not a frequenter of stables. Like Fannia canicularis, it is active in the early summer, and in appearance it resembles a large house fly. It is a vegetable feeder, and lays its eggs in rotting animal or vegetable matter.

Two other flies found in houses, from time to time, are the latrine fly, Fannia scalaris, and the cluster fly, Pollenia rudis. The former closely resembles the lesser house fly, 
though it is slightly larger; the larvæ also are similar, but they may be distinguished by the fact that, instead of a double row of lateral spines, they have rows of featherlike appendages. The eggs are commonly laid in human excrement, and in about eighteen hours the larvæ emerge; in a little over a week they are full grown, and the pupal stage is of approximately the same duration. Pollenia rudis, the cluster fly, despite its reddish-grey colour and stout build, is often mistaken for the house fly. It frequents houses in spring and autumn, is very sluggish in its movements, and has a habit of collecting in numbers where it is unlikely to be disturbed; hence its popular name.

Some other less frequent visitors to houses may be mentioned, because their occasional appearance indoors gives rise to considerable conjecture as to their identity. Often, especially in outhouses, a long-bodied, black, sluggish, hump-backed fly, with yellowish legs and wings, may be found on the windows; it is the window fly, Scenopinus fenestralis. Its larvæ are much more elongated than those of the other flies we have mentioned, quite snake-like in fact. Verrall says: "The larva was at one time supposed to feed on stable clothing and old carpets, especially when thrown into a heap and neglected, whence the perfect insect obtained the name of 'carpet fly.' It is now, however, known to be predaceous and to feed on the larvæ of the clothes moth, Tinea pellionella, or of the Pulicida, fleas, which are the real culprits, and consequently is a benefactor instead of being injurious."

Fruit flies, Drosophila fenestrarum, and its relatives, are attracted to houses by the smell of over-ripe and decaying fruit. They are very small, thick set, yellowish flies, and some very interesting experiments have been carried out with them, with a view to testing their sense of smell. Space, or lack of it, forbids any account of these experiments; reference is made to them in the bibliography; it is interesting to note, however, among other things, that the 
sense of smell by which their food is discovered is situated in the last segment of their antennæ. The yellow dung fly, Scatophaga stercoraria, spends most of its time in the vicinity of cow dung; nevertheless, at times it finds its way into country houses. The female is yellowish brown with a hairless body and the male is bright yellow and hairy.

The green-bottle fly, Lucilia caesar, is not very common in houses, though decaying animal matter, especially fish, will often tempt it indoors. In appearance it resembles a small blow fly, except that it is of a metallic green colour. Many other flies, among them the cheese fly, mentioned elsewhere, are known to enter houses, and the list of these occasional intruders is a lengthy one. Though it cannot be said that all, or even the majority, of the flies we have mentioned carry diseases, all, with the exception of the window fly, are closely associated with excrement and decaying animal or vegetable matter, so that their bodies are, perforce, soiled with unpleasant, if not injurious, substances, and accordingly they should be looked upon as enemies of mankind. We may aptly conclude our brief review of the house flies in the words of $\mathrm{Dr}$ Hewitt: "Many inquirers have asked whether house flies do not perform some good service, in accordance with the doctrine that there is some good purpose bound up in the existence of every creature. To such persons my reply is in the affirmative. House flies certainly perform a valuable service; they indicate the presence of filth, and are the sanitarian's danger signals, his red lamps, in fact. House flies are indications of the fact that insanitary conditions are present, that the machinery requisite for an epidemic of typhoid fever is in excellent working order, and that more children are dying each year from intestinal disease than should be the case. When these facts are realised, the house fly will stand out in its true light as a potential destroyer of human life."

What can be done to abate this evil? Much has been 


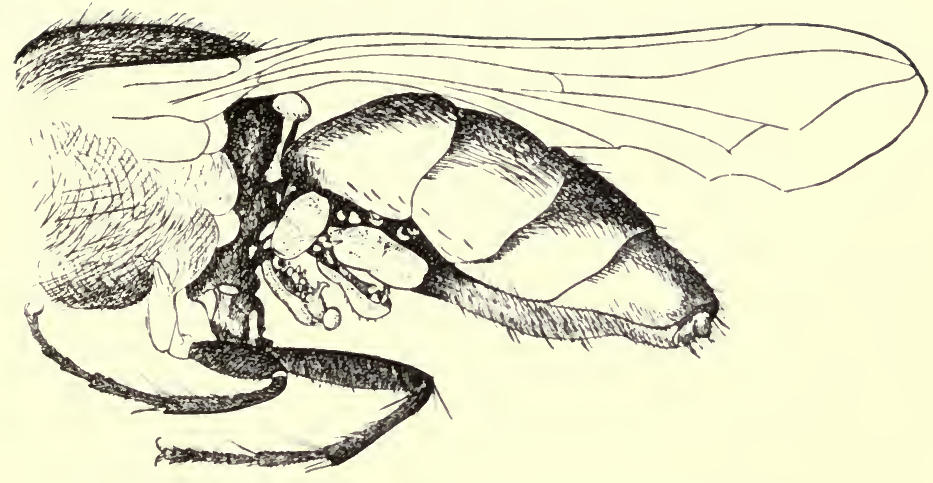

Fig. 63. PARASITIC TICKS ON BOIY OF HOUSE FIY

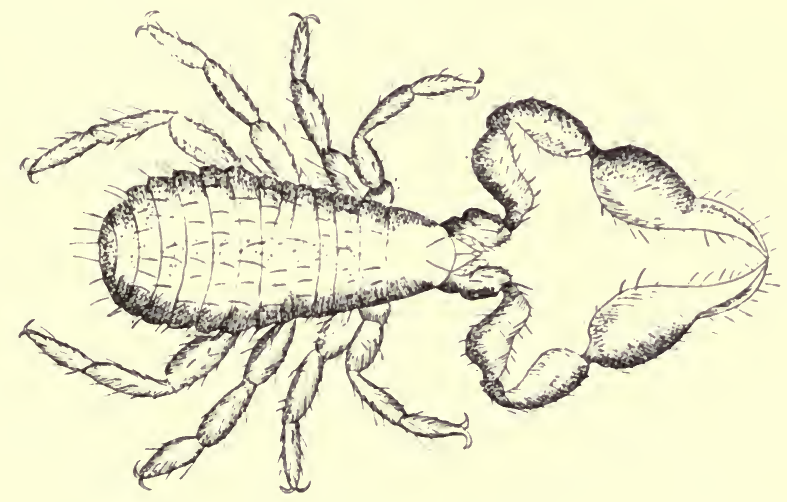

Fig. 64. A CHELIFER 


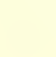


done by man, and much remains to be done, but the subject is somewhat beyond our sphere. Let us consider for a moment what natural agencies are at work in the control of house flies. Towards autumn many flies are to be seen, in perfectly natural positions, attached to walls, etc. A careful examination of these dead insects will reveal the fact that they are more or less covered by a white fungus. They have been killed, in fact, by the fungus, Empusa musce, belonging to a group of non-green plants, the various members of which confine their attacks to insects, and collectively are responsible for a considerable mortality. The exact means by which the flies become infected is not known, but it appears to be the only disease which normally attacks house flies, though individuals which have become infected with plague bacilli have been shown to be short-lived.

Various mites may be found attached to the bodies of house flies, some of them truly parasitic, others merely using the insect as a means of transport. Minute, red mites, belonging to the family Trombidiide, are often found clinging at the base of the wings and sucking up the juices of their host with their thread-like mandibles: the fact of their being six-legged shows that they are immature. Later, they leave their hosts, moult, and appear as bright red, hairy, free living adults. Mites, of the family Tarsonemida, are sometimes found clinging to the abdomens of house flies, though whether as true parasites or merely as passengers is not known. Cheese mites in the hypopus stage, described elsewhere, are also often fixed by their suckers to flies, and in this respect these insects must be considered as frequent carriers of food-destroying mites. Other mites, belonging to the group Gamasida, frequent rubbish heaps in the larval stage, and are therefore frequently transported by flies. The small, flat brownish creatures are, on occasion, parasitic, and adhere by their mouths to the ventral surface of their hosts (fig. 63). 
On the legs of house flies, small reddish-brown chelifers or false scorpions (fig. 64) are often found. Armed with a pair of relatively formidable pincers, they are enabled to obtain a firm hold of their host, but whether they so obtain their food is not known. When not attached to a host their habitat is the manure heap.

A number of internal protozoon parasites are known to occur in the alimentary tracts of flies; they belong to the genera Crithidia and Herpetomonas, and in some respects resemble the trypanosomes which are responsible for sleeping sickness in man; they appear to have little or no effect on their hosts.

A nematode worm, Habronema musca, has also been found infesting various domestic flies, in this country and abroad, without ill effect. It usually takes up its abode in the head or proboscis. Ransom found "that the worm lives in the stomach of the horse, and that the embryos which pass out in the fæces enter the fly larvæ. When the flies emerge the larvæ are full grown, but have to pass into the intestinal canal of the horse before reaching maturity."

Hymenopterous parasites, of various species, are known to attack the house-fly maggots, but the subject has not, as yet, received the study it deserves. The adults are caught and killed by various robber flies, and in the United States a small centipede, Scutigera forceps, kills large numbers. Lizards, toads, and birds destroy both larvæ and adults. Predatory beetles and, in the tropics, ants cause considerable havoc among pupæ and larvæ, but man is the house fly's greatest enemy, and man alone can materially lessen the numbers of this death-dealing insect.

\section{Two Pests of Cheese}

Very common, and accordingly well known, household pests are the cheese mites (fig. 65), Tyroglyphus longior and Tyroglyphus siro. Strictly speaking, of course, these 
little animals are not insects at all, for they are possessed of eight legs, instead of the six with which all true insects are provided. Despite their minuteness, they have been known from very early times, and, by Aristotle, they were considered to be the smallest of living creatures. Their small size, varied diet-they can live upon ham, flour, and other stored goods, as readily as upon cheese,--coupled with a fecundity that is almost incredible, has resulted in their attaining an almost world-wide distribution. The two species are often to be found feeding together; both are almost colourless, but Tyroglyphus longior is the larger of the two and has longer hairs projecting from its more elongated and cylindrical body; it is also less lethargic in its movements. The life-history of the cheese mite is curious and interesting. One stage, the hypopus, is so unlike the parent mite that, for a long time, it was considered to belong to another genus; in fact, it was not till 1868 that Claparide showed that the hypopus was really a stage in the development of the Tyroglyphids.

Every housewife knows how a cheese, once attacked by a few mites, quickly becomes a crawling mass and is finally reduced to the state of a powder, composed of mites, together with their excrement and cast-off skins-an appetising morsel for the most fastidious palate! This rapid increase in the cheese mite community is specially noticeable in the warm summer months, and is partly accounted for by the fact that the females are viviparous-they produce living young, and so, by eliminating the egg stage, there is a considerable saving of time. The young are soon full-grown, and at once proceed to their main business of life, the multiplication of their kind.

The most interesting question in the life-history of a cheese mite is, What becomes of the mites when all the cheese is eaten? A study of the mites during the summer months will not be much help. Their powers of locomotion are feeble, and their bodies are soft and easily damaged, so 
that it is highly improbable that they will walk from one cheese to another. When no more food is at hand, the young mites and the old ones die off, and considerately leave the field clear for the more vigorous, middle-aged individuals. The survivors completely change their form by acquiring a hard, brown, protective covering, into which their legs can be drawn, and, at the same time, their existence, without food, can be almost indefinitely prolonged. This is known as the hypopus stage. As everything comes to him who waits, sooner or later a mouse or a house fly or perhaps a cockroach comes along in quest of food, the hypopus shoots out its legs and eagerly seizes some convenient hair, to which it clings, till it is carried to a spot where suitable food is at hand, then, relaxing its hold, it throws off its horny coat and begins life afresh.

Another inhabitant of cheese and ham is the "skipper," Piophila casei (fig. 66). It is, perhaps, not quite so well known as the mites, though more repulsive when encountered, because its greater size makes it more obvious, and the old dictum about "What the eye doesn't see, etc.," applies just as forcibly in household entomology as in other directions. Like the cheese mites, the cheese skipper is cosmopolitan. It derives its name from the wonderful leaping powers of the maggot or larva, which, although only one-fifth of an inch long, can jump to a height of three to four inches, by bringing the two ends of its body together and then suddenly releasing them like a spring. The "skipper" is the larval form of a small, glistening, black, two-winged fly, which lays its eggs in the outer, fatty parts of hams or in cheeses, preferably the best. Each female lays about thirty slender, oblong, and slightly curved white eggs, either in compact clusters of five to fifteen, or, occasionally, they are scattered singly. In thirtysix hours the eggs hatch into small white, cylindrical, legless maggots or skippers, which taper gradually to the anterior or head end, whilst the posterior truncate end is 


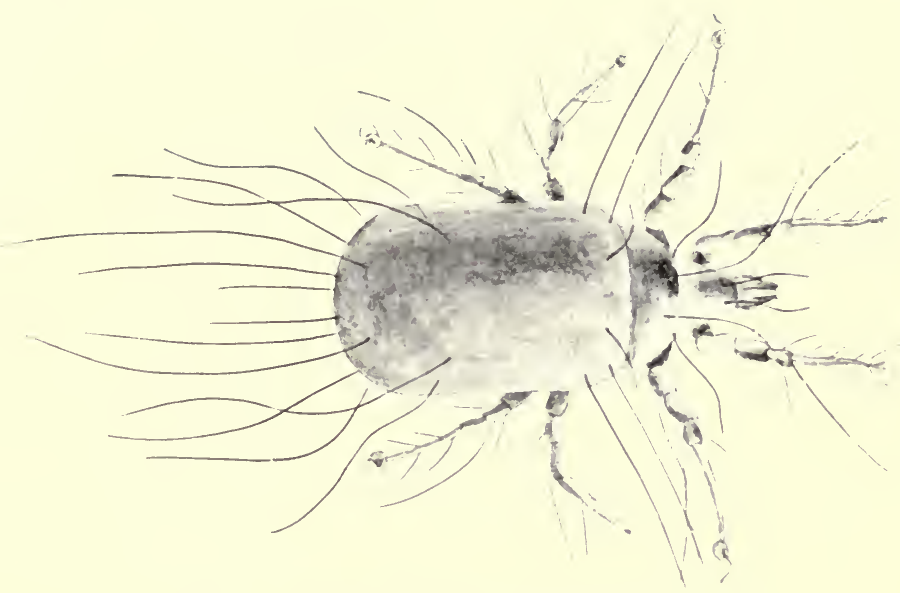

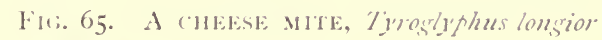

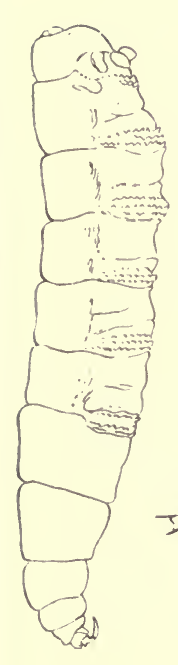

Fil. 67.

THE CHEESE "SKIPPER" I.ARVA

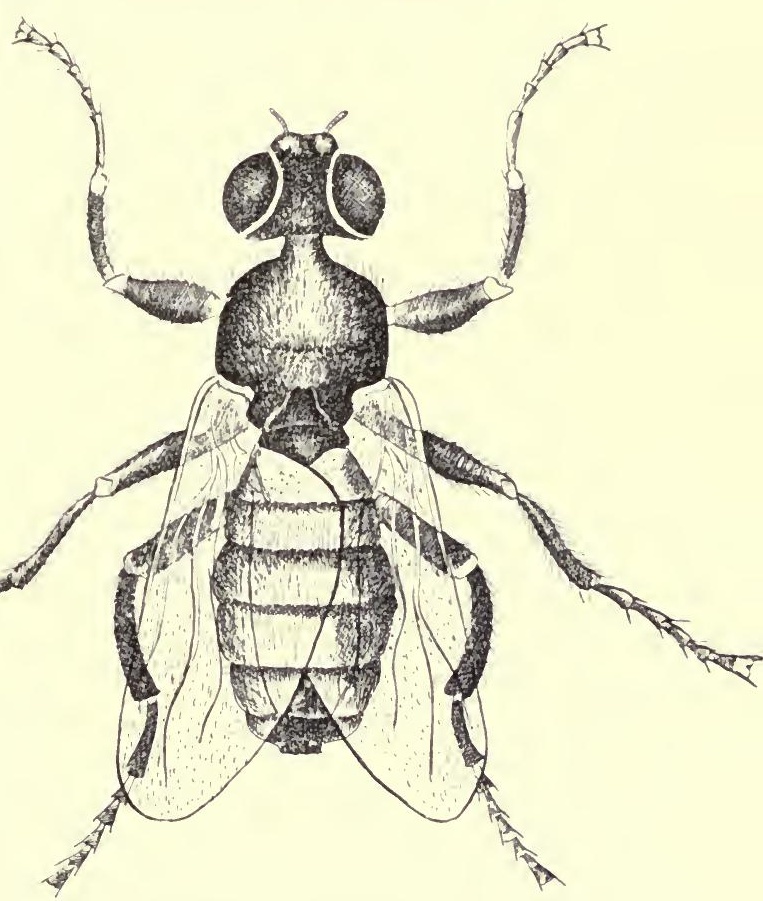

Fi(s. 66. The cheese "skipper" Firy, Piophila casei 

furnished with a pair of horny, projecting breathing organs or stigmata and a pair of fleshy filaments (fig. 67). If the food supply is plentiful, the skippers move but little, and often complete their growth in seven to eight days in the cavity in which the mother laid her eggs. When full grown, the skippers continue to feed for a period of seven days, then they move to a dry spot, contract, turn yellow, and gradually change into golden brown pupæ. In ten days the flies issue, and thus the life-cycle is completed, in a little over three weeks. If the conditions are unfavourable, owing to a shortage of food or low temperature or both, some or all of the stages may be prolonged, so that five weeks may elapse before the completion of the life-cycle. There are three broods in a year. Although the cheese skipper can scarcely be designated a serious household pest, it is an annoying one, for, given the choice between, say, a Canadian cheese and a Stilton, the discriminating fly would invariably select the latter as the domicile for its offspring.

\section{The Argentine Ant}

The Argentine ant, Iridomyrmex humilis (fig. 68), finds a place in these pages, not only on account of the inherent interest of its habits, but also because it is, what may be termed, one of the "coming" pests in the great North American Continent. It is included here amongst the household pests, because it takes front rank as such; but, at the same time, it is a serious pest to sugar planters and others engaged in agriculture and horticulture. The ant has received its popular name from the fact that Argentina is believed to be one, at least, of the countries in which it is native. At first it was called the "New Orleans ant," for a reason which will be apparent later; other names which have been suggested and dropped, on account of their inapplicability, are the "crazy ant," the "tropical ant," and the "pernicious ant." 
The naming of the ant after the country of its origin finds its counterpart in the Colorado potato beetle, the Mexican cotton boll weevil, the American cockroach, the San José scale, etc. American entomologists declare that this insect is not excelled in destructiveness by the gipsy moth, the boll weevil, or the San José scale-a statement the gravity of which will be realised by those who read the pages devoted to these pests. Limited at present in the United States to relatively small areas, the insect is steadily advancing, and is likely to spread over a large district. First observed in New Orleans, Louisiana (hence one of its names), a little more than twenty years ago, it has now increased from " a few scattered and apparently insignificant specimens to armies and hordes numbering myriads of individuals. It has spread from a few blocks on the water front of the Mississippi River over practically the entire city, and has sent out vast numbers of colonists for hundreds of miles along the railways and waterways radiating from New Orleans. These pioneers have succeeded in founding scores of communities of more or less importance in the smaller cities and towns. Each of these communities is in turn furnishing its quota of migrants, and these are extending the affected territory in all directions from the original source of infestation. Thus, instead of the dispersion being from one source only, it is now taking place from hundreds of different points.

"From an unknown and little noticed insect this ant has developed into one of the foremost household pests in the world, and its ravages affect, directly or indirectly, the majority of the crops grown in the South. Former indifference to its movements has given way to concern at its approach." America is not the only country that has fallen under the spell of this voracious and destructive little insect. Introduced, by accident, into Madeira, it entirely exterminated another ant, Pheidole megacephala, which itself had, on its introduction to the island, ex- 


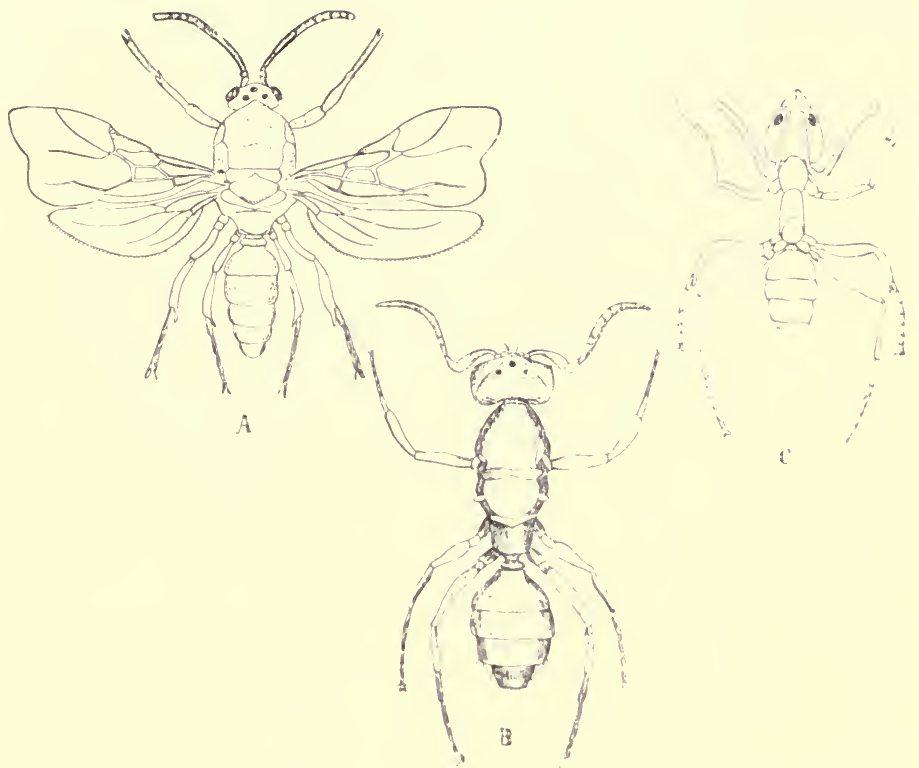

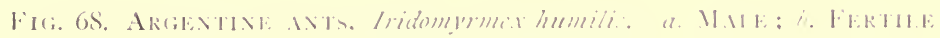

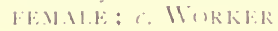



terminated the native ants, and the author can vouch for the extreme personal discomfort caused by this little insect, in certain parts of its adopted home. During the late Boer War, large quantities of forage were imported to Cape Town from Argentina. With it came the Argentine ant, and established itself so well that in five years it became a household nuisance. Indeed, so readily does the insect become established, under suitable climatic conditions, that there is every reason to believe it will eventually become a pest of the first order in all the semitropical countries of the world. It is of interest to note that man himself is the main distributing agent of the Argentine ant. Under normal conditions, the natural rate of spread does not amount to more than a few hundred yards in each year, but, by means of railways, boats, etc., this natural distribution rate is completely put in the shade. Packing material of all kinds, plants, cases of groceries, and even of household utensils, all form suitable vehicles for transport, and the only essential to the successful founding of a new colony is that a fertile queen and some workers be present, for the workers alone are unable to reproduce their kind, and, in a strange land, would eventually die off.

From the economic point of view the Argentine ant is of extreme importance. During rainy weather they invade houses in myriads, and, if allowed to do so, they literally swarm over all kinds of food stuffs, those most eagerly sought being honey, sugar, sweetmeats of all kinds, jams, marmalades, preserved fruits, cream, olive oil, lard, eggs (raw or cooked), raw meat of all kinds, and, to a slight extent, flour. Quite apart from their feeding habits, they become an intolerable nuisance in a house, the discovery of even small quantities of anything edible is quickly signalled to the nest, whence thousands of workers issue to carry away the plunder. Their very intelligence renders them obnoxious. They run all over one's person without compunction, and will attack any part of the body, where the 
skin is tender enough for their mandibles to pierce. In short, it requires the greatest ingenuity to circumvent these little insects; they will even enter refrigerators in search of food.

In gardens they are no less a pest. Their depredations on the plant tissues are bad enough, in all conscience, but the damage does not stop there, for these insects have an interesting, though disastrous, habit of cultivating countless thousands of scale insects and plant lice, whose excrement furnishes the choicest delicacy with which the ants regale themselves. The result of this protective care is that these insects increase rapidly, with resultant damage to the infested plants. In sugar plantations this habit is specially noxious, because the ant shows great partiality for the excretions of the sugar-cane mealy-bug, Pseudococcus calcolarioe. So solicitous for the welfare of these noxious insects is the ant, that it builds shelters over their colonies to protect them from storms and enemies, and tends them with unremitting care (Plate XV.). In orange groves this habit of the Argentine ant has resulted in a vast increase of scale insects; and in fig plantations an injurious scale insect, Pseudococcus citri, is also a protégée of this little insect. Green flies or aphides, too, are always more abundant when the Argentine ant is present, and, in addition to being very unpleasant when they occur on vegetables, they are exceedingly harmful to all kinds of crops. In maizegrowing districts, and in cotton fields, aphides have been found to be not only more numerous but more widely distributed when the ants are present, for they, like the scale insects, are carefully nurtured by the ants. The control of scale insects and aphides, therefore, in such districts, practically resolves itself into control of the ants. So much for indirect damage, which in itself is considerable, but is not the only fault that can be laid at the door of Idiomyrmex humilis. Great damage is done by the ants to flowers of all kinds in their search for nectar-the fruit 


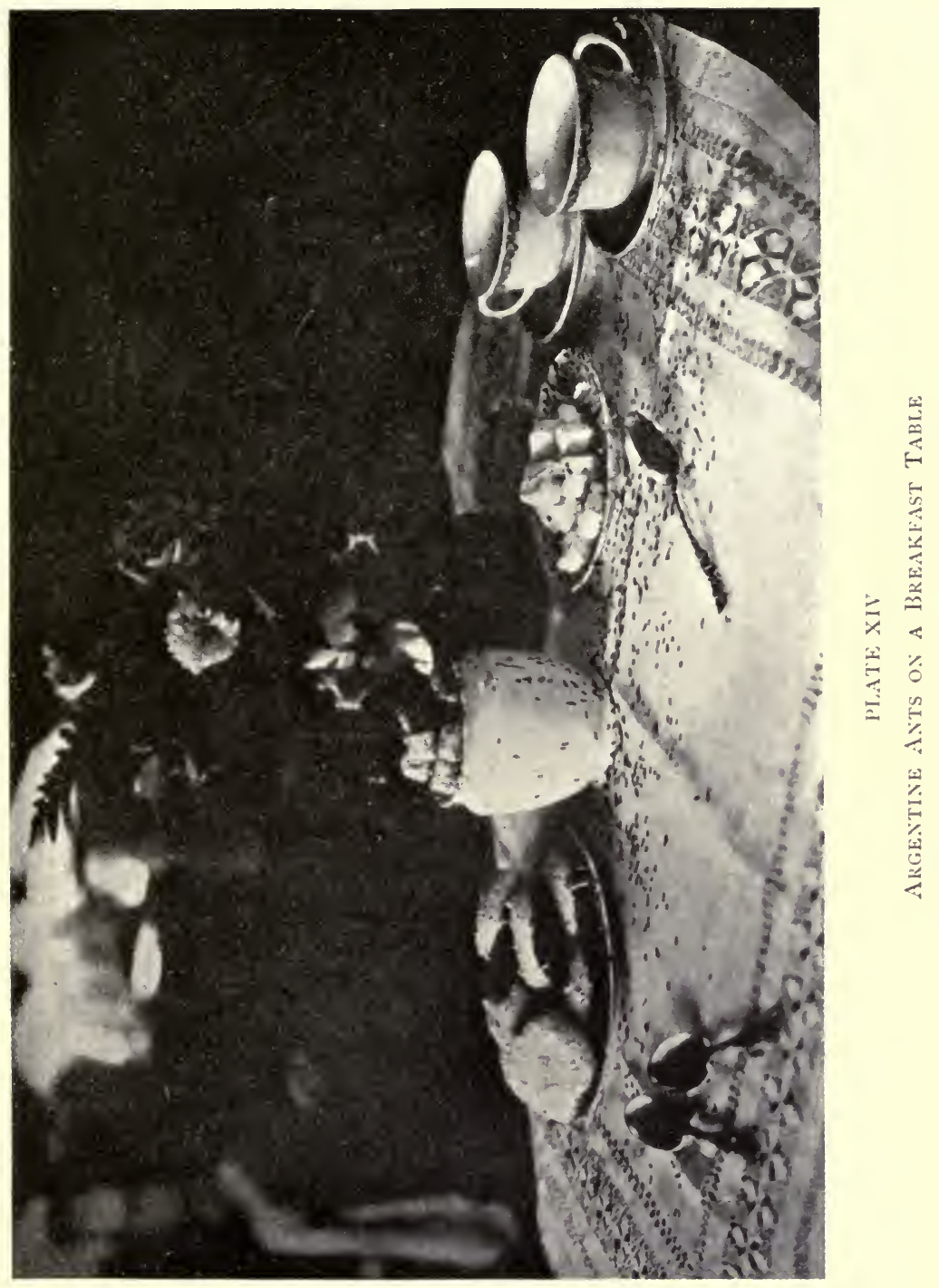



buds of the orange, immature figs, and the floral organs of the cotton pay a heavy toll to these insects. Garden seeds also, in variety, are removed before they have germinated; for seeds of lettuce these insects show a special predilection.

Turning, for the moment, from the plant world, we find that the animal world is no less favoured by the Argentine ant. Among bees these insects are especially destructive, and their appearance, in appreciable numbers, is always the signal for the abandonment of bee-keeping. The nests of sitting hens possess a particular attraction, and a broken egg attracts the ants in such numbers as to cause the hen to forsake her nest; even newly hatched chicks are frequently attacked by such a numerous host as to rapidly succumb. Wild birds, too, suffer in the same way, and many young birds are thus destroyed, the ubiquitous English sparrow alone appearing to survive the ordeal unscathed. Even this lengthy indictment does not exhaust the activities of the Argentine ant, for it is slowly but surely annihilating a beneficial American native species known as the "fire ant," Solenopsis geminata, which is valued on account of the fact that it destroys vast numbers of the immature cotton-boll weevils.

As a probable, though as yet unconvicted, carrier of disease the Argentine ant should be carefully watched. Attracted by the odours common to such places, it is a frequent visitor to sick-rooms, and it has actually been seen busily carrying away the sputum of a negro who was suffering from tuberculosis. Such a pest, in fact, has the ant become in parts of Louisiana, that the value of land depends to a considerable extent on its presence or absence.

For the benefit of that considerable section of the public who maintain that every living thing serves some useful purpose, and in fairness to the insect itself, it must be said to have a few good points. In the poorer districts of New Orleans the ant has completely exterminated the bed 
bugs; termites, the so-called "white ants," which may be classed as noxious insects, are captured and killed at every opportunity. Sorghum midges, Contarinia sorghicola, inveterate enemies of sorghum, maize, etc., find their greatest natural enemy in the Argentine ant; whilst its action, in destroying other ants, assumes either a beneficial or an injurious aspect according to whether the annihilated ant is itself beneficial or injurious.

The Argentine ant is gregarious, living in colonies comprised of females or queens, males (fig. 68, A) and workers. There are no major and minor workers and no special scouts or soldiers, such as occur in some other ant colonies. The females (fig. $68, \mathrm{~B}$ ) are 4.5 to 5 millimetres, the males $2 \cdot 8$ to 3 millimetres, and the workers $2 \cdot 2$ to $2 \cdot 6$ millimetres in length; all are dark brown, nearly black, in colour. The white elliptical eggs have a pearly lustre, and the very delicate and thin shells are mucilaginous, so that they adhere to one another. On this account they can be deposited on the walls and ceilings of the ant's dwellings, and can, when necessary, be handled en masse by the workers. When the eggs are about to hatch they become less lustrous, quite dull in fact, and they frequently assume the general contour of the contained larvæ, making it very difficult to distinguish between such eggs and newly hatched larvæ. In specially constructed cages, where the ants can be kept under observation, it is interesting to note the great care which the workers (fig. 68, c) take of the eggs, in order to secure the proper amount of humidity. Now the workers are piling up the eggs in one corner of their cage, now collecting them in the centre, next, may be, they will be moved to another compartment altogether or stuck to the ceiling. Many times a day, in fact, is their position changed by the assiduous workers, and sometimes eggs and pupæ are carefully separated; at other times they are jumbled together in seemingly hopeless confusion. This care of the eggs by the workers appears to be absolutely essential to 
complete embryonic development, for eggs deposited by the queens and kept for experiment away from the workers have only partially developed and never hatched. The queens are, in short, nothing more nor less than living eggproducing machines, paying no attention whatever to the eggs when once they are laid. Not so, however, the workers, for several are always in attendance on the queen when she is about to oviposit, apparently anxiously awaiting the advent of the eggs, and immediately one is deposited, often before it has even touched the floor, it is laid hold of by the worker and rushed off to the nearest "egg pile." Although the queens oviposit throughout the year, the majority of eggs are produced in the summer. The exact number of eggs laid by each queen has not been determined, but one queen was observed to deposit eggs at the rate of thirty a day over a considerable period.

After about twenty-eight days, though the time may vary from twelve to fifty-five days, the larvæ appear, and, at first, a magnifying glass is necessary to distinguish them from the eggs. The larvæ, which in their initial stages are at first much curved, though they straighten out as they grow older, are practically incapable of movement and therefore quite helpless, relying altogether on the ministrations of the attendant workers. Their reliance is not misplaced, for the workers perform their duties faithfully, feeding and grooming their charges continually, and transporting them from one place to another whenever the need arises. In times of danger, the first instinct of the worker appears to be to remove the larvæ to a place of safety, and they will readily sacrifice their own lives to save their young. The larvæ feed upon the regurgitated, and probably predigested, food of some of the workers, which do not appear, either structurally or by their actions, to be in any way different from the workers which do not carry out the duty of nurses.

The feeding of the larvæ by the workers is interesting, 
and, in the words of Professors Newell and Barber, who have several times observed the process, "the larva ordinarily lies upon its side or back. The attending worker approaches from any convenient direction, usually from one side or from the direction in which the head of the larva lies, and, spreading her mandibles, places them over the mouth parts of the larva, which are slightly extended. The tongue of the worker is also in contact with the larval mouth. While the worker holds the body and mandibles stationary a drop of light-coloured, almost transparent, fluid appears upon her tongue. This fluid disappears within the mouth of the larva, but it cannot be ascertained to what extent the larval mouth parts are moved during the operation, as they are obscured from view by the mandibles and head of the attending worker. Slight constrictions of the larval abdomen during feeding are sometimes noticeable, at other times not. The time required for feeding a single larva varies from three to thirty seconds, depending doubtless on the hunger of the 'baby.' The workers proffer food to, or at least inspect, each larva, for the worker doing the feeding will place her mandibles to the mouth of one larva after another, feeding those who seem to require it."

Feeding the larvæ is but one of the duties of the attendant workers, keeping them clean is another, and by constantly licking their charges with their tongues they keep them in a state of absolute cleanliness. As in the case with other larval ants, there is no open connection between stomach and intestine, and all undigested food is retained in the former organ till just before the semipupal stage, when communication with the intestine is established and the undigested food voided. Towards the end of the larval stage it is possible to distinguish between workers and males. The worker larvæ are not so large as the male larvæ, though in other respects they are similar; the queen larvæ have not been observed. The duration of 
this stage varies from eleven to sixty-one days, the average being about thirty-one days. In the pupal stage workers, males, and queens can be readily distinguished. The worker pupæ are, at first, almost pure white, except for two prominent jet black spots on the head-the compound eyes. Towards the end of this stage, which averages about fifteen days, the colour changes through cream and light brown to quite dark brown. The male pupa, which is half as large again as the worker pupa, is also white at first and passes through various colour changes to very dark brown. This stage lasts, usually, about twenty-three days, and, when the time for transformation to the adult male arrives, the workers render every assistance in the shedding of the pupal skin. The queen pupa is much larger than the male pupa and more than twice as large as the worker pupa, and, apart from its size, may be readily recognised by the presence of prominent wing pads. Colour-changes from white to brown take place, but the duration of the stage is not known exactly, though it is probably about four weeks.

In the artificial formicaries, in which the ants were kept under observation, no queens appeared. By analogy with the honey bees, whose queens arise from eggs apparently similar to those producing the workers, the development taking place during the larval stage, owing to special food provided by the workers, it is possible that the workers, kept in confinement, could not obtain the requisite material from which to elaborate the food necessary for rearing queens. In all three forms, during the last few hours of the pupal stage, the workers are busily engaged in assisting in the transformation, being employed, for the most part, in attempting to straighten out the legs and antennæ. The newly emerged ants are almost colourless and of feeble gait, they are then known as "callows"; quickly, however, their colour deepens and they become indistinguishable from the adults, but in the meantime the workers are 
responsible for their safety, and, at the slightest sign of danger, grab them up and carry them off to some hidingplace.

Complete colonies may be formed of a queen and workers only; of queens and workers; or of a queen (or queens), males, and workers; and, with each of these combinations, there may be associated one or more of the three immature stages, corresponding to each of the three adult forms, or nine immature stages in all. There is only one caste of workers, and in a large colony there is considerable division of labour, some workers being foragers, some nurses, and others engineers engaged in excavation or sanitary work; but any individual can, and frequently does, assume the duties of any other, when necessity arises. The nests may be set up practically anywhere from which light and water are excluded; a certain amount of humidity is necessary to them, but light they detest, and, although they will go into daylight in search of food, they always build their protective "sheds" over the colonies of scale insects and aphides which they cultivate.

A few facts concerning the highly developed senses of these ants may prove interesting. Their sense of smell is exceedingly acute, and to it they owe their success in finding food. Wrapping meat in paper does not suffice to keep these insects away, for they quickly work their way through the folds of the paper till they reach the food within; even dainties kept in screw-stoppered bottles are reached, for the workers, by following the spiral threading of the screw, eventually attain the interior. Again, these ants may at times be observed moving in a trail across a floor or courtyard towards some favoured food, as often as not the route is a circuitous one, but, whether straight or roundabout, if all the ants be swept away temporarily, thousands more will promptly take their place and follow exactly the same trail. That this phenomenon is due to 
their sense of smell, is shown by the fact that if some strong-smelling substance, such as paraffin, be laid in the trail, the ants at once become confused and show, by their aimless wandering, that they can no longer scent out their original route. Except that light repels them, their sense of sight is probably wanting, in fact experiments in this direction all tend to show that they cannot see, in the usually accepted manner; their sense of hearing too is no better developed, though loud and sudden noises, which cause a violent vibration of the surface of the earth on which they are located, throws them into a state of alarm.

We have already mentioned that the workers are in the habit of washing the larvæ and pupæ with their tongues, but the adults are kept equally clean. Workers keep themselves clean by rubbing their bodies and antennæ with their legs, which are in turn cleaned by being drawn through their mandibles. Sometimes, when very dirty, the workers will clean one another, and, on one occasion, Professor Wilmon Newell "observed one worker industriously cleaning the mandibles of a companion. During the operation, which lasted for several minutes, the worker receiving the kindly ministrations stood with her head well raised, mandibles extended, and feet firmly braced, while the teeth of her mandibles were thoroughly cleaned by those of her sister." The queen usually attends to her own toilet, but is, occasionally, cleaned and groomed by the workers. Dead adults or larvæ and decaying animal or vegetable matter are not tolerated for a moment, but are promptly removed to a distance or, if too large for removal, are buried, the ants carrying particles of earth with which to effect the interment. Unlike many other species of ant, Iridomyrmex humilis does not store up food in its nests, against emergencies; food is taken into the nests, in plenty, but experience shows that it is promptly consumed, within a few hours. The foraging workers are in the 
habit of feeding the other workers who are on duty within the nest, and one such worker was actually observed to feed no less than fifteen of her companions, till, her supply being exhausted, she went on her way, leaving some of them hungry and still unsatisfied.

The antagonism of the Argentine ant to all forms of insect life, except scale insects and aphides, is remarkable; as a rule, however, only those insects which are previously injured fall an easy prey to these blood-thirsty insects. Uninjured beetles, for example, are too fleet of foot and too pachydermatous to be troubled, even by numbers of the ants; but should misfortune overtake one of them, thousands of individuals will overcome him and clean his body piecemeal from his integument. Newly emerged adult beetles also fall victims to these ants, for then their bodies are soft and easily devoured; in fact, the Argentine ant is an adept at catching its prey in a helpless state, either on account of injury or lack of development. Cockroaches are especially esteemed, but here, again, only the injured are attacked; at the same time, one of the few natural enemies of this ant is the larva of a cockroach, Thyrsocera cincta.

The attention bestowed upon scale insects and aphides by the Argentine ant has already been mentioned. Both classes of insects are in the habit of inserting their beaks or rostrums into plant tissues and withdrawing sap; at the same time, they exude a secretion which is usually sugary. Newly hatched mealy-bugs_-individuals that have never fed, and therefore never given off any secretion-are totally ignored by the ants, so it is evident that the secretion is the attraction. Wherever the ants occur, these insect pests have increased in numbers, and the reason is not far to seek. The first, and most important, cause of increase is the habit possessed by the ants of building shelters over the insects; these so-called sheds are composed of fine particles of earth, and they effectually protect the inmates 
from storms, from the attacks of parasites, and from the chastening influence of various sprays that may be used to kill them. Wherever the Coccidae or plant lice are exposed to the weather, the ants build shelters for them. Another and less easily explained reason for the prevalence of these insect pests, where ants are present, is the fact that the stimulation resulting from the attention of the ants, while collecting the sweet liquids which they exude, appear's to have the effect of greatly encouraging their fecundity. Why this should be so is not precisely understood, but numberless experiments, carried out with the greatest care, have shown, beyond doubt, that coccids and aphides, attended by ants, multiply to a much greater extent and far more rapidly than similar unattended insects, kept under otherwise identical conditions. A third cause of increase is the fact that the ants, not content with protecting their charges from the attacks of parasites and predatory foes, especially ladybirds, persistently drive away these exceedingly beneficial insects from the neighbourhood of the coccid colonies. The last method by which the ant assists in the increase of insect pests, is by actually transporting them from place to place. This habit probably never assumes any great economic importance, still it is one that cannot be ignored. On sugar-canes especially the ants have been seen carrying mealy-bugs about, though they probably only pick them up when disturbed or frightened.

The Argentine ant is unable to cross water, and, as a consequence, streams and ditches form the best check on its nomadic habits. These waterways are often crossed by bridges composed of planks which do not meet in the middle (Plate XV.), and therefore afford no passage for the insects.

The future of this noxious insect is one that will be eagerly watched by economic entomologists-that it will spread to all the semitropical regions of the earth is 
practicaliy assured, and factors of climate alone will, for the present, keep it within reasonable bounds. Whether it will eventually become hardened and capable of withstanding the rigours of a northern climate and so overrunning the globe, is a conjecture that time alone can answer.

\section{Cockroaches}

One of the commonest insects of British households is the "black beetle" (fig. 69). How the insect earned its nickname would be hard to say. It is not even related to the beetles, being a member of the order Orthoptera and of the family Blattidae, though here, again, some early scientist must have been at fault, for the Latin word "blatta," from which the family name is derived, means a beetle. Periplaneta orientalis, for that is the insect's name, is a native of tropical Asia, and no better illustration could be taken of the manner in which an insect, and a tropical one at that, can adapt itself to conditions so totally at variance with those of its original habitat. Once confined to somewhat arbitrary limits in the Orient, this insect has followed man throughout the world till, at the present time, it is practically cosmopolitan. Climatic conditions have not set a limit on its travels as they have, up to the present, upon another household pest, the Argentine ant; perhaps some day it too may travel in the wake of commerce to temperate latitudes, then it may quite conceivably rank as the worst household pest of all. Common, for several centuries, in all seaport towns of this country, it was only at a later date that the common cockroach spread inland, and, at the present day, it may be found in practically every village in England.

As a household pest it, for the most part, frequents kitchens, bake-houses, and all places where the warmth is greatest, and, being nocturnal in its habits, it is not so often encountered as might be supposed. But it is not necessary 


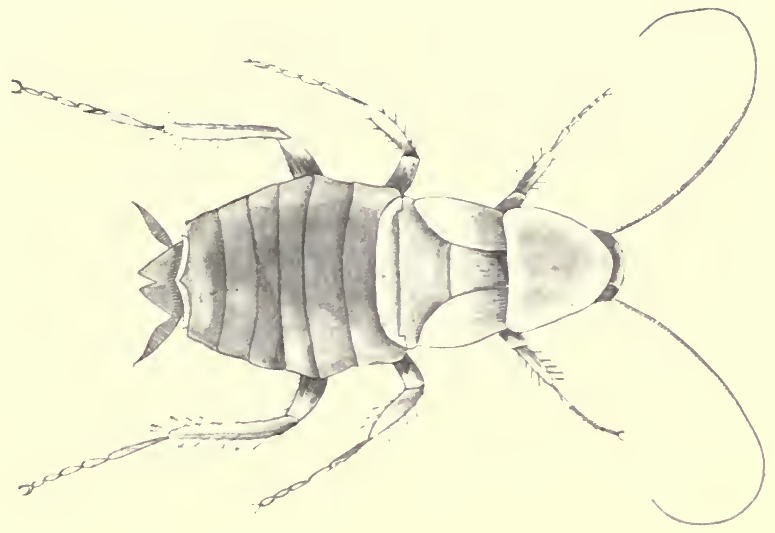

Fili, 69. Fenale cockroach, Periplaneta orientalis

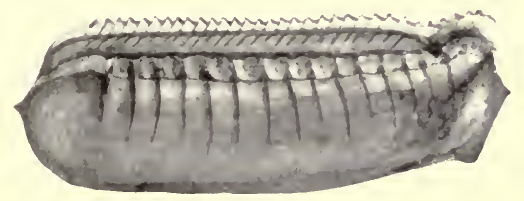

Fis. 7O. EgG CASE OF A COCKROACH

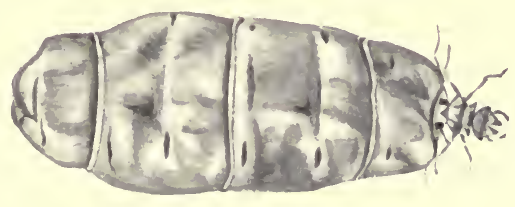

Fig. 7I. A Female termite 

to see this odious insect in order to detect its presence, for it scents the atmosphere of its haunts with a peculiar, characteristic, and unforgettable odour. The insect has been rightly termed disgusting, for it is unclean of habit, soiling everything with which it comes in contact, and not too particular in its choice of food, consuming garbage as readily as the choicest morsels, often falling to leather, blacking, and even its own sick relatives; on occasion it is as persistent as the house fly in seeking out the family larder, and crawling, as it does in its hundreds, over any eatables that are left uncovered, it quickly renders them inedible.

But though an insect to be rigorously excluded from man's dwellings, its life-history is of peculiar interest. The adult males and females may be readily distinguished; the former are winged, whilst the latter possess, at most, the rudiments of wings. The males too are smaller than their partners, and, quite apart from structural differences, the sexes may be distinguished from the fact that the females drag their abdomens along the ground, whilst the healthy males never do so, but lift them up an appreciable distance from the surface over which they are crawling.

The females, like some other members of the Orthoptera, do not lay their eggs singly or even in clusters, but in neat purse-like cases each containing sixteen eggs. These egg cases (fig. 70) are about half an inch long, dark brown in colour, and of a horny texture; oblong in shape, they have rounded ends, and the upper edge appears as a longitudinal, toothed ridge, which in reality is a slit, kept closed by the elasticity of the material composing the egg case. The eggs within the case are arranged in two alternating rows of eight each, in such a manner that the heads of the larvæ are directed towards the serrated edge. When the egg case is full it is carried about by the female, partially protruding from the end of her abdomen, for a considerable time, often as long as a week, and not until she finds a 
suitable hiding-place is the precious burden deposited. The eggs hatch within the case and the larvæ then make their way out, leaving the case to all appearance undamaged. The larvæ are very similar to the adults, except that they are almost colourless, with the exception of their eyes, which are black. Needless to say, these newly hatched larvæ are very much smaller than the adults, moreover, they are wingless. Almost immediately after hatching a moult takes place, and with it a darkening in colour; a second moult takes place four or five weeks later, and a third at the end of the first year.

Although so common an insect, there is considerable dubiousness as to its length of life and the exact number of moults that take place before the adult stage is reached; at any rate, after the first year, moults only take place annually, and some observers have stated that the total number is seven. If this be correct, the cockroach is imbued with considerable longevity as insects go. After each moult, at whatever age, the cockroaches are very pale, almost white in colour, and only after the lapse of three or four hours do they resume their typical brownish colour, which, by the way, becomes deeper and deeper with each moult. At the penultimate moult the rudiments of wings appear, and now the insect has reached its nymphal stage. At the final moult, the males acquire their wings, and for the first time in the life-cycle it is possible to distinguish the sexes. It will be observed that there is no pupal stage, such as takes place with the moths and flies, and a metamorphosis of this nature is said to be incomplete.

Two other species of cockroach may also be termed domestic : the American cockroach, Periplaneta americana, and a European, though not British, species, Phyllodromia germanica. The latter is well known in the United States, where it has been nicknamed the "Croton bug," and it is also occasionally encountered in England; the former, a native of tropical America, is met with from time to time 


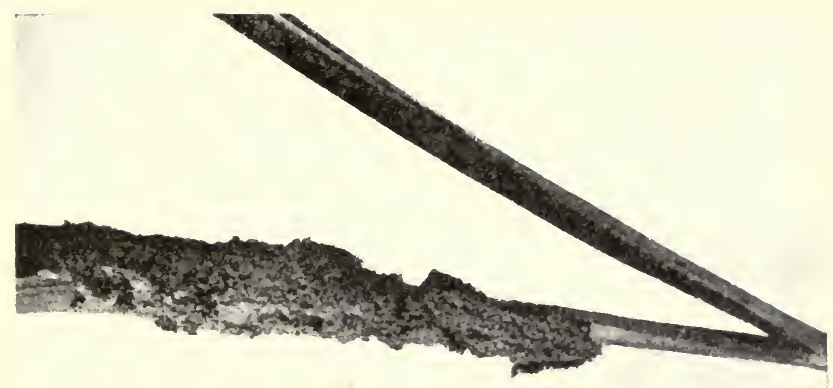

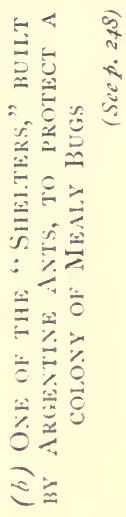

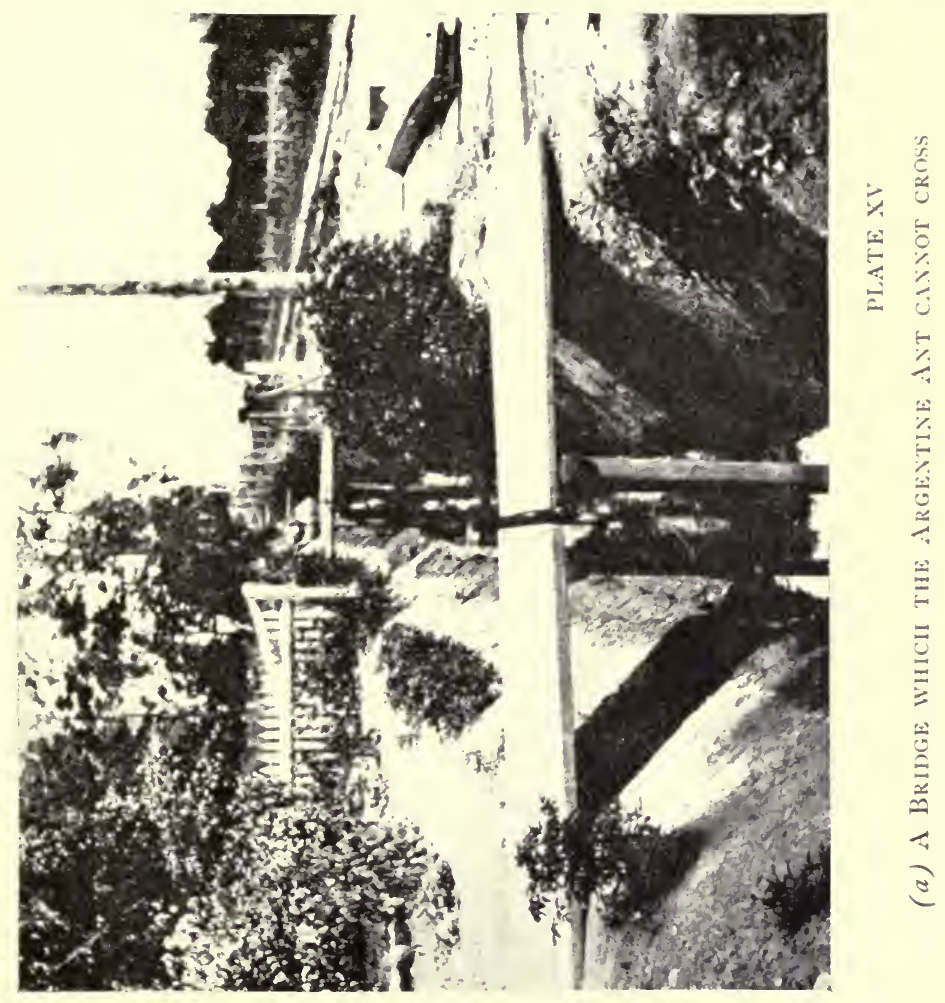



in this country. It is very much larger than the common cockroach, in general colouring it is chestnut, and both males and females are winged.

Though no actual proof has been put forward to show that the common cockroach is a carrier of disease, there is every reason to believe that before long it will be shown to be so. It is not very many years since the house fly was looked upon as a harmless nuisance, and the cockroach is no less fond of contaminating human food. On its behalf we may add that it is an inveterate enemy of the bed bug.

\section{Termites}

The critically minded may raise some objection to the inclusion of Termites among the household insects; true, they are dwellers in the open, but, at the same time, many species enter houses and prove more destructive than any other insects. Popularly, but erroneously, called "white ants"-probably, it has been said, because they are neither white nor ants,- these little insects certainly bear some resemblance to ants in their habits. It is in Africa and Australia that the termites are encountered in the greatest numbers, but some species hail from Asia and North and South America. To woodwork of all kinds, furniture, books, wall-paper, clothing, boots, and all leather goods, many termite species are terribly destructive and their mode of attack is particularly insidious. Woodwork, for example, is always eaten away from the inside, so that nothing but a mere shell remains-an external skeleton, that will crumble to nothing with the merest touch; in fact, the sudden collapse of woodwork is often the first intimation that "white ants" have been at work.

Although a considerable literature is devoted to these insects and their habits, there remain many points on which much light must be shed, if we are ever to obtain a clear understanding of their ways. Again, there are so 
many different species, and the differences which exist between the economy of one and another are so pronounced that generalisation is well-nigh impossible. At times, towards evening, after a summer shower, the air in the neighbourhood of a termite colony will be darkened with flying creatures, everywhere along the ground round about the insects will be scurrying. They are the male and female termites in their nuptial flight, and, despite the fact that they stream from the nest in prodigious numbers, but few escape destruction; their appearance is the signal for hosts of hungry birds and reptiles, which collect in force, to dispose of the hapless insects. When the flight is over, the termites of both sexes shed their wings, and to this end a crease runs right across the base of each wing, along which the wing falls away at the will of the insect. Hurrying along in couples, the objective of the now wingless insects is some crack or hole in the earth, some sheltering stone or woodwork where they may hide from their enemies.

Each pair that manages to escape destruction founds a new termite community, being known henceforth as the king and queen. These royal insects dwell in a large earthen cell, situated in the heart of the termite nest, and usually, though not invariably, the entrances to and exits from the cell are so small that escape is impossible. In some species more than one king termite may be found in the royal cell, in others again no king is present. In any case it is only the queen that is of special interest, for she rapidly becomes nothing more nor less than an egg-laying machine, capable, it is said, of laying one egg per second, or eighty thousand per day. Her head, thorax, and legs are still of the same dimensions as on the day she founded the colony, but her abdomen has become enlarged to the size of one's little finger, or about twenty thousand times the size of the worker termite. This enormous distension is enabled to take place owing to the expansion of the elastic tissue between the original abdominal segments; 
the chitinous plates, which originally marked the segments, appear as mere islands in a sea of flesh (fig. 71).

For some time the royal pair attend to their own wants, but eventually from the eggs laid by the queen the new community is formed. These termite communities vary considerably in composition; but in some of them are to be found a king and queen, large and small "workers," large and small "soldiers," winged males and females, together with peculiar immature males and females which, should occasion arise, can be developed and made capable of producing further progeny - they are known as complementary or substitution kings and queens. The bulk of the community is composed of "workers" and "soldiers," both of them sexually imperfect adults, either males or females, and in this respect they differ from the true ants, whose workers are imperfect females.

The "workers" and "soldiers" are blind in most species, as are the winged forms, though they possess eyes. All the individuals of a community work together for the common good; upon the king and queen falls the duty of continuing the species. The workers remove the eggs to places where they may best be incubated, collect food for the rest of the community and prepare it for the king and queen, for the young, and for all other members of the community unable to forage for themselves. The feeding operations are peculiar, the very young individuals are fed on food which is regurgitated by the workers, whilst all other individuals are fed on voided food. When a hungry termite encounters a foraging worker, it strokes the hinder part of the latter individual with its antennæ and mouth parts, when the creature yields some of its food, which is eagerly eaten. The habit is peculiar, but results in exceedingly clean nests, for the voidings are eaten over and over again, till they contain no nourishment; all refuse matter, cast skins, bodies of dead and sick individuals are likewise consumed. The duty of the soldiers is to protect the other members of a 
colony. They are provided with relatively enormous mandibles, set on substantial heads. Should the wall of a termite nest be broken, the soldiers at once run to guard the breach, threatening with their mandibles any and every one who approaches. This defensive attitude they maintain till the workers have repaired the damage. In dealing with termites as household insects, we are but little concerned with their nests, which are exceedingly varied in size and form; some are mere labyrinths of galleries tunnelled out in the ground, others are huge mounds which may reach a height of twenty feet.

\section{Crickets AND Earwigs}

Of the other British household insects, the majority are so common that they need little more than passing notice. Besides the cockroach, the order Orthoptera is represented in our houses by the cricket and the earwig. The housecricket, Gryllus domesticus, is the only member of the family Gryllidae that has assumed domestic habits. Chestnut brown in colour, winged in both sexes, and provided with well-developed hind legs, the house cricket bears considerable resemblance to a brown grasshopper. The wings are worthy of study for they are sound organs, serving the same purpose as the sound organs of the periodical cicada, though totally different in structure and action. The lower membranous wings are similar in both sexes and have veins radiating from the base, so that they can be folded fan-wise, hence the name Orthoptera or straight wings; the upper, more rigid wings of the male, however, are peculiar. On the portion of the wing that lies flat on the insect's back, as opposed to the portions that lie against its sides, there are strongly veined areas and also clear ones; by the former the sound is produced, by the latter it is intensified. When about to make its well-known chirp, the male cricket depresses its abdomen 
and rubs the forewings over one another rapidly; the under surfaces of the veins are rigid and file-like, so that, as they rub against the veins of the other wing, they produce squeaking sounds which the clear areas or "drums" render more audible.

Why, it may be asked, does the cricket make the chirping noise? It is undoubtedly a signal to others of its kind and especially females. A close examination of the outside of the cricket's foreleg, on the part just below the thigh, will reveal an oval membranous portion, and, at the same point, on the inner surface of the leg, a round membranous portion; between these two membranes is an air sac, connected with a breathing tube and well supplied with nerves. These peculiar organs of the forelegs are the ears or auditory organs of the cricket.

The life-history of this cricket is so similar to that of the cockroach that there is no need to describe it. The young arising from the eggs are very similar to, though smaller than, the parents, and they reach the adult stage by a series of moults, at the final one of which they attain their wings. Their food consists of all kinds of odd scraps, for the most part of a vegetable nature, and they are also moisture- and heat-loving creatures. Whence they came originally is unknown, but now they are not only widely distributed in the Old World, but in North America as well. Britain boasts four representatives of the family: two field-crickets, Nemobius sylvestris and Acheta campestris, the mole-cricket, Gryllotalpa vulgaris, and the house-cricket; and of these the house-cricket, at any rate, is steadily becoming rarer in Britain.

Of the common British earwig, Forficula auricularia, little need be said; it is not a true household insect, though a very frequent intruder. Its general appearance is known to everyone in Europe, where, in each country, its popular name is associated with the ear, and is derived perhaps from the scientific name of the species, or from its supposed 
habit of entering the human ear and causing serious damage. Its scientific name was given to it because of the remarkable resemblance of the insect's expanded wing to the human ear, but it is hardly likely that the popular name has been bestowed upon it on this account, for it is exceedingly rare to see an earwig in flight, and so intricate is the method of folding its wings that it is a difficult operation to unfold them by hand. The pincers of this insect are curious appendages and their use is unknown; by some entomologists it is said that they are used in folding the wings, this may be so, but it is curious that the wingless species are also provided with pincers. By others they are considered to be weapons of defence, and this is probably a correct surmise, though they are only capable of giving a most feeble nip.

The yellowish, oval eggs are deposited in some hidingplace, such as below a stone, and the mother is said to evince considerable solicitude for their welfare. The most extraordinary tales have been told with regard to this supposed trait on the part of these insects; in real truth, though they are so common their life-history is but little known. The young are white when first hatched, and, as in other Orthoptera, their metamorphosis is incomplete and they reach maturity by a series of moults, becoming light coloured with each change of skin and growing darker and darker as the next moult approaches.

With regard to the earwig's food: most gardeners would assert that the insect is destructive to cultivated plants. Careful observation and experiment, however, show that it is carnivorous and that it devours caterpillars, snails, slugs, etc. It shuns the light on every occasion, and its habit of hiding in such flowers as the sunflower and dahlia have earned it an undeserved reputation for evil.

Of the house-frequenting Hymenoptera, the most usually encountered are the common wasp, Vespa vulgaris, the German wasp, Vespa germanica (the latter is at times 


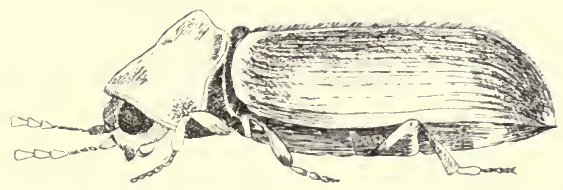

A

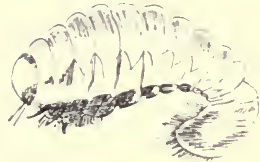

$\mathbb{B}$

Fig. 72. A hestrective household beetra, fluohizm domesticum. a. AIULT; b. LARVA

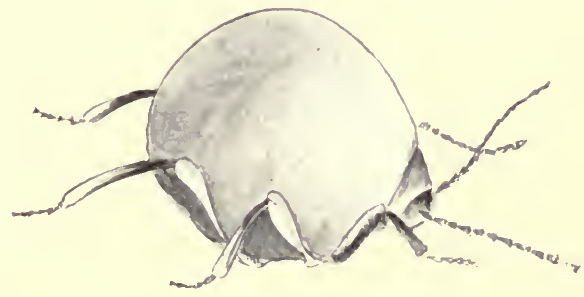

Fici. 73. Gibbium scotias 

more common than the former), the hornet, Vespa crabro, and various species of ants. The wasps have so often been described and are so common that we will pass them over. Hornets, closely resembling big wasps with brown markings in place of black, we may also leave out of consideration and turn our attention for the moment to the ants. Only one British species, Monomorium pharaonis, frequents houses. It is a diminutive, red-coloured insect which was imported into this country rather more than eighty years ago, and even now has not spread everywhere throughout Britain. So small is the insect that "seventeen thousand individuals weigh one gramme, and it is probable that the nest may contain millions of specimens." Like the Argentine ant, this insect is social in its habits, and the nembers of the community exhibit the same division of labour. The workers are indefatigable in their search for food, as every housekeeper who has experienced their attacks can testify, sweet and fatty substances being specially relished.

\section{Some Injurious Beftles}

It will be no surprise to learn that so large an order as the Coleoptera, or beetles, supplies a number of household insects, and that many of them are exceedingly destructive. The most harmful are the beetles of wood-boring habit; one species is described briefly in our chapter on "Insects and Plants," and of the domestic wood-borers the commonest is Anobium domesticum (fig. 72). This insect is of a dark-brown colour and about one-sixth of an inch in length. Within its burrows eggs are laid, and the white, curved, fleshy, six-legged larvæ rarely come to the surface of their hiding-place. Nourishment is derived from the wood, often of the oldest and dryest description, for, unlike the larvæ of Xyleborus dispar, these grubs have mouths well adapted to such fare. Pupation takes place within the 
burrow, and there, of course, the adults emerge. Anobium paniceum, the biscuit weevil, is also a wood-borer, though less so than domesticum, for it prefers dry vegetable food such as bread, biscuits, ginger, etc.

Another wood-boring beetle of our houses is Xestobium tessellatum, the well-known "death watch," which, except for its larger size-it is about half an inch long,-resembles Anobium domesticum fairly closely. The insect and its tapping was described so long ago as 1698, and, till quite recently, was supposed to portend death; now, however, we live in more matter-of-fact times, and the wood-boring habits of the beetle are more dreaded than its ill-omened tapping.

Two common and peculiar household beetles are Niptus hololeucus and Gibbium scotias. The former, which is of a yellowish colour and silky sheen, is almost spider-like in appearance, though in reality quite distinct from these creatures, which are not insects. Niptus is peculiar in having no wings and fused wing-cases; it obtains its nourishment from various household provisions, and is said to have been introduced into this country in Turkey carpets. Gibbium scotias (fig. 73) when at rest, on account of its colour, resembles a drop of blood, or it may be likened to a large mite. Like many other insects, it feeds upon dried paste, which it finds on wall-paper, book bindings, etc.

The leather beetles, Dermestida, are a most destructive family, and of them Dermestes lardarius and Dermestes vulpinus must serve as examples for the whole family. Lardarius, known as the larder beetle, is widely distributed in Britain, Europe, America, and Asia. In colour it is very dark brown or almost black, banded with a pale yellowish-brown band right across the bases of the wing covers; in length it is about a third of an inch. Its lifehistory has not been fully and carefully studied, but it is known that the beetle deposits its eggs on such substances 
as ham, bacon, and meat, fresh or dried, and that from them arise brown, hairy larvæ which feed on the fatty parts of their food and eventually bury themselves therein to pupate. Horns, hoofs, feathers, skins, beeswax, and hair are also damaged by these beetles.

Vulpinus, a beetle of similar shape and size to lardarius, may be distinguished by the absence of the yellow-brown band and the presence of a white patch on each side of the thorax. In habit the two beetles are very similar, but vulpinus is especially destructive to skins.

\section{The Cigarette Beetle}

This is another highly destructive household insect. A tiny, but withal, practically omnivorous little fellow, the cigarette beetle is known to science as Lasioderma serricorne. It is common in nearly all tropical and sub-tropical countries, and, as a sample of its catholic tastes, we may mention that it will breed in raisins, rhubarb, cayenne pepper, rice, ginger, dried fish, upholstery, ergot, turmeric, books, cane work, gun wads, liquorice, saffron, belladonna, and in pyrethrum powder strong enough to kill cockroaches -a varied catalogue to be sure! It is chiefly as a pest of tobacco, in various forms, however, that the cigarette beetle has become notorious. Mainly on account of its ravages, the export of tobacco from the Philippines to the United States of America decreased from 4,023,404 pesos in 1910 to $1,483,544$ pesos in 1911 . The greatest damage is done to the wrappers of cigars and cigarettes, through which it eats small holes.

The female beetle deposits her eggs, singly, in the crevices of leaf tobacco, usually along the midrib; oviposition also frequently takes place within the open tip of a cigar or cigarette, and the whitish, tough-shelled eggs are most difficult to detect. After about a week the larvæ emerge from the eggs, and then destruction of the tobacco 
begins. The larvæ live upon the tobacco leaf, and a very interesting fact is that the size of the adult beetles, into which the larvæ eventually develop, depends, not only on the quantity, but also on the quality of tobacco that has been devoured in the immature stages. Experiment has shown that in every case beetles obtained from selected cigars were double the size of those from low-grade tobacco. It will be remembered that the cheese "skipper " is partial to the better cheeses; similarly, the cigarette beetle is somewhat of a connoisseur, for, given a free choice, Claro cigars and Turkish cigarettes are always the first to be infested, whilst cheap-grade tobacco and Madura cigars, kept in the same room, will remain uninfested for years. Apart from the actual destruction of the tobacco leaf, the larvæ spoil its aroma and accordingly depreciate its value; it is some consolation to know that the adults themselves do no damage. This little beetle is most difficult to eradicate, and, to that end, an experimental X-ray machine was specially built recently, at great expense, in America. This machine was capable of " sterilising" cigars, on a commercial scale, at the rate of forty thousand a day, voltages of sixtyfour thousand to seventy-five thousand and exposures as long as an hour were tried without the slighest effect upon eggs, larvæ, pupæ, or adults - the experiment was a failure. In 1913 an enemy of dry Cuban tobacco was discovered and named Catorama tabaci, but little is known of its lifehistory as yet.

\section{Grain-EATING Insects}

Many beetles are exceedingly injurious to flour, and those most frequently encountered are the meal worm, Tenebrio molitor, the confused flour beetle, Tribolium confusum, and the rust-coloured flour beetle, Tribolium ferrugineum. The earliest mention of meal worms occurs in the works of Thomas Mouffet in 1634, and at a later date Linnæus gave them their scientific name, which is curiously apt, for 


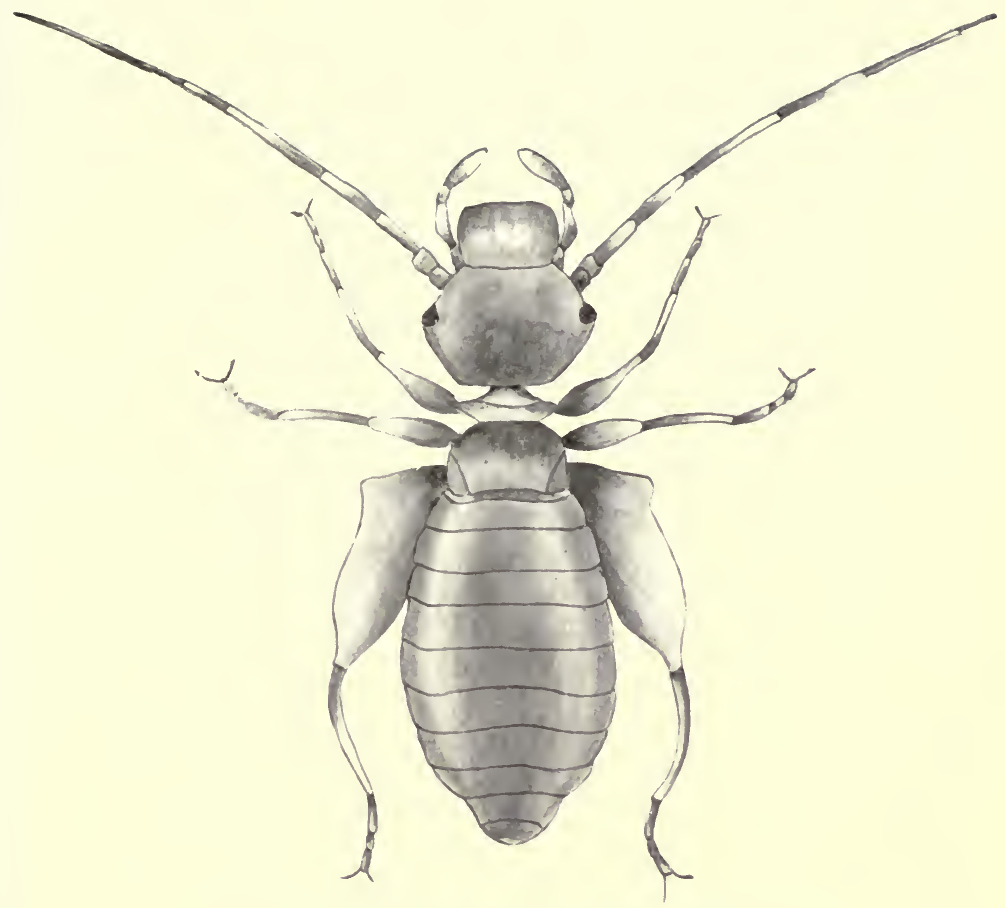

FIs. 74. THE BOOK Iovse, Alropos dizinaloria

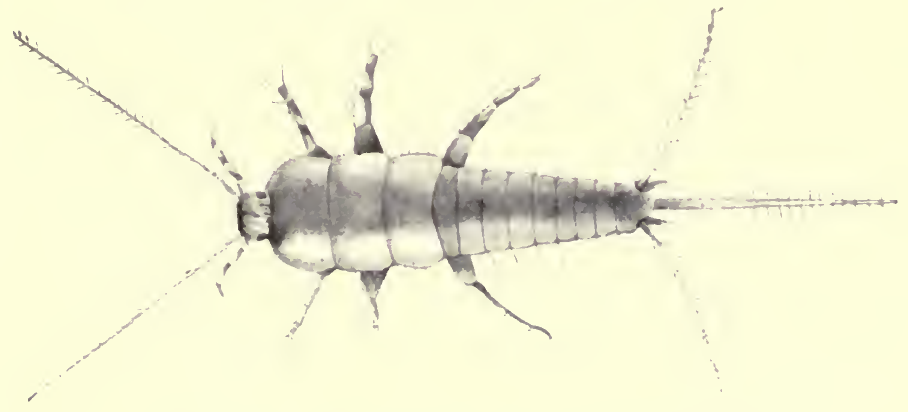

F1G. 75. THE SILver FISH, Lepisma saccharina 

it means a miller who shuns the light. The female beetle lays her white, bean-shaped eggs in flour, bran, or other similar substance which will form a suitable food for the larva. Each egg is about one-twentieth of an inch long, and may be deposited alone or in a batch with others; in any case, it is covered with a sticky secretion, so that particles of flour become attached to its surface and form a complete covering. The larvæ emerge in about a fortnight; at first they are creamy white in colour, but later they turn yellowish and waxen-looking. In about three months, during which they feed voraciously and undergo at least a dozen moults, they reach their full growth and are about an inch long, and in this state they hibernate through the winter, turning to pupæ in the spring. The pupal stage lasts a fortnight, and the whole life-cycle occupies practically a year.

The two beetles of the genus Tribolium are so similar to one another that they are often confused; ferrugineum is the commoner in Britain, confusum is more often met with in America. In appearance they closely resemble the adult meal-worm beetle, but are much smaller, being rarely longer than one-sixth of an inch. Their food consists mainly of ground cereals such as flour, oatmeal, etc., but they have also been known to damage ginger, cayenne pepper, baking powder, orris root, dried peas and beans. Under favourable circumstances the life-cycle is completed in five weeks, so there are several generations in a year.

Beetles are not the only household insects with a partiality for ground cereals; the larvæ of the meal moth, Pyralis farinalis, feed on cereals in any state, also on other seeds and dried plants. The adult moth measures about an inch from tip to tip of its wings, which are beautifully shaded with reddish brown and white. 


\section{Clothes Moths}

The mention of moths, as household insects, will at once suggest the clothes moths, which have earned for themselves a place in the front rank of destructive insects. The true clothes moth is Tinea pellionella, but allied species, in the shape of Tinea biselliella and Tinea tapetzella, are also destructive. Pellionella is a greyish-yellow moth, measuring about half an inch across its expanded wings, on the middle of which there are a few indistinct spots. That these insects have been known from Biblical times is shown by two references, in Job and Isaiah respectively, to moths eating clothes. The female lays her eggs on some material which will furnish the larvæ with food, woollen goods, carpets, furs, and feathers are most frequently attacked. The eggs are so small as to be scarcely visible to the naked eye, and from them the dull white larvæ emerge. The first duty of this caterpillar is to build for itself a case in which to live, and of the larva Pliny says, "It is clad in a jacket, gradually forming for itself its own garment, like a snail in its shell, and when this is taken from it, it immediately dies; but when its garment has reached its proper dimensions it changes into a chrysalis, from which at the proper time the moth issues." The description is wonderfully accurate, but it is of interest to add that the case must perforce be enlarged, from time to time, to keep pace with the larval growth. While still within the case, the larva makes a slit down one side and inserts a triangular gore of new material, the operation is then repeated on the opposite side. If the larva be moved periodically to materials of varied colour, its case will present a mixed coloration, corresponding to the materials of which it is comprised. Additions to the length of the case are made at either end. When full grown, the larva usually attaches its case to the material on which it has been feeding. Pupation takes place within the case, and the adult moth appears three weeks later. 
Biselliella makes no case like pellionella; it feeds on similar substances, with the addition of cobwebs, and as proof that the insect obtains all necessary nourishment from this curious fare, the larvæ have been raised on cobwebs alone. The full-grown larva pupates in a silken cocoon to which bits of wool are attached, giving it somewhat the appearance of the larval case of pellionella. The tapestry moth, Tinea tapetzella, attacks coarser material than its relations, and damages them rather by constructing a series of tunnels through them than by eating them.

\section{Two Starch-Loving Insects}

A common household insect which is probably known by sight to everyone, though its identity may be a mystery, is the book louse, Atropos divinatoria (fig. 74). A very small, nearly colourless, soft-bodied, wingless insect, it is often to be found frequenting old books and papers, for the sake of the starchy paste used in binding, etc. Minute and soft-bodied as this insect is, it nevertheless has the power of making a tapping sound, probably by beating its head against woodwork, and, needless to say, like the true "death watch," it has given rise to much superstition. Lastly, let us mention the silver fish, Lepisma saccharina (fig. 75), first noticed by Hooke in 1665 . It is a great enemy of all goods containing starch. It is fishlike in form, scaly, about a third of an inch long, and silvery in colour. On the head are a pair of relatively long antennæ, and from the hinder end of its body three long, soft bristles project. An allied species, Lepisma domestica, has earned the name of "fire brat" from the curious habit it has developed of disporting itself in places so warm that they would be fatal to other insects. 


\section{VII}

\section{SOME HUMAN PARASITES}

\section{Fleas}

ONE of the most persistent of what may be termed the truly domestic insects is the human flea, Pulex irritans (fig. 76). Go where one will, and be one ever so clean in one's clothing and person, sooner or later, one is certainly destined to receive the attentions of these unpleasant little creatures. The order Siphonaptera, to which the human flea belongs, is, by some, approximated to the Diptera or two-winged flies, by others to the Coleoptera or beetles, in short, its exact systematic position is uncertain; it is comprised of over four hundred species. All fleas are parasitic in habit, but, unlike the majority of parasites, they do not spend all their time on the host; they have been aptly termed temporary parasites. Many parasites, again, are found on only one host, in fact we often find parasites possessing special modifications, fitting them for life on some particular host; but although certain species of flea are associated with certain species of host, they will at times pass from one host species to another. Practically all mammals and many birds have fleas, and sometimes the same species of flea is found on strangely different hosts: for example, the human flea is also parasitic on the badger; dog fleas (fig. 77), too, will bite human beings; again, certain species of flea have never been found on more than one host.

What may be termed an exchange of fleas is so common as to be exceedingly puzzling to those who are engaged in trying to learn their habits, and the subject is not rendered 


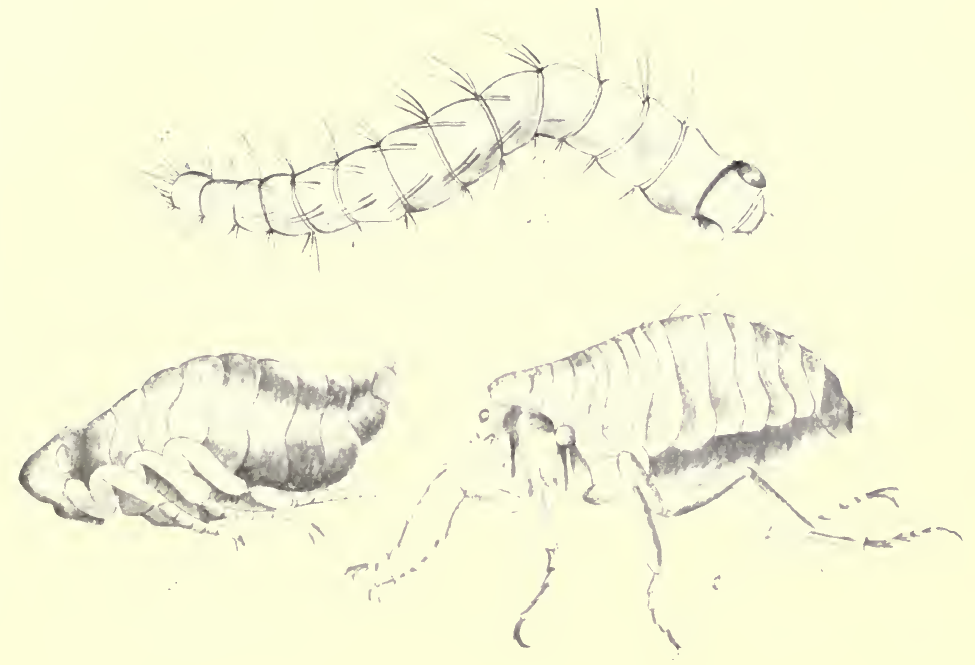

Fis. 76. The humax rlea, Fulex irrilans. $a$. Lakva; $b$. PUPa ; Anult

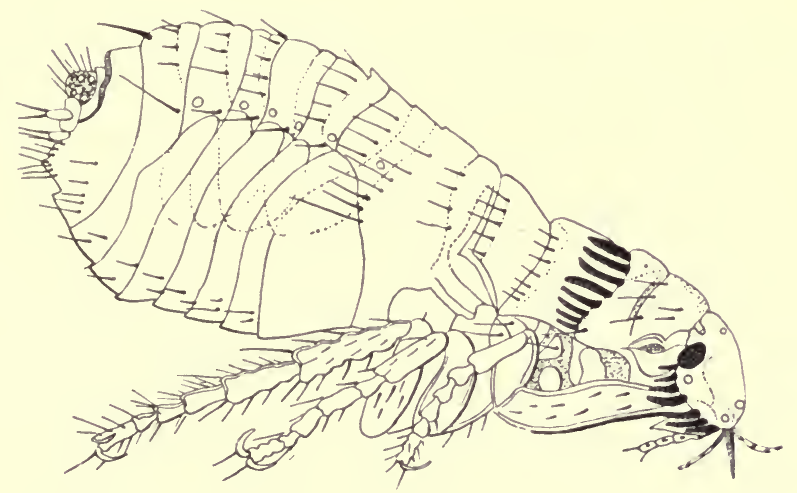

FIG. 77. A DOG FIEA IN THE ACT OF SUCKING BI.OOI) 

easier by the fact that some closely allied animals have absolutely distinct fleas. A statement that is always received with incredulity by the unscientific, though nevertheless true, is that monkeys have no fleas. Their habit of diligently searching in one another's fur has given rise to the belief that they are particularly susceptible to these parasites; but as a matter of fact, when in captivity, if they harbour these insects at all, they have most certainly caught them from some neighbouring animal or mayhap from some human being.

Another group of animals singularly free from fleas is the order of Ungulates, including oxen, sheep, goats, etc. To which species of flea numerical pride of place must be awarded is a moot point, but "a German naturalist collected 2,036 fleas from theatres, concert halls, ballrooms, schools, and barracks in the Grand Duchy of Baden, and found that more than fifty per cent. were dog fleas. . . . In Zoological Gardens cat fleas are generally numerous in most of the cages."

The fleas are usually divided into three families, $(a)$ the Chigoes, truly parasitic fleas, (b) the typical fleas, of which the human flea is an example, and (c) the bat fleas. The general structure of a typical flea is too well known to everyone to necessitate any description, and, as we are not concerned here with minute anatomical details, we will rest content with noting a few points of interest. The whole flea is entirely covered with plates of chitin, a hard resistant substance, as may be easily learned by trying to squash one of these insects in the fingers; below this armour is the true skin. Varying in colour from pale yellow to dark brown, all fleas are more or less covered with bristles, pointing backwards in every case and aiding the insect materially in its progress. One anatomical feature, which is almost peculiar to these insects, is their lateral flattening; it is quite usual to find insects flattened dorsiventrally, the bed bugs and cockroaches are examples, but 
the special shape of the fleas enables them to pass more easily between the hairs of their host, just as the other form of flattening enables the cockroaches to squeeze into narrow crevices. Many fleas are eyeless, and this is notably the case in the bat fleas; whether provided with eyes or not, these insects appear to rely mainly on their antennæ for finding their way about, and that these useful organs may not hinder the insects' progress over the body of a hirsute host or be damaged in any way, they fit into grooves at the side of the head and are only protruded when actually in use. Many fleas are provided with peculiar horny appendages known as combs, which may occur on the head, thorax, or abdomen. These combs are not peculiar to the fleas, but are found on other insects of parasitic habit, and they probably serve as aids to locomotion by holding on to the host's hairs. The enormous development of the flea's hind legs, which enables the insect to leap prodigious distances, is of course a striking feature in its anatomy. Although the adult flea is all too common and well known, it is very rarely that the housewife has any idea of the appearance of the eggs, larvæ, and pupæ, for the insect undergoes complete metamorphosis. All the year round, unless subjected to severe cold, the female flea deposits her eggs to the number of one to five at a time. In a few days the white, worm-like, legless larvæ emerge from the eggs, and they do so in a very curious and interesting manner. On the head of each newly hatched larva a thin knife-edged plate may be seen, it is an eggbreaker. When ready to emerge, the larva works this sharp-edged plate against the interior of the shell till a crack is made in it; more vigorous action causes the crack to open sufficiently to allow the larva to escape. Like the larvæ of other insects, this one moults several times as it grows, and with the first moult the egg-breaker, or hatching-plate as it is sometimes called, is lost-the insect has no further use for it. At this stage, of course, no blood is 
eaten, but, being provided with mouth parts adapted for biting, the insect lives on any decaying organic refuse it can find; in fact, larvæ have been raised on ordinary room sweepings. When fully developed, a matter of a few days at most, the larva spins a small cocoon within which it pupates. The duration of the pupal stage depends largely on the temperature, but it is never prolonged over more than a few days; then the adult appears and at once proceeds to seek a meal of blood, though fleas, like all parasitic insects, can exist for an extraordinarily long time without feeding.

The cat flea has so many points in common with the human flea, that it is unnecessary to describe its life-history and habits in detail ; one or two facts are, however, worthy of mention. Like the human flea, this insect is practically cosmopolitan, but whenever it is encountered it may be distinguished from its relative by the fact that it is provided with six to nine spines on its head and fourteen to eighteen on the hind border of its pronotum. The adults adhere much more closely to their hosts than do human fleas, and another striking and important difference between the two species is, that whereas the human flea never oviposits on its host, the cat flea always does so, and its eggs adhere lightly to its host's fur, but they are easily shaken off and so distributed. The very small, oval, white eggs give rise to white, footless maggots in about a fortnight. Like the larvæ of the human flea, they live on decaying animal and vegetable matter, and in rather less than a fortnight they attain their full growth, spin a small cocoon and pupate. The pupæ, although inactive, closely resemble the mature fleas, and are peculiar in that their legs are free. In ten days or so the adult fleas issue from the cocoons. There may be several broods each season, and the winter is passed either in the mature or larval stage.

A peculiar feeding habit of fleas is worthy of notice, because of its probable bearing on the transmission of disease, as described in our notes on plague. The flea, like 
many other blood-sucking insects, ejects a drop of blood from the rectum during feeding operations. Experiment shows that this ejected fæcal matter is frequently highly charged with disease germs, hence it is a probable source of infection.

A frequent though not a specific parasite of man is the jigger flea or Chigoe, Dermatophilus penetrans. Natives of South America, these fleas were introduced into Ambiez, in the south of the Congo, forty or more years ago, by a ship from Brazil, and they were supposed to have been taken to the great lake regions by Stanley's expedition.

The jigger fleas are more truly parasitic than the true fleas, for the female jigger embeds herself beneath the skin of the host, forming a kind of pocket, in which to carry out part of her life. Both male and female are small and live upon blood. After mating, the female seeks a host, into whose skin she may burrow; often a human being is selected, though pigs, dogs, mice, and other animals may all fall victims to this insect. Some soft portion of the host's anatomy is selected for operations, and a favourite situation is the skin beneath the toe nail. A suitable place having been found, the female jigger perforates the skin and works her way beneath the surface so far that only the tip of her abdomen projects. Within this hidingplace her body swells to the size of a pea (fig. 78), and in this state the segmentation of the abdomen is completely lost, even the head and thorax being visible only with the help of a lens. Needless to say, this increase in size, due to the formation of eggs, causes a considerable amount of suffering to the host, and in some cases death ensues. After a while the eggs are laid, to the number of about one hundred, not within the host but outside, and this is the reason for the female jigger leaving the tip of her abdomen exposed. The larvæ are very similar to those of the humian flea, but they are to be found in dry, sandy places, rather than in houses. 


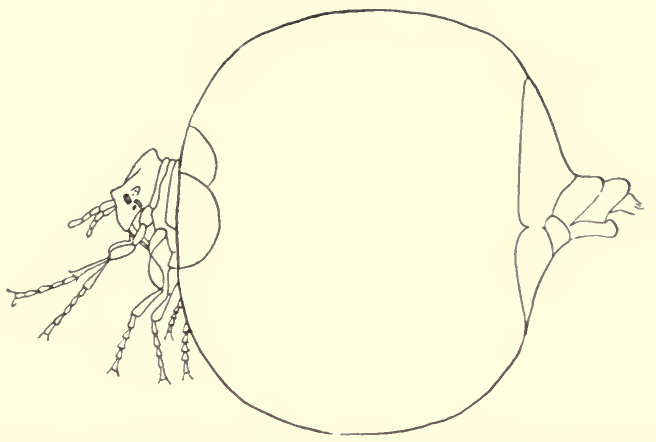

Fin. 78. A FEMALE CHIGoe ri.e., Dermatophilus penetrans

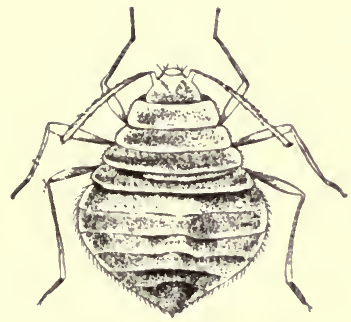

A

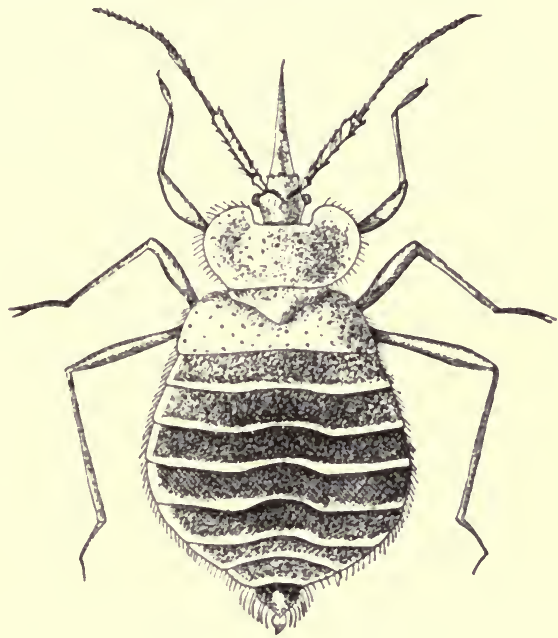

$\Gamma$

Fig. 79. The ben bug, Cimex lectularius. a. Youxg; b. Antrit

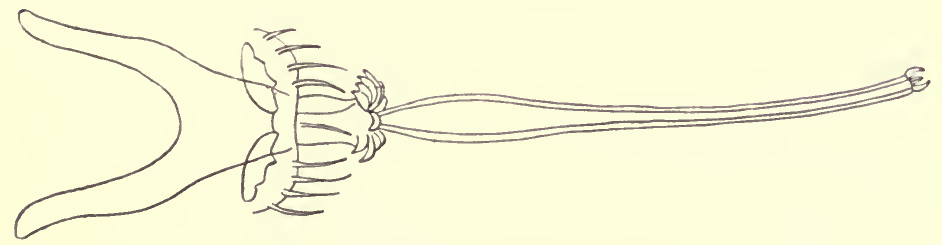

Fig. So, Rostrum OF IOLSE 



\section{Bed Bugs}

The common bed bug, Cimex lectularius (fig. 79, B), has been recognised in this country for over four hundred years, although, like the common cockroach, it is an introduced species. Well known to the Romans, by whom it was considered to possess medicinal properties, as a specific against snake bites, the "wall louse," to give it its old English name, was apparently introduced into Great Britain about the year 1503. Like many other domestic insects, the bed bug has followed in the wake of man all over the world.

Usually associated with dirt, this insect does not scorn clean dwellings, especially if there is a reasonable chance of obtaining a meal of human blood. The bed bug is popularly and scientifically so called on account of its habit of visiting beds and attacking their inmates. Abandoning beds by day, it hides in masses, in cracks, beneath paper, etc., a habit in which it is aided by the extreme flatness of its body. In its efforts to escape observation during the hours of light, it evinces a very remarkable degree of intelligence. It is commonly supposed that the demise of the old wooden four-poster and the substitution of metal bedsteads sounded the death-knell of this loathsome little animal. It has, however, been found hiding in the crevices of iron bedsteads, and the general improvement in domestic cleanliness of the present day is probably the reason why it is less common now than formerly. As is the case with all insects that have assumed a wholly or partially parasitic habit, the bed bug exhibits considerable structural degradation. Its normal food is human blood, and, as this is always partaken of at night, there is little need for active locomotion, so that the insect, unlike the majority of bugs, is wingless, or, to be more correct, the wings are represented by a pair of pads, quite useless for flight. It is fortunate perhaps that there are no wings, for, bad enough pest as 
the bed bug now is, he would be many times worse if blessed with this additional aid to distribution. Many other bugs are provided with two compound eyes and two simple eyes; in the bed bug the latter are wanting, sight being efficiently maintained by a pair of somewhat protruding, black eyes, resembling minute blackberries in appearance.

The adult bed bug is about a quarter of an inch long, obovate in outline, and very much flattened; its general colour is rust-red, and the abdomen is tinged with black. The most important part of its anatomy, from the human point of view at any rate, is the rostrum or beak. This organ, common to all bugs, is a piercing, suctorial organ which, when out of use, can be bent downwards below the head, but when required can be extended, as shown in the figure. A similar organ is found in those very common bugs, the green flies, and may easily be seen with the aid of a pocket lens. On account of the structure of the rostrum, and because there is no actual mouth, liquid food can only be partaken of by the Rhynchota, and to speak of the "bite" of a bed bug is hardly correct, though it must be admitted that the operation is none the less painful.

The female bed bug is very prolific; breeding is continuous throughout the year, unless lack of food or a low winter temperature brings domestic affairs to a standstill. It is erroneously believed that these insects hibernate during the winter; but this is not the case when conditions are favourable, and in such circumstances several broods are brought into the world in a year. The white, oval eggs are deposited in batches of six to fifty, in various crevices out of harm's way, and, at first, are covered with a sticky liquid which causes them to adhere to the place where they are laid. Round the free end of each egg is a projecting ring, within which there is a lid or operculum, this the young bug pushes up as it emerges, usually at the end of 
seven to ten days. When first hatched the young are quite white and nearly transparent, becoming straw-coloured after several hours, and except in colour and the absence of wing pads they somewhat resemble their parents (see fig. 79, A). After the first full meal of blood their bodies become red, except for the head, thorax, legs, and extreme tip of the abdomen. Five moults occur before the adult stage is reached, and the wing pads appear with the last moult. A single full meal is always taken before the skin is shed, so that in the seven to eleven weeks occupied in attaining maturity the young bed bug feeds five times, and although the time taken to grow up may be protracted, owing to lack of food or a low temperature, the number of feeds remains the same. Another full meal is taken by the female before ovipositing, in fact it is the almost invariable rule that insects, and allied animals, which feed on blood are quite incapable of laying fertile eggs till they have become engorged.

We have seen that the normal food of the bed bug is human blood, but these insects have been fed artificially on mice, English sparrows, guinea-pigs, and the North American mole. Like all animal parasites, the adults can exist for almost incredible periods without food-specimens have been kept foodless for over a year, without apparent injury. This wise provision of nature, which reaches its greatest pitch in some of the ticks, is of the greatest importance to the insects concerned, for it is obvious that suitable food may not always be forthcoming. Disgusting as the bed bug is in its habits, it is endowed with an even more disgusting smell, arising from a clear, oily liquid secreted by glands situated between the legs. This secretion, common to many of the Rhynchota, is probably protective against insectivorous birds, though in our subject it is of little avail against cockroaches and ants, both of which devour the bed bug with avidity.

America is blessed with an inveterate enemy of the bed 
bug in the shape of Conorhinus sanguisugus, popularly known as the blood-sucking cone-nose, the Mexican bed bug, or the big bed bug. Having stated that it feeds on the bed büg, we have quickly summarised its good points, for it efficiently takes the place of its smaller relative as a noxious insect, partially parasitic on mankind. Most of the members of the genus are natives of South America, and many of them live upon other insects-indeed, they are the normal food of sanguisugus; its taste for human blood is evidently acquired, and may have arisen, in part, from the fact that it shows a partiality for bed bugs distended with the blood of man.

The adult is fully an inch long, with a much-flattened body, and a long narrow head armed with a formidable beak or rostrum. It is dark brown in colour, striped and spotted with pink. In habit it resembles the bed bug in feeding by night and hiding by day; in odour it easily excels its relative.

The female lays her white eggs in masses out of doors, not having acquired the domestic habit to the full. Each egg is of an oval shape and provided with a lid or operculum, through which the larva emerges. The young appear in about three weeks, but before that time the eggs have changed through various shades of cream to yellow and finally pink. The larvæ are sluggish and wingless and they feed solely upon other insects, hence the necessity of their hatching out of doors; after two moults they reach the pupal stage and acquire wing pads; two further moults occur and they attain their full growth, wings, and often a taste for human blood. In the Mississippi and Arizona valleys they are especially abundant.

The effect of a bite from the cone-nose is often of a serious nature, and at best is exceedingly painful. At times the bites are followed by such serious after-effects as to lead to the supposition that some poison is injected, but whether this is a specific poison occurring in the insect's 

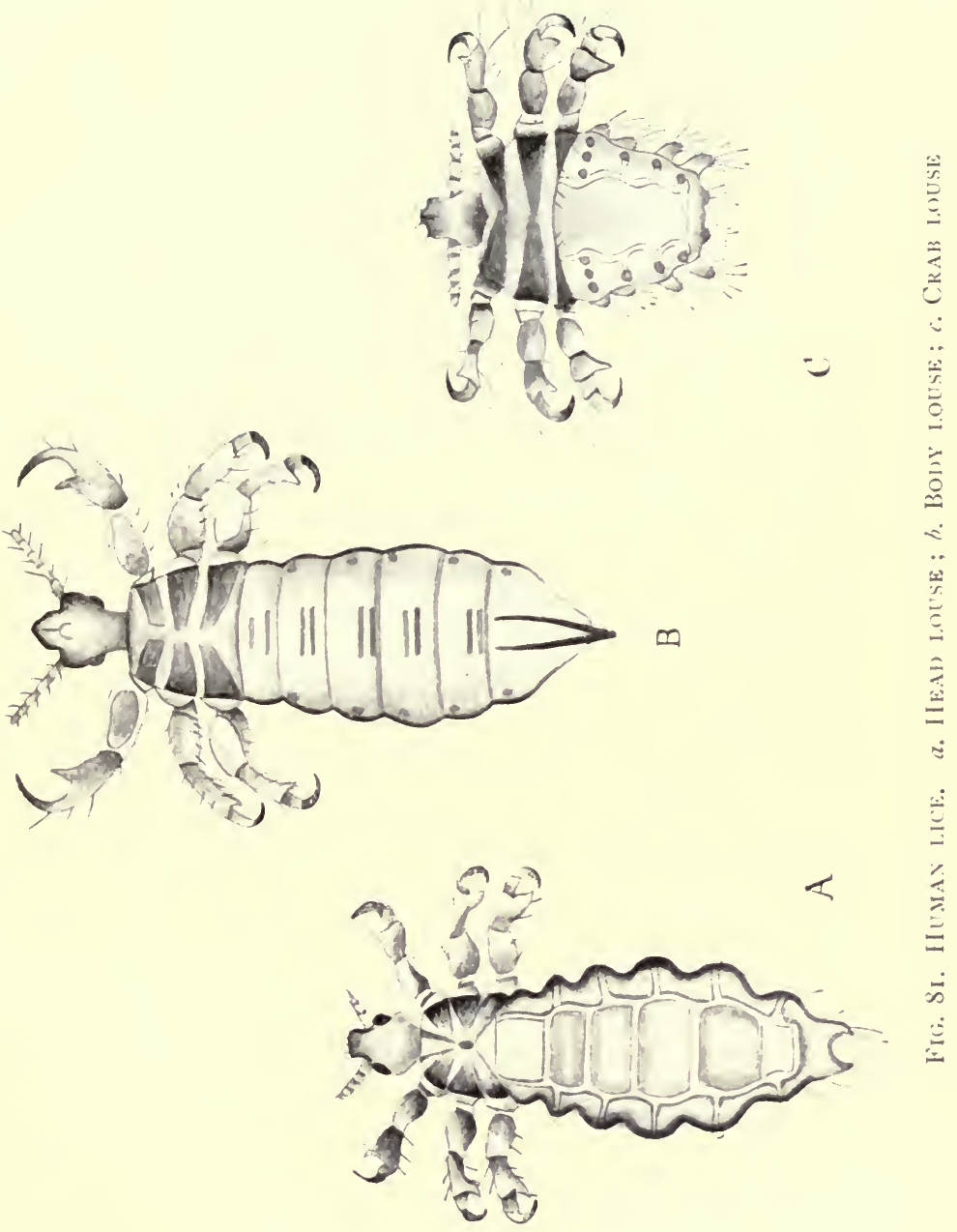

saliva, or arises because the parasite has previously fed upon some decaying animal matter, has not been proved.

\section{LICE}

Even more disgusting than the bed bugs and fleas are the Pediculce or lice, of which three species are associated with the human body. These little animals are constantly confined to their hosts, they spend their entire life on the mammalian body, and from it derive all their nourishment. Their courtship takes place there, their eggs are attached to hair, and, except by accident, they are never dissociated from their host; in short, they are true parasites, and, as such, have specially modified organs. All true lice are confined to mammals, they are wingless, their feet are adapted for holding and clasping hairs, their mouth parts, which are always completely withdrawn into the head when not in use, consist of tubular sectorial organs, provided with an armature of lancets for piercing the skin (fig. 80). Writing of these organs, Uhler, in his Standard Natural History, says they have "a fleshy unjointed rostrum, capable of great extension by being rolled inside out (like a glove finger), this action serving to bring forward a chaplet of barbs which embed themselves in the skin to give a firm hold for the penetrating bristles, arranged as chitinous strips in a long, slender, flexible tube, terminated by four very minute lobes, which probe to the capillary vessels of a sweat pore. The blood being once reached, a current is maintained by the pulsations of the pumping ventricle and the peristaltic movements of the stomach."

One interesting feature, common to all the lice, is that they are very rarely found on any other species of mammal than the one they normally infest, and then only on closely related species; thus human lice would not be found on the elephant, nor the elephant louse on the mouse. This 
may be due to differences in the calibre of the hairs, to which they are compelled to cling and to which their feet are adapted. It would be quite impossible for claws fitted for clinging to very coarse hair to obtain a firm hold on fine hair, and vice versa. Again, thickness of skin may have its bearing on this phenomenon, mouth parts adapted only for piercing a thin skin would prove useless on a thick hide. Difference in temperature, odour, and taste of the host may have their effect.

The three species of louse common to man are the head louse, Pediculus capitis, the body louse, Pediculus vestimenti, and the crab louse, Phthirius inguinalis (fig. 81, A, B, C). They are all three commonly and correctly associated with a dirty, unkempt condition of their host, but, unfortunately, owing to the exigencies of present-day civilisation, even the cleanest among us cannot claim immunity from their unwelcome attentions; though it is comforting to know that while some two hundred and fifty years ago these parasites were the constant companions of even the upper classes in England, they are now of comparatively rare occurrence.

The head and body louse closely resemble one another, and are often confused; both of them appear to have been known from the earliest times, and the former is the commoner. It is usually confined to the hair of the head, being rarely found on other parts of the body. The small, white, pear-shaped eggs (fig. 82) are laid singly, by the female, and, at the same time, glued towards the end of a hair, the back of the ears being a favoured position. These eggs, popularly known as "nits," give the hair somewhat the appearance of having been singed, and are more obvious than the adults to the casual observer. The young, which appear in about a week after oviposition, are very similar to the adults except in size, and, till they have had their fill of blood, their abdomens are proportionately smaller. The adults of both sexes are almost white, with indistinct 


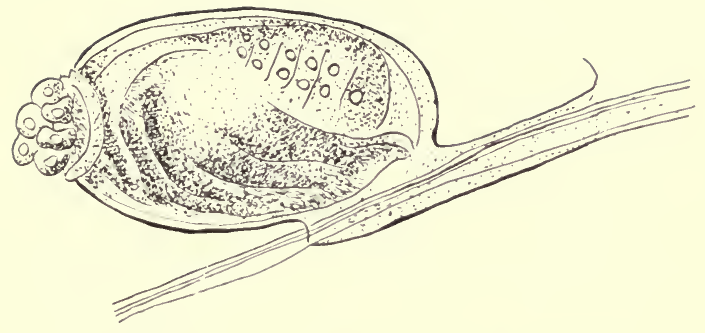

HI(i. S2. EGG OR "NIT" OF HEAI) LOUSE

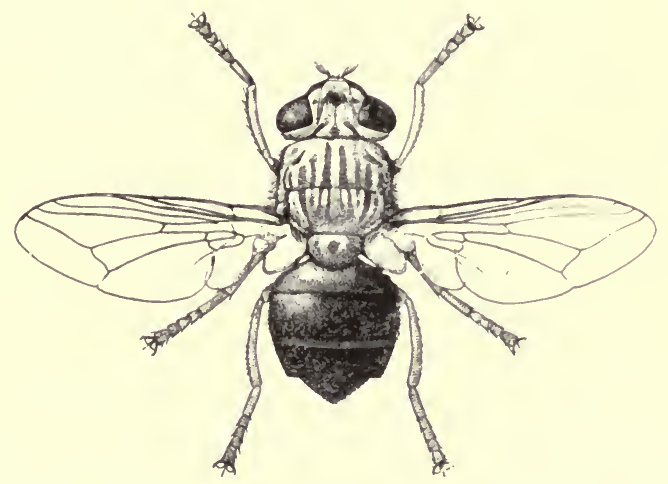

Fig. 83. The huMAN Bo' Fly, Dermatobia hominis 

dark markings at the sides of the thorax and abdomen. The female is larger than the male, being about one-eighth of an inch long, and the last segment of her abdomen is forked, whilst in the male it is rounded. There is no sharp distinction between thorax and abdomen, the former merging into the latter. The whole body is covered with short, straight hairs. Several moults take place during life, and maturity is attained in about a month.

That different species of mammals harbour different species of lice is easy to believe; more remarkable is the discovery that different races of mankind are the hosts of distinct races of lice. The lice of Caucasians are nearly white, those making their homes on West Africans and Australian natives are nearly black, those on Hottentots are orange, on Hindus smoke-coloured, on South American Indians brown, and on Chinese and Japanese yellow; there are also distinct differences in the claws, corresponding to the differences in texture of the hair of the various races. The use of lice as food by certain uncivilised peoples has already been noted. Sometimes, however, the insects become too numerous; then certain races-among them the Australian natives, the Apache Indians, and the Andamanese-cover their heads and bodies with a layer of mud, thereby reducing the population of their lively companions.

The adult body louse may be distinguished from the head louse by the fact that its back is marked with dark transverse bands; differences in habit also serve to distinguish the two species. The body louse only visits the human skin when hungry, and spends the rest of its time secreted in clothing, where also the eggs are laid. They are exceedingly prolific, and it has been estimated that a single adult female may have a progeny of eight thousand in eight weeks, and in warm weather this number may be largely exceeded; in fact, the remarkable fecundity of lice was once a popular byword, it being said, with a 
naïve disregard for the truth, that a louse becomes a grandfather in twenty-four hours.

The crab louse appears to be a product of rather more modern times than its confrères, though it is recorded by Herodotus and by Aristotle. As its name implies, it somewhat resembles a minute crab in outline. This loathsome creature, measuring from one-twentieth to one-tenth of an inch in length, nominally inhabits the pubic regions, though it may extend to the beard, armpits, eyebrows, and even eyelashes; it does not attack the head, perhaps because its enormously developed claws are not fitted for clasping the fine hairs of that region. The adult is nearly white, with a dark patch on each shoulder, and reddish legs and claws. It is even more prolific than the head and body lice, and, when present in large numbers, is probably the cause of the mysterious disease known as phthiriasis.

\section{Fly Parasites}

Precise details concerning the bot flies of man may be said to be "wropt in mystery." The great naturalist Linnæus, in his Systema Natura, first called attention to the fact that the larva of a certain South American species of fly had been found, from time to time, dwelling hypodermically on some of the natives. Subsequent authors, doubting Linnæus's description, dubbed the whole affair a myth and attributed the attacks, if attacks they were, to the ox warble fly. In 1822 Say actually received specimens of the larvæ from South America, and gave a detailed account of them, and from that time onwards meagre and spasmodic accounts of the human bot fly, known as Dermatobia hominis (fig. 83), have been published, though much still remains to be discovered. It is certain, at any rato, that the attacks of these insects are not confined to human beings; in fact, man must be considered as only an occasional host, dogs, monkeys, and cattle being the subjects most 


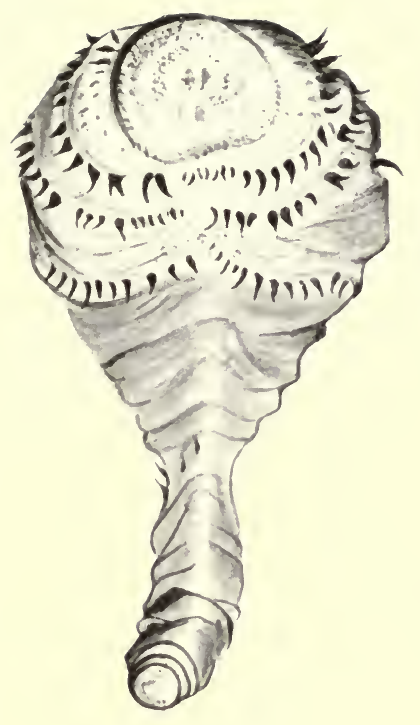

A

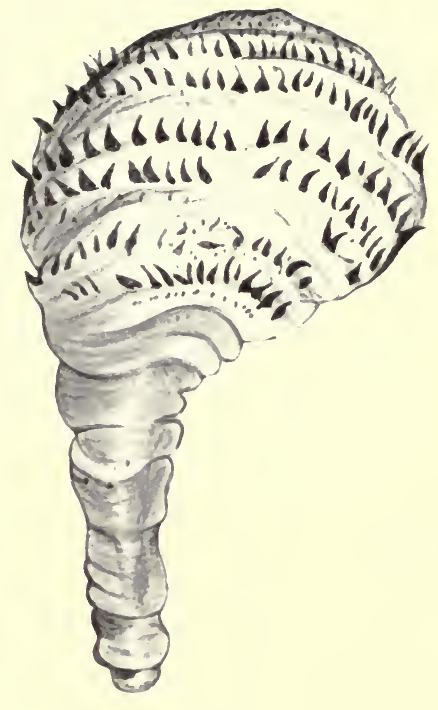

$\mathbb{B}$

FIG. 84. EARLY LARVAL STAGE of Dermatobia hominis

$a$. Vextrai.; $b$. Dorsal Iiew 

commonly affected. Both species are indigenous to Central and South America, and are known as "Ver macaque" in Cayenne and Mexico; "Ura" in Brazil; "Torcel" in Costa Rica ; and "Gusana peludo" or "Muche" in New Grenada.

From the figures (84 and 85 ) it will be seen that the young larvæ are roughly of the shape of a comma, and are strongly armed with a formidable array of spines. From time to time these maggots had been removed from the tumours which they made in the flesh of those whom they attacked, though how they got there was unknown. The adult flies had never been seen, and it was conjectured that their eggs were laid in clothing, and that the larvæ, on hatching, penetrated the human skin-a feasible conjecture, no doubt, in the case of properly clothed Europeans, but one that hardly applies to natives, who wear little more than their birthday clothes.

Quite recently light has been thrown on this muchdebated point. In 1900 Blanchard described some large eggs, which he had found arranged in bundles and attached to the ventral side of the abdomens of certain Central American mosquitoes. In 1910 Morales of Costa Rica discovered that the eggs were those of Dermatobia, he stated that they were laid directly on the abdomen of the mosquito, which then transported the larvæ to their host. As the bot fly is the size of a blue-bottle and the mosquito is a small, frail creature, the statement seemed incredible, in spite of the fact that in 1912 Tovar of Venezuela, by placing specimens of the blood-sucking mosquito, Janthinosoma lutzi, carrying Dermatobia eggs (fig. 86), on various animals, succeeded in producing tumours, which, after eleven days, were found to contain larvæ of the fly. A short time afterwards, however, Rincones of Caracas announced that the bot fly is in the habit of ovipositing on leaves, in damp places, frequented by Janthinosoma lutzi. He said that the eggs are covered with an adhesive cement, but are only fixed lightly to the leaves; moreover, 
they are deposited with their micropyles-the points from which the larvæ escape-downwards. As the mosquito crawls over the leaves its abdomen comes in contact with the bases of the eggs, which, for the time being, are, so to speak, standing on their heads. The adhesive cement causes the eggs to adhere to the ventral surface of the mosquito's abdomen, and, in their new position, their micropyles are at their free ends. Sooner or later the mosquito will seek a meal of blood, human for choice, and the minute Dermatobia larvæ (fig. 84), escaping from their eggs, will find a wound in the skin of their host, readymade for them to enter. The larval growth, of course, takes place beneath the skin, and rapidly causes an angry boil, which necessitates immediate surgical attention. If left undisturbed, the larvæ would possibly leave their host to pupate, though this is merely conjecture, based on the habits of other larvæ with similar life-histories.

In addition to Dermatobia, three other Diptera-the Tumbu fly and Congo flour maggot of Africa, and the screwworm fly of the New World-are parasitic upon man. The Tumbu fly, Cordylobia anthropophaga (fig. 87), which, in its larval stage, is known as the Cayor maggot, is essentially African. Both man and animals are attacked, the favourite hosts being dogs, rabbits, and goats, which are usually injured in the scrotum; but whatever part of the body is attacked, and whatever the host, the nature of the infestation is the same. The larva forms a considerable swelling or boil beneath the skin, through the centre of which there is an opening for breathing; when mature the host is forsaken, and pupation takes place in the ground. Exactly how the larva passes beneath the skin is unknown. By some travellers it is thought that the fly oviposits in soil, and that when the larvæ hatch from the eggs they penetrate the skin of people sleeping on the ground; by others it is thought that the eggs are laid in clothing, so that when they hatch the larvæ find their food close at 


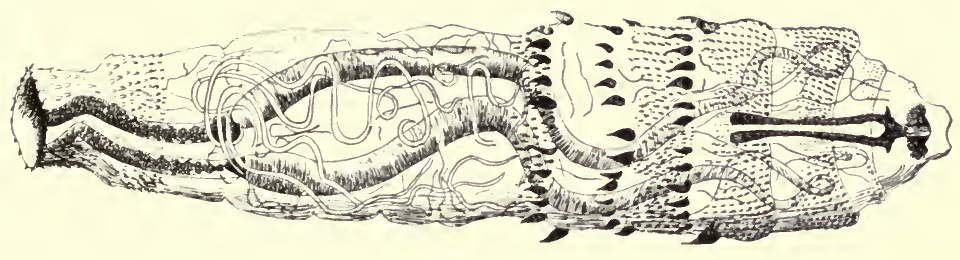

FIG. 85. LATER IARVAI STACE OF Dermatobia hominis

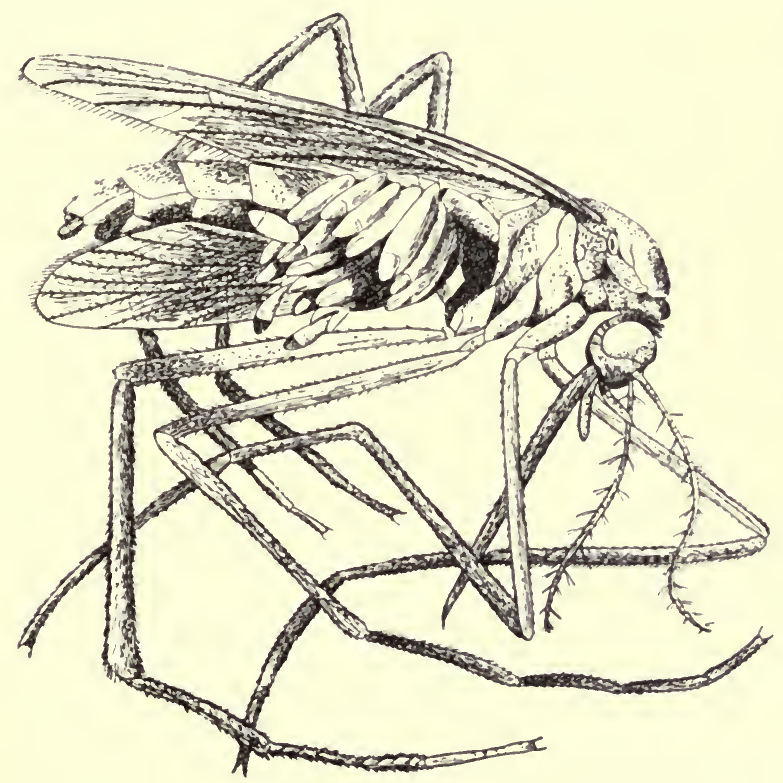

FIG. 86. A Mos(guito, Janthinosoma hutzi, CARRYING THE FGGS OF THE DERMATOBIA ON ITS ABDOMEN 
hand. Whatever may be the true explanation, it is certain that oviposition takes place where there is an odour of human or animal perspiration, because the parts of the body which most frequently come in contact with the ground are those in which tumours most usually occur; oviposition has also been known to take place on clothing saturated with perspiration. The adult Tumbu fly is of a yellowish colour, shading off to deep brown at the posterior end. The larva (fig. 88) is barrel-shaped and almost completely covered with minute spines in groups of two and three, which aid in locomotion, and also probably by their irritant action beneath the skin cause an increased flow of pus, on which the larva feeds.

Very similar in appearance to the Tumbu fly is Auchmeromyia luteola (fig. 89), known in its larval state as the Congo floor maggot. Although this fly has been known for many years, it was thought, till recently, that its larva formed a temporary home beneath the skin, after the manner of the Tumbu fly. In 1904 Dutton, Todd, and Christy discovered that the maggot possesses a habit, unique among dipterous larvæ, of sucking human blood. They observed the natives of the Congo digging and scraping the cracks in the mud floors of their huts and so collecting the larvæ. Only those floors were so treated on which the natives were in the habit of sleeping, for where there are beds, or the people sleep raised from the floor, the larvæ are seldom found. The female fly always lays her eggs on the ground, selecting, if possible, places soiled with urine.

The adult flies are about the size of a blue bottle, only yellowish in colour and marked dorsally on the thorax with black and brown stripes; their legs are black. They are shade-loving, spending most of their time resting in the dark corners of native huts. Oviposition takes place in two stages, separated by about a month, and, in all, about eighty eggs are laid, always in the ground. The larvæ (fig. 90) are dirty white in colour and composed 
of seven segments; at the hinder margin of each segment is a set of three pads, each covered with minute spines, directed backwards; these assist in locomotion. On the last segment are three spiracles or breathing pores; whilst on the first segment are two black mandibles surrounded by paired groups of small spicular teeth, forming a sort of cupping instrument. Under normal conditions they pass through two moults and become fully grown in about a fortnight.

The larvæ are exclusively blood feeders, and in this connection one or two interesting points may be noticed. As is so often the case with insects which rely on an active host for their food, they are able to endure long fasting periods. A more curious trait is that when below ground and hungry they show a remarkable sensibility to heat, the slightest rise in temperature causes them to become active and to travel towards the source of heat; when fully fed slight changes in temperature do not appear to affect them. The reason for this phenomenon is obviousa hungry Congo floor maggot is anxiously waiting beneath the soil for a meal; should he venture above ground he would probably be injured, accidentally or purposely, so, like many more noted individuals, he waits, and mayhap some native, seeking rest and sleep, will throw himself on the ground; soon the warmth from the human body will penetrate to the waiting maggot, this is the signal that a meal is at hand; aided by his spinous foot-pads, he wriggles through the soil and takes his fill, before again retiring to his subterranean home. The pupa, as is so frequently the case with Diptera, is dark brown and tubshaped. We have mentioned that this species is African; it ranges from Natal to Nigeria, and its distribution is aided by the fact that it is often carried from one village to another, in the egg or larval stage, in the dirty mats which the natives are in the habit of transporting from place to place. 


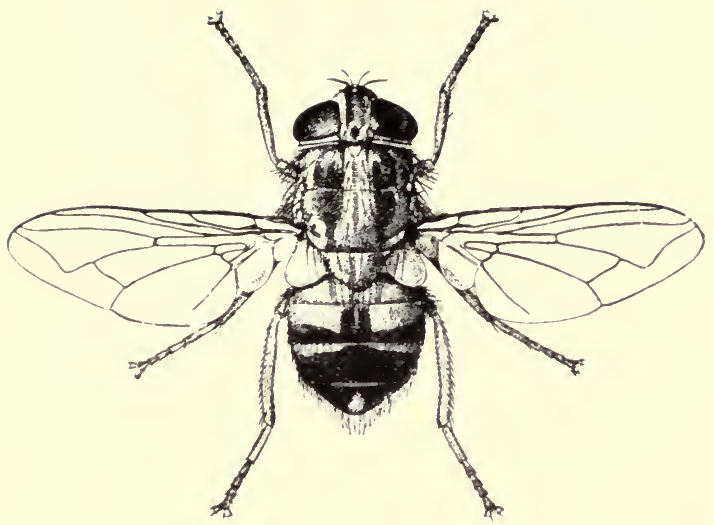

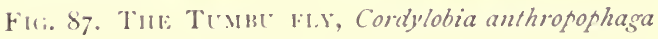

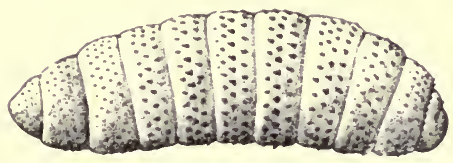

Fili. S8. THI: CaYOR WOR.M, Corly'lobia anthropophaga 

The screw-worm fly, Chrysomyia macellaria (fig. 91), is confined to America and the West Indies. The adult flies are about ten millimetres long and of a metallic green or blue colour, marked with three longitudinal black lines on the thorax; they have hairy abdomens, black legs, and transparent wings. The larva (fig. 92) is dirty white in colour and is divided into twelve segments, each one of which is furnished with one or more rings of spines. The larval form takes its sustenance from men or animals; eggs are laid by the adult fly wherever there is a wound, indeed blood has a great attraction for these flies. Sometimes oviposition takes place in the human ear or nostril, especially if there is any discharge from either organ. The pupa is dark brown and spiny.

\section{Human Body Mites}

Of the mites inhabiting the human body, the itch mite is becoming a rare pest in civilised communities; the follicle mite rarely attains serious proportions; and the mites causing grain itch, copra itch, and the like only attack people engaged in certain trades.

The itch mite, Sarcoptes scabei (fig. 93), occurs not only on man, but on various domestic and wild animals, among them being the horse, sheep, goat, camel, hog, dog, ferret, llama, hare, rabbit, lion, wolf, fox, and wombat. The adults are flattened, circular, and very minute; their general structure is shown in the figure. All stages in the life-cycle are passed on the host, in fact many successive generations may occur on the same host. In man, an attack of the mite is characterised by intense itching, usually at the base of the fingers and between the knuckles, though in bad cases the whole hand may be inflamed and covered with pustules. The itching is caused by the mites burrowing in the skin; as they extend their channels deeper and deeper they deposit their eggs, and the young which develop from them feed on the surrounding tissue. After four moults maturity 
is attained, then the adults leave the burrows and travel to the surface of the skin to mate; afterwards the females make fresh burrows in which to lay their eggs.

Somewhat akin to Sarcoptes scabei is the copra itch mite, Tyroglyphus longior, castellani, a variety of the cheese mite. This minute animal, as its name implies, causes intense irritation to the skin of hands, arms, legs; in fact, the whole body, except the face, of Coolies and Europeans who are brought into close contact with the dried coco-nut kernels, known as copra. In Ceylon, the home of this mite, kernels are removed from fresh coco-nuts and dried in the sun for two days. At the end of this time a portion of the kernels crumbles away; this is the copra dust, which swarms with the mites.

Little or nothing is known of the life-history of these minute animals. They closely resemble the cheese mite in appearance, being eight-legged and well armed with stiff bristles, and, though they cause the intense itching characteristic of the common itch mite, they do not burrow into the skin, and, for some unexplained reason, they never attack certain individuals. Other mites causing severe dermal irritation and eruptions in man are Glycyphagus domesticus, causing grocers' itch, and Rhizoglyphus parasiticus, the cause of water itch in the Coolies employed on Indian tea plantations.

A mite of curious habit, Demodex folliculorum var. hominis, was discovered by Simon of Berlin, more than seventy years ago, in "blackhead" pustules. It is now known that these worm-like, eight-legged mites are quite common in the sweat glands of the face, chiefly those of the nose, chin, and forehead; whilst in the hair follicles they often occur in large numbers, with their heads pointing away from the surface of the skin. In order to see these creatures, the white oily substance, extracted by pressure on the sides of the sweat glands, should be examined in a drop of oil, spirit or xylol, under the 


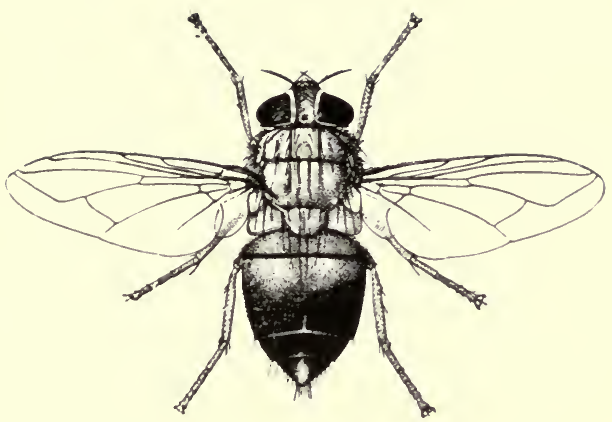

Fig. 89. THE Coxgo floor Malicot lis, Auchmeromyia luteola

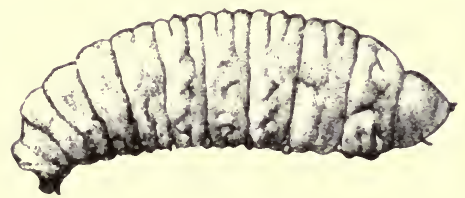

FIli. 90. THE Coxio rlOOR MAlint, Auchmeromyia luteola 
. 
microscope; it is quite impossible to see them with the naked eye.

The structure of the adult is clearly shown in fig. 94 . Its short legs, striated, worm-like abdomen, and its mouth parts arranged for sucking, render it so curious an object that it cannot be confounded with any other mite. The female mite lays heart-shaped or fusiform eggs, from which legless larvæ emerge; they later become six-legged, then they transform into eight-legged nymphs, and after two moults become adult. Very similar mites have been found in the dog, cat, pig, and ox. The human species is cosmopolitan and possibly pathogenic; it has been considered as a probable agent in the spread of cancer, leprosy, and a tropical skin disease known as Lichen spinulosus.

Annoying pests in this country during the autumn months are the harvest mites, Leptus autumnalis (fig. 95), first described by Shaw in 1790 ; there are two American species, known as Leptus irritans and Leptus americanus. These six-legged insects are the larvæ, or the immature forms, of eight-legged members of the family Trombidiidas; the life-history of the British species is not fully known, and, as a consequence, its identity is uncertain. In size these creatures are exceedingly small; in colour they are blood red. They belong to the same class as the ticks and spiders, so they are not true insects.

Their attacks are most frequent on those parts of the body nearest the ground, so that the ankles and legs, just below the knee, suffer most. A ccording to some authorities, these minute creatures penetrate the sweat glands; in any case, they cause intense irritation by burrowing beneath the skin of their human host. The life-history of an American species is as follows:-Minute, brown, spherical eggs, to the number of three hundred, are laid in or on the ground by each female. Almost immediately they are laid the outer skin splits, exposing a pale membrane within. The larvæ are six-legged, circular or ovoid creatures, and 
each leg is tipped with two or three substantial claws. After each feeding the larva becomes elongated and swollen with blood. It then falls to the ground, seeks shelter, and below the larval skin new organs are developed, so that, when this skin is thrown off after a few weeks, the adult Trombidium emerges. Aphides, lepidopterous larvæ, and, in the case of one species, locust eggs form the usual fare of these adult mites. The winter is spent in hibernation beneath the ground, and in the spring oviposition takes place. 


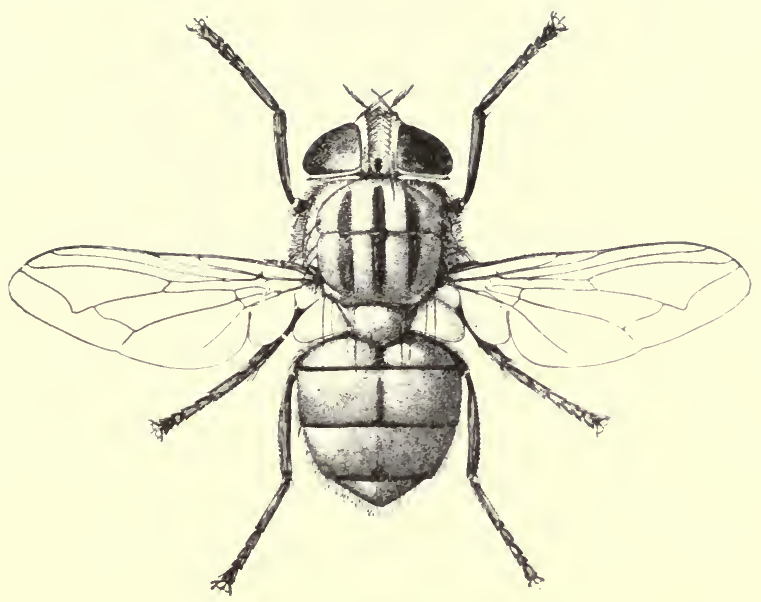

FIr. 9I. THE SCREW WORM FIs, Chy'somyia macellaria

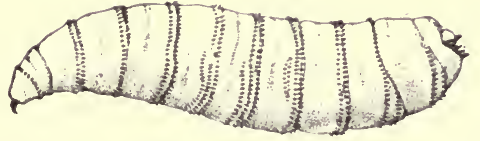

FIG. 92. THE SCREW WORM, Chrysomyia macellaria 



\section{INSECT CONTROL}

THE study of parasitic and predaceous insects is not by any means new. Aldrovandi, an Italian naturalist, appears to have been the first in the field when, in 1602, he observed the exit of the larvæ of Apanteles glomeratus from the common cabbage caterpillar. Not, however, till nearly a century later was the true significance of the phenomenon realised by another Italian scientist, Vallisnieri. To enumerate but a fraction of the names of the workers in this interesting field would occupy too much valuable space; but it is of interest to note that Ratzeburg, whose work on the subject was for long considered the best contribution in Europe to our knowledge of insect parasitism, "did not believe that insect control could in any way be facilitated by man."

Probably the earliest workers to suggest the artificial handling of beneficial insects were Kirby and Spence, who, in their work on entomology, published in 1816, referring to the destruction of the hop aphis by the common ladybird, said, "If we could but discover a mode of increasing these insects (ladybirds) at will, we might not only clean our hot-houses of aphides by their means, but render our crops of hops much more certain than they are now." Records seem to point to Professor Boisgiraud of Poitiers as being the first man to utilise beneficial against injurious insects. In 1840, or thereabouts, he freed some trees of the harmful gipsy moth by placing upon them the beetle, Calosoma sycophanta; and also destroyed earwigs by means 
of a rove beetle, Staphylinus sp., and a ground beetle, Carabus auratus.

The next efforts in this direction were carried out both in Europe and America, and consisted in collecting large numbers of destructive insects, many of them probably smitten by internal parasites, and keeping them in cages covered with fine wire-netting of such a mesh that the adult injurious insects were unable to escape; but their parasites, on reaching maturity, would have no difficulty in gaining their freedom and thereby parasitising other hosts. This method was tried in America with the imported cabbage worm Pontia rapce and the cotton caterpillar Alabama argillacea, and in Italy with the olive fly Dacus olece, among others.

A further stage in this important branch of economic entomology appears to have been the transportation of beneficial insects from one part of a country, where they were plentiful, to another part of the same country, where they were lacking. This method of natural insect control has been successfully carried out in America, a striking case being that of the destructive Hessian fly, Cecidomyia destructor, and its hymenopterous parasite, Polygnotus hiemalis. In 1906 a serious outbreak of this fly occurred in Pennsylvania, but was kept in hand because quite ninety per cent. of the pupæ were found to be parasitised by Polygnotus. At a later date the Hessian fly pest broke out in Maryland, and, in 1907, parasitised pupæ were brought from Pennsylvania, with the result that by midsummer all the fly pupæ were discovered to be parasitised and the pest was effectually controlled.

Quite recently various species of ladybirds have been collected in California, during their winter hibernation, for shipment to various parts as a control for plant lice. As an illustration of the magnitude of the undertaking, Mr E. K. Carnes, who was in charge of the work, wrote, in 1910: "We have quite a sight at the insectary now-over a ton 


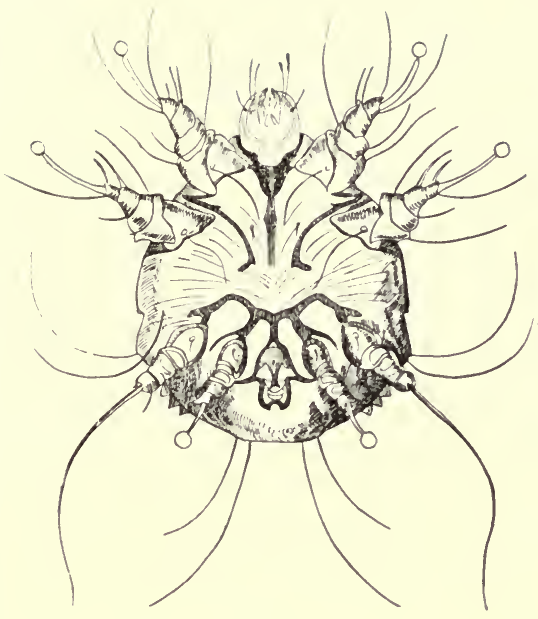

A

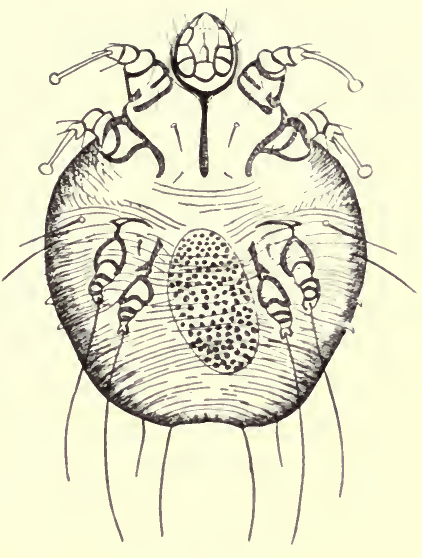

B

Fig. 93. Humax itch mites, Sarcoptes scabei. a. Malf; b. Framal.e

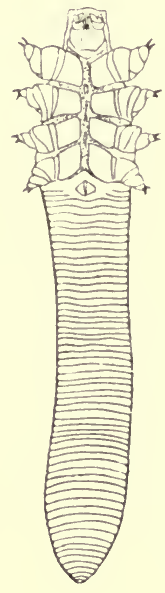

Fig. 94. The humaN FOLLICle Mite, Demodex follicu'orum VAK hominis

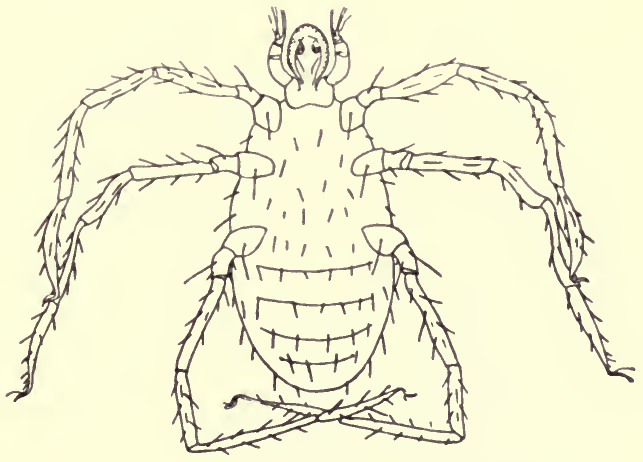

FIs. 95. A HARVEST MITE, l.eptus autumnalis 

of Hippodamia convergens (a species of ladybird) boxed in 60,000 lots each, in screened cases, and in our own cold storage. We handle them in large cages, run them into a chute, and handle them like grain. They are for the melon growers of the Imperial Valley."

The final, and most important, stage in this work is the transfer of beneficial insects from one country to another, and, though his efforts were unsuccessful, the credit for priority belongs to Dr Asa Fitch, an American entomologist. Sometime in the early eighties the European wheat midge, Contarinia tritici, had been introduced into America, and in 1854 a most disastrous attack by this insect devastated the wheat crops of the Eastern United States. Dr Fitch knew that in Europe the midge was heavily parasitised and that, accordingly, it did relatively little damage. Speculating as to the cause for the dissimilarity of the status of the pest in the two countries, he wrote: "There must be a cause for this remarkable difference. What can that cause be? I can impute it to only one thing-we here are destitute of nature's appointed means for repressing and subduing this insect. Those other insects which have been created for the purpose of quelling this species and keeping it restrained within its appropriate sphere have never yet reached our shores. We have received the evil without the remedy, and thus the midge is able to multiply and flourish, to revel and riot, year after year, without let or hindrance. This certainly would seem to be the principal if not the sole cause why the career of this insect here is so very different from what it is in the Old World." Requests by Dr Fitch to British entomologists to study the matter and send parasites to America came to naught. In 1873 an American predatory mite, Tyroglyphus phylloxerce, which in its own country feeds on the vine phylloxera, that scourge of European vineyards, was imported into France, without appreciably checking the pest.

The transportation of parasitic and predatory insects 
from one country to another, for the benefit of mankind, forms one of the romances of applied entomology. As the Americans were the pioneers in this work, it is to their country that we will turn for our examples.

The practice of the control of insect pests by their natural enemies is one of modern times, for the earliest record of the work, on anything approaching a commercial scale, dates back but twenty-five years. It is based on the assumption that all nature is in a state of equilibrium, that is to say, that all life, in its native home, is kept in check by other forms of life which prey upon it.

For many years the orange and lemon groves of California were threatened with ruin, owing to the depredations of a relatively large scale insect known as the fluted or cottony cushion scale, Icerya purchasi. A considerable amount of research showed that in all probability this noxious insect had been introduced into the United States from Australia in 1868. It was found in Portugal in 1873, near Naples in 1900, and has been subsequently met with in Egypt, Syria, Greece, Dalmatia, Sicily, and France in 1910. All mechanical means of control having failed, in 1889 Professor C. V. Riley, chief of the American Bureau of Entomology, sent Mr Albert Koebele to the Antipodes to try and discover what insect, if any, kept the cottony cushion scale in check in its native land. His voyage of discovery was eminently satisfactory, for he found that the scale insect was rendered almost harmless in Australia, because, whenever and wherever it appeared, it was eagerly devoured by a small ladybird, known to science as Novius cardinalis. This little beetle was accordingly transported to California, where, fortunately for the citrus growers, it flourished and multiplied from the day of its introduction, and, as a consequence, the cottony cushion scale is now no longer a serious factor in the citrus production of California. But, to this day, large numbers of the ladybird are reared annually at Sacramento, 
and whenever an outbreak of the scale occurs, an army of the little beetles is despatched to deal with the trouble. The chief anxiety of the State entomologists is how to keep a sufficient supply of the scale insects alive wherewith to feed their charges.

Novius has also been successfully introduced into Portugal, Italy, Syria, France, Egypt, and Hawaii. The fact that this ladybird only feeds on the cottony cushion scale and closely allied forms was, however, overlooked by the Florida citrus growers. Impressed by the success of the venture in California, the Southern State was anxious to try the mettle of Novius cardinalis on some other scale insects, and in due course a shipment of the little beetle arrived, together with some cottony cushion scales as food for the jourmey. On arrival, the beetles and their food were liberated in an orange grove, with the result that the ladybirds died, and the cottony cushion scale spread and flourished to such an extent that it took several years and considerable expenditure before the pest was eventually subdued.

The outstanding success of the importation of Novius may be ascribed to the fact that the beetle is much more active than its prey, which remains stationary for the greater part of its life; it has two broods to every one of the scale insect, and, strangest of all, it appears to have no enemies of its own.

The good work of the ladybird has become an historical event in the annals of applied entomology, and though much effort and many dollars have been expended on similar importations, often, be it said, with very satisfactory results, yet the fact remains that in no other case has the work been duplicated, in that no other single natural enemy has been able to control an important pest in the land of its adoption. Nevertheless, Novius cardinalis gave a distinct fillip to the science of natural control of insect pests in America.

Another most serious pest of fruit trees in America is 
the San José scale, Aspidiotus perniciosus, so called because it first appeared in the New World at San José, California. Efforts were made by American entomologists to discover its original home, just as had been done in the case of the cottony cushion scale. Europe was out of the question, for it was unknown there; suspicion fell on Australia, Hawaii, and Japan, where the pest was rife, but investigations proved that all these countries had received their original supply on nursery stock imported from America. In $1901 \mathrm{Mr}$ Marlatt started on a tour of exploration to the countries of Eastern Asia, with the object of discovering a control insect. Six months were spent in Japan, but a thorough investigation revealed that that country was not the native home of the San José scale. Finally, its original home was discovered in Northern China, in a region between the Tientsin-Pekin road and the Great Wall, and its habitat a small haw apple which grows wild over the hills. Everywhere in this district there occurred a little ladybird, Chilocorus similis, feeding on all stages of the San José scale.

Although two hundred living specimens of the beetle were shipped to Washington, all but two perished during the winter. One of the survivors, however, proved to be a female, which commenced to oviposit in April, and from this single individual two hundred eggs were obtained. Subsequent generations throve so admirably that by August over a thousand specimens were sent out to various experiment stations in America, and at the end of the summer there were still over a thousand survivors left at Washington. Everything pointed to the duplication of the Novius cardinalis achievements, but this was not to be. Colonies in the Northern States perished, and in the South the almost universal use of various washes, to destroy the scale, effectually prevented the rapid multiplication of the beetle, and in many cases exterminated it altogether. Apart from this mitigating circumstance, there is every 
reason to believe that this little ladybird would have become firmly established in the land of its adoption, and would have rendered the dreaded San José scale comparatively innocuous.

We will not reiterate the story of the introduction and spread of the gipsy and brown-tail moths in America, but we may point a moral and adorn a tale by mentioning the fact that the State of Massachusetts ceased its appropriations towards the expenditure of exterminating these moths from 1900 to 1905 , and during these five years the pests spread from a restricted area of three hundred and fifty-nine square miles to an extended range of over two thousand two hundred and twenty-four square miles. Matters came to a head in 1904, when it was said that "from Belmont to Saugus and Lynn a continuous chain of woodland colonies presented a sight at once disgusting and pitiful. The hungry caterpillars of both species of moths swarmed everywhere; they dropped on persons, carriages, cars, and automobiles, and were thus widely scattered. They invaded houses, swarmed into living- and sleeping-rooms, and even made homes uninhabitable. . . Real estate in the worst infested districts underwent a notable depreciation in value."

Acting on the dictum that desperate diseases require desperate remedies, the American authorities set themselves the gigantic task of establishing, "not one or half-a-dozen of the natural enemies, but all of them, aiming at the same time to avoid the introduction of hyperparasites-that is, those species that prey upon the true parasites of the injurious forms-thus, if possible, bringing about an even more favourable situation for the primary parasites in New England than exists in Europe." Several visits were paid to various centres in Europe, from which colonies of parasitised gipsy and brown-tail moths were sent to the State insectary at North Saugus, Massachusetts, and from them a number of 'beneficial insects were reared. 
During the course of this indoor work an unlooked-for difficulty arose. The larvæ of the brown-tail moth are exceedingly hairy, their hairs are freely shed and are irritating and poisonous. The atmosphere of the laboratory in which the work was carried on soon became charged with them, they penetrated the skin, noses, and throats of the laboratory assistants, many of whom became ill and resigned their posts. Gloves, masks, and even head-pieces were designed to mitigate the evil, but with only partial success, and eventually Mr Titus, who had been in charge of the work, was obliged to resign in order to save his life, for intense irritation of the lungs had been set up by the hairs.

Shortly after this misfortune, a move was made to larger central laboratories at Melrose Highlands, and an European depôt was established at Rennes, in France. At the French depôt insects from Eastern Europe, destined for America, were examined, repacked, and taken by hand to Cherbourg and Havre for shipment; permission was also given for the landing of all such packages without customs examination, in short, everything possible was done to expedite transit.

Why, it may be asked, have the Americans gone to such trouble and expense to introduce several parasites to assist in the control of these two moths, when a single species of ladybird was capable of rendering a destructive scale insect innocuous? A study of insect parasitism is necessary before the question can be adequately answered, but, in brief, it may be stated that parasitism plays varied rôles in the economy of different hosts. Some insects support an abundant parasitic fauna, while others are attacked only by a few and perhaps relatively uncommon parasites. Probably no two hosts, unless they be practically identical in habit and life-history, are attacked by quite the same species of parasites. There are, however, certain features in the parasitism of each species which are common to 
each of the others, one of the most common of which is that each host supports a variety of parasites, often differing among themselves to a remarkable degree in habit, natural affinities, and methods of attack. The conclusion, therefore, has been drawn that to be effective in the case of insects like these moths, parasite control must come about through a variety of parasites working together harmoniously, rather than through one specific parasite, as in the case with less specialised insects such as the scale insects, having a less well-defined seasonal history. In short, there must be a seasonal sequence of parasites to effectually control the gipsy and brown-tail mothsparasites of eggs, larvæ, and pupæ.

"In a country where the conditions are settled, each species of insect is subjected to a certain fixed average percentage of parasitism, which, in the vast majority of instances and in connection with numerous other controlling agencies, results in the maintenance of a perfect balance. The insect neither increases to such abundance as to be affected by disease or checked from further multiplication through lack of food, nor does it become extinct, but throughout maintains a degree of abundance in relation to other species existing in the same vicinity, which, when averaged for a long series of years, is constant." Though storms and other climatic conditions, birds, and even disease all play their part in insect control, it is probable that only through parasites and predators is an insect brought under complete natural control, because their increase numerically is directly affected by the numerical increase of the insects on which they prey.

After this digression, let us return to the consideration of the gipsy and brown-tail moths and learn what steps have been taken for their actual control. Seeing that more than thirty distinct parasites, and seven kinds of predatory beetle, have been introduced into the United States to wage war on these two moths, it is plain that 
no more than a mere passing mention can be given here of the majority. With regard to the actual numbers of this beneficial army, official records give the totals as one million, eight hundred and sixty-two thousand, nine hundred and eighty-three parasites and eighteen thousand, eight hundred and thirty-five predatory beetles. These little immigrants comprise egg parasites-laying their eggs, in some cases, in the recently deposited lepidopterous eggs; in other cases, ovipositing in eggs just about to hatch, or, to be more correct, in the young caterpillars within the eggs,-caterpillar parasites, and pupal parasites.

From such an array it follows, as a matter of course, that some failures have been leavened with a fair number of successes, and, of the latter, none has been more conspicuous than that of a little beetle which has accomplished more than lay in the power of mortal man towards ridding the United States of what threatened to be a veritable scourge. The beetle, known to scientists as Calosoma sycophanta, belongs to the family of Carabida, or ground beetles. Ábout an inch in length, and provided with the long legs common to all members of its family, it is exceedingly active and can run along the ground or climb trees with remarkable agility. Of a beautiful metallic green colour, this showy insect, which is fairly common in Central Europe and not unknown in England, can vie with many of the tropical forms in brilliance of colouring. It has long been known to European entomologists as a most voracious feeder on lepidopterous larvæ and pupæ, with a preference for those of the gipsy and brown-tail moths; accordingly, when the ravages of these insects attained serious proportions in the United States, Calosoma was called upon to assist.

An army of collectors was organised in Europe to ship the beetle to America. In 1905 the first shipment of two hundred and sixteen specimens was sent from Sardinia, but, owing mainly to errors in packing, only one arrived 
alive. In the following year, six hundred and ninety-three specimens of an allied species, Calosoma inquisitor, safely reached the land of the Stars and Stripes from Switzerland and Italy. Of these, several colonies were liberated in the field, and others were confined in outdoor cages and their habits were very carefully studied and recorded. In 1907, nine hundred and fifty-seven specimens were received alive, in spite of a fifty per cent. mortality; in 1908, the numbers imported were six hundred and seventy-five; in 1909, four hundred and five; and in 1910, one thousand three hundred and five. In all, four thousand and fortysix specimens became useful, naturalised citizens of the United States in six years, and of these sixty-seven per cent. were liberated to begin operations against their lepidopterous enemies, and the remainder were confined in a State insectary for experimental work and to reproduce their kind for future use in the field.

That profitable use was made of the insectary inmates is evident, for, in 1908, two thousand three hundred beetles were raised; in 1909 the numbers had increased to six thousand one hundred, and in the following year a further increase, to six thousand three hundred and eighty, was recorded. Figures are dry matter to the lay reader, and, it is said, they may be made to prove anything, but there is no juggling with the truth here, and they have been quoted not so much for their intrinsic value, but rather to demonstrate, beyond question, the enormous amount of labour that is entailed in combating even one insect pest in a single country.

Consider, alongside the figures, the careful packing necessary to keep the little exiles healthy on their long voyage across the Atlantic: each beetle was packed in a separate box, for it was found that if several were packed together they relieved the tedium of their journey by devouring one another. Consider too the work that was, of necessity, expended on the insects in the State insectary 
in America-to provide constant meals of living larvæ to over six thousand hungry beetles is, in itself, a tall order and one not lightly undertaken, for Calosoma and its larvæ feed day and night, and, being of a fastidious, cannibalistic nature, will not accept raw meat or any other substitute for their living food. Consider the care lavished on the females during oviposition, the countless experiments to learn everything in the beetle's life-history that could possibly be turned to good account by man, and the hundred and one little details that always arise during such an undertaking, and some small idea of the magnitude of the work will be gleaned.

Now let us turn our attention for a moment to the work of this little beetle in the field, and learn how wonderfully it is adapted by habit to wage war on the larvæ of moths in general and the gipsy and brown-tail moths in particular. The moth larvæ we know infest trees, and the larvæ of Calosoma, unlike the grubs of many beetles, are active and addicted to tree-climbing in search of food. This trait in itself is of incalculable value, for this little friend of man is of practical utility both in the larval and adult stages of its life. Day and night these voracious youngsters attack caterpillars, seizing them from the side or in the middle of the back, or, if the caterpillars are hairy, between the segments, where the skin is smooth. Even the newly hatched larvæ are able, by means of their strong mandibles, to master caterpillars, regardless of size. After making an incision in the body wall, the Calosoma larva feeds on the juices of its prey and consumes the greater part of its fat. The moth pupæ are not exempt from attack, vulnerable spots between the segments are selected, characteristic holes, irregular in outline and extending nearly the whole length of the chrysalis, are made and the contents eaten. And this brings us face to face with a most extraordinary and useful trait-the beetle larvæ prefer the female pupæ. In an experiment at the State insectary it was found that, 


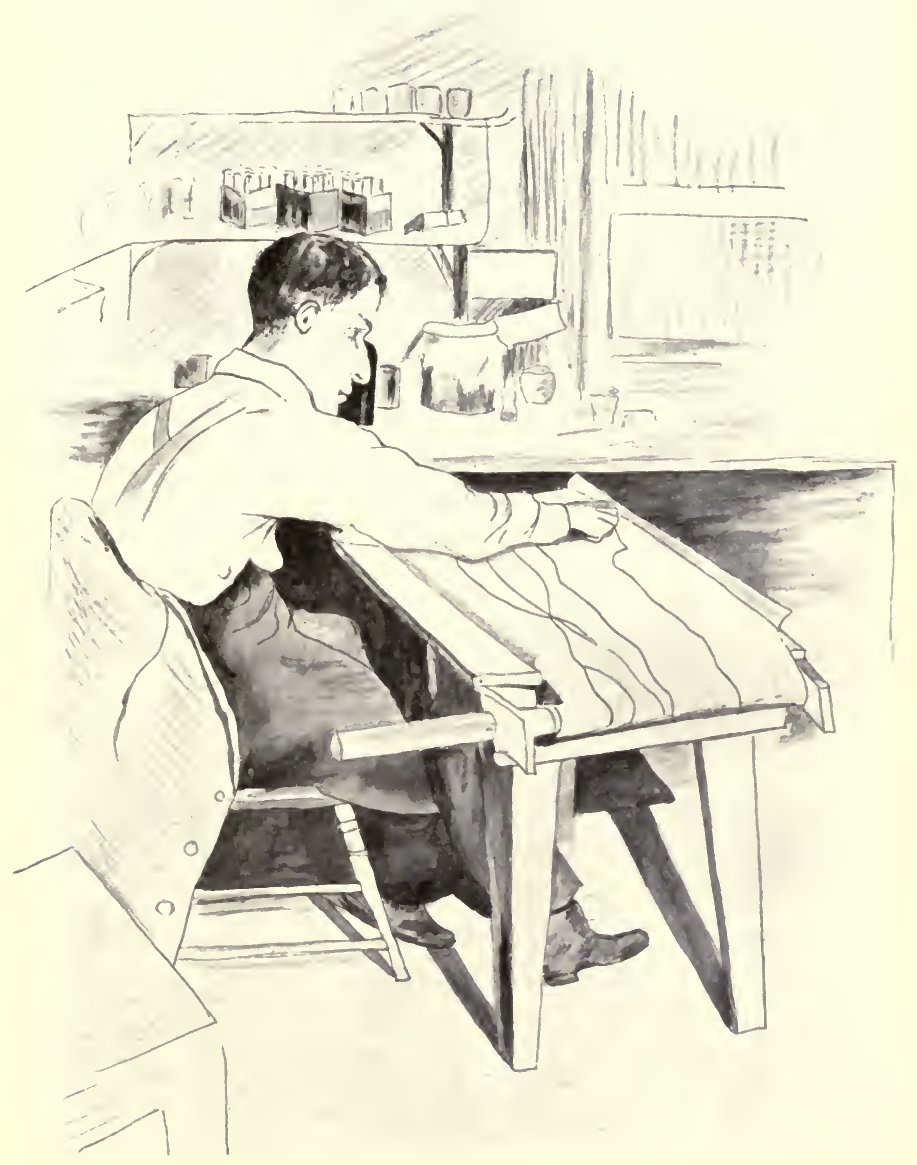

Fic. 96. Conindetixg AN Experimext With Calosoma sycophanta LARva 


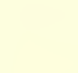


of one hundred pupæ eaten, out of a large number made up of equal proportions of both sexes, seventy-five and a half per cent. were females as against twenty-four and a half per cent. of males. As every female pupa case contains a potential mother moth, the wisdom of nature in endowing Calosoma with its predilection is self-evident. These larvæ will also catch and kill adult female gipsy moths, which, being too heavy and clumsy to fly, fall an easier prey than would otherwise be the case. The adult beetles are scarcely less voracious than their larvæ; they climb the highest trees, going out to the branches, twigs, and even leaves in search of caterpillars, which they eagerly devour after having nipped them in the middle of the back. If disturbed in their work, the beetles instantly fall to the ground and hide till the danger, or supposed danger, has passed.

One of the experiments carried out by the American entomologists is well worth recording here. It has been mentioned that Calosoma and its larvæ will not accept substitutes in the way of food, and it is hardly necessary to add that food is necessary, even to a beetle, for proper development. These questions then arose, Could the larvæ, on being turned loose in a new land, obtain their own food, and how far could they travel in search of it? To answer these questions, a young larva was taken when just hatched and a record kept of its travels till it died, no moisture or food being supplied throughout the experiment. For recording purposes, a small table three feet eight inches long by two feet wide was fitted with spools at each end, near the top, so that a roll of paper could be reeled across the top of the table by turning the spools (fig. 96). Beneath the roll was placed a piece of stiff paper, which extended beyond the sides of the paper connected with the reels, and the edges were bent upwards, so as to prevent the escape of the larva from the sides of the table. The paper on the reels was eighteen inches wide. The larva 
was placed on the table, and, by means of a lead pencil, a continuous record of its movements was made throughout its active life of seventy-two hours. The larva travelled more rapidly than expected, eleven rolls of paper were used, and careful measurements showed that it travelled nine thousand and fifty-eight feet. Its greatest speed, for a four-and-a-half-hour period, was four and nine-tenths feet per minute; whilst for the first twenty-four hours it averaged over three and a half feet per minute. Weighed before and after the experiment, the larva was found to have lost weight to the extent of eleven grains or onethird of its original weight.

Of the imported parasites of the gipsy moth, we must rest content with a brief notice of but three. Two of them, Anastatus bifasciatus and Schedius kuvance are worthy of mention on account of their innate interest, and Apanteles fulvipes because of its "unquestioned importance as an enemy of the gipsy moth."

Anastatus bifasciatus (fig. 97) was introduced into America from Europe and Japan in 1908. The insect is a diminutive member of the order Hymenoptera, that is to say, it is related to the bees, wasps, and ants. The female oviposits in the eggs of the gipsy moth, soon after the latter have been deposited and before the embryo has developed. Within the lepidopterous eggs the greater part of the life-cycle of Anastatus is enacted, with the result that the adults do not emerge till some time after the healthy gipsy moth eggs have hatched. The fact that the life-cycle of this parasite is correlated, perfectly, with that of its host, renders it especially valuable as a beneficial insect. By the time the new generation of moths are attending to their maternal duties, the female Anastatus is on the watch for host eggs in which to deposit her own. It is a curious coincidence that the females, of parasite and host, are of exceeding feebleness on the wing. Two phenomena have mitigated against the complete success of Anastatus 


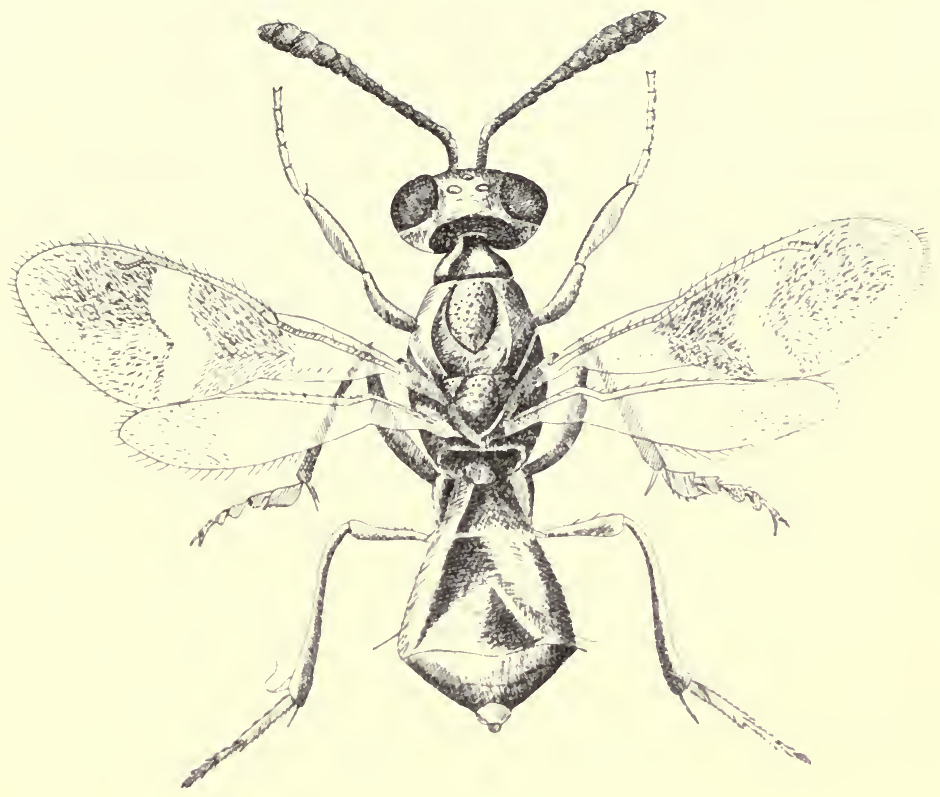

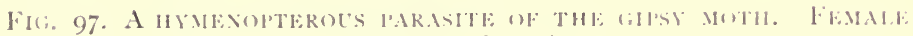
Anastatus hifasciatus:

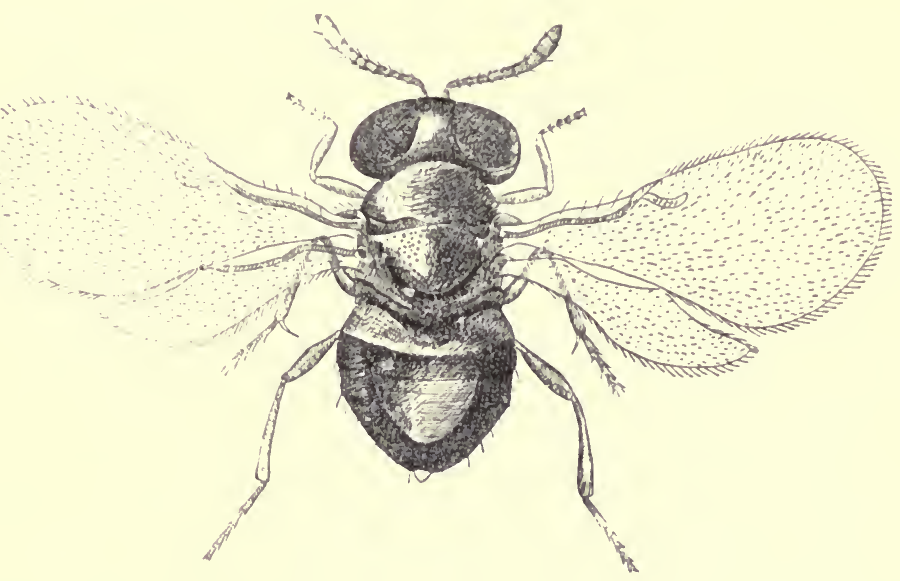

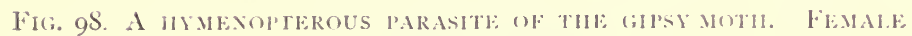
Siheraius küe'anate 

as a beneficial insect-its slow rate of dispersion, and the fact that, owing to physical limitations, it can only parasitise the uppermost layer of eggs in each egg mass, leaving the second and third layers untouched.

Like the insect just mentioned, Schedius kuvana (fig. 98) is a minute Hymenopteron; like Anastatus, too, it attacks the same host and is also physically incapable of ovipositing in any but the top layer of eggs in a mass. In other respects the two insects differ. Anastatus is a true egg parasite, Schectius is an internal parasite of the unhatched caterpillar. Again, Anastatus is responsible for one generation annually, and its seasonal history is correlated with that of its host. Schedius, on the contrary, passes through a generation a month, under suitable climatic conditions, and probably an alternate host is necessary, to carry it through the period, after the gipsy moth eggs have hatched in the spring and before the moths begin depositing eggs for a new generation. It was not till 1909 that a successful importation of the parasite from Japan was accomplished, the eleven individuals which then reached America were the progenitors of a numerous and prolific race.

The first Schedius ever raised in America was a single male, in 1908, which died before a mate could be provided for it. Shortly afterwards a single female was raised, she oviposited in gipsy moth eggs, and her offspring amounted to twenty-eight parthenogenic males, i.e. produced without previous mating of the two sexes. In the hope that this single female might be fertilised and produce females for the furtherance of the race, she was confined with some of her asexually produced sons, but she had evidently laid her full complement of eggs, at any rate she died without further oviposition. A few months later a somewhat similar experiment was tried; but in this case, after the female had deposited a few eggs she was put into cold storage to await events. As before, the parthenogenic young were all males; when they had emerged the female 
was brought from her compulsory retirement, mating took place, and the subsequent progeny consisted of both sexes.

The female Schedius places her egg within the body of the unhatched but fully formed moth caterpillar. Each curiously formed egg is provided with a very long stalk, the end of which passes not only through the body of the caterpillar, but through the egg shell as well. At the time of hatching of the Schedius larva the stalk becomes functional, forming a connection with the outer air. The host larva is quite destroyed except for the harder parts, head, claws, and hair, whilst the parasite larva moults twice and pupates within the shell.

An interesting and important point in connection with this insect is that often two or more eggs are deposited in one host caterpillar, but, out of thousands of such cases kept under strict observation, never more than one adult has issued from one egg. The supernumerary individuals simply disappear and the survivor is nourished on their substance. Whether there is a trial of strength or a contest of appetites, in which the more skilled individual eventually devours his companions, or what exactly takes place, is one of nature's secrets.

Before abandoning the consideration of this little insect, we may relate a tragedy that actually came under the observation of an American entomologist. The egg of a gipsy moth had been parasitised by Anastatus, whose larva, after consuming the entire egg contents, had settled down to a hibernation of ten months or so (fig. 99, I.). Nemesis swifty overtook this fat and happy grub, for three Schedius individuals in succession deposited their eggs in his inviting carcass (fig. 99, II.). Sad to relate, this triple tragedy was cut short in the interests of science; but, in the ordinary course of events, gipsy moth, Anastatus, and two Schedius would have gone to the Ewigkeit that one Schedius might live. To quote the words of the United States Government report, from which this account is derived, "This conflict 

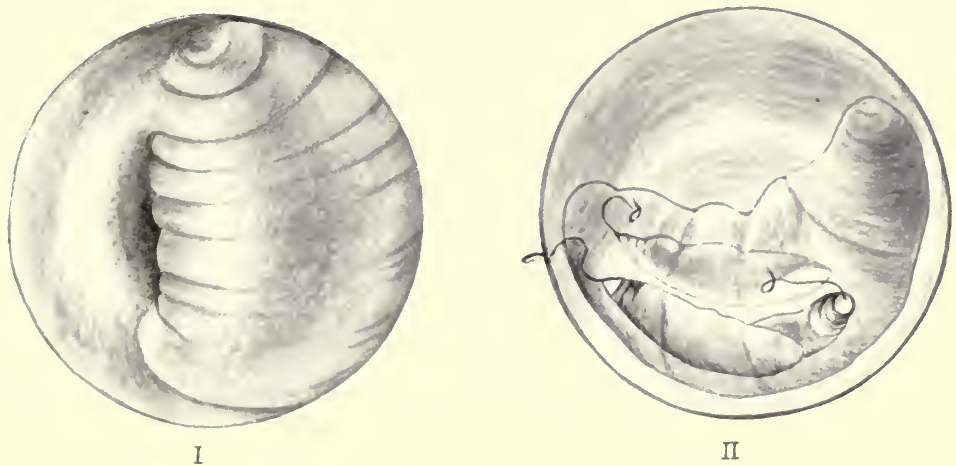

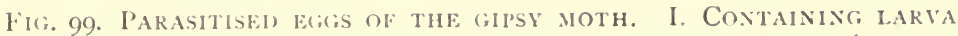
OF Anastatus bifasciatus; II. CONTAINING HYBRNATING LARVA OF Anastatus bifasciatus, WHICII IN TURN IS PARASITISEI BY THREE SECOND STAGE L.ARV.T OF Schedius kuz'anae

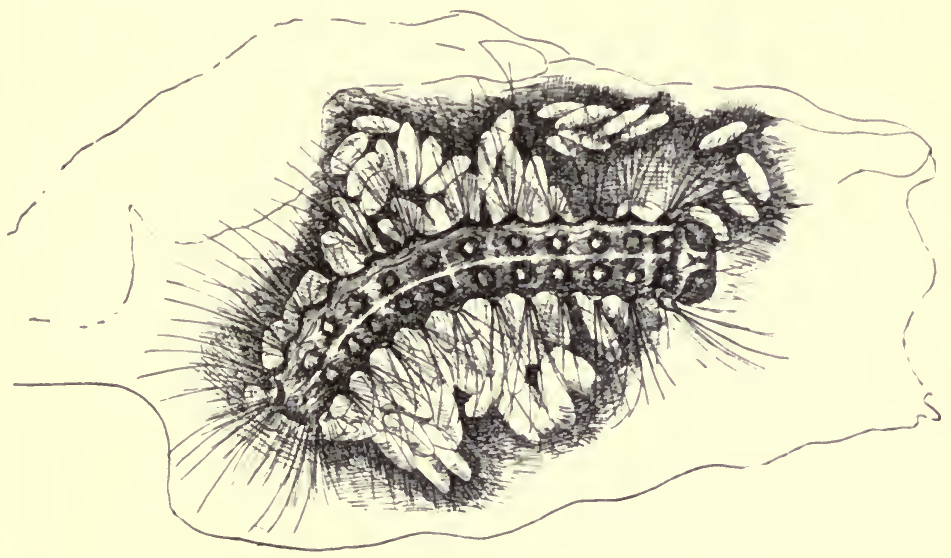

Fi(;. IOO. GIPSY MOTI LARVA KILI.EI) BY THE HYMENOITEROUS PARASITE Apanteles fulvipes, OVER WHOSE PUPAE THE LARVA APPEARS TO BE BROODING 

for supremacy, sanguinary as it is, is only the beginning of what might occur in the open in Japan. Tyndarichus and Pachyneuron (Hymenoptera) are both habitually and essentially secondary parasites, and both prey not only upon Schedius but upon each other with perfect impartiality. Either might attack the surviving Schedius and be in turn the victim of the other, and there is no apparent reason why Schedius should not return to the fray and, by destroying its own secondary, start the battle all over again."

This Schedius habit of ovipositing in the larvæ of the useful Anastatus mitigates considerably against its own utility; in fact, one of the problems of this branch of economic entomology is to sift the wheat from the chaff, to encourage the purely beneficial insects to the exclusion of those that may mitigate against their spread.

Our last example, Apanteles fulvipes, was the first parasite of the gipsy moth which it was attempted to import into America, and one of the last to be liberated there. The difficulties to be overcome in importing the little Hymenopteron from Japan appeared, at one time, almost insuperable; but no mean assistance was rendered by the Japanese entomologists, who have proved themselves pastmasters in the art of packing such tender and small fry as parasitic insects in such a manner that they may survive long and tedious journeys.

Apanteles is a caterpillar parasite, the adult female depositing her eggs beneath the skin of the active gipsy moth caterpillars, at any stage. The eggs hatch within the body of their host and live there till they become adult, in from two to three weeks, then they work their way through the skin of the still living caterpillar. When they reach daylight each caterpillar immediately spins a small white cocoon, and the moribund though still living host never moves from the spot, and its appearance, surrounded by and apparently brooding over the cocoons, is peculiar and characteristic (fig. 100). The number of the 
parasites living within the body of a single caterpillar may be anything from a single individual to two hundred. That this beneficial parasite has not come up to expectations in America appears to be due to the fact that some unknown, yet apparently necessary, alternate host is absent from that country. With this perfunctory account of but a fraction of the work that has been done in the United States to control the gipsy and brown-tail moths, we must bid adieu to the subject, though well aware that it deserves more extended treatment, if only because it represents the most stupendous effort that has ever been made by man, aided by insect allies, to gain the upper hand in a war to the death with an insect enemy.

Let us consider a few of the other cases. The Florida citrus growers, like their Californian brethren, have been and are seriously handicapped by a minute insect known as the citrus white fly, Aleyrodes citri, a near relative of the scale insect that has proved so destructive in California; in fact, the citrus white fly and the cottony cushion scale were once included in the same family, the Coccidae, though nowadays scientists place the former in a separate family, the Aleyrodidoe or mealy wings.

The citrus white fly attacks the leaves of citrus-trees in battalions, and, by destroying their assimilative powers, weakens and eventually destroys the trees. The eggs are laid on the undersides of the leaves, to the number of many thousands, so that each leaf appears as if sprinkled with dust; each female laying on an average about one hundred and twenty-five eggs. When first hatched the young six-legged insect resembles a small louse in general appearance, and is so small and transparent that its presence is easily overlooked. For a time the immature insect crawls about the leaves, but eventually it inserts its long thread-like beak into the leaf tissues and then remains stationary till it becomes adult. Nourishment is derived from the plant juices, which are sucked up through 
the beak, and, as the insect grows, three moults take place; but with the first moult the legs are lost, so that further locomotion is rendered impossible. At the third moult the pupal stage is attained, and this is the most obvious period of the insect's life-cycle. The first formed pupa is pale green and transparent, but as the changes within the pupal skin take place it becomes more and more opaque, and before maturity is attained a bright orange spot appears on the back of the pupa, and a little later two purple spots towards the anterior end. These purple spots are the eyes of the adult. The fully developed pupa case, now about the size of a pin's head, splits down the back and the light orange-yellow coloured, four-winged adult emerges.

It has been mentioned that the citrus white fly damages the trees by sapping their vitality, but it also causes indirect injury in the following manner. Like many insects that derive their nourishment by, as it were, embedding their mouths in the plant on which they live and sucking its juices, these insects secrete a sugary liquid, known as honeydew, which forms the nutritive medium of a sooty mould. The fungus growth does more damage to the plants than the inscets themselves, pervading, as it does, not only the leaves but the branches and even the fruit itself.

Seeing that more than forty-five per cent. of the citrus groves in Florida are infested with white fly, estimated to cause a loss of from forty-five to fifty per cent. of the value of an orange crop, it is hardly surprising that scientists called to mind the success of the little Australian beetle against the cottony cushion scale and turned their attention to hunting for another benefactor to come to the rescue of their orange crops.

In 1910 the American Congress made a special grant towards a world-wide search for the native home of the citrus white fly and the collection of its natural enemies, 
if any were found. The work was entrusted to Mr Russell S. Woglum, and, having previously decided that his ultimate goal was most likely to be attained in the tropical or semi-tropical portions of the Orient, he set sail from New York in July 1910. Visits to Spain, Italy, and Sicily showed that, though the great European citrus belt was beset by many injurious insects, the white fly was not one of them. Investigations in Ceylon, Java, and the Philippines also provided negative results-there were citrustrees in plenty and countless insect pests, but no white fly. At the Indian Museum, in Calcutta, the investigator knew he was "getting warm," for there he found specimens of Aleyrodes citri that had been collected from orange leaves in the North-Western Himalayas seventeen years previously. In the autumn of $1910 \mathrm{Mr}$ Woglum found himself at Saharanpur, and there had the satisfaction of encountering the living white fly for the first time since he left America; the infestation, however, was light, and the sooty mould, which always accompanies the fly in Florida, was absent.

The discovery of the white fly was quickly followed by the recognition of its natural enemy, a small reddish-brown ladybird, about a tenth of an inch in length. Was Cryptognatha flavescens, for that was the insect's name, to prove a second Novius cardinalis, the inveterate foe of the cottony cushion scale? One may imagine with what feverish anxiety two hundred specimens of this minute beetle were collected, by placing large sheets beneath the trees in the early morning before the insects had become active, and then beating the branches with sticks. With what expressions of good fortune the little emigrants were packed in double-chambered boxes, one half filled with damp sphagnum moss, the other with dry fibre from a palm-tree, forwarded post-haste to Calcutta and shipped to the United States. One may conjure up visions, too, of the chagrin of the collector on learning that not one of his 
charges had reached Florida alive; a second shipment also resulted in failure. Undismayed by this contretemps, Mr Woglum proceeded to Lahore, where he also found the white fly, though, once more, not in sufficient quantity to be a serious pest. Examination of the infested leaves showed that some of the pupa cases were abnormally thickened and they were always pierced by a small round hole. It was surmised, and correctly so, that a hymenopterous parasite had been at work. Material was collected and sent to Washington, where it was found that the parasite was a member of the genus Prospaltella, new to science, so it was named, after its native home, Prospaltella lahorensis. Further travels in India by this intrepid entomologist forced him to the conclusion that the citrus white fly is distributed throughout that country south of the Himalaya Mountains, and that evidences of parasitism were everywhere apparent.

In the spring of 1911 a second visit was made to Lahore, with the object of collecting parasites in sufficient quantity for shipment to Florida. Difficulties arose from the start. We have seen how the white fly larva soon after emergence from the egg becomes stationary upon the leaf, and if an infested leaf be broken off and thereby killed, the larva dies also through lack of nourishment. To use Mr Woglum's own words: "Prospaltella is dependent on the living condition of its host in order to attain maturity. From a consideration of this situation, it was at once evident that the only practicable way of transporting the parasite to America in a living condition was by means of healthy nursery trees, infested with parasitised Aleyrodes citri. Moreover, the journey from India to Florida occupies between five and six weeks, while the entire life-cycle of the parasite, at high temperatures, is of about three weeks duration. This would mean that, even if the parasite left India in the egg stage, a complete cycle of development would take place and the adults emerge before America was reached. This 
latter feature necessitated the presence of living Aleyrodes throughout the journey, so that the parasites at the time of their emergence would have material upon which to work." Young infested citrus-trees could nowhere be found, so a number of young healthy trees were dug up, placed in pots, and, as the white fly prefers tender growth for oviposition, cultural methods were enforced to induce the trees to send out new shoots. No sooner, however, did the desired growth appear than it was attacked by a lepidopterous leaf miner, Phyllocnistis citrella, and a bud worm, Agonopteryx sp., and their combined attacks rendered the trees useless for the purpose for which they were required. A second set of potted trees was accordingly grown in large cloth cages, to protect them from extraneous insect pests, and these were successfully infested with white fly and its hymenopterous parasites.

En passant, it may be mentioned that the parasite prefers the larval stages of its host, but will, on occasion, oviposit in the pupa. Whether larvæ or pupa, the parasitised individuals are much thicker and more opaque than healthy ones, thus becoming more easily recognised. With a lens the whitish parasite larvæ can be seen within the white fly host. The pupal stage of the parasite is almost black, a fact which causes the parasitised white flies containing pupa cases to appear very dark. On attaining maturity the parasite eats a small hole in the back of its host, and through the opening emerges into the open air.

About the middle of October appeared a favourable time for shipment of the parasites to America, accordingly Wardian cases were made for their transport. These cases are specially constructed for the transportation of tender plants over long distances; each case resembles a greenhouse on a small scale, and is perfectly air-tight, except for two small holes at the top for ventilation; plants can travel in them for long distances without watering. Five cases, each containing between ten and twenty young citrus-trees, were 
prepared; three of them were filled with material parasitised with Prospaltella, and each of the other two cases contained about one hundred and fifty specimens of the ladybird Cryptognatha in the larval and pupal stages. After a sea voyage extending over a month, New York was reached, and four days later the Wardian cases and their contents were ensconsed in the Government laboratory at Orlando. An examination showed that twenty-eight ladybirds and eight adult Prospaltella had survived the journey, an alarmingly small number certainly, but one that did not deter the Government entomologists from hoping that they would be able to form from them a large and prosperous colony.

This was in December, with winter conditions differing in no small degree from those in India. The first problem was how to carry the parasites through the winter-should they be artificially forced or allowed to pass through the winter in a normal state of hibernation. The latter course was decided upon with all the insects except a few ladybirds, and the result-at the end of the year two ladybirds only were still alive, all the other transported insects had perished. As the survivors ultimately turned out to be of the same sex, a magnificent effort, magnificently carried out, in the cause of economic entomology ended, for the time being, at the death of the last surviving ladybird. One adds "for the time being" advisedly, for it is certain that, if the economic entomologists on the other side of the "herring pond" consider that the discoveries already made can be put to commercial account, they will eventually devise some means by which the apparently insuperable difficulties of transport can be overcome. At any rate, a very important step has been made by the discovery of both a predaceous and parasitic parasite of the citrus white fly, and although it is probable that the climate of India, rather than the parasite, renders the white fly comparatively innocuous in that country, there appears no reason 
why, when once established in Florida, these two minute insects should not work miracles among the orange groves.

America has done its share of exporting, as well as importing, enemies of injurious insects. For a number of years the larva of a moth known as Chloridea obsoleta has been an inveterate enemy of various crops, among them being cotton, maize, tomato, and tobacco. This moth, which is practically cosmopolitan, also occurs in Sumatra, where it does immense damage to rice, maize, tobacco, and cotton. In the United States the pest has been kept under control by a hymenopterous parasite, Trichogramma pretiosa, and the experiment was tried of shipping a number of parasitised Chloridea eggs to Sumatra in cold storage, in the hopes that the resultant insects would lessen the pest. As with almost all similar experiments, the early efforts were doomed to failure-the parasitised lepidopterous eggs could not be transported in good condition over the long journey from America to Sumatra. Not to be thwarted, an intermediate station was instituted at Amsterdam in Holland; parasitised material was safely transferred there from America, carefully tended in its new home ${ }_{i}$ and a fresh generation was transhipped to the South Seas. This second effort proved more successful than the previous one, in that all the parasites arrived alive, but when they emerged from their hosts they were found to be all males. Further efforts showed that the trouble that had been expended was not in vain, a large percentage of parasites hatched out in their new home, and there was such a proportion of males and females as to ensure a continuance of the race.

As in America, so in the land of its adoption, Trichogramma proved catholic in its tastes and was observed to parasitise over twelve species of lepidoptera. The importance of this will be easily realised when we consider that in a new country the supply of one insect may fail for a season, owing to climatic or other causes. If the imported 

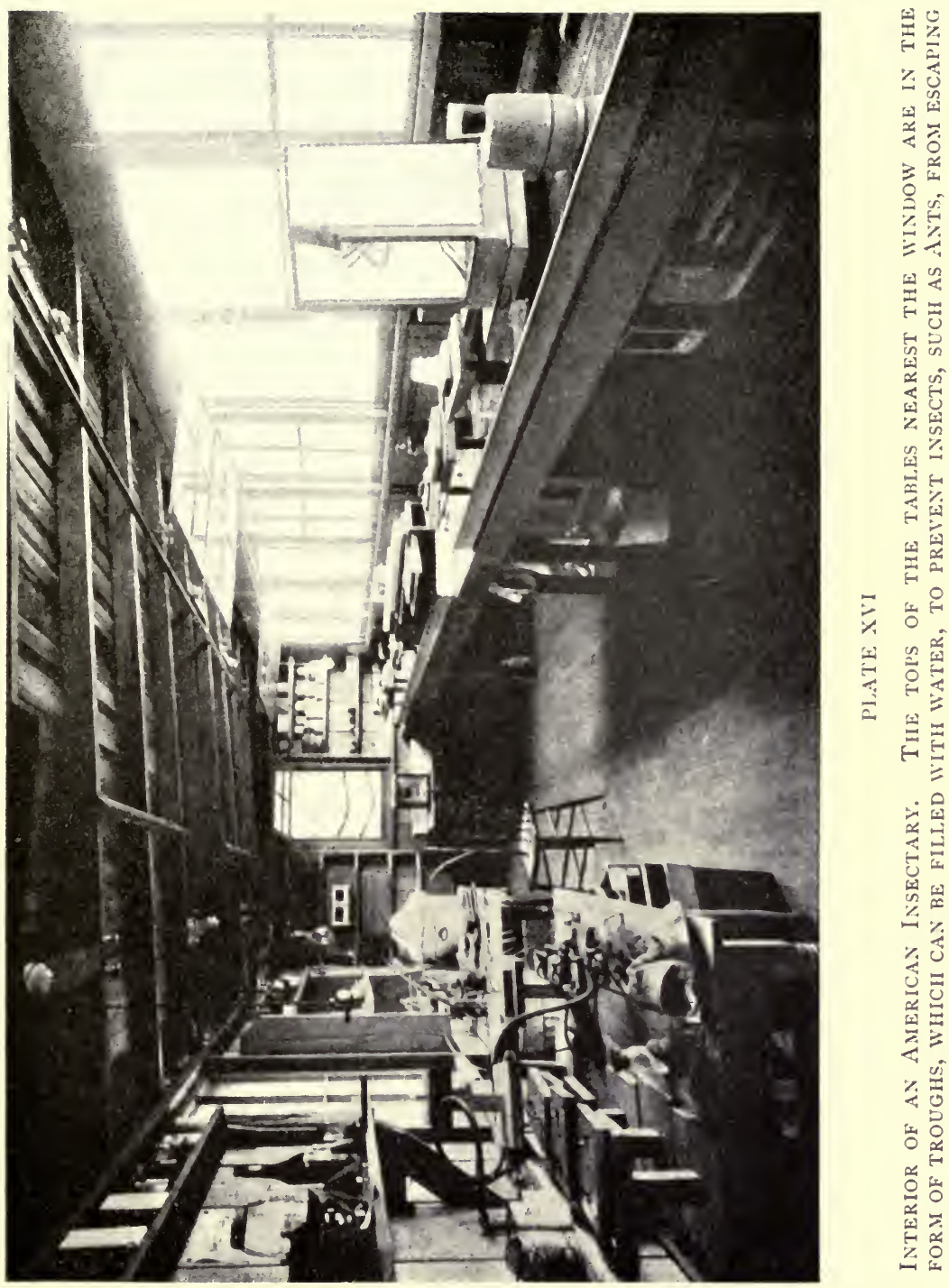

parasite is only able to exist on a single species, and that species fail temporarily, the newcomer will be rapidly exterminated through lack of food, and the trouble and expense incurred over its importation be brought to naught.

The adult Trichogramma lays its eggs in the eggs of lepidoptera, and from the eggs the new parasite generation arises; not so, however, with all parasitic hymenoptera, for another insect, Chelonus texanus, which, like Trichogramma, belongs to the family Chalcidida, also deposits its eggs in the eggs of butterflies and moths, but the new parasite emerges from the lepidopterous larvæ which hatch from the parasitised eggs. This second Chalcidid is also an enerny of Chloridea obsoleta.

It will be recognised that unless a parasite shows greater fertility than its host, its power of controlling the latter must be very greatly diminished. In this connection nature has come to the rescue in a marvellous manner, by endowing certain of the parasitic Chalcidida with the power of "polyembryony," a phenomenon that is unique in the animal kingdom. Parasites so endowed lay eggs, similar in external form to those of their less fortunate relations, but from each egg emerges in due course not one larva but a number of larvæ, and by this means their fertility is much increased.

This science of insect control by the aid of other insects, though one of the nost important branches of economic entomology, can be but lightly reviewed in these pages. Despite the fact that it is as yet in its infancy, a large volume would have to be filled to do it justice. Mention should be made of many other important predaceous and parasitic insects that have been pressed into service in America: the aphis-eating ladybird, Megilla maculata, that has done such yeoman service in the tobacco plantations, to mention only one.

Before passing to another theme, let us see what the Old World has done in this connection. In many European 
countries great damage is done by a scale insect, Diaspis pentagona, so called on account of its pentagonal form, to various crops, for the insect does not confine itself to one food-plant. An inveterate enemy of this scale insect is a small hymenopterous parasite, Prospaltella berlesei, a near relation of the Indian Prospaltella lahorensis. The parasite was introduced into Italy in 1908, and into Switzerland in 1912, and has now established itself near Locarno. Fortunately, the cultivators and landowners soon learned to look upon the newcomer as a benefactor, so there has been no difficulty in ensuring it a wide distribution. Speaking of the pest and its parasite, Professor E. Voglino says, "The countrymen about Valenza have learned to recognise the parasitised scales perfectly, and, as they all have small properties, they pick out twigs with plenty of scales and their parasites on them at pruning time and take them to fasten on their own trees. In some parts of Venetia the farmers who have material infected by Prospaltella make a regular trade of it, selling twigs of a foot long with sixty to eighty per cent. of parasitised scales for half a lira each." A contrast to the American methods, indeed, this trade in infected twigs, still a step in the right direction, and for that one ought to be thankful. That the trade in these twigs is worth cultivating is evident from the returns of one grower, who from a small lot in 1909 increased his stock to one hundred in the next year, to five hundred in 1911, and to thirtyfive thousand in 1912. Hopes are entertained that the parasite will eventually rid Italy and other countries of the harmful scale on which it lives.

It is impossible here to give a detailed account, or even a résumé, of all the attempts, successful or otherwise, that have been made in the transportation of beneficial insects, but two of the apparently unsuccessful experiments may be mentioned on account of their general interest. For a long time the dromedaries in Algeria have suffered from 
trypanosomiasis, transmitted by tabanid flies, and as these flies are preyed upon by a large wasp, Monedula carolina, in the South-eastern States of America, it was decided to try the experiment of shipping the wasp pupæ to Algeria, in the hope that they would continue their beneficial work in their North African home. Although the adults duly emerged they do not appear to have flourished, at any rate they have done little to control the tabanid flies.

The second instance is that of the attempted introduction of the common American bumble bee, Bombus pennsylvanicus, into the Philippine Islands. The red clover in these islands was not a flourishing crop, owing to the fact that there were no insects, properly equipped, for carrying the pollen from flower to flower and so effecting fertilisation. For this reason the bumble bee was introduced, but, despite the fact that the pupæ were carried by hand by Filipino students from the United States to the Philippines, the attempt does not seem to have realised expectations.

A second, and still more modern, method of natural insect control is carried into effect by means of fungoid diseases of insects. A few examples may be quoted with advantage. As long ago as 1878, the larvæ of some beetle pests of wheat in Russia were observed to be badly infested with a fungus, known to science as Metarrhizium anisopliae and popularly named green muscardine. Since that time green muscardine has been found practically all over the world, and on all sorts and conditions of insects of widely different families. Scientists discovered that the fungus would thrive on a medium of boiled rice as readily as on its insect hosts. Accordingly, in 1909, the fungus was cultivated on a large scale in Trinidad and used with good effect against the "frog hoppers" which infested the sugarcane plantations and damaged the plants. Two methods of spreading the fungus were adopted, according to the size of plantation; in both cases the spores of the fungus were used. For the benefit of the unbotanical, it may be men- 
tioned that fungus spores serve the same purpose as seeds in the flowering plants, i.e. from them, by a round-about process, new plants arise, though they are not analogous to seeds. When large plantations were to be treated the spores were spread broadcast with a dusting machine, many of them of course fell to the ground and died, others reached their favoured insect host and germinated, with disastrous results to the host. On small estates the method adopted was more interesting. In these cases a number of native boys, each provided with a tube laden with fungus spores, were sent into the cane-fields; there they caught by hand as many "frog hoppers" as they were able and inserted them at one side of the tube. As the insects emerged at the other end they were allowed to escape, but each one was doomed to a fatal fungus attack and was, too, a source of infection to its relatives. In this case fungus control has proved eminently satisfactory.

Artificial cultures of another fungus, Sporatrichum globuliferum, have also been used successfully in the control of another injurious bug, Pentatoma ornatum. The same method of control has been used, with strangely varying success, against those almost cosmopolitan pests, the locusts. In the Argentine a scientist, F. d'Herelle, used a bacterial preparation, which he called Coccobacillus acridiorum, with the greatest success against these insects; but a similar preparation similarly used in South Africa proved a failure. Time will probably reveal many new and successful methods of this newest form of natural insect control. 


\section{BIBLIOGRAPHY}

IT is hoped that every publication to which reference has been made in the preceding pages is mentioned here. So many references have been made, however, that it is possible some sources of information may have been inadvertently overlooked.

\section{INTRODUCTION AND GENERAL.}

1895. Sedgwick, Sinclair, and Sharp, "Peripatus, Myriapods, and 표 Insects," Camb. Nat. Hist., vol. i.

1899. Sharp, "Insects," Camb. Nat. Hist., vol. ii.

1907. Collinge, "The Application of Economic Biology to Agriculture," Journal of Economic Biology, vol. ii. pp. 96-106.

1908. Morgan, "The Relation of the Economic Entomologist to Agriculture," Journal of Econonic Entomology, vol. i. p. 11.

1909. Forbes, "Aspects of Progress in Economic Entomology," Journal of Economic Entomology, vol. ii. p. 25.

1909. Gossand, "The Relations of Insects to Human Welfare," Journal of Ėconomic Entomology, vol. ii. p. 313.

1909. Herms, "Recent Work in Insect Behaviour and its Economic Significance," Journal of Economic Entomology, vol. ii. p. 223.

1912. WEISS, "Some Economic Methods of a Hundred Years Ago," Journal of Economic Entomology, vol. v. p. 88.

1913. TRÄGARDH, "On the Chemotropism of Insects and its Significance for Economic Entomologists," Bulletin of Entomological Research, vol. iv. pt. 2, pp. 113-117.

\section{INSECTS AND PLANTS.}

1669. Moreton, New England's Memoriall. (First mention of the Periodical Cicada.)

1746. Roesel, Insecten Belustigung, vol. i. pt. 6, No. 13, pp. 33-37. (Excellent hand-painted figures of the Codling moth.)

1747. Wilkes, The English Moths and Butterfies, book 1, class 1, No. 9, p. 5. (The first English account of the Codling moth.)

1758. Linné, Systema Natura, p. 436. (Original description of the Periodical Cicada.)

1843. Boheman, Genera et species Curculionidum cum synonymia hujus familice, ed. v. pt. 2, p. 232. (Original description of the Cotton-boll weevil.) 
1860. Curtis, Farm Insects.

1887. Ormerod, "The Hessian Fly," Entomologist, vol. xx. pp. 262-264.

1890. ORMEROD, Manual of Injurious Insects.

1891. French, Handbook of the Destructive Insects of Victoria.

1896. Lounsbury, Rept. of the Govt. Entomologist for the Cape of Good Hope for 1895.

1898. Marlatt, The Periodical Cicada, U.S. Dept. of Agriculture, Bureau of Entomology, Bulletin No. 14.

1898. Marlatt, The Vine Phylloxera, U.S. Dept. of Agriculture, Farmers' Bulletin 70 .

1898. Osborn, The Hessian Fly in the United States, U.S. Dept. of Agriculture, Bureau of Entomology, Bulletin 16.

1903. Srmpson, The Codling Moth, U.S. Dept. of Agriculture, Bureau of Entomology, Bulletin 41.

1904. Mally, "The Fruit Fly," reprint No. 21, from Cape of Good Hope Agric. Journal.

1904. Marlati, Year-Book of the United States Dept. of Agriculture.

1905. Quaintance and Brues, The Cotton-boll Worm, U.S. Dept. of Agriculture, Bureau of Entomology, Bulletin 50.

1906. Marlatt, The San José or Chinese Scale, U.S. Dept. of Agriculture, Bureau of Entomology, Bulletin 62.

1907. Bishopp and Jones, The Cotton-boll Worm, U.S. Dept. of Agriculture, Farmers' Bulletin 50.

1907. French, Fruit Flies, Dept. of Agriculture Intelligence, South Australia, Bulletin 24.

1907. French, Fruit Flies, Dept. of Agriculture, Victoria, Bulletin 26.

1907. Froggati, Australian Insects.

1909. LEFROY, Indian Insect Life.

1909. THEOBALD, Insect Pests of Fruit.

1910. How ARD, C. W., "Locust Destruction in South Africa," Journal of Economic Entomology, vol. iii. p. 260.

1911. Britton, "The Leopard Moth as a Pest of Apple Nursery Stock," Journal of E'conomic Entomology, vol. iv. p. 298.

1911. Cushman, "Studies in the Biology of the Boll Weevil in the Mississippi Delta Region of Louisiana," Journal of Economic Entomology, vol. iv. pp. 432-448.

1911. Norton, "The Health of Plants as related to Insects," Journal of Economic Entomology, vol. iv. p. 226.

1911. TownsEnd, "The Cotton-square Weevil of Peru," Journal of Economic Entomology, vol. iv. p. 241.

1912. Collinge, Manual of Injurious Insects.

1912. Hunter and Prence, The Mexican Cotton-boll Weevil, U.S. Dept. of Agriculture, Bureau of Entomology, Bulletin 114.'

1912. Mrlurken, "The Position assumed by Female Grasshoppers when Ovipositing," Journal of Economic Entomology, vol.iv. p. 232.

1912. Sanderson, Insect Pests of Farm, Garden, and Orchard.

1912. TRUFFAUT, Les ennemis des plantes cultivées.

1913. Burgess, The Dispersion of the Gipsy Moth, U.S. Dept. of Agriculture, Bureau of Entomology, Bulletin 119. 
1913. Borgess, "Remarks on the Gipsy Moth," Journal of Economic Entomology, vol. vi. p. 258.

1913. FeLt, "The Codling Moth," Journal of Economic Entomology, vol. vi. p. 173.

1913. Headlee, "A Brood Study of the Codling Moth," Journal of Economic Entomology, vol. vi. p. 389.

1913. Jones and MAckie, "The Locust Pest," Philippine Agri. Revue, vol. vi., No. 1, pp. 5-22.

1913. SchNeLder-OrelLI, "Untersuchungen über den pilzzüchtenden Obstbaumborken-Käfer Yyleborus dispar und seinen Nährpilz," Centralbl. Bakter., Paras. und Infekt., 2. Abt., xxxviii., No. 1-6, pp. 25-110.

1913. SEveris, "The Life History of the Mediterranean Fruit Fly," Journal of Economic Entomoloryy, vol. vi. p. 399.

1913-1914. Review of Applied Entonology, London, Series A.

1914. How ARD, "Explorers of a New Kind," Nat. Geographic Mag., vol. xxvi., No. 1, pp. 38-67.

1914. Kellock, "The Winged Armageddon," Century Mag., pp. 75-82.

1914. Seymour, "The War on Agricultural Pests," World' Work, May, p. 93.

\section{INSECTS AND DISEASE.}

1895. Barber, "The Tick Pest in the Tropics," Nature, vol. lii. pp. 197-200.

1898. Manson, "The Mosquito and the Malarial Parasite," Brit. Med. Journal, pp. 849-853.

1901. How ARD, "Insects as Carriers and Spreaders of Disease," U.S. Dept. of Agriculture Year-Book, pp. 177-192.

1901. How and, Mosquitoes: How they Live.

1901. Howa RD, "Mosquitoes as Transmitters of Disease," Reviewo of Reviews, vol. xxiv. pp. 192-195.

1901. HowARD, "Flies and Typhoid," Popular Science Monthly, pp. 249-256.

1901. Sambon and Low, "Report of two Experiments on the Mosquito Malaria Theory," Medico-Chirurgical Transactions.

1902. Ross, Malarial Fever, Liverpool School of Tropical Medicine, Memoir I.

1903. Sambon, "The Chief Disease Scourges of the Tropics," Climate, vol. iv. pp. 297-317.

1903. Stephens and Christopher, The Practical Study of Malaria.

1904. Lankester, "The Sleeping Sickness," Quarterly Review, July, p. 113.

1905. Baker, "Fleas and Disease," Science, N.S., xxii., No. 559, Sept. 15, p. 340.

1906. Adaus, "Yellow Fever: A Problem Solved," McClure's Mag., xxvii. p. 178.

1906. Howard, House Flies, U.S. Dept. of Agriculture, Circular 71.

1906. Minchis, "The Breeding Habits of the Tsetse Fly," Nature, Oct. 25 , p. 636. 
1906. Minchis, Gray, and Tullock, "Preliminary Report of the Sleeping Sickness Commission," Proceedings of the Royal Soc., vol. Ixxviii. pp. 242-258.

1906. Newstead, "On the Life History of Stomoxys calcitrans," Journal of Economic Biology, vol. i. p. 157.

1906. Novy, "The Trypanosomes of Tsetse Flies," Journal of Infectious Diseases, vol. iii. pp. 394-411.

1906. Simpson, A Treatise on Plague.

1907. Ayers, "The Secrets of the Mosquito," World's Work, xiv. pp. 8902-8910.

1907. Barrows, "The Reactions of the Pomace Fly (Drosophila ampelophila) to Odorous Substances," Journal of Experimental Zoology, vol. iv. pp. 515-537.

1907. Dutrox and ToDd, The Nature of Human Tick Fever in the East Part of the Congo Free State, Liverpool School of Tropical Medicine, Memoir XVII.

1907. Dutton, 'ToDd, and Harkivgton, "Trypanosome Transmission Experiments," Annals of Tropical Medicine and Parasitology, vol. i., No. 2, pp. 201-229.

1907. Hunter and HoOKER, Information concerning the North American Fever Tick, U.S. Dept. of Agriculture, Bureau of Entomology, Bulletin 72.

1907. Jones, Ross, and Eluetr, Malaria.

1907. Manson, Tropical Diseases, 4 th edition.

1907. Mrtcheld, Mosquito Life.

1907. Suith, "The General Economic Importance of the Mosquito," Popular Science Monthly, pp. 325-329.

1907. WARD, "The Relation of Animals to Disease," Trans. of the American Microscopical Soc., vol. xxvii. pp. 5-20.

1908. Banks, "Tick-borne Diseases and their Origin," Journal of Economic Entomology, vol. i. pp. 213-215.

1908. Duncan, "Industrial Entomology," Journal of the Royal Soc. of Arts, May 22nd, pp. 688-696.

1908. GrIfFITH, "Life History of House Flies," Public Health, vol. xxi., No. 3, pp. 122-127.

1908. HowaRD, How Insects affect Health in Rural Districts, U.S. Dept. of Agriculture, Farmers' Bulletin 155.

1908. KLEIN, "Flies as Carriers of Bacillus typhus," Brit. Med. Journal, Oct. 17, pp. 1150-1151.

1908. NutTall, "Piroplasmosis," Journal Royal Inst. of Public Health.

1908. ShIPley, "Rats and their Animal Parasites," Journal of E'conomic Biology, vol. iii., Oct. 28.

1908. VerJBITSKI, "The Part played by Insects in the Epidemiology of Plague," Journal of Hygiene, vol. viii., No. 2, pp. 162-208.

1909. Repts. to the Local Govt. Board: Flies as Carriers of Infection, N.S., No. 5.

1909. Ibid., No. 16.

1909. Boyce, Mosquito or Man.

1909. Felt, "The Economic Status of the House Fly," Journal of Economic Entomology, vol. ii. pp. 39-45. 
1909. Gorgas, "The Part Sanitation is playing in the Construction of the Panama Canal," Journal of the American Medical Assn., vol. liii. pp. 597-599.

1909. Hearsey, "Sleeping Sickness," Journal of Tropical Medicine and Hygiene, vol. xii. pp. 263-264.

1909. Herms, "Medical Entomology, its Scope and Aims," Journal of Economic Entomology, vol. ii. pp. 265-268.

1909. Howard, The Economic Loss to the People of the United States through Insects that cause Disease, U.S. Dept. of Agriculture, Bureau of Entomology, Bulletin 78.

1909. RuCker, "Fighting an Unseen Foe," Sunset Mag., vol. xxii. No. 2.

1910. Castellani and Chalmers, Manual of Tropical Medicine, 1st edition.

1910. DoAne, Insects and Disease.

1910. Felt, "Observations on the House Fly," Journal of Economic Entomology, vol. iii. pp. 24-26.

1910. Morrell, The Death-dealing Insects and their Story.

1911. AlCOCK, Entomology for Medical Officers.

1911. Hunter and Bishop, The Rocky Mountain Spotted-fever Tick, U.S. Dept. of Agriculture, Bureau of Entomology, Bulletin 105.

1911. Maver, "The Transmission of Spotted Fever by the Tick in Nature," Journal of Infectious Diseases, vol. viii. pp. 327-329.

1911. Ransom, "The Life History of a Parasitic Nematode (Habronema musc(e)," Science, vol. xxxiv. pp. 690-692.

1911. Sambon, "The Rat Plague in East Anglia," The Times, Jan. 30 and Feb. 4.

1912. Brues and Sheppard, "The possible Etiological Relations of certain Biting Insects to the Spread of Infantile Paralysis," Journal of Economic Entomology, vol. v. p. 305.

1912. Hersis, "Economic Entomology from the point of view of the Sanitarian," Journal of Economic Entomology, vol. v. p. 355.

1912. Howard, Dyar, and KNaB, The Mosquitoes of North and Central America and the $W$ est Indies.

1912. Jennings, "Some Problems of Mosquito Control in the Tropics," Journal of Economic Entomology, vol. v. pp. 131-141.

1912. KinghorNe and YoRke, "Further Observations on the Trypanosomes of Game and Domestic Stock in N.-E. Rhodesia," Annals of Tropical Medicine and Parasitology, vol. vi. pp. 485-487.

1912. KNAB, "Unconsidered Factors in Disease Transmission by Bloodsucking Insects," Journal of Economic Entomology, vol. v. pp. 196-200.

1912. Rosenau and BRUes, "Some Experimental Observations on Monkeys concerning the Transmission of Poliomyelitis through the Agency of stomoxys calcitrans," Monthly Bulletin of the Board of Health, Mass., vol. vii., N.S., No. 9, pp. 314-317.

1913. Bishop and King, "Additional Notes on the Biology of the Rocky Mountain Spotted-fever Tick," Journal of Economic Entomology, vol. vi. p. 200.

1913. Bruce, Harvey, Hamerton, and Davy, "The Trypanosomes found in the Blood of Wild Animals living in the Sleeping 
Sickness Area, Nyasaland," Proc. Roy. Soc. Lond., Series B, vol. Ixxxvi., No. B 587, pp. 269-277.

1913. Brues, "The Relation of the Stable Fly to the Transmission of Infantile Paralysis, Journal of Economic Entomology, vol. vi. p. 101.

1913. BUTTRICK, "The Effect of Tides and Rainfall on the Breeding of Salt-marsh Mosquitoes," Journal of Economic Entomology, vol. vi. p. 352.

1913. Cooley, "Notes on little-known Habits of the Rocky Mountain Spotted-fever Tick," Journal of Economic Entomology, vol. vi. p. 93.

1913. Dunbar-Brunton, "Sleeping Sickness and Big Game," Brit. Med. Jour., July 19, pp. 150-151.

1913. Graham-SMith, Flies and Disease.

1913. Honter, "American Interest in Medical Entomology," Journal of Economic Entomology, vol. vi. p. 27.

1913. Marett, "The Phlebotomus Flies of the Maltese Islands," R.A.M.C. Journal, vol. xx. pp. 162-171.

1913. Patton and CragG, A Text-book of Medical Entonology.

1913. Sambon, "The Natural History of Pellagra," Brit. Med. Journal, July 5th, pp. 5-12.

1913. ТномsоN, "Sanitation in the Panama Canal Zone, Trinidad, and British Guiana," Annals of Tropical Medicine and Parasitology, vol. vii. pp. 125-152.

1913. Townsend, "The Possible and Probable Etiology of the Transmission of Verruga Fever," Journal of Economic Entomology, vol. vi. p. 211.

1913. Townsend, "Progress in the Study of Verruga Transmission by Bloodsuckers," Bulletin of Entomological Research, London, vol. iv. No. 2, pp. 125-128.

1913. Townsend, "The Vector of Verruga," Insecutor Inscitice Menstruus, vol. i. No. 9, pp. 107-109.

1913. Yorke, "Sleeping Sickness and Big Game," Monthly Mag. Liverpool Chamber of Commerce, vol. xii. No. 1, pp. 4-9.

1914. Bacot and Martin, "Plague and Fleas," Nature, March 19.

\section{INSECTS AND LIVE STOCK.}

1896. Osborn, Insects affecting Domestic Animals, U.S. Dept. of Agriculture, Bureau of Entomology, Bulletin 5.

1902. Alaveran and Msevil, "Mal de Caderas," Compt. rend. Acad. Sci., Paris, vol. cxxxv. No. 20, pp. 838-840.

1902. Sivori and Lecler, "Mal de Caderas," An. Min. Agr. Argentine, Zoot., Bact., Vet. y Zool., vol. i. No. 1, p. 79.

1905. Collinge, "On the Deposition of Eggs and Larvæ of Estrus ovis," Journal of Economic Biology, vol. i. p. 72.

1905. Imms, "Life History of the Ox Warble Fly," Journal of Economic Biology, vol i. p. 74.

1906. Some Common Parasites of the Sheep, Dept. of Agriculture for Ireland, Leaflet 74. 
1906. Metray, "Red Water in Cattle," Journal of Dept. of Agriculture for Ireland, vol. vi. pp. 248-260.

1908. Сотton, "Some Life History Notes on Southern Cattle Ticks," Journal of Economic Entomology, vol. i. p. 51.

1908. Herrick, "Notes on the Hen Flea," Journal of Economic Entomology, vol. i. p. 355.

1908. Hooker, "A Review of Present Knowledge of the Rôle of Ticks in Transmission of Disease," Journal of Economic Entomology, vol. i. p. 65 .

1909. Herrick, "Notes on Mites affecting Chickens," Journal of Economic Entomology, vol. ii. p. 341.

1909. Hooker, "Some Host Relations of Ticks," Journal of Economic Entomology, vol. ii. p. 251.

1910. Brumpt, Précis de Parasitologie, lst edition.

1910. Mrgone, "Mal de Caderas," Bull. Soc. Path. Exot., vol. iii. pp. 524-525.

1912. Carazzi, Parassitologia Animale.

1912. Moore, "The Tick Problem in South Africa," Journal of Economic Entomology, vol. v. p. 377.

1912. Nfiveu-Lemaire, Parasitologie des animaux domestiques.

1913. Bishopp, "The Stable Fly an important Live-stock Pest," Journal of Economic Entomology, vol. vi. p. 112.

1913. Coppens, "L'affection hypodermique du bœuf," Annales de Médecine Vétérinaire, Ixelles-Bruxelles, vol. Ixii. No. 6, pp. 309328 ; No. 7 , pp. 384-388.

1913. Nuttall, "Spirochætosis," Parasitology, vol. v. pp. 262-274.

1913-14. Review of Applied Entomology, London, Series B.

1914. Froggatt, "Sheep Maggot Flies," Agricultural Gazette of New South Wales, vol. xxv., No. 2, p. 107.

\section{BENEFICIAL INSECTS.}

1618. Avgelus, Pharmacopoia persica ex idiomate persico in latinum conversa. (The earliest scientific account of Manna.)

1729. De RUUSCHER, Histoire naturelle de la Cochenille.

1787. Dr Ménonville, Traité de la culture du Nopal et de léducation de la Cochenille dans les colonies francaises de l'A mérique, 2 vols.

1789. RoxBURgh, "On the Lacsha or Lac Insect," Asiatic Researches, vol. ii. p. 561 .

1822. HARDWICK, "Description of a Substance called Geg or Manna, and the Insect producing it," Asiatic Researches, vol. xiv. pp. 182-186.

1829. Ehrenberg, "Coccus manniparus et Tamarix mannifera," Symbolce Physicae Insectorum Decas, vol. i.

1850. MacGowan, "Abstract of a Paper on the White Wax and the Insect by which it is produced," Proceedings of the Entomological Soc. London (2), vol. il. pp. 93-95.

1854. Berthelot, De l'industrie de la Cochenille aux îles Canaries.

1855. De Gomara, Historia general de las Indias con la conquista de Mexico y de la Nueva España. 
1874. Silliman, "The Chinese Wax Insect," American Naturalist, vol. v. p. 683.

1876. O'Conor, Lac Production, Manufacture and Trade.

1882. BARGAGLI, Insectes Comestibles.

1883. De Alzate, "Memoria en que se trata del insecto grana ó cochinilla, de su naturaleza y série de su vida," La Naturaleza, vol. vii.

1883. Blanchard, "Les Coccidés utiles," Bulletin de la Société Zoologique de France, vol. viii. pp. 217-328.

1893. Kunzé, Entomological Materia Medica.

1901. WATT, "Lac and Lac Industries," Agricultural Ledger, No. 9.

1905. Froggatr, "Crickets, etc.," Agricultural Gazette of New South Wales, vol. xvi. p. 477.

1907. Cockerelu and Hellems, "A Scientific Comedy of Errors," Popular Science Monthly, vol. lxxxi. pp. 217-295.

1907. Gale, "The Influence of Bees on Crops," Agricultural Gazette of New South Wales, vols. xviii. and xix.

1908. Root, A. I. and E. R., The A, B, C and $X, Y, Z$ of Bee Culture.

1908. Stebbing, "A Note on the Lac Insect (Tachardia lacca), its Life History, Propagation, and Collection," Indian Forest Records, vol. i. pt. 1, pp. 1-84.

1909. Froggatt, The Fruit Fly and other Pests in Various Countries.

1910. Skinver, "Insects as Human Food," Journal of the New York Entomological Society, vol. xviii. pp. 264-26i.

1911. Diquar, "Histoire de la Cochinelle au Méxique," Bulletin de la Société Nationale d'Acclimatation, pp. 330-334.

\section{HOUSEHOLD INSECTS.}

1868. MAYr, "Formicidæ novæ Americana," Annario della Soc. Naturalista Modena, vol. iii. No. 4, p. 164.

1896. Butuer, Our Household Insects.

1896. Howard, Marlatt, and Chitrenden, The Principal Household Insects of the United States, U.S. Dept. of Agriculture, Bureau of Entomology, Bulletin 4, N.S.

1906. WHEELER, "On certain Tropical Ants introduced into the United States," Entomological News, vol. xvii. p. 23.

1907. Martins, "Une fourmi terrible envahissant l'Europe," Broteria Revista de Sciencias Naturaes, vol. vi. pt. 1, p. 101.

1908. Foster, "The Introduction of Iridomyrmex humilis into New Orleans," Journal of Economic Entomology, vol. i. p. 289.

1908. Neweld, "Notes on the Habits of the Argentine or "New Orleans' Ant," Journal of Economic Entomology, vol. i. p. 21.

1909. Lounsbury, Rept. of Govt. Entomologist of Cape of Good Hope for 1908 , pp. 66-68.

1909. NewELL, "The Life History of the Argentine Ant," Journal of Economic Entomology, vol. ii. p. 174.

1909. NewELt, "Measures suggested against the Argentine Ant as a Household Pest," Journal of Economic Entomology, vol. ii. p. 324. 
1910. Felt, "Observations on the House Fly," Journal of Economic Entomology, vol. iii. p. 24.

1910. Hertzog, "Notes on the Cigarette Beetle," Journal of Economic Entomology, vol. iii. p. 198.

1910. Lounsbury, Rept. of Gort. Entomologist of Cape of Good Hope for 1909, pp. 90-91.

1910. WhEeler, Ants: their Structure, Development, and Behaviour.

1911. Dean, "Heat as a means of controlling Mill Insects," Journal of Economic Entomology, vol. iv. p. 142.

1911. Howard, House Flies, U.S. Dept. of Agriculture, Farmers' Bulletin 459.

1911. Nickels, "Field Work in the Control of the Argentine Ant," Journal of Economic Entomology, vol. iv. p. 353.

1912. Fuller, White Ants in Natal, Union of South Africa Dept. of Agriculture, Leaflet 54.

1912. Hewitr, House Flies.

1913. Assuoth, "Wood-destroying White Ants of the Bombay Presidency," Journal of Bombay Nat. Hist. Society, vol. xxii. p. 372 .

1913. Dean, "Further Data on Heat as a means of controlling Mill Insects," Journal of Economic Entomology, vol. vi. p. 40.

1913. Hesse, "Parasitic Mould of the House Fly," Brit. Med. Journ., June 4, p. 41.

1913. Jonks, "The Cigarette Beetle (Lasioderma serricorne) in the Philippine Islands," The Philippine Journal of Science, rol. viii. pp. 1-42.

1913. Morgan, "An Enemy of the Cigarette Beetle," Proceedings of the Entomological Society, Washington, vol. xv. pp. 89-90.

1913. Morgan and Runver, "Some Experiments with Röntgen Rays upon the Cigarette Beetle," Journal of Economic Entomology, vol. vi. p. 226.

1913. Newell and Barber, The Argentine Ant, U.S. Dept. of Agriculture, Bureau of Entomology, Bulletin 122.

\section{HUMAN PARASITES.}

1906. Chittendwn, Harvest Mites, U.S. Dept. of Agriculture, Bureau of Entomology, Circular 77.

1912. Casteldani and Hirst, "Notes on the Copra Itch, with a Report on the Mite causing it," Journal of Tropical Medicine and Hygiene, Dec. 16.

1912. Spencer, "The Chiger Flea or Chigoe in the Transvaal," Transvaal Medical Journal, vol. viii. No. 5, p. 833.

1913. Marzocchi, "Sur le Phthirius inguinalis," Archiv Parasitologie, Paris, July 10, pp. 314-317.

1913. Morrill, "Entomological Pioneering in Arizona," Journal of Economic Entomology, vol. vi. p. 185.

1913. Rouhain and BequaErt, "Nouvelles observations sur Auchmeromyia luteola, F. and Cordylobia anthropophaga, Grunb.," Revue Zoologique Africane, vol. ii. pp. 145-154. 
1913. Roubadd, "Recherches sur les Auchmeromyies, Calliphorinés à larves suceuses de sang de l'Afrique tropicale," Bull. Scient. de la France et de la Belgique, Paris, vol. xlvii. fasc. 2, pp. 105-202.

1913. Russelu, The Flea.

1913. SuRCodf, "La transmission du Ver Macaque par un Moustique," Compt. Rend. Acad. Sci., Paris, May 5, vol. clvi. No. 18, pp. 1406-1408.

1914. Giradut, "Researches on the Bed Bug," Journal of Economic Biology, vol. ix. pp. 25-45.

\section{INSECT CONTROL.}

1890. Koebele, Report of a Trip to Australia to investigate the Natural Enemies of the Fluted Scale, U.S. Dept. of Agriculture, Bureau of Entomology, Bulletin 21.

1908. BRUES, "The Correlation between Habits and Structural Characters among parasitic Hymenoptera," Journal of Economic Entomology, vol. i. p. 123.

1910. Fiske, "Superparasitism," Journal of Economic Entomology, vol. iii. p. 88.

1911. BuRgess, Calosoma sycophanta, its Life History, Behaviour, and successful Colonisation in New England, U.S. Dept. of Agriculture, Bureau of Entomology, Bulletin 101.

1912. Howard, "The Activity of Prospaltella berlesei, Howard, against Diaspis pentagona, Targ., in Italy," Journal of Econonic Entomology, vol. v. p. 325.

1912. HowARD and FISkE, The Importation into the United States of the Parasites of the Gipsy Moth and the Brown-tail Moth, U.S. Dept. of Agriculture, Bureau of Entomology, Bulletin 91.

1912. KELLOG, "The Distribution of Ecto-parasites," Journal of Economic Entomology, vol. v. p. 357.

1913. Gallardo, "La destruccion de la langosta por sus enemigos naturales," Anales del Museo nacional de Buenos Aires, vol. xxiii. pp. 155-156.

1913. Lounsbury, "Locust Bacterial Disease," Agricultural Journal, Union of South Africa, vol. v. pp. 607-611.

1913. BuRgess and Rogers, "Results of Experiments in controlling the Gipsy Moth by removing its favourite Food Plants," Journal of Economic Entomology, vol. vi. p. 75.

1913. Marchal, "L'acclimatation de Novius cardinalis," Bull. Soc. d'Acclimatation, Paris, No. 17, pp. 558-562.

1913. Le Mont, "Destruccion de insectos," Rivista del Instituto Agricola Catálan de San Isidru, vol. Ixii. p. 191.

1913. Rorer, "The Green Muscardine Fungus and its Use in Canefields," Board of Agriculture, Trinidad and Tobago, March 31.

1913. WogLum, Report of a Trip to India and the Orient in search of the Natural Enemies of the Citrus White Fly, U.S. Dept. of Agriculture, Bureau of Entomology, Bulletin 120. 


\section{INDEX}

Acarina, 22.

Acheta bimaculata, 204. campestris, see Field Cricket.

Acridiidæ, 23, 38.

Agonopteryx sp., 316.

Agrotis infusa, see Bugong Moth.

"Aluuhutl," 211.

Alabama argillacea, see Cotton-leaf Worm.

Aleyrodes citri, see Citrus White Fly. Aleyrodidæ, see Mealy Wing.

Amblyomma sp., 152.

hebræum, see Bont Tick.

A mœba, 167.

Anasa tristis, 35 .

Anastatus bifasciatus, $308,309,310$, 311.

Anobium domesticum, 267, 268.

paniceum, sce Biscuit Weevil.

Anopheles sp., 89, 90, 91, 100, 101, $102,103,104,108,109,113$, $118,193$.

albimanus, 90 .

maculipennis, 109, 193.

pseudopunctipennis, 90 .

tarsimaculata, 90.

Ant, 24, 144, 204, 222, 242, 261, $266,267,281,308$.

Argentine, 245, 258, 267.

and disease, 249.

distribution, 246.

economic importance, 247.

history, 246.

life-history, 250.

and scale insects, 248, 256.

cow, 24.

crazy, see Argentine Ant.

fire, see Argentine Ant.

house, 267 .

lion, 23.

New Orleans, see Argentine Ant. pernicious, sce Argentine Ant.
Ant, red-headed, 208.

trupical, see Argentine Ant.

white, see Termites.

wood, 208.

Antheræa paphia, see Tassar Silk Moth.

Anthomyidx, 27.

Anthonomus grandis, see Cotton-boll Weevil.

vestitus, 45 .

Anthrax, 120, 125.

A panteles fulvipes, 308,311 .

glomeratus, 295.

Aphides, 18, 35, 219, 248, 254, 256, $257,280,294$.

Aphis chenopodii glauci, 219. hop, 295.

Apidæ, see Bees.

A pis dorsata, 213.

Aptera, 23, 30 .

Arachnoidea, 22.

Araneida, see Spiders.

Argantinæ, 162.

Argas sp., 160. persicus, see Fowl Tick.

Aromia moschata, see Musk Beetle.

Arthropods, 22, 28.

Asilidæ, see Robber Flies.

Aspidiotus perniciosus, sce San José Scale.

Aspongopus nepalensis, 212.

Atropos divinatoria, see Book Louse.

Auchmeromyia luteola, sse Congo Floor Maggot.

Babesia, 165.

bovis, 165 .

canis, 165.

equi, 165.

ovis, 165.

Babesiasis, 165 . 
Bacillus pestis, 155, 157, 159.

prodigiosus, 127.

solanacearum, 34 .

tracheiphilus, 35 .

Barbados leg, 116.

Barbeiro, 153.

Bartonia bacilliformis, 149 .

Barton's $x$-bodies, $149,150$.

"Bedeguar," 218.

Bees, 24, 197, 212, 219, 308.

American bumble, 321 .

carpenter, 24.

disease, Isle of Wight, 196.

honey, 24, 180, 249, 253.

leaf-cutter, 24, 200.

Beetle, blister, 216.

cigarette, 269.

click, 25.

Colorado, 35, 246.

dung, 25, 215.

flour, confused, $270,271$.

rust-coloured, $270,271$.

grain, 33, 270.

ground, 25, 296, 304.

ladybird, 25, 57, 215, 257, 295, $296,298,299,300,314$.

aphis-eating, 319 .

larder, 268.

leather, $25,215,268$.

longicorn, $25,37$.

meal worm, 216,270 .

musk, 217.

rose, 25 .

rove, $25,296$.

scarab, 25, 210, 215.

stag, 25, 206, 215.

tiger, 25.

wood-boring, 36, 267, 268.

"Benchuca,"154.

"Bicho de parede," 153.

"Black beetle," 22, 30, 217, 258.

Blaps mucronata, 210, 216.

sulcata, 210, 216.

Blattidæ, see Cockroaches.

"Blues," 26.

Bombus pennsylvanicus, see American Bumble Bee.

Bombycidæ, see Silkworm Moths.

Bombyx mori, see Silkworm Moths. processionea, see Procession Moth.

Brachonidæ, 24.

Bugs, bed, 128, 151, 220, 221, 249, $275,279,283$.

big, see Blood-sucking Cone-nose. Indian, 153.
Bugs, bed, Mexican, see Blood-sucking Cone-nose.

black pampas, 154 .

chinch, 18.

croton, 260.

Buprestidæ, 25.

Butterflies, 25, 28, 31, 205, 219.

cabbage, 26, 31, 219, 295.

swallow-tail, 26.

Byrrhus pilula, 215.

"Cænis kungu," 212.

Calandra fralmarum, see Palm Weevil.

Calliphora erythrocephala, see Blow Fly.

oceaniæ, 183.

rufifacies, see Hairy Maggot Fly. villosa, 183.

Calocoris rapidus, see Cotton-leaf Bug.

Calosoma inquisitor, 305. sycophanta, $295,304$.

Cancer, 293.

Cantharides, see Blister Beetle.

Cantharis vesicatoria, 216.

Carabidæ, see Ground Beetles.

Carabus auratus, 296.

Carpocapsa pomonella, see Codling Moth.

Catorama tabaci, 270.

Cayor maggot, see Tumbu Fly.

Cecidomyia destructor, see Hessian Fly.

Cecidomyidæ, see Gall Gnats.

Cerambycidæ, see Longicorn Beetles.

Ceratitis capitata, see Mediterranean Fruit Fly.

Ceratophyllus fasciatus, see European Rat Flea.

Ceratostomella pilifera, 35 .

Cetonia aurata, 194.

Cetonidæ, see Rose Beetles.

Chalcididæ, 24, 319.

Cheese "skipper," 27, 244, 270.

Chelifer, 242.

Chelonus texanus, 319.

Chemotropism, 31.

Chermes mannifer, 213.

Chilocorus similis, 73,300 .

Chironomidæ, 26.

Chloridea obsoleta, see Cotton BollWorm.

Cholera, 120, 124, 125.

Chrysomelidæ, 25.

Chrysomyia macellaria, see Screwworm Fly. 
Chrysops, 128.

"Chupanca," 153.

Cicada, 28, 212, 219.

periodical, $30,55,264$.

damage, 56 .

enemies, 57 .

life-history, 56 .

oviposition, 62 .

ovipositor, 61 .

song, 59.

types, 58.

septendecim, see Periodical Cicada. tredecim, sce Periodical Cicada.

Cicindela curvata, 211.

Cicindelidæe, see Tiger Beetles.

Cimex lectularius, see Bed Bug.

Citrus white fly, 312, 313, 314, 315, $316,317$.

Classification, 21.

Coccidæ, see Scale Insects.

Coccinella septem punctata, 215.

Coccinellidæ, see Ladybird Beetles.

Coccobacillus acridiorum, 322 .

Coccus pela, 231.

Cochineal, 220, 225.

Cockchafer, 194, 210.

Cockroach, 23, 30, 217, 258, 264, $275,276,281$.

American, 217, 246, 256.

Cone-nose, blood-sucking, 282.

Congo floor maggot, 27, 288, 289, 290.

Conorhinus sanguisugus, see Bloodsucking Cone-nose.

Contarinia sorghicola, 250. tritici, see Wheat Midge.

Copris sp., 215.

Cordylobia anthropophaga, see Tumbu Fly.

Coreidæ, 28.

Corixa femorale, 211. mercenaria, 211.

Cossus ligniperda, sce Goat Moth.

Cotton boll-worm, 52, 55, 318, 319. cannibalism, 53.

life-history, 54 .

Cotton-leaf bug, 55 . worm, 51, 52, 55, 296.

Cotton-square borer, 55 . stainer, 55.

Cricket, 23, 204, 217, 264. field, 265.

house, 217, 264.

mole, 265.

Crithidia, 242.
Crustacea, 22.

Cryptognatha flavescens, $314,317$.

Culex sp., 90, 101, 102, 103, 104, $193,212$.

fatigans, 115 .

pipiens, 100, 115.

quinquefasciatus, 88,90 .

Culicidæ, 26, 92.

Curculionidæ, see Weevils.

Curtilla africana, 204.

Cuterebra emasculator, see Emasculating Bot Fly.

Cyclorrapha, 26, 27.

Cynips gallæ tinctoria, 218. rosæ, 218.

Cyrtacanthacris septemfasciata, sce Red Locust.

Cytodites nudus, see Air-sac Mites.

Dactylopius coccus, see Cochineal.

Dacus oleæ, sce Olive Fly.

"Death watch," 267, 273.

Demodex folliculorum, var. hominis, see Follicle Mite.

Iendroctonus ponderosæ, 35 .

Dermacentor sp., 152.

andersoni (venustus), see Rocky Mountain Spotted-fever Tick. nitens, see Tropical Horse Tick. reticulatus, 172.

Dermanyssus gallinæ, sce Red Mite.

Dermatobia hominis, sce Human Bot Fly.

Dermatophilus penetrans, see Chigoe Flea.

Dermestes lardarius, see Larder Beetle. vulpinus, 268, 269.

Dermestidæ, see Leather Beetles.

Diabrotica vittata, 35 .

Diarrhœea, infantile, 122.

Diaspis pentagona, 320 .

Diphtheria, 126.

Diptera, see Flies.

Dourine, 130.

Dragon flies, 24.

Drosophila fenestrarum, see Fruit Fly.

Dysdercus suturellus, see Cotton Stainer.

Dysentery, 126.

Earwig, 23, 217, 264, 265, 295.

Elateridæ, see Click Beetles.

Elephantiasis, 116.

Elmis chilensis, 216.

Empusa muscæ, 241. 
Enteritis, 122, 123.

Ericerus pela, see Pela Wax Scale.

Eunectes sticticus, 210.

Euplæa hamata, 207.

Euproctis chrysorrhœa, see Browntail Moth.

Fannia canicularis, see Lesser House Fly.

scalaris, see Latrine Fly.

Fever, Carrion's grave, 148.

enteric, 122.

phlebotomus, 136.

red water, 166.

relapsing, 141.

Rocky Mountain spotted, 144.

splenetic 144.

swine, 126.

Texas, 160, 164, 166.

tick, 141, 166.

typhoid, 96, 120, 121, 122, 123, 240.

verruga, 147.

yellow, 110, 137, 150.

Filaria bancrofti, 116, 119, 193.

cruel, 193.

immitis, 193.

Filariasis, 116.

Fire brat, 273.

Flata limbata, 219.

Flea, 128, 136, 144, 155, 239.

bat, 275,276 .

Californian ground squirrel, 158.

cat, $275,277$.

Chigoe, 275, 278.

European rat, 158.

hen, 191.

human, 28, 29, 158, 191, 274, 283. plague, 158.

Fly, bat, 27.

blow, 27, 237, 238, 240, 287, 289.

blue-bottle, 27, 237, 238, 240, 287, 289.

bot, 27.

carpet, see Window Fly,

cluster, 238, 239.

crane, 26

emasculating bot, 181 .

flesh, 27, 32 .

fruit (Drosophila), 239.

(Mediterranean), 80.

gad, 27, 88, 128.

gall, 26, 218, 321.

green-bottle, 37, 182, 240.

hairy maggot, 183.
Fly, heel, see Ox Warble Fly.

Hessian, 18, 34, 78, 296.

damage, 78 .

distribution, 78 .

life-history, 79.

parasites, 80 .

horse, 151.

bot, 177,180 .

house, $26,27,29,119,128,129$, $174,175,234$.

hover, 27.

human bot, 286 .

latrine, 238.

lesser house, 27, 234, 237, 238.

nostril, see Sheep Bot Fly.

olive, 296.

ox warble, 178, 179, 205, 286.

robber, $27,242$.

sand, 136.

screw-worm, 27, 288, 291.

sheep bot, 176, 181.

maggot, 182.

stable, 27, 32, 128, 174, 175, 237, 238.

tick, 27.

tsetse, 26, 27, 129.

Tumbu, 27, 288, 289.

typhoid, see House Fly.

window, 239, 240.

yellow dung, 240.

Forficula auricularia, see Earwig.

Forficulidæ, see Earwig.

Formica, major, 218.

minor, 218.

Formicidæ, see Ant.

"Frog hoppers," 321, 322.

Gall insects, 24.

Gamasidæ, 241.

Gangrene, 120.

Gastrophilus equi, sce Horse Bot Fly.

Gattina, 195.

Gibbium scotias, 268.

Giganthorhynchus hirundaceus, 194.

Glossina fusca, 132.

morsitans, 131.

pallidipes, 132.

palpalis, 129.

Glow-worm, 216.

Glycyphagus domesticus, see Grocers' Itch Mite.

Gnat, see Mosquito.

buffalo, 26, 88, 103, 128, 137, 139, $149,151$.

fungus, 26. 
Gnat, gall, 26, 78 .

Gossyparia mannifera, see Manna.

Grasshopper, 23, 204, 217. semni, 218.

Green fly, see Aphides.

Green muscardine, 321.

"Grougrou," 210.

Gryllidæ, see Cricket.

Gryllotal pa vulgaris, see Mole Cricket.

Gryllus domesticus, see House Cricket.

"Gusana peludo," 287.

Habronema muscæ, 242.

Hæmaphysalis sp., 152, 164.

leachi, 172.

leporis palustris, see Rabbit Tick.

turicata, 168.

Herpetomonas, 242.

Hesperidæ, see "Skippers."

Hexapoda, 22.

Hippobosca camelina, 185.

equina, 185.

maculata, 185.

nigra, 185.

rufipes, 185 .

taurina, 185.

Hippoboscidæ, 27, 185.

Hippodamia convergens, 297.

Hoplopsyllus anomalus, see Californian Ground Squirrel Flea.

Hornet, 266.

Hyalomma ægyptium, sce Senegal Tick.

Hypoderma bovis, see Ox Warble Fly. lineata, sec $\mathrm{Ox}$ Warble Fly.

Icerya purchasi, see Fluted Scale.

Ichneumonidæ, 24.

Insecta, 22.

Invertebrates, 21, 22, 28.

Iridomyrmex humilis, see Argentine Ant.

Ixodes hexagonus, 168, 172. ricinus, see Castor-bean Tick.

Ixodid $x, 162$.

Ixodinæ, 151, 162.

Janthinosoma lutzi, 287.

"Kimputu," 141.

"Ked," see Sheep Tick.

Kermes ilicis, 220.

Lac insect, 222.

Lace wings, 23.
Lachnosterna arctuata, 195.

Lampyris noctiluca, see Glow-worm.

Lamus megistus, 89, 153.

Lasioderma serricorne, see Cigarette Beetle.

" Leaf hoppers," 34.

Leather jacket, see Crane Fly.

Lepisma domestica, see Fire Brat. saccharina, see Silver Fish.

Leprosy, 120, 293.

Leptoconops, 139.

Leptus americanus, see Harvest Mite. autumnalis, sce Harvest Mite. irritans, see Harvest Mite.

Lichen spinulosus, 293.

Locust, 18, 23, 38, 203, 204, 209, $217,218,294,322$.

brown, 40 .

Chargol, 217.

red, 40.

Rocky Mountain, 203.

Locusta africana, 217.

migratoria, 218.

Locustidæ, see Grasshoppers.

Louse, 128, 151, 213, 221, 222, 283.

bird, 188, 189, 190 .

body, 284.

book, 273.

crab, 284.

head, 284.

plant, see Sicale Insects.

wall, see Bed Bug.

Lucanidæ, see Stag Beetles.

Lucanus cervus, see Stag Beetle.

Lucilia cæsar, sce Green-bottle Fly. sericata, see Sheep Maggot Fly.

Lycænidre, see "Blues."

Lygæidæ, 28.

Malaria, 92, 137, 150.

bovine, 166 .

parasite of, 98.

Mal de caderas, $130,1 \% 3$.

la rosa, 137.

Mallophaga, see Bird Lice.

Manna, 213, 214.

insects, 28.

Mansonoides sp., 97.

Mantidæe, 23.

Margaropus sp., 161.

annulatus, 160, 168, 169, 173.

australis, 152, 168 .

decoloratus, 168.

May fly, 24, 212. 
Mealy-bug, common, 248, 256, 257, see also Scale Insects. sugar-cane, 248.

Mealy wing, 312 .

Megachile, see Leaf-cutter Bees.

Megilla maculata, see Aphis-eating Ladybird.

Melolontha hypoleuca, 210. vulgaris, see Cockchafer.

Melophagus ovinus, see Sheep Tick.

Membracidæ, 28.

Merisus destructor, 80 .

Metamorphosis, complete, 29. incomplete, 29.

Metarrhizium anisoplise, see Green Muscardine.

Midges, 26.

gall, 34 .

owl, 26, 136.

sorghum, 250.

wheat, 297.

Mites, 22, 241, 291, 292, 297.

air-sac, 192.

cheese, 241, 242, 292.

chicken itch, 190.

copra itch, 291, 292.

follicle, 292.

grain itch, 291.

grocers' itch, 292.

harvest, 293.

hypopus stage, 241, 243, 244.

itch, 291, 292.

mange, 192.

red, 190, 241.

water itch, 292.

Mixosporidia, 195.

Monas prodigiosa, 127.

Monedula carolina, 321 .

Monilia candida, 37.

Monomorium pharaonis, see House Ant.

Moor ill or evil, 166.

"Mosca brava," 174.

Mosquitoes, 26, 88, 113, 114, 119, $149,174,193,212,257$.

breeding places, 97 .

life-history, 101.

Moths, 18, 26, 33, 37, 38, 64, 68, $205,219$.

brown-tail, 18, 219, 301, 302, 303, 306.

Bugong, 206.

clearwing, apple, 38 .

clearwing, currant, 38 .

clothes, 26, 237, 271, 272.

codling, 18, 33, 37 .
Moths, codling, damage by, 74 .

description of, 77 .

enemies, 77.

history, 74 .

life-history, 74 .

gipsy, 18, 64, 246, 301, 302, 303, $307,308,311$.

damage by, 66 .

description of, 67 .

distribution, 67.

history, 64 .

goat, 38, 206.

grain, 33.

hawk, 26.

leaf-rolling, 26.

meal, 271.

nun, 68.

procession, 219.

silkworm, 26, 64, 207.

tassar silk, 208.

tapestry, 272, 273.

wood leopard, 37.

"Muche," 287.

Mule warts, 148.

Musca domestica, see House Fly.

Muscidæ, 27.

Muscina stabulans, 237, 238.

Mutilla antiguensis, 219.

Mutillidæ, see Cow Ants.

Mycetophilidæ, see Fungus Gnats.

Mylabris cichorii, 216.

pustulata, 216.

Myriapoda, 22.

Nagana, 130, 135, 173, 174.

Nemobius sylvestris, see Field Cricket.

Niptus hololeucus, 268.

Noctuidæ, 26, 52.

Nosema apis, 196.

bombycis, 195, 196.

Notonecta unifasciata, 211.

Novius cardinalis, $73,298,299,300$, 314.

Nycteribiidæ, see Bat Flies.

CEcodoma cephalotes, see Red-headed Ant.

Ecophylla smaragdina, see Wood Ant.

Estridæ, see Bot Flies.

Estrus ovis, see Sheep Bot Fly.

Ophionectria coccicola, 35 .

Ophthalmia, 125, 126.

Ornithodorus megnini, see Spinous Ear Tick.

moubata, see Fever Tick. 
Orthorrapha, 26.

Oscinidæ, 27.

Osmia, 200.

Pachyneuron sp., 311.

Pachytilus sulcicollis, see Brown Locust.

Papilionidæe, see Swallow-tail Butterfly.

Paralysis, infantile, 127.

Parasitic insects, 24, 241.

l'ébrine, 64, 195.

Pediculus, sce Louse.

capitis, see Head Louse.

vestimenti, sce Body Louse.

Pela wax, 220, 230.

Pellagra, 137.

Pentatoma ornatum, 322.

Pentatomida, 28.

Periplaneta americana, 217, 260. orientalis, 217, 258.

Peste de caderas, 173.

Phasmidre, sce Stick Insects.

Pheidole megacephala, 246.

Phlebotomus sp., 153.

papatasi, see Sand Fly.

verrucarum, 153.

Phyllocnistis citrella, 316.

Phyllodromia germanica, 260.

Phylloxera vastatrix, 84, 297.

Pieridæ, see Cabbage Butterflies.

Pieris brassicæ, see Cabbage Butterflies.

Piophila casei, see Cheese "Skipper."

Piroplasms, 151, 165.

bigeminum, 166 .

Piroplasmosis, 152, 165.

of dogs, 172.

of horses, 172.

of sheep, 172.

Plague, 119, 126, 155.

Plant lice, 28.

Poliomyelitis, 127, 128.

Pollenia rudis, see Cluster Fly.

Polyembryony, 319.

Polygonotus hiemalis, 296.

Pompilidæ, see Sand Wasps.

Pontia rapæ, 296.

"Poroponjy," 141.

Porthetria dispar, see Gipsy Moth.

Potato rot, 34.

Prionus coriarius, 206.

Priophorus padi, 32.

Proctotrypidæ, 24.
Prospaltella berlesei, 320 .

lahorensis, $315,317,320$.

Pseudococcus calcolariæ, see Sugarcane Mealy-bug.

citri, see Common Mealy-bug.

Psilura monacha, see Nun Moth.

Psychodidæ, see Owl Mlidges.

Psyllidæ, 28.

Phthirins inguinalis, see Crab Louse.

Pulicidæ, see Flea.

Pulex irritans, see Human Flea.

Pyralis farinalis, see Meal Moth.

Red murrain, 166.

Reduviidæ, 28, 128, 154.

Rhipicephalus sp., 152.

bursa, $161,172,173,188$.

evertsi, 161, 172.

sanguineus, 172.

Rhizoglyphus parasiticus, see Water Itch Mite.

Rhizotrogus assimilis, 210. pini, 210.

Rhynchota, sce Bugs.

Sarcophagidæ, see Flesh Flies.

Sarcopsylla gallinacea, see Hen Flea.

Sarcoptes nutans, see Chicken Itch Mite.

scabei, see Itch Mite.

"Sauba," 208.

Saw fly, 24.

Scale insects, $18,27,28,35,69,214$, $219,248,254,256,257,296$, $298,312,320$.

cottony cushion, see Fluted Scale.

fluted, 298, 299, 300, 312, 314.

lac, 222.

manna, see Manna.

Pela wax, 220, 230.

San José, 18, 69, 246, 300, 301.

control, 73.

description of, 70 .

life-history, 71 .

parasites, 69.

Scarabæidæ, see Scarab Beetles.

Scarabæus sacer, see Scarab Beetles.

Scatophaga stercoraria, see Yellow Dung Fly.

Scenopinus fenestralis, see Window Fly. Schedius kuvanæ, 308, 309, 310, 311.

Scolytidæ, 36 .

Scorpions, false, see Chelifers.

Scutigera forceps, 242.

Sepsidæ, 27. 
Sesia myopiformis, see Apple Clearwing Moth.

tipuliformis, sce Currant Clearwing Moth.

Sheep tick, 27, 182, 184.

Silkworm, see Silkworm Moth.

Silver fish, 273.

Simulidæ, see Buffalo Gnats.

Simulium lineatum, 139. reptans, 139.

Siphonaptera, see Fleas.

"Skippers," 26, 211.

Sleeping sickness, 129, 151, 242. and big game, 133.

Smallpox, 126.

Solenopsis geminata, see Fire Ant.

Spanish fly, see Blister Beetle.

Sphenophorus sericeus, 35.

Sphingidæ, see Hawk Moths.

Spiders, 22.

Spirochætes, 141.

Spirochæta gallinarum, 191.

Sporatrichum globuliferum, 322.

Staphylinidæ, see Rove Beetles.

Stegomyia fasciata, 88, 89, 90, 92, $100,102,103,104,110,111$, $113,114,119$.

Stenodontes damicornis, 210.

Stick insects, 23, 28.

Stomoxys calcitrans, sce Stable Fly. nebulosa, 174.

Stone fly, 24.

Surra, 130.

Syrphidæ, see Hover Flies.

Tabanidæ, see Gad Flies.

Tachardia lacca, see Lac Insect.

Tachinidæ, 27.

Tarsonemidæ, 241.

Tenebrio molitor, see Meal Worm Beetle.

Tenebrionidæ, 25.

Tenthredinidæ, see Saw Flies.

Termes arborum, 209.

fatale, 209.

flavicolle, 208.

smeathmanni, 209.

Termites, 23, 250, 261.

Termitidæ, see Termites.

Tettigonia verrucivora, 217.

Thrips, 27, 30, 34 .

Thyroscera cincta, 256.

Thysanoptera, see Thrips.

Ticks, 22, 30, 128, 141, 151. bont, 161, 188.
Ticks, castor-bean, 161, 168, 172, 188. fever, 161, 191.

fowl, $163,190$.

rabbit, 163 .

Rocky Mountain spotted-fever, 145.

Senegal, 162, 168.

spinous ear, 152, 160, 161, 164.

tropical horse, 161.

Tinea biselliella, 271, 272.

pellionella, see Clothes Moth.

tapetzella, see Tapestry Moth.

Tineidæ, 26.

Tipulidæ, see Crane Flies.

Tomicus typographus, 215.

"Torcel," 287.

Tortricidæ, 26.

Tribolium confusum, see Confused Flour Beetle.

ferrugineum, see Rust-coloured Flour Beetle.

Trichogramma pretiosa, 318, 319.

Trombidiidæ, 241, 293.

Trombidium, 293.

Tropical sore, 126.

Trypanosma brucei, 174.

cruzi, 153.

equinum, 173, 175.

gambiense, 129, 130, 133, 134.

rhodesiense, 130, 133, 134.

Trypanosomes, 129.

'Trypanosomiasis, 130, 321 .

Trypetidæ, 27.

Tsetse fly disease, see Nagana.

Tuberculosis, 120, 126, 249.

"Tumby-a," 173.

"Tumby-baba," 173.

Tyndarichus sp., 311.

Tyroglyphus longior, see Cheese Mite. castellani, see Copra Itch Mite. phylloxeræ, 297.

siro, see Cheese Mite.

Ungulates, 274.

"Ura," 287.

Uranotes melinus, see Cotton-square borer.

Ustilago violacea, 35 .

"Ver macaque," 287.

Vertebrates, 21.

Vespa crabro, see Hornet. germanica, see German Wasp. vulgaris, see Common Wasp.

Vespidæ, see Wasps. 
Wasps, 24, 266, 308, 321.

common, 266.

German, 266.

sand, 24.

Weevils, 18, 25, 33, 34, 35, 42, 216, 217.

apple, 34 .

biscuit, 267 .

cotton-boll, 18, 33, 42.

control, 50.

damage, 43.

distribution, 49 .

food plants, 45 .

history, 42.

life-history, 45.

oviposition, 47 .

rate of development, 49 .
Weevils, cotton-boll, related species, 45.

systematic position, 42 . palm, 209.

Wilt disease, 35 .

Xenopsylla cheopsis, see Plague Flea.

Xestobium tessellatum, sce "Death Watch.'

Xyleborus dispar, 36, 267. perforans, 35.

Yaws, 126.

Zeuzera æsculi, see Wood Leopard Moth. 


\section{INDEX OF AUTHORITIES, ETC.}

Ellian, 209.

Aldrovandi, 295.

Alessi, 126.

Arce, 150.

Aristotle, 243, 286.

Babes, 166.

Balbiani, 195.

Bancroft, 116, 117.

Barber, 252.

Barton, 149.

Bastianelli, 105.

Beaumont, 221.

Beauperthuy, 111.

Bignami, 105.

Birt, 136.

Blair, 111.

Blanchard, 287.

Boheman, 42.

Boisgiraud, 295.

Buchanan, 125, 126.

Budd, 125.

Calverley, 120.

Carnes, 296.

Carrion, 148.

Casal, 137.

Celli, 125, 126.

Christy, 289.

Claparide, 243.

Columbus, 111.

Commodus, 107.

Crawford, 120.

Creighton, 93.

Curtis, 19.

Darwin, 154,

Defoe, 158.

De Gomara, 226.

Demarquay, 116.

De Ménonville, 228.

De Smet, 203, 213.

D'Herelle, 322.

Dioskorides, 215, 219.

Doer, 136.

Drury, 141.

Dutton, 129, 289.

Ehrenberg, 213.

Elmassian, 173.

Esculapius, 158.

Esten, 123.

Faichne, 235.

Fernald, 66.

Finlay, 111.

Fitch, 297.

Fletcher, 221.

Froggatt, 211.

Galen, 215, 216, 219.

Garlach, 192.

Gergi, 216.

Goedeart, 74.

Gorgas, 112.

Grassi, 105, 126.

Greenfield, 216.

Guettard, 221.

Hardwick, 213.

Hauschalter, 126.

Hayward, 126

Heine, 127.

Helm, 127.

Herms, 235.

Herodotus, 203, 286.

Herrick, 79.

Hewitt, 240.

Hildreth, 212.

Hippocrates, 94.

Hofmann, 126.

Homer, 59.

Honigberger, 218, 220.

Hooke, 273.

Howard, 124, 212.

Howe, 125. 


\section{INDEX OF AUTHORITIES, ETC.}

Howlett, 32.

Humboldt, 111, 227.

Hunter, 47, 140.

Huxley, 18.

Justinian, 155 .

Kinghorne, 130, 131, 135.

Kirby, 295.

Kitasato, 157.

Koebele, 298.

Kornauth, 68.

Kunzé, 207.

Laveran, 125.

Leidy, 120.

Lewis, 116, 117.

Linnæus, 286.

Livingstone, 141, 142.

Low, 106.

Macrae, 125.

Manson, Sir P., 16, 92, 97, 105, 110, $116,117,118$.

P. T., 110 .

Marchoux, 191.

Marlatt, 69, 73, 300.

Mason, 123.

Mercurialis, 119.

Moore, 120, 124.

Morales, 287.

Morgan, 122.

Mouffet, 215, 270.

Nevius, 70.

Newell, 252, 255,

Nicholas, 124.

Odriozola, 148.

Ogata, 157.

Pasteur, 195, 196.

Pericles, 94.

Pierce, 47.

Pliny, 18, 203, 205, 206, 215, 216, $217,221,272$.

Plumier, 226.

Pym, 136.

Raimbert, 125.

Ransom, 242.

Ratzeburg, 295.

Réaumur, 59, 60, 228.

Reclus, 231.

Richthofen, 232.
Riley, 64, 212, 298.

Rincones, 287.

Ross, $17,93$.

Rufus of Ephesus, 155.

Ruusscher, 226, 227.

Salimbini, 191.

Sambon, 17, 106, 108, 137, 139, 158.

Sandel, 212.

Sangree, 125.

Say, 286.

Schroeder, 215, 218, 221.

Serenus, Quintus, 221.

Shaw, 293.

Simon, 292.

Simond, 157.

Smith, Theo., 166.

Spence, 295.

Spillman, 126.

Stanley, 278.

Stiles, 126.

Sydenham, 119.

Terzi, 106.

Titus, 302.

Todd, 289.

Tooth, 121.

'Torry, 123.

Tovar, 287.

Townsend, 149.

'Trägardh, 32.

Trajan, 109, 155 .

Trallian, 181.

Trouvelot, 64 .

Tsuzuki, 125.

Uhler, 283.

Vallisnieri, 179, 295.

Varro, 221.

Vaughan, 120.

Verjbitski, 157.

Verrall, 239.

Verschaffelt, 31 .

Verus, Lucius, 158.

Voglino, 320.

Wachtl, 68.

Wallace, 208, 213.

Warren, 110.

Woglum, 314, 315.

Yersin, 157.

Yorke, 130, 131,135. 
PRINTED BY

NEILL AND COMPANY, LIMITED, EDINBURGH. 



\section{RETURN TO DESK FROM WHICH BORROWED}

\section{CIRCULATION DEPARTMENT}

This book is due on the last date stamped below, or on the date to which renewed. Renewed books are subject to immediate recall.

\begin{tabular}{|c|c|c|}
\hline RCD GIRC DEPT & MAY & $8^{7} 7413$ \\
\hline te & & . \\
\hline & & \\
\hline & & \\
\hline & & \\
\hline & & \\
\hline & & \\
\hline & & \\
\hline & & \\
\hline & & \\
\hline & & \\
\hline & & \\
\hline & & \\
\hline $\begin{array}{c}\text { LD 21-32m-3,' } 74 \\
(\mathbf{R} 7057810) 476-A-32\end{array}$ & Uni & $\begin{array}{l}\text { eneral Library } \\
\text { rsity of California } \\
\text { Berkeley }\end{array}$ \\
\hline
\end{tabular}


52.3271

UNIVERSITY OF CALIFORNIA LIBRARY

$\because \quad \because \cdots$ 
